\title{
(Re)negotiated Identifications: Reproducing and Challenging the Meanings of Arab, Canadian, and Arab Canadian Identities in Ottawa
}

\author{
by
}

Samah Sabra

A thesis submitted to the Faculty of Graduate and Postdoctoral Affairs in partial fulfillment of the requirements for the degree of

Doctorate of Philosophy

in

Canadian Studies

Carleton University

Ottawa, Ontario

(C) 2011, Samah Sabra 
Library and Archives

Canada

Published Heritage

Branch

395 Wellington Street

Ottawa ON K1A ON4

Canada
Bibliothèque et

Archives Canada

Direction du

Patrimoine de l'édition

395 , rue Wellington

Ottawa ON K1A ON4

Canada
Your file Votre référence

ISBN: 978-0-494-87751-7

Our file Notre référence

ISBN: $978-0-494-87751-7$

\section{NOTICE:}

The author has granted a nonexclusive license allowing Library and Archives Canada to reproduce, publish, archive, preserve, conserve, communicate to the public by telecommunication or on the Internet, loan, distrbute and sell theses worldwide, for commercial or noncommercial purposes, in microform, paper, electronic and/or any other formats.

The author retains copyright ownership and moral rights in this thesis. Neither the thesis nor substantial extracts from it may be printed or otherwise reproduced without the author's permission.
AVIS:

L'auteur a accordé une licence non exclusive permettant à la Bibliothèque et Archives Canada de reproduire, publier, archiver, sauvegarder, conserver, transmettre au public par télécommunication ou par l'Internet, prêter, distribuer et vendre des thèses partout dans le monde, à des fins commerciales ou autres, sur support microforme, papier, électronique et/ou autres formats.

L'auteur conserve la propriété du droit d'auteur et des droits moraux qui protege cette thèse. $\mathrm{Ni}$ la thèse ni des extraits substantiels de celle-ci ne doivent être imprimés ou autrement reproduits sans son autorisation.
In compliance with the Canadian Privacy Act some supporting forms may have been removed from this thesis.

While these forms may be included in the document page count, their removal does not represent any loss of content from the thesis.
Conformément à la loi canadienne sur la protection de la vie privée, quelques formulaires secondaires ont été enlevés de cette thèse.

Bien que ces formulaires aient inclus dans la pagination, il n'y aura aucun contenu manquant. 


\section{Abstract}

This dissertation is based on data collected through informal conversations, formal interviews, and participant observation at community events over sixteen months of fieldwork with Arab Canadians living in Ottawa, Ontario. Most literature on Canadian national identity focuses on the institutional reproduction and circulation of national identity discourses. Moreover, the few scholars who have recently written about the lives of Arabs in Canada and the United States tend to take a "post 9/11" approach which sometimes dehistoricizes the use of security discourses in Canadian and American governance. Rather than begin from the premise that "post/9/11" security discourses are most salient for constituting the subjectivities of Arab Canadians, I employ a multidimensional and multi-scalar analysis to investigate how research participants encountered, (re)interpreted, and negotiated numerous historically and institutionally produced Canadian and Arab national identity discourses. My focus is on the multidimensional experiential scale at which they encountered discourses that are institutionally (re)produced at, and through the interactions of, global, national, and local scales. Although institutionally produced and circulated national identity discourses whether or not they are about "security" - might aim to govern immigrants' behaviours and desires in ways that keep them subservient to "the Canadian nation," I argue, these discourses do not shape immigrants' subjectivities in unidirectional or predictable ways. Indeed, such discourses intersect with other, equally salient, multi-scalar and multidimensional discourses in ways that shape research participants' subjectivities and produce their agency. Research participants' commitments to and desires for social and political change in Canada and the Middle East were particularly important for their 
interpretations of Canadian and Arab national identity discourses. Thus, the meanings they attributed to their immigration narratives and senses of national identity cannot be fully understood without paying attention to multiple dimensions of their social experiences and the intersections between the broad geographic, socio-historical, and political contexts in which they have lived in the past and live presently. 


\section{Acknowledgements}

I would like to thank the Social Sciences and Humanities Research Council of Canada for their generous financial support of this project in the form of a Canada Graduate Scholarship (award 767-2005-1791). I would also like to thank Carleton University's Faculty of Postdoctoral and Graduate Affairs and School of Canadian Studies for their logistical and financial support throughout the last few years. I am especially indebted to Cathy Schmueck and Lori Dearman whose patience, dedication, and knowledge about every element of university life ensured that my time as a graduate student at Carleton University was both enjoyable and free of administrative snags.

I also want to express my sincerest and deepest gratitude to the people who participated in this study. I could not have completed this research without your generosity: from suggestions about my research methods, to analyses of current political events, to the food you offered when I entered your homes, to the candidness with which you spoke about issues of concern in regards to the lives of Arab Canadians in Ottawa, your words are at the heart of this project. I hope that I have done justice to the stories you have so kindly shared with me.

Eva Mackey, my supervisor, mentor, and friend, you consistently inspire me to do better work. You have an uncanny ability to know when I need a kind word, a gentle push, or a substantial shove in any direction. I am immensely grateful to have gone on this journey with you and, especially, for your flexibility and willingness to explore numerous paths with uncertain endpoints. Your confidence in me sometimes overwhelmed me, but always made me strive to be worthy of that confidence. You and Mary were my first friends in Ottawa and I thank you for your ongoing love and support. 
I was lucky enough to have three wonderful committee members whose scholarship and personalities I greatly admire. Jasmin Habib, I have been so grateful for your willingness to discuss the many forms this project took, your careful and generous critique, and the long, long phone conversations we have had along the way. While it scared me a bit at first, I thank you for pushing me to consider the merits of ethnography; it has been one of the most difficult and rewarding tasks I have taken up as an academic and I wouldn't have it any other way. Davina Bhandar, you have also been there for multiple permutations of my dissertation and have worked with me across the cities that separated us and, for that, I am sincerely thankful. Your careful reading and thoughtful suggestions consistently helped me to clarify my writing. Patrizia Gentile, you are one of the busiest people I know and yet somehow always make time to be there for students. I learned a lot from you in the last few years. Working as your teaching assistant helped me bring together many strands of thought that frame this project. I felt both fully supported and taken seriously as an academic in all our interactions. Thank you for always challenging me to push myself further.

I am also grateful to Dr. Jenny Burman for her willingness to act as an external examiner on this project. Her work has been inspirational for me and a consistent reminder that it is possible to explore the complexities of social life without losing analytic depth and rigor. Dr. Jacqueline Kennelly acted as an internal external at my defense. Her questions, like her scholarship, challenge me to delve deeper into the meanings and interrelationships of agency, subjectivity, and citizenship.

My gratitude to my parents is immeasurable. You have supported me financially, emotionally, and intellectually through my entire life. I consider this project an 
expression of my gratitude to you for all you have done, and especially for having dared to dream of a better life for your children. Undertaking this research gave me an ever greater appreciation for the many ways in which you struggled along the way. I wouldn't be who or where I am today without you. I love you both so much. Bilo, the best little brother anyone could ever wish for, you have listened when I needed to vent and understood when I was "in writing mode." You and Erica were often treated to late night phone calls when I took a night off or worked all day and lost track of time. Thanks for always answering the phone! I love you and thank you for all you do. Nabila and Al, you are always there through the ups and downs, always have your home open and a meal on the table, and make sure I laugh through it all. Your stories have also inspired this dissertation. My grrrrrls, Nagham and Farah, what would I have done without the awesome dances, giggles, and baking?! I am, every day, in awe of the beautiful and intelligent women you have become.

Julie Gregory, you continue to be a constant support in my life and you know the place you hold in my heart. You listened to many sections of this dissertation, proofread the earliest drafts, challenged me to fully express my half-formed ideas, and made sure I took breaks along the way. Your carefulness with words inspires me to write more clearly and your love, support, and courage often leave me speechless. I remember, many years ago, talking with you until four o'clock in the morning about race being a social construct, my first introduction to this idea being through a class you were taking. Writing this dissertation, I often reflected on the lasting impact of that discussion. Thank you for that conversation and the many others that followed, and thank you for being you. 
Gabrielle Etcheverry and Alma, your love and support have made Ottawa feel like home to me. Whether we are talking about work, life, or toys, the conversation is seamless, fun, and energizing. You two are the best. Manal Chakra and Helena, I am so glad fate led to our meeting in Ottawa and to living so close to one another. I always look forward to your visits and to the reminder that there is always time for the most important thing in life: playing! Thank you.

Oren Howlett, when I first met you shortly after I moved to Ottawa, at a time when I was feeling lost, my first thought was "I'm going to be fine here." Your friendship got me through those awkward first years in the program. Julie Tomiak, Robyn Green, and Mihaela Vieru, you have been there to celebrate every milestone along the way, are always willing to discuss my latest theoretical challenges, and to laugh about life. Chrissy Kelly, TAing with you was so much fun and opened the door to a supportive friendship. Thank you for always texting at just the right moment and for the awesome jigs. I am also immensely grateful for the support and intellectual stimulation I got from Katherine Arnup, Sacha Geer, Bill Rodman, Harvey Feit, Peter Nyers, and Jean Michel Montsion. 


\section{Table of Contents}

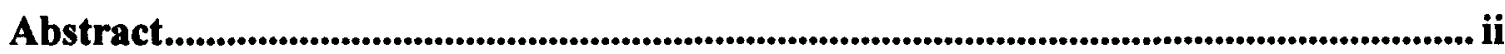

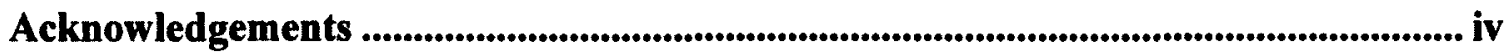

Table of Contents .................................................................................................. viii

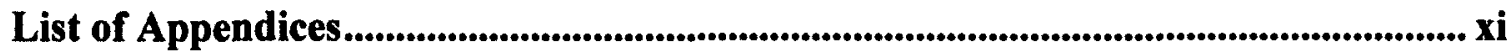

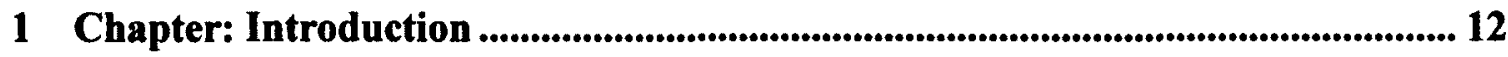

$1.1 \quad$ Research Questions, Methods, and Argument .................................................. 16

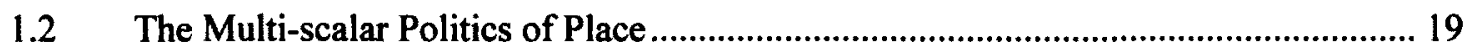

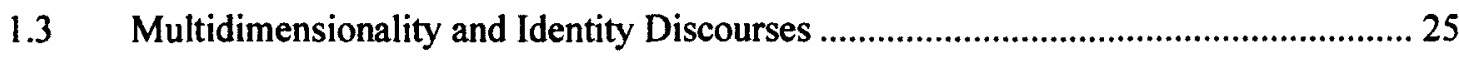

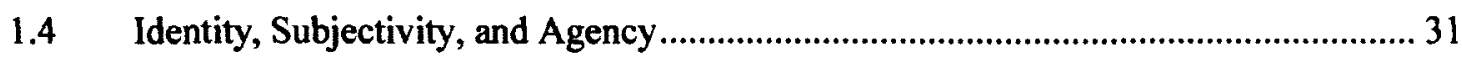

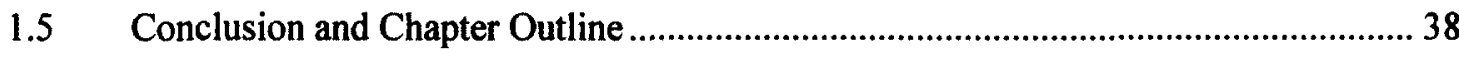

2 Chapter: Canadian Nationalism, Citizenship, and Immigration ......................... 46

2.1 Nations as Imagined Communities ................................................................... 47

2.2 Canadian National Identity Discourses and Nation-Building Projects ....................... 54

2.2.1 Postwar Citizenship and Liberalizing Immigration Policy ................................. 59

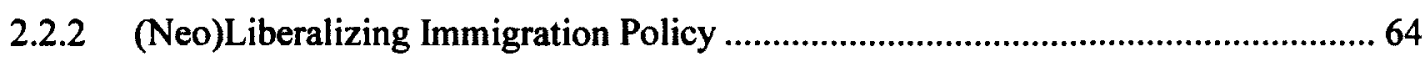

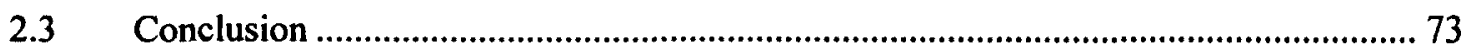

3 Chapter: Coloniality, Orientalism, and Arab Canadians ..................................... 75

3.1 Defining Arab (Pan)National Identity........................................................................ 78

Colonialism and Orientalist Conceptualizations of Arabs .......................................... 86

3.3 Coloniality and Representations of Arab Americans and Canadians ........................ 89

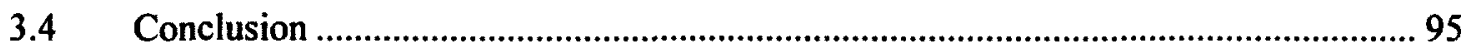

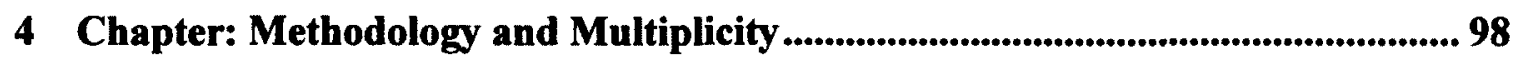

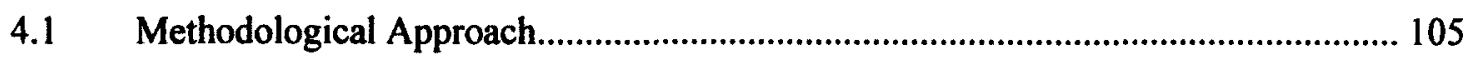


4.2 Why Ottawa

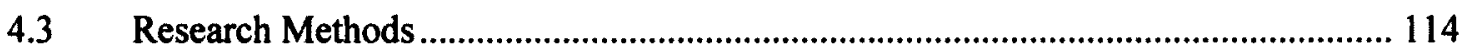

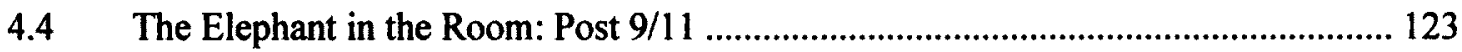

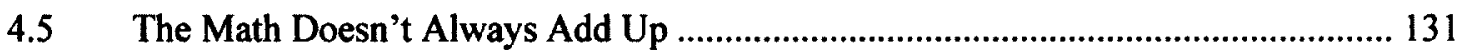

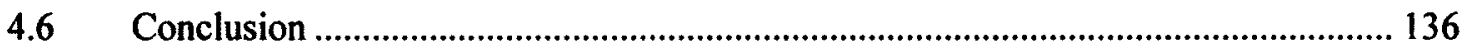

5 Chapter: Getting (T)here/First Encounters .................................................. 139

5.1 Academic Representations and Representatives of Nation-States ........................... 146

5.2 Circulating Discourses of Canadian Nationhood and National Identity ................... 152

5.2.1 Canada as Defined by a Cold Climate ................................................................ 153

5.2.2 Canada as Welcoming to Immigrants and Refugees .................................... 157

5.3 Official Canadians and State Representatives..................................................... 170

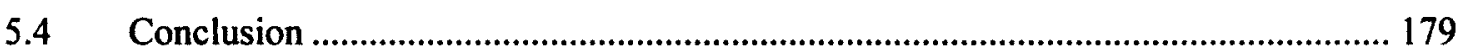

6 Chapter: Multidimensionality and "the Canadian Experience"....................... 181

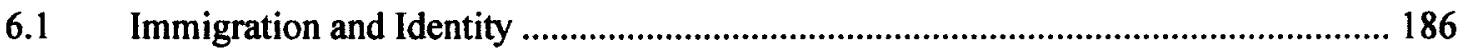

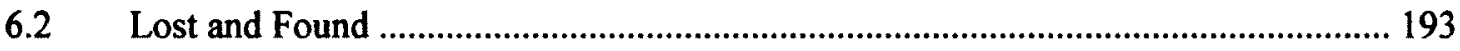

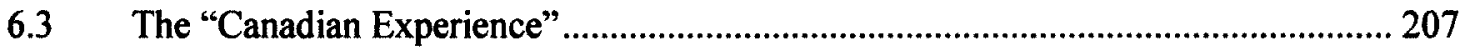

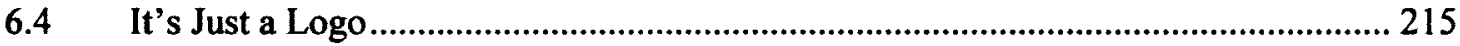

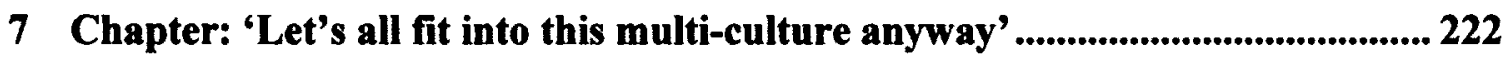

7.1 National Identity Discourses, Immigration, and Multiculturalism .......................... 227

7.2 Critiques, Defences, and Counter-critiques ........................................................ 231

7.3 (Re)Defining Canada and Canadian National Identity .......................................... 236

7.3.1 Multiculturalism as Distinctly Canadian ............................................................... 238

7.3.2 Individualism, Institutions, and (Racialized) Exclusion ..................................... 244

7.3.3 Peacekeeping and Shifting Images of Canadian National Identity.......................252

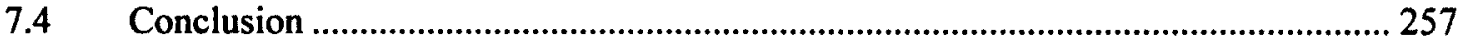


8 Chapter: Mediating Arab (Pan)National Identity ................................................. 259

8.1 Identity, Community and Anti-Colonial Politics ....................................................267

8.1.1 Identity, Community, and Multi-scalar Desires.................................................... 268

8.1.2 Language, Multidimensionality, and Community ……………………………..... 274

8.2 Multi-scalar Disciplinary Discourses and the Politics of Community ........................ 280

8.3 "Building Bridges" and Enacting Community......................................................... 290

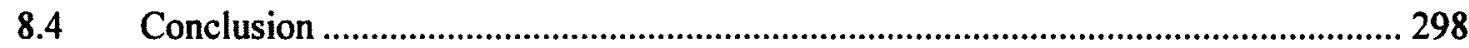

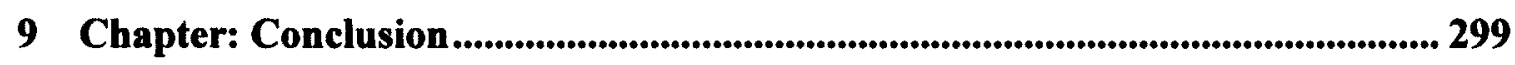

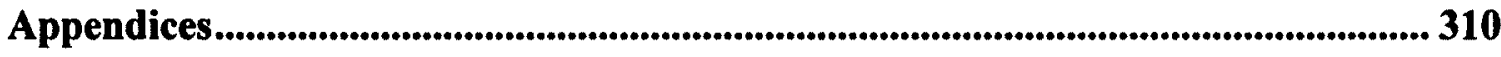

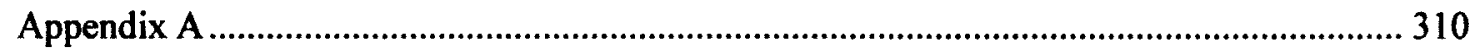

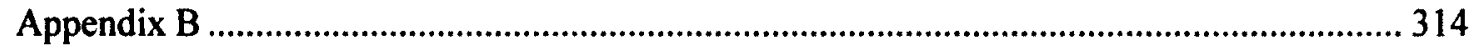

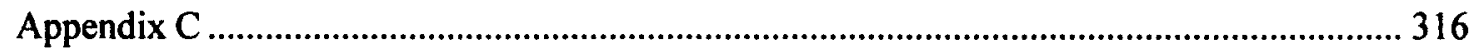

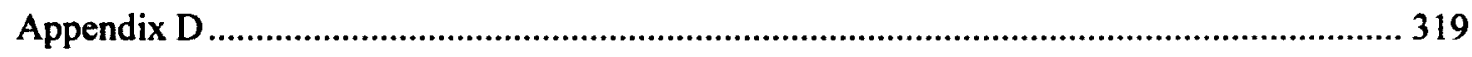

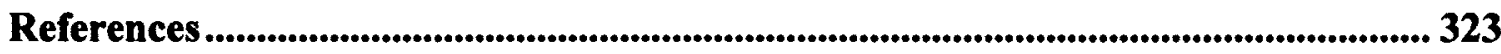




\section{List of Appendices}

Appendix A: Research Interests Document................................................................

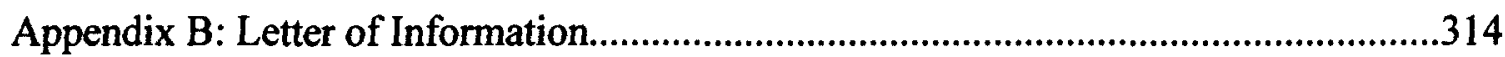

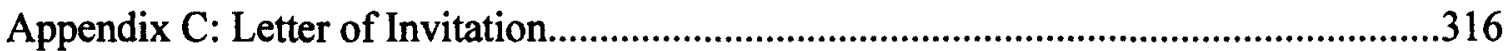

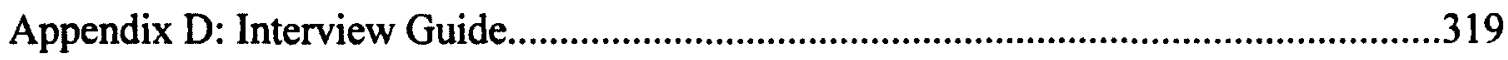




\section{Chapter: Introduction}

In this dissertation I explore how a group of research participants who identify as Arab Canadian and live in Ottawa, Ontario draw on and negotiate national identity discourses as they narrate and interpret their immigration experiences. In particular, I examine the multidimensional interpretations of Canadian and Arab national identity discourses $^{1}$-and the relationships between them - research participants employ to narrate their senses of national identity. In a context where a "Clash of Civilizations" thesis has been revived and is used in academic, media, and policy circles, discourses abound which imply that Middle Eastern and North American - and thus Arab and Canadian - identities are diametrically opposed (Haldrup, Kofoed, and Simonsen 2006; Joseph and D'Harlingue 2008; Shryock 2002). ${ }^{2}$ My project is both motivated by a desire to challenge this deeply institutionalized dichotomy and undergirded by the goal of exploring how people might interpret, complicate, and negotiate such dichotomizing discourses as they encounter them on a day-to-day basis. This project is also deeply personal and motivated by anti-racist political commitments which began to form in December 1995 when, at the

\footnotetext{
${ }^{1}$ Below, 1 define the term discourse in relation to the concept of identity. For now, suffice it to say that it "refers to a social language that is tied to social power relations - relations that define how we can name and define problems and how we can speak about our lives" (Kinsman and Gentile 2010: 7).

${ }^{2}$ As Mahmood Mamdani $(2002,2004)$ notes, there is a prevalent contemporary media discourse that distinguishes "good Muslims" from "bad Muslims." Mamdani argues that within this discourse - according to which Islam itself is not bad but there are "bad Muslims" who interpret the Quran literally -a political violence that is a product of a modern encounter is recast as a pre-modern remnant of a violent cultural identity. In other words, within discourses distinguishing "good" from "bad" Muslims there remains an underlying idea of a clash between two civilizations: one is supposedly modern, liberal, and secular while the other is supposedly premodern, fundamentalist, and fanatical. While Muslim and Arab identities are not coterminous, they are often used interchangeably in media depictions (see Joseph and $D^{\prime}$ Harlingue 2008). Thus, elements of Mamdani's argument, which I discuss in Chapter Eight, are applicable to depictions of Arabs.
} 
age of sixteen, I applied for a citizenship card and passport by virtue of which I would have official proof of being "Canadian."

By December 1995, I had lived in Canada for six years: I spoke English fluently, was familiar with Anglo-Canadian and American popular cultural references, was an avid reader of English language Canadian literature, and was learning French in hopes of becoming fluent. Based on the discourses defining (Anglo-)Canadian identity with which I was familiar, these "facts" already confirmed my sense of Canadian national identity, even if this self-understanding was not yet reflected in my official, government-issued identity documents. I was also born in Lebanon and thought of myself as Arab: I often spoke Arabic with family members and was familiar with Arab history, politics, and popular culture - especially Egyptian and Lebanese music and movies. I interpreted these experiences and interests as evidence of my Arab (pan)national identity and did not understand them as detracting from my ability and right to claim Canadian identity, not least because I accepted the official image of Canada as a multicultural country.

When I arrived at the bland-looking passport office with my family, I was excited to procure documentation confirming what I understood as a key dimension of my identity. Yet, a brief moment that day initiated my questioning of what it meant to call myself Arab Canadian. While I was at the kiosk to sign my passport application, the woman behind the desk asked me about my middle name. When I told her it was Mohammad, she glanced up at me with what I interpreted as a questioning look and asked again about my middle name. I repeated it and explained, "In Lebanon, you get your father's first name as your middle name." Her response was immediate: "In Canada, you don't have to do that." 
Today, my Canadian passport is the only piece of identification I have which does not list my middle name. Although I never discussed the above incident with my parents, I reflect on it every time I travel with my passport, remembering and questioning the meanings of what happened that day. Did my father interpret my silent complicity in the erasure of his name from my passport as a double renunciation - of him personally and of a "cultural tradition" of naming he and my mother had passed on to me? Had he hoped I would defend my inheritance of his name? Did the woman at the kiosk think of herself as "saving me" from a patriarchal tradition? If so, did she consider inheriting a father's first name as a more patriarchal tradition than the common practice in Canada of inheriting his surname? Did the act of not taking my father's first name as my middle name somehow define what it meant to become Canadian? If so, why did she not also offer to erase my brother's middle name from his passport? What did my mother think as she watched all of this? Did she and my father know how conflicted I felt in that moment?

I interpret the above moment at the passport office as an interaction wherein I was faced, at an experiential and subjective level, with negotiating the tensions between discourses signifying the meanings of Arab and Canadian (pan)national identities. It is one instance in an ongoing and emotionally charged process of identity negotiation which, I argue here, cannot be understood separately from broad national and global discourses that shape individual and collective understandings of various identity "categories" and the relationships between them. Possibly, the woman behind the desk removed my father's first name from my passport because she interpreted my explanation to mean I did not want it there. Yet, read in relation to a series of multi-scalar and multidimensional discourses, her gesture can equally be interpreted as one that 
"welcomes" me into a purportedly less patriarchal Canadian cultural milieu than that of my Arab background - especially since it was directed at me but not my brother. While I cannot know what she was thinking, throughout this introductory chapter, I periodically return to the above vignette to take up the latter possibility, analyzing this moment through its reverberations with pertinent gendered discourses defining Canadian and Arab national identities. I do so to illustrate the theoretical framing that emerged out of my fieldwork experiences and shaped the analysis I undertake in this project. Specifically, in my analysis of this vignette and my research data, I draw on three bodies of academic literature which suggest that experiential encounters with and negotiations of national identity discourses are inseparable from multi-scalar socio-political histories and processes, are multidimensional, and simultaneously produce subjectivity and agency. Part of my aim in this project is to push the boundaries of the existent literature on the relationships between Canadian national identity discourses and "immigrant" subjectivities. As I explain in the final section of this chapter, most critical scholarship on Canadian national identity tends to focus on the relationships between national institutions, discourses, and global political economy (e.g. Bannerji 1993b, 1995, 2000; Berger 1966; Day 2000; Handler 1988; Kernerman 2005; McKittrick 2006; Razack 2002, 2004, 2008; Thobani 2007; Walcott 1999, 2000, 2001, 2003). My argument is not that we ought not to engage in such analyses. Instead, I want to build on this work to consider what a multidimensional and multi-scalar examination of how people encounter and employ national identity discourses at an experiential scale might contribute to understandings of the relationships between national identity, agency, and subjectivity, particularly for immigrant Canadians. I contend that a nuanced understanding of the 
complex ways people employ the national identity discourses that shape their

subjectivities requires a multidimensional, multi-scalar analysis which takes into account the life histories of the social actors who encounter them, a project I undertake herein.

In the remainder of this chapter I elaborate on this argument by offering an overview of the main bodies of literature that frame my analysis of my primary materials. I begin in the next section with a brief description of my research methods and research questions. I then review arguments about the importance of the concept of scale for analyses of forms of governance and (national) identity. In the following section, I discuss literature on the multidimensionality of identity discourses. I go on to examine the relationships between power, subjectivity, and agency which are central to my project. In each of these three sections, I return to and analyze the vignette from the passport office with which I opened the chapter to illustrate the pertinence of each body of academic literature for this project. I conclude by explaining the contribution my analysis makes to existing literature on Canadian national identity and offering an overview of the remaining chapters of this dissertation.

\subsection{Research Questions, Methods, and Argument}

The people who participated in this project have several things in common with each other and with me: we live in Ottawa (Ontario), self-identify as Arab Canadian, and are first generation immigrants to and citizens of Canada. As I discuss at greater length in Chapter Four, between August 2008 and November 2009, I spent time with research participants at various "community" events organized by Arab Canadian organizations in Ottawa, went out for coffee with them, had the odd dinner at someone's house, and joined a group of Arabic-speaking social service providers during their monthly 
meetings. In these settings, I engaged in many "informal" conversations with people about immigration, the meanings of Arab and Canadian national identities, and their lives in Canada generally and Ottawa specifically. I also, unexpectedly at first, had informal conversations about these issues with numerous Arab Canadian taxi drivers who passionately shared their views on these issues when they discovered my research interests. Finally, I conducted numerous formal in-depth, semi-structured interviews with people I met during fieldwork who were willing to take the time to participate.

In this dissertation, I draw on data collected through these methods to explore how research participants experience, interpret, and narrate the relationships between their immigration experiences and their senses of national identity. I frame this exploration in terms of three research questions: (1) On which specific discourses did research participants draw in explicating the relationships between their immigration experiences and senses of national identity? (2) Where and how did they encounter these discourses? (3) How did they interpret and engage them?

One way I can now answer these questions is to say that in narrating their immigration experiences, research participants engaged Arab and Canadian national identity discourses in complex ways, sometimes simultaneously reproducing, challenging, and/or rejecting specific elements of the same discourse. While national identity discourses are institutionally (re)produced at global, national, and local scales, people encounter them at a micrological, embodied scale in their day-to-day experiences. As I suggest in the forthcoming pages, a multi-scalar, multidimensional analysis of research participants' engagements with national identity discourses allows for a nuanced understanding of the ways in which these discourses simultaneously shape people's 
subjectivities and ipso facto their agency. In other words, such an analysis helps to clarify the mutual constitution of subjectivity and agency, not as two sides of the same coin, but as inseparable products of the same discursive encounters.

It is important to note that I begin my analysis in this dissertation with research participants' discussions of their senses of Canadian national identity and leave their conceptualizations and enactments of community until the final analysis chapter. There are two reasons for this decision: (1) to counteract institutionalized, racializing discourses according to which "immigrant Canadians," Arab or not, are not "real" Canadians and do not value their sense of Canadian identity and (2) to challenge inclinations to want to read them through a lens of sameness based on a shared "cultural" identity by illustrating the importance of difference in their interpretations of various identity discourses and experiences prior to and after immigrating to Canada. By ending rather than beginning with "community," I also aim to foreground that it is not a pre-given, taken-for-granted point of departure for talking about Arab Canadians who live in the same city - or any other "cultural group" for that matter.

Finally, I want to note that research participants often represented specific global, national, or local events as pivotal to how they engaged Canadian national identity discourses. After reviewing his interview transcript, $\mathrm{Sam}^{3}$ captured this idea with the assertion that "feelings of belonging are influenced by events on the world stage." In keeping with Sam's assertion, the meanings research participants attributed to their personal immigration narratives and senses of national identity were often shaped by multiple facets of their social experiences and the multi-scalar geographic, socio-

\footnotetext{
${ }^{3}$ I use pseudonyms that research participants chose or which I have supplied throughout this dissertation.
} 
historical, and political contexts in which they have lived in the past and live presently. In the next section, I explain my use of the term multi-scalar.

\subsection{The Multi-scalar Politics of Place}

Reproductions of national identity discourses "take shape within: global geographies of colonization, modernity, and migration; national policy contexts that mediate other scales of negotiation; and local geographies of everyday life" (Anderson 2000: 386). As Kay Anderson argues, it is important to consider the relations between these scales in order "to clarify how the forces of nation building extend and interact across a wide range of surfaces" (386). Anderson's additional observation that few scholars link "contested claims to space and place at the local level to the meanings and practices of national identity and belonging" (386) motivates my project. ${ }^{4}$

A clear understanding of the ways scholars mobilize the notion of scale helps to explain Anderson's above point and, by extension, an important motivation for this project. Geographers use the term "scale" to refer to a "level" of analysis, an ontological category, an epistemological analytic concept, a discourse, and/or a material effect of historical and social processes of spatialization (MacKinnon 2011; Moore 2008; Paasi 2004; Silvey 2004). While I do not have space here to provide a detailed account of all uses of the concept, I will briefly explore the features they share in common which I find useful in analyzing research participants' engagements with national identity discourses.

Geographers and other scholars agree that modern policies and (non)academic habitual ways of thinking tend to rely on "scalar thought." As Engin Isin (2007) explains, scalar thought is "a way of representing and instituting relations" between spaces of

\footnotetext{
"I discuss the work of scholars who make such links in the final section of this chapter.
} 
social activity (such as cities and states) "as if these relations were exclusive..., hierarchical..., and ahistorical" (211). Engin's succinct genealogical research into the emergence of scalar thought during "modernity" in Western Europe illustrates a key point on which scholars who study scale agree, namely that scales are socially constructed through processes and discourses that produce the sociality of space - i.e. the ways in which social relations produce, are produced by, and are lived out through contests over space and place (e.g. Brenner 2001; Marston 2000; MacKinnon 2011; Moore 2008; Paasi 2004). Thus, for instance, our ability to conceive of things on a "global scale" depends on the production of "the global" through a set of discourses, relations of governance, and relations of production brought about by processes of colonization and imperialism.

In keeping with this, and driven by Marxist political economic analyses, radical geographers tend to focus on the expansion of capitalist modes of production as a process which differentiates places from one another (often through the notion of modernization) even as it "equalizes" these places by bringing them all into the fold of international capitalist production (Smith 1992, Brenner 2001). The same process, they argue, produces hierarchical relationships between these places (e.g. some are seen as more "modern" than others) as well as between scales themselves (e.g. whereby "national interests" may be subsumed to the interests of "international capital"). Working from a feminist Marxist perspective, Sallie A. Marston (2000) calls on these geographers to take seriously that processes of social reproduction and consumption also produce scales of governance (such as "the household") and thus to expand a limited focus on the relations between "the local" (often seen as cities), "the national," and "the global" (Cf. Smith 
1992). ${ }^{5}$ Adding another layer of complexity, geographers who work with theories of performativity (Butler 1990, 1993) also argue that the body is a scale of governance which requires analysis (e.g. Fortier 2006).

Arguing that the foci of political economy, feminism, and performativity are not incommensurate, David MacKinnon (2011) uses the concept of "scalar politics" to highlight "that it is often not scale per se that is the prime object of contestation between social actors, but rather specific processes and institutionalized practices that are themselves differentially scaled" (MacKinnon 2011: 207). I agree with MacKinnon that attention to the discursive production of scales does not have to preclude analyses of processes of institutionalization and the practices of institutions. Based on my fieldwork, I would add that such intimately intertwined processes and practices are not only differentially scaled but multi-scalar. In this context, it is important to consider that certain processes are discursively constituted in ways that direct our attention to and naturalize a specific scale of analysis. In relation to Anderson's (2000) above call to consider how "the meanings and practices of national identity and belonging" (386) take shape at multiple scales, resisting "naturalized" scalar thought requires studying such meanings and practices as multi-scalar.

The key point here is that the scales at which we locate and study particular processes have political and analytical implications (Isin 2007; Smith 1993). I therefore consider it necessary to heed Mariana Valverde's (2008) call for "greater reflexive selfawareness about the implications of falling into certain 'scale' habits" (7) which might

\footnotetext{
${ }^{5}$ As Marston and Smith (2001) suggest, it is perhaps telling of a tendency not to take feminist critique seriously that Marston's (2000) call was met with the claim that the concept of scale had been "blunted" through overextension beyond material relations of production (Brenner 2001).
} 
analytically and politically "fix" the social processes we aim to study. In the context of my project, as with Kay Anderson's (2000) above argument that a comprehensive understanding of the production of national identity requires us to take into account and "relationally conceive" (386) multiple scales, Valverde's (2008) caution not to fall into "scale habits" foregrounds the importance of highlighting the multi-scalar nuances involved in processes of social in/exclusion and the production of national subjectivities.

Valverde (2010) illustrates the fruitfulness of a multiscalar analysis in her study of citizenship as a form of governance; she refuses to fall into the habit of studying citizenship at the scale of the nation-state, instead taking into account multiple temporal and spatial scales at which notions of citizenship are used to govern particular subjects. Her account confounds attempts to define belonging in terms of either inclusion (as a normalized state of affairs) or exclusion (as what must be corrected). Instead, Valverde illustrates that the same person might be alternatively included and excluded at different points in governance practices. Following her analysis, "due regard for scale-shifting moves and the unpredictable interactions of governing orders working at different scales, may help to deepen our understanding of crucial political and legal issues facing us today" (240, emphasis added). Again, her analysis highlights how different scales direct our attention in specific ways and reinforces that there is rarely a singular, natural scale for studying an issue. I am driven by her work to study national identity discourses in a multi-scalar way that leaves room for the unpredictable elements that emerge out of the relationships between embodied, local, national, and global scales.

For example, the personal interaction described in the above vignette from the passport office, evokes and is embedded within multiple global, national, familial, and 
embodied scales of power and privilege that revolve around and differentiate me and the woman whose paid labour produced my Canadian passport along axes of age, citizenship, nationhood, and gender as well as colonial histories and presents. As suggested above, regardless of this woman's intentions, her words and actions resonate with global colonial discourses and processes that relationally define an opposition between (1) "(Middle) Eastern" nations (such as Lebanon) as patriarchal, oppressive spaces where women have yet to be liberated from the burdens of "tradition" and (2) "Western" European nations (such as Canada) as secular, liberal, and democratic spaces where women have fought for (and won) "equality" with men under "the law." ${ }^{6}$ Within these discourses, my personal geographic movement from the first to the latter of these places is (re)framed as the potential start of a "progressive" and linear process of "liberation" in which she might play a part by erasing evidence of (and, thus, perhaps freeing me from) a tradition of naming deemed oppressive. By (re)framing my geographic movement via a linear narrative of (gender) liberation, this same global discourse (re)produces a spatial relationship between Lebanon and Canada as a temporal teleological narrative wherein the latter is more "advanced" (i.e. less "primitive") than the former.

In this case, as the above suggests, the meanings of "national" spaces/identities are embedded in a globally spatialized politics of place that is inseparable from the power relations produced through histories of colonization and imperialism and, thus, intimately

\footnotetext{
${ }^{6}$ Discourses defining Western European and North American nations as more advanced in their gender politics than those in Asia and Africa have a long history, but are also flexible (Abu-Lughod 2001, 2002; Mohanty 2000, 2002, 2003; Ong 1988; Spivak 1988, 1999). Today's claim that "Middle Eastern" countries are especially bogged down by patriarchy, for example, can be interpreted as a civilizational discourse (Abu-Lughod 2001, 2002; Ahmed 1992) which is continuous with those used by the British in the late 1800 s to justify closing Egypt's School for Hakimas (female doctors) with the claim that "throughout the civilized world, attendance by medical men is still the rule" (Lord Cromer, quoted in Ahmed 1992: 153).
} 
tied with the "imaginative geographies" (Gregory 1995a, 1995b, 2000, 2004; Said 1994) and discursive constructs of "the West" and "the Middle East." Since the meanings of national spaces are often relationally (re)produced, this is to say, Canada's definition as a non-patriarchal space of "liberated" women depends, in part, on continual differentiation from purportedly patriarchal spaces of "oppressed" women which exist elsewhere. Read in relation to, and as an embodied enactment of, such global and national discourses, this woman's gesture of erasure appears to usher me and my parents into a Canadian national milieu which, given the necessity of her signature for procuring our legal Canadian identity documents, she seemed authorized to define for us as "newcomers." Indeed, at the time and at an experiential scale, I interpreted my interaction with her as an encounter with someone who represented an embodiment of Canada as a nation-state.

Significantly, the interaction between me and this woman also had implications at a familial scale which I felt most immediately at the passport office: it was an interaction that challenged my parents' authority over me by literally renaming me according to an ostensibly "more Canadian" (read: less patriarchal) tradition. Yet, a relational, multiscalar analysis of this interaction points to a fissure that calls into question the globally spatialized discourses which appear to define Canada and Lebanon in opposition to one another. At sixteen, a legal name change in Canada usually requires "written consent of the person(s) who have lawful custody" over me, namely my parents (Government of Ontario 2011; see also Uniform Law Conference of Canada 1988). In giving my parents this right, Canadian law converges with Lebanese law. Thus, the woman's challenge to my parents' authority to name me, which took place at a localized place and scale, also challenged an authority legally given over to them by Canadian national law. In 
simultaneously challenging Canadian and Lebanese law/tradition, her gesture (perhaps inadvertently) calls into question the global and national discourses which dichotomize Canada and Lebanon as entirely different national spaces.

Based on the above, I suggest that a relational analysis of global, national, familial, and embodied scales of discourse production and enactment facilitates a nuanced understanding of the simultaneously diverging and converging implications of our encounters with multi-scalar national identity discourses - e.g. a single gesture of erasure may seem both to reinforce and challenge globalized discourses according to which Lebanon and Canada are wholly dissimilar. The above analysis also points to the importance of a multidimensional analysis. In the next section of this chapter, I return to the opening vignette to consider how the notion of multidimensionality builds on and extends from the multi-scalar analysis I have offered thus far.

\subsection{Multidimensionality and Identity Discourses}

The multi-scalar analysis of the vignette at the passport office I present above already gestures toward the multidimensionality of the processes through which national identity discourses are produced, interpreted, and negotiated (Crenshaw 1989, 1991; Fortier 2006; Froc 2010; Hutchinson 1999, 2001, 2003, 2004). For example, discourses of gender and nation give one another a specifically contextualized meaning within this moment: that the woman at the passport office enacted her gesture of erasure with me, a young woman, but not with my brother suggests that she was mobilizing a gendered interpretation of this tradition of naming which resonates with national and global discourses differentiating Canada and Lebanon. Her doing so also underscores that discourses of gender and nation are reproduced in and through one another. In other 
words, the meanings of gender and nation were produced for me in this specific context simultaneously through an enactment of a national identity discourse which constitutes gender as having different implications in Canada and Lebanon.

Following from the above, a nuanced analysis of the interaction between me and the woman at the passport office must take into account, in addition to multiple scales of national identity discourses, the intersections of multiple discourses, power relations, and histories which imbued this experience and each of our positions with meaning for me. Such a multidimensional analysis requires accounting for the "complex, irreducible, varied, and variable effects which ensue when multiple axis of differentiation economic, political, cultural, psychic, subjective and experiential - intersect in historically specific contexts" (Brah and Phoenix 2004:76). At the same time, although it is important to account "for multiple dimensions of social life," it is equally necessary to remember that these "cannot be separated out into discrete and pure strands" (76). To further illustrate these points, I want to add a few more dimensions (capitalism, colonialism, age, racialization) to the analysis I have offered thus far.

The national and global discourses, power relations, and histories I may drawn on to examine the interaction at the passport office include capitalist relations of production which necessitate that my interlocutor engage in paid labour, thereby placing her at the kiosk and authorizing her to issue Canadian passports to me and my family. The same capitalist relations of production are thoroughly intertwined with imperial histories that led to the settlement and colonization of Canada by the British and French in the first place. They have played a role in dispossessing Indigenous nations of their lands, instituting a "Western European" notion of sovereignty and forms of governance 
(Lawrence 2004), and producing the need for me, my family, and other would-be citizens to apply for Canadian citizenship and identity documents - or at least to have some official authorization (e.g. work permits) to enter into licit forms of labour to meet the material needs of our day-to-day lives, even if poorly so (Armstrong and $\mathrm{Ng} 2005$ ).

Similar (but not identical) globally interconnected colonial histories also led to the dispossession of my mother's family in Palestine/Israel in 1948 and their exile to Lebanon where she met and married my father but remained a stateless refugee. ${ }^{7}$ At the end of World War One, these latter colonial histories also led to Lebanon coming under French tutelage by a mandate of the League of Nations, ${ }^{8}$ which played some part in shaping the forces that culminated in a civil war in Lebanon and led to our immigrating to Canada (Hage 2009; Said 1997). The discursive and material effects of these colonial and imperial histories precede and play a role in the very possibility of this interaction taking place in its present, seemingly common-sense, form.

Age-related discourses form an important experiential dimension framing and mediating the interaction between me and this woman. Perhaps if I had been older than her, she might not have felt quite as entitled to take on an authoritative role in relation to

\footnotetext{
'My maternal grandparents' exile from their home in 1948 highlights the complexity of desires for (im)mobility is a complex issue (see Addey 2006; Hannam, Sheller, and Urry 2006).

${ }^{8}$ The British and French mandate governments instituted throughout the Arab world at the end of World War One were justified by the League of Nations according to this logic: "To those colonies and territories ... inhabited by peoples not yet able to stand by themselves under the strenuous conditions of the modern world, there should be applied the principle that the well-being and development of such peoples form $a$ sacred trust of civilisation... The best method of giving practical effect to this principle is that the tutelage of such peoples should be entrusted to advanced nations who by reason of their resources, their experience or their geographical position can best undertake this responsibility" (Covenant of the League of Nations: Article 22 emphasis added; see also Gregory 1995a, 2000). The supposedly self-evident "truth" of the necessity of such a mandate emerged out of a long history of Eurocentric civilizational discourses. I elaborate on this point in Chapter Three.
} 
me and my name. At the same time, part of the authority I understood her to have in this situation was predicated on her being older than me. This converged with my sense that I had been let into and allowed to remain in "her" country and that she was thus entitled to define what is acceptable here.

In keeping with the colonial histories I have discussed, it is possible that her white skin and "Canadian" (or at least Torontonian) accent added to the level of authority I imputed to her, at least at a subconscious level. Admittedly, however, I do not recall consciously considering either of these factors in that moment for two reasons. First, since I had been living in Toronto since the age of ten, I spoke with the same accent as her so I considered this accent as something that could develop from living in the country/city rather than something which differentiated us. Second, she and I both had "white" skin. Based on vernacular understanding of race as something which denotes skin colour, I did not understand myself and this woman as being "of different races." Thus, what I recall most is that I thought of her authority as a product of her age and her physical location behind the kiosk at the passport office. In retrospect, and with a more complex understanding of racialization as a discursive process in mind, I would now argue that we were certainly differently racialized since I wore the hijab at the time. It is thus likely that racializing discourses which define Islam as particularly patriarchal factored into her interpretation of me as someone who was "in need of saving," unlike my unveiled mother (Abu-Lughod 2002). Each of these factors - gender, capitalism, colonialism, age, and racialization - sheds partial light on a multidimensional process of (national) identity (re)production and negotiation enacted in a single moment at a passport office in Toronto, Ontario, Canada. 
What, then, does it mean to speak of multidimensionality? The concept of multidimensionality emerged in the field of legal scholarship as an analytic tool which aims to "recognize the multiple and complex ways ... all individuals experience oppression and construct categories of identity" (17). Multidimensionality theorists aim to extend the insights of (feminist) critical race theory which has been conceptualized in response to critical legal scholars (Froc 2010; Hutchinson 1999, 2001, 2003, 2004).

Traditional (Western European) legal scholarship is built on liberal discourses according to which "the law" is a neutral tool that guarantees, or can be used to guarantee, equality because it is conceptualized in relation to an abstract individual devoid of any specifically located social identity. In contrast, critical legal scholars argue that laws reflect and protect social privilege and play a role in oppressing socially disadvantaged people (Crenshaw, 1989, 1991; Delgado and Stefancic 2001; Kobayashi 1990; Kobayashi and Peake 2000; Peake and Kobayashi 2002). Extending this appraisal, critical race scholars argue that law "reinforces racial hierarchy, reflects the viewpoints of privileged classes, serves as a weak vehicle for social change, is indeterminate and unable to provide fixed, predictable outcomes for civil rights litigants" (Hutchinson 2004: 1192; see also Crenshaw, Gotanda, Peller, and Thomas 1995; Delgado and Stefancic 2001; Price 2010). They aim to complicate the liberal meanings attributed to law but, unlike critical legal scholars, they argue that the law, despite its flaws, can be used strategically to fight social injustices. Thus, as Angela Harris (1994) points out, critical race scholars rely on both liberal and critical legal theories to demonstrate the limitations of law and use it where necessary. In this way, they point to the tensions within legal discourses and their work implies that law is not either inclusive or exclusive (see also Valverde 2010). 
Infusing this strand of legal scholarship with a gendered analysis (e.g., Crenshaw 1989, 1991; Harris 1994), feminist critical race scholars challenge "the single-issue paradigms of antiracist and feminist discourse" (Hutchinson 2004:1198; see also Bhandar 2000). Taken up under the term "intersectionality theory" (e.g. Brah 1996; Razack 1998, $2002,2004,2008$; Nash 2008), their work aims to highlight the complexity of social life by considering a multiplicity of factors that shape people's experiences and senses of identity. Darren Hutchinson (1999) depicts the idea of multidimensionality as a "substantive extension" of intersectionality theory's focus on two dimensions of identity - i.e. race and gender (Hutchinson 1999: 9). Yet, Kimberlé Crenshaw (1991), who coined the term "intersectionality," writes that her "focus on the intersections of race and gender only highlights the need to account for multiple grounds of identity when considering how the social world is constructed" (1245 emphasis added). Elsewhere, Crenshaw explicitly argues that identity is multidimensional (1989: 139) - as does Avtar Brah (1996: 128-151). Rather than intersectionality, I use the term multidimensionality to evoke the multiplicity and simultaneity of various discourses of differentiation.

My use of the term multidimensionality is also motivated by Jasbir Puar's (2005, 2011) comprehensive critique of how intersectionality theory is often employed:

The theory of intersectionality argues that all identities are lived and experienced as intersectional... But ... the method of intersectionality is most predominantly used to qualify ... the specific 'difference' of 'women of color', a category that has now become... simultaneously emptied of specific meaning on the one hand and overdetermined in its deployment on the other. In this usage, intersectionality always produces an Other, and that Other is always a Woman Of Color (WOC), who must invariably be shown to be resistant, subversive, or articulating a grievance. (Puar 2011: $₫ 3$ )

At a theoretical level, Puar's critique is made on two counts. First, she suggests intersectionality theory tends to produce the very "othering ... it meant to alleviate" (ף 4). 
Second, while she clarifies that Crenshaw's work must be understood as a "formative, generative, and necessary intervention," Puar is nonetheless concerned about "the tendency towards reification in the deployment of intersectionality" today ( $\$ 6)$. The issue of reification is of particular concern, she suggests, because it tends to collude with "modernist colonial agendas and regimes of epistemic violence" which produced many of "the categories privileged by intersectional analysis" (\$7).

One way of colluding with such agendas and regimes is to treat our categories of analysis as if their meanings were self-evident. For me, Puar's (2011) claim that "the category 'nation' appears to be the least theorized and acknowledged of intersectional categories" points to the necessity of undertaking analyses that ask about the multidimensional processes through which national identity discourses are produced, encountered, and negotiated (\$ 8). Taking this point together with Valverde's (2008) warning about the dangers of falling into scale habits, I argue that instead of engaging in analyses which produce fixed categories that humans simply inhabit, we ought to map the flexible and complex renderings of multidimensional and multi-scalar histories, discourses, and experiences which shape subjectivity and agency. In other words, we must proceed from the understanding that "what we call 'identities' are not objects but processes constituted in and through power relations" (Brah and Phoenix 2004: 77), an understanding I take up in the next section of this chapter.

\subsection{Identity, Subjectivity, and Agency}

A multi-scalar and multidimensional analysis of experiential encounters with identity discourses is tied in with questions of subjectivity, agency, and power, which are at the heart of all processes of identity production and negotiation. In considering how 
colonial histories produced my encounter with gendered Canadian national identity discourses at the passport office, for example, I examine how the interaction is shaped by (personal, national, and global) power relations. Such discourses and power relations, as I show in this section of the chapter, also shape my subjectivity and agency and those of my passport office interlocutor.

One possible interpretation of the relationships between power and agency may seem straightforward: the asymmetrical power relationships between us - shaped by dominant discourses about age or citizenship status, for example - place her in a position of authority and enable her, in a seemingly unselfconscious manner, to inform me that "in Canada, you don't have to do that" before erasing my father's middle name from my passport while I stand and watch. From this perspective, she seems to have power while I do not; she has an agency which I seem to lack. Yet, agency and power are not zero-sum games. They are deeply interconnected with subjectivity and identity, and they complicate such a unidirectional analysis.

As already suggested in the previous section on multidimensionality, I do not understand identities as inherently meaningful, fixed categories describing a person's essential self. From an anti-essentialist perspective, the very idea that identities can be depicted as a priori meaningful categories is itself a discourse which bespeaks a will to knowledge (Puar 2005: 128). This anti-essentialist understanding of identity developed in several fields of research including diaspora studies (e.g. Gilroy 1987, 1989; Habib 2004) and sexuality studies (e.g. Butler 1990, 1992, 1993; Puar 2004, 2005, 2011). In relation to ideas about "national" or "cultural" identities, anti-essentialism breaks with "old meanings of culture" (Wright 1998: 8; see also Mitchell 1995) as a distinct and 
homogeneous set of practices, values, and modes of thought by which a group of people - associated with a specific place - could be defined and delimited (see also Appadurai 1988; Brah 1996; Burn 2001; Coombes 1994; Gupta and Ferguson 1992; Malkki 1992; Mufti and Shohat 1997; Rosaldo 1988). ${ }^{9}$ Temporally and substantively overlapping with this work, feminist theorists' deconstruction of the category "woman" also calls into question essentialist notions of identity (e.g. Butler 1990, 1993; Haraway 1991, 2004; Mills 2001; Mohanty 2000, 2002).

In keeping with such critiques, as well as my fieldwork experiences, I conceptualize identities as discursively constituted. Our senses of identity, this is to say, are produced within, informed by, and reflective of discourse as "a field of strategies (statements, views, theories, concepts, and objects of analysis and their interrelations) that create knowledge about something and create differentiations by posing limits on what can be said and by whom" (Routledge 2002: 311; see also Foucault 1980, 2003; Mills 2001, 2004). Specific discourses within this field "define how we can name and define problems and how we can speak about our lives" (Kinsman and Gentile 2010: 7). Discourses are thus tied in with power/knowledge, a term coined by Michel Foucault (1980) to suggest that multiple power relations pervade our social worlds, define what counts as "true" and/or "expert" knowledge, and thus shape our interpretations of our social worlds and our very senses of self.

\footnotetext{
9 Academically and politically motivated critics depict this "old meaning of culture" as "a crucial element of colonialism" (Wright 1998:8; see especially Asad 1973; Fabian 1983; Said 1993, 1994). Building on Edward Said's Orientalism (1993), they highlight colonial administrators' use of academic definitions of ostensibly fixed cultural identities to produce administrative and military policies (see also Butz 1995; Butz and MacDonald 2001; Butz and Ripmeester 1999; Gregory 1995, 1998, 2000, 2001, 2004, 2006).
} 
From this perspective, power relations produce specific knowledges and subject positions even as they delimit what counts as true knowledge or the subject positions available to us. This understanding of power as productive follows from Foucault's (1995) admonition to

cease once and for all to describe the effects of power in negative terms: it 'excludes', it 'represses', it 'censors', it 'abstracts', it 'masks', it 'conceals'. In fact, power produces; it produces reality; it produces domains of objects and rituals of truth. The individual and the knowledge that may be gained of him belong to this production. (194)

As suggested in this quote from Foucault, power relations and discourses play a role in producing our very understanding of ourselves as individuals; we come to know and interpret our "selves" and social surroundings through discursive truth claims. In other words, discourses shape our subjectivities and the things we think of as most personal and individual - our thoughts, desires, or senses of self.

Yet, as Saba Mahmood (2001) argues, scholars tend to define agency either implicitly or explicitly as the ability to act autonomously in opposition to the dominant discourses which produce subjectivity. Mahmood illustrates that in much of the literature discussing the lives of Middle Eastern women, for example, scholars exclusively locate agency in actions or words that seem to oppose oppressive patriarchal discourses (e.g. Abu-Lughod 1986, 1993). While these scholars importantly challenge stereotypical representations of Middle Eastern women as silently overdetermined by patriarchal power relations, they use agency as "a synonym for resistance to relations of domination" (Mahmood 2001: 203; Asad 2000). From this perspective, she suggests, "in order for an individual to be free, it is required that her actions be the consequence of her 'own will' rather than of custom, tradition, or direct coercion" (Mahmood 2001: 207). 
Such theorizations of agency thus continue to be "encumbered by the binary terms of resistance and subordination" and are "insufficiently attentive to motivations, desires, and goals that are not necessarily captured by these terms" (Mahmood 2001: 209). The result is to locate agency only in actions or words we (scholars) deem "progressive" based on our preconceived understandings of the term. For Mahmood, there are two problems with this. First, we tend to take "the language of social science" as "a selftransparent universalism" and dismiss "the language used by 'ordinary people'... as a poor approximation of their reality" (209). Second, we implicitly suggest that agency signifies some residual, pre-discursive autonomous portion of the self, a theorization that is inconsistent with the above discussion of power as productive of subjects (210).

Building on these critiques, Mahmood (2001) argues compellingly that such theories of agency lose track of the idea that power is "a set of relations that do not simply dominate the subject, but also, importantly, form the conditions of its possibility" (210). If this is the case, power relations are "also the means by which [the subject] becomes a self-conscious identity and agent" (210; see also Asad 2000; Butler 1997; Foucault 1980,1983$)$. One way to keep this latter element of power relations in mind, she proposes, is to move beyond conceptualizing agency as a "the capacity to realize one's own interests against the weight of custom, tradition, transcendental will, or other obstacles (whether individual or collective)" (206, emphasis added).

Mahmood's analysis is particularly important for the discussions of identity discourses I explore in this project. Indeed, if I were to look for agency only in words or actions that go "against the weight of custom, tradition, transcendental will, or other obstacle," I may (1) deny contests over the meanings of customs and traditions, (2) leave 
little room for the unpredictable elements of the interactions of various discourses, and/or (3) represent research participants as lacking any agency, especially in cases where they reproduce dominant Canadian or Arab national identity discourses. Thus, following Mahmood, I define agency "as a capacity for action" that historically and geographically located power relations "enable and create" (203). ${ }^{10}$ From this perspective, the same power relations that shape someone's subjectivity simultaneously produce her/his agency.

For me, one of the strengths of Mahmood's (2001) definition of agency is her refusal to separate it from subjectivity or to tie it only to specific, predefined forms of resistance. She highlights that our actions sometimes reinforce and sometimes challenge the very discourses and power relations which produce the subject positions from which we act - regardless of whether we are researchers or research participants. She thereby allows us to move beyond simple analyses that (re)signify our disagreements with research participants as evidence of their being acted upon by discourse and power relations in ways that we are somehow able to escape (see also Mahmood 1996). To illustrate the implications of her argument for the analysis I undertake in this project, I continue to analyze the vignette from the passport office in the remainder of this section. As I illustrated above, the actions of the woman at the passport office resonate with broad colonialist discourses defining Arabs (and Muslims) as especially patriarchal. This resonance complicates a straightforward discussion of her agency by highlighting its inseparability from subjectivity: while she seems to act as an "autonomous" subject, her actions are likely informed by the globally spatialized discourses defining Canada as

\footnotetext{
${ }^{10}$ The idea that power relations enable and create certain capacities for action has overlaps with the above-discussed arguments of critical race scholars that law produces both the limitations on and possibilities for legal action from specific subject positions (Harris 1994).
} 
liberal and Lebanon (and the Middle East in general) as patriarchally oppressive. These discourses shape her subjectivity and agency, but she is no less of an agent for this. My point instead is that her agency is a product of processes of subjectivation (Butler 1997; Foucault 1980, 1983; Mahmood 2001; Sabra 2005).

These same discourses also shape my interpretation of her actions as unselfconscious as well as my feeling in that moment that I lacked the ability to act in the same manner. I could have insisted that I wanted "to do that," but I admittedly felt a lot of emotional ambivalence about her offer. To be perfectly honest, there was something appealing about feeling like I had "the choice" and was being "empowered" to move from one national cultural milieu to another. I felt that I was, despite my age and dependence on them, able to resist my parents' authority (to name me) with the backing of a government worker. This was a seductive offer which worked on and through my desires to act "freely," unconstrained by both "cultural baggage" and parental authority.

Accepting her offer seemed out of the question, however. I felt that I was being asked to betray my parents: to choose between being their dependent (Arab) daughter or an independent (Canadian) woman. I thought accepting her offer might confirm her reading of my name as evidence of my (ostensibly cultural) oppression through "Arab patriarchy," especially if she interpreted my acceptance as a desire and willingness to throw off the yokes of "Arab patriarchy." Yet I feared that rejecting it could be interpreted the same way: she might take keeping my name as evidence that I was so yoked by "Arab patriarchy" that I could never resist it which would, once again, confirm her reading of me as oppressed. I was free to act, even as my freedom was simultaneously constrained and enabled by long, intersecting personal and political histories, discourses, 
and power relations. Under the weight of my ambivalence about these histories and about the discourses that seemed to mediate her reading of my body, my name, and the hijab I wore, I stood and watched as she finished filing my application for a Canadian passport, one in which I would no longer be Samah Mohammad Sabra.

The woman who worked at the passport office and I both had agency during this interaction. Both of our agency and subjectivity were products of multi-scalar and multidimensional discourses and power relations that seemed to exceed and make possible this single interaction, but did not predetermine it. Put differently, our actions, senses of identity, and the subject positions from which we (could) speak must be understood within the context of familial, national, and global power relations and discourses. To analyze our interaction in this way does not imply that she and I are instruments of these discourses. Instead, it focuses attention on how multi-scalar identity discourses shape our subjectivity and agency in ways that allow us to negotiate and mobilize them at an experiential scale. As I explain in the next section, such an analysis pushes the boundaries of existing literature on Canadian national identity.

\subsection{Conclusion and Chapter Outline}

Much of the critical literature on Canadian national identity over the last two decades has been motivated by political economy and feminist, anti-colonial, and/or critical race theories. The work of Sherene Razack (1998, 2002, 2004), Himani Bannerji (1993b, 1995, 2000), Sunera Thobani (2007), and Enakshi Dua (2003), for example, all challenges deeply institutionalized teleological discourses defining Canada as a place that has emerged out of a troubling racist past into a liberal present where racial (and gender) equality has been realized (see also Day 2000; Kernerman 2005; Mackey 1997, 1999; 
Walcott 1999, 2000, 2001). These scholars highlight Canada's constitution as a settlercolonial state whose formation and position as a "First World" nation depends on several things: dispossessing Indigenous nations of their land and sovereignty; a physical and cultural genocide of Indigenous peoples; the undervalued, indentured, and/or underpaid labour of (mostly) racialized peoples from the "Third World;" and a racialized immigration system and citizenship regime both of which continue (more insidiously than in the past) to favour Western European people as "desirable" nationals.

This critical literature poses an indispensible challenge to state-orchestrated discourses of Canadian national identity which aim to over-determine historical and present day unjust power relations with liberal discourses about an abstract equality "under the law." I take this critical tradition of scholarship as the starting point of my analysis and hope to push the conversations taking place within this field by adding a layer of complexity to the above-discussed arguments. To this end, I illustrate the fruitfulness of a multi-scalar and multi-dimensional analysis of first-generation immigrant Canadians' encounters with national identity discourses in all aspects of their lives for moving beyond questions of the types of national subjectivities such discourses aim to (re)institutionalize. Scholars who helped to extricate the governing rationalities pervading institutionalized Canadian national identity discourses have tended not to ask what roles institutionalized national identity discourses might play in producing immigrant Canadians' subjectivity and agency. My dissertation begins to answer this question in relation to a group of Arab Canadian research participants.

My point throughout this dissertation is not to deny the critical importance of analyses of institutionalized national discourses and expert knowledges or to suggest, in 
any way, that they have run their course. Such analyses continue to be necessary for historicizing and tracking changes in nationally institutionalized discourses, which are continuously in flux. A few recent studies, however, also illustrate the possibilities for more complex and nuanced academic engagements with Canadian national identity discourses that can be opened up by adding other analytic scales and foci. More specifically, my analysis is inspired by elements in the work of Eva Mackey (1997, 1999), Gary Kinsman and Patrizia Gentile (2010), Rinaldo Walcott (2000, 2001, 2003), Katherine McKittrick (2010), and Jenny Burman (2010). In this dissertation, I combine elements of their approaches to the study of Canadian national identity discourses.

For example, Mackey (1999) documents the production of state-sponsored and institutionalized discourses of Canadian national identity, but also uses ethnographic research methods to examine how people she calls "Canadian-Canadians" - who are white and European-descended - draw on these discourses to (re)inscribe their subject positions as rightful managers of national space. While her work illustrates the complexity of her research participants' engagements with institutionalized national identity discourses, she does not address how racialized immigrant Canadians might encounter, interpret, and employ these same discourses, a project I undertake here.

Kinsman and Gentile (2010) also highlight the productive potential of examining people's experiential encounters with state policies and discourses in their study of the Canadian state's use of national security discourses to govern gender and sexuality. They integrate policy analysis, archival research, and interview data to demonstrate how institutionalized discourses affected the lives of the social actors they target, who, in turn, engage these discourses and develop ways of resisting their application to their bodies. 
They also illustrate continuities between "the Canadian war on queers" and contemporary racialized security discourses targeting Muslim and Arab Canadians as potential terrorists. Their analysis inspires my focus on how people negotiate restrictive discourses which aim to govern their behaviours.

Furthermore, the work Rinaldo Walcott $(2000,2001,2003)$ and Katherine McKittrick (2006) convinces me of the importance of analyses that trouble dominant versions of Canadian national identity discourses by highlighting the simultaneous presence of counter-discourses. For example, Walcott $(2000,2001,2003)$ draws on black Canadian cultural productions to challenge multicultural discourse's erasure of black Canadians' historical presence in Canada. Using archival material and literary works, McKittrick (2006) also complicates discussions of black Canadian identities; she foregrounds the intricacies of black women's histories and geographies of struggle, illustrating the centrality of diasporic linkages related to histories of slavery and violence in producing North America and the Caribbean as a (dis)continuous racialized space that remains both limiting to and opposed by black women. Thus, both scholars investigate how people who are not defined as "dominant" respond to Canadian national identity discourses by focusing on oppositional cultural productions. I take from their work the importance of recognizing the multiplicity of ways people may counter institutionalized images of "the nation" through local, national, and global linkages and commitments.

Finally, Jenny Burman's (2010) Transnational Yearnings is an ambitious and inspiring work in Canadian (and transnational) studies. Burman undertakes a multi-scalar analysis, and offers a multidimensional conception, of a richly textured "global pathway" connecting Toronto and Jamaica (4). Her approach "challenge[s] prevailing binaries 
between 'Northern' agents and 'Southern' pawns" (5) and "attend[s] to the popular desires and practices of the actors who fuel transnational mobilities, in spite of these mobilities' inherent obstacles" (7, emphasis added). While Burman foregrounds the "deeply and structurally inequitable" processes of globalization, she avoids producing images of "the global oppressed... as inherently subversive" and "locate[s] multiple sites of agency and vernacular critique" (7).

As this brief depiction of Burman's book suggests, my project shares much in common with her work. It also significantly differs from it. I do not, as I explain in Chapter Two, theorize research participants' senses of national identity as transnational nor am I interested in whether Ottawa can be conceptualized as a diasporic city produced through transnational linkages with the Arab world. Rather, my specific aim is to understand how research participants' subjectivities and agency, resistant or not, shape and are shaped by their multidimensional encounters and engagements with Arab and Canadian national identity discourses which are products of multi-scalar processes.

Based on the scholarly work I have outlined in this chapter and my fieldwork experiences, I argue that an exclusive focus on nationally institutionalized discourses in studies of Canadian national identity poses two potential dangers. First, if we always take "the national" as our main scale of analysis, we risk colluding with the discourses and state powers we may seek to challenge by re-inscribing the dominance and centrality of "the Canadian nation-state" in the production and governance of national subjects and subjectivities. Second, we risk overdetermining people's subjectivities, daily experiences, and agency with analyses of the governing rationalities that pervade institutionalized discourses. Thus, I offer an analysis that allows us to nuance theories about the 
productivity of Canadian national identity discourses. I do so by focusing on the experiential scale at which the social actors who participated in this research project encountered and negotiated such discourses while keeping in mind the life histories and local, national, and global power relations that necessarily shaped these multidimensional encounters and engagements. My theoretical and methodological contribution is to illustrate that a multi-scalar and multidimensional analysis of national identity discourses - one which takes people's engagements with such discourses as an important site of their (re)production and circulation - can provide a nuanced understanding of if and how these discourses enter into first-generation immigrant Canadian's interpretations of their senses of national identity. This contribution is particularly important for foregrounding the inseparability of the processes through which subjectivity and agency are produced.

To set the groundwork for my analysis, in the next two chapters I offer a literature review which introduces readers to the multi-scalar and multidimensional national identity discourses, policies, and historical events to which research participants often referred during fieldwork. In Chapter Two, I discuss anti-colonial and feminist critiques of (neo)liberal nationalist discourses of Canadian national identity which have and continue to infuse Canadian immigration legislation. This forms the springboard for my review, in Chapter Three, of conceptions of Arab (pan)national identities in relation to language, colonial histories, and ideals of secular nationalism which are central to contests over the meanings of Arab identity in "the Arab world" but which are overdetermined by Eurocentric colonialist discourses in institutionalized American and Canadian discursive and policy arenas. 
In Chapter Four, I discuss the details of the interpretive critical methodology which guides my analysis throughout this study. I also explain the specific methods I used to collect my primary data and why I chose Ottawa as my site of study. Finally, I provide a brief sketch of Ottawa's Arab Canadian community and discuss how some of my interactions with members of the community inform this project.

In Chapters Five, I begin to analyze research participants' narratives of immigrating to and living in Canada. Specifically, I analyze their first encounters with what I call an "extra-national" Canadian state, examining their interpretations of discourses defining Canada in accordance with its cold climate and its ostensibly welcoming attitude to immigrants. I argue that research participants' encounters with these discourses prior to immigrating to Canada illustrate the multi-scalar circulation of institutionalized Canadian national identity discourses and that their interpretations of these discourses were themselves multi-scalar and multidimensional, shaped by key elements of their previous life experiences.

In Chapter Six, I go on to discuss research participants' narratives of their first few years in Canada, which demonstrate the multidimensionality of experiences which tend to be subsumed under the rubric of integration as matters of practical adjustment to resettlement. I argue that integration and settlement discourses are best understood as multidimensional governing rationalities that define desirable behaviour and aim to produce (neo)liberal national subjectivities. Yet, I argue, these rationalities do not always produce the national subjectivities "the state" may desire since some immigrants may interpret disjunctures between their settlement experiences and Canadian national identity discourses in ways that challenge images of Canada as welcoming to immigrants. 
Building from the argument that research participants' settlement experiences shaped their interpretations of Canadian identity, in Chapter Seven I examine the relationships between their subjectivities, agency, and three institutionalized discourses of Canadian national identity: multiculturalism, individual humanism, and peacekeeping. The main insight in this chapter is that research participants were not governed through Canadian national identity discourses in a unidirectional way, but sometimes drew on discourses of an authentic and liberal Canadian national identity to critique the Canadian nation-state for failing to live up to these institutionalized liberal ideals.

In Chapter Eight, I continue to examine research participants' engagements with national identity discourses but shift my focus more directly to their conceptualizations of Arab (pan)national identity within a Canadian context and their understandings and practices of community. I argue that while many research participants lamented divisions within Ottawa's Arab Canadian community, the value they placed on building a sense of unity is a product of the interactions between local, national, and global discourses and policies as well as their local and global political commitments and desires. I conclude the dissertation in Chapter Nine by considering the implications of the arguments made in the previous chapters for conceptualizing the work Canadian national identity discourses play in shaping people's subjectivity and agency. More specifically, I suggest that understanding "immigrant" Canadian subjectivities and agency requires taking into account more than a singular dimension or scale of their immigration experiences. 


\section{Chapter: Canadian Nationalism, Citizenship, and Immigration}

As explained in Chapter One, I aim to highlight the multidimensionality of the experiences through which people encounter and negotiate the meanings of national identity discourses. While the idea that people's engagements with multi-scalar identity discourses are multidimensional has implications beyond the study of national identity, the entry point for my analysis and my main focus is on the relationships between research participants' immigration narratives and senses of national identity. I argue that the meanings research participants attributed to their immigration narratives and senses of national identity have been influenced by multiple facets of their social experiences and the broad geographic, socio-historical, and political contexts in which they have lived in the past and live presently. To lay the groundwork for my analysis, in this chapter I locate my project in relation to academic literature on Canadian national identity.

I divide my literature review into three sections. In the next section I discuss Benedict Anderson's (1983) definition of nations as "imagined communities" and outline feminist and anti-colonial critiques of his work, which are central to my understanding of national identity discourses as produced through multi-scalar and multidimensional processes. In the following section, I provide an overview of the centrality of such critiques in contemporary critical research on (especially "official") definitions of Canadian national identity and immigration policies. My focus is on elements of this research which figure prominently in my analysis, including critiques of liberal and neoliberal policies and definitions of national identity which represent immigration as a "problem" threatening Canadian nation-hood and identity. I conclude the chapter by 
discussing how the (neo)liberalization of immigration laws relates to the continued racialization of Canadian national identity discourses.

\subsection{Nations as Imagined Communities}

Early theorizations of nations and national identity took for granted and reinforced "Enlightenment concepts of individual sovereignty and autonomy" (Mackey 1999: 11). In such theorizations, romanticized images of fully autonomous individuals serve as models for idealized images of nations as territorially bounded and selfgoverning (Voegelin 1987 [1952]). Moreover, this idealization extends to the definition of "the nation" and "nationals" as sharing the same "national character" (Hall 1999; Handler 1984, 1988; Mackey 1997, 1999).

In the early 1940s, this idea was foundational in large-scale anthropological studies of "national character," often funded by the American Office of Naval Research during World War II to aid in morale (e.g. Hoebe1967; Mandelbaum 1953; Mead 1951, 1961; Wallace and Fogelson 1962). Critics of national character studies highlighted the relationships between the conclusions drawn in these studies and broad international power struggles. For example, Jules Henry (1951) pointed out that "it must have been comforting to us [Allied Forces] during and immediately after the war to know that our enemies were subject to 'mass megalomania,' were 'rigid,' 'hypochondriacal,' 'paranoid' or just 'neurotic"' (134; see also Embree 1950). While taking issue with the content of such studies, however, critics did not challenge their theoretical underpinnings or their collusion with nationalist (and colonialist) worldviews. Early scholarship on nationalism thus converged with nationalist worldviews around three assumptions: (1) nations are "natural" entities which exist objectively, (2) each nation has a unique identity 
differentiating it from all others, and (3) each nation's unique identity might be "contaminated" if its boundaries are not protected (Handler 1984: 60). One danger of such scholarly literature is its potential use to justify policies and discourses according to which those deemed "uncharacteristic" threaten "national unity." Driven in part by the recognition of such dangers, today most scholars "understand the idea[s] of 'national character' and ... 'core' national values as discursive constructions which have emerged in battles over the right to define national identity" (Sabra 2007: 95).

The space for such contemporary conceptualizations was opened up in the 1980s with the work of scholars such as Ernst Gellner (1983) and Benedict Anderson (1983). In particular, a common starting point for studies of nationalism and national identities today is these two scholars' compelling claim that nations, and what tend to be thought of as their attendant national identities, are products of local and global socio-political forces rather than natural expressions of primordial affiliations (see also Breuilly 1985 ; Gellner 1983; Greenfield 1982; Hobsbawm 1990). ${ }^{11}$ This argument set the stage to (1) question the socio-political organization of our world by "discrete territorial units" (Murphy 1991: 81) called nations, (2) take the production of nations as a site of analysis, and (3) study the relationships between nations, states, and identity discourses. ${ }^{12}$

\footnotetext{
${ }^{11}$ This is not to suggest that those doing "national character" studies necessarily saw such characteristics as inherited rather than socially reproduced. Instead, I would suggest that a key difference between Anderson (1983) and scholars of "national character" is that even where the latter highlighted these characteristics as socio-culturally reproduced, they still took "the nation" as an inherently meaningful category of analysis while the former aimed to excavate the socio-cultural and political processes which have produced the very possibility of its use as an analytic category.

${ }^{12}$ Despite shared insights, Anderson and Gellner differ significantly in their theorizations of nations and nationalism. Geliner argues that as a modernizing social force rationally necessitated by industrialization and capitalism, nationalism is so (unconsciously but materially) compelling that it melts away social difference and produces homogeneous populations within the territorial bounds of nations. He is thus
} 
There are three key aspects to Anderson's (1983) definition of nations as "imagined communities" (15). First, the term "imagined" points to the centrality of sociocultural and political processes in producing images of nations as coherent, meaningful entities such that those who never meet one another come to understand themselves to share a common national identity (15). Second, within idealized images of nations, "fellow nationals" are imagined as if they are equal. Third, nations are imagined as geographically and demographically limited (16) in part because nationalist imaginings involve processes of boundary production and maintenance.

Yet Anderson (1983) does not specify who imagines the limits of nations except in relation to cases where, he suggests, local elites start to imitate organically produced (Western European) nations. Despite arguing that nations cannot be compared on the basis of their genuineness or falsity (15), Anderson's distinction between organically formed nationalisms versus ones based on following their blueprint nevertheless gives primacy and a sense of greater legitimacy to Western European nations (Chatterjee 1991; Mahmood 1996). Moreover, Anderson's definition implies that there exists a singular national imagination and places more emphasis on the outer limits of nations than on differences between "fellow nationals" (Kandiyoti 1991; McClintock 1995; Mufti and Shohat 1997). Both of these issues have been central to anti-colonial, anti-racist, and feminist critiques of Anderson's work which are, in turn, central to my project.

unable to account for social inequalities within the territorial boundaries of nation-states except to claim they (a) have simply not yet been phased out by nationalism or (b) result from characteristics (such as a "hypothetical" example of blue skin pigmentation) that somehow resist the rational, equalizing forces of capitalism and industrialization. For Anderson, on the other hand, feelings of national belonging are emotionally and psychically powerful due to nationalism's similarities to kinship and religion. In this sense, Anderson naturalizes ideas of national belonging through an appeal to normative models of "the family." 
For instance, Anne McClintock (1995) interprets nationalism as a discourse which is inseparable from variously gendered, racialized, sexualized, and colonial power relations related to capitalist modes of (re)production. Although she does not use this terminology, McClintock shows national discourses to emerge out of multi-scalar and multidimensional processes and her work illustrates the fruitfulness of analyses based on such an understanding. Indeed, she demonstrates that nationalist discourses often rely on and naturalize a gendered division of labour whereby women are relegated to the role of bearers of national tradition while men represent future-oriented national progress. She also convincingly argues that British imperialism was central to the production of hierarchically-racialized, teleological models of progress according to which people must (be made to) "evolve" from tribal affiliations toward North-Western European models of nationhood. Her work thus directs our attention to the centrality of gendered, racialized, and heterosexualized power relations in the production of difference at a national scale among "co-nationals" and at a global scale across national boundaries.

Like McClintock (1995), most anti-racist, feminist, and/or anti-colonial scholars argue that once we take into account multiple dimensions of the production of national discourses, we uncover numerous conflicting meanings and narratives of national identity. They also suggest national(ist) discourses - as attempts to define coherent, unified national identities - may alternatively be used to produce and/or deny "social contests" about national boundaries, differentiated access to resources, and degrees of belonging. In keeping with this, their analyses show state-sponsored liberal discourses historically represented as "neutral" and progressive - to define some members of national populations as "real" nationals and, thus, legitimate managers of national spaces, 
narratives, and identities (Arat-Koç 1999, 2005; Aretxaga 2003; Asad 1997; Bell 2003; Chatterjee 1986, 1991; Hage 1998, 2009; Kofman 2005; Mackey 1997, 1999;

McClintock 1995; Werbner 2005; Yuval-Davis 1997).

More recent work theorizing the role of globalization in producing transnational citizenship and senses of belonging simultaneously reinforces and complicates some of the above-discussed arguments and highlights the importance of multi-scalar analyses of national identity discourses. Scholarship on globalization and transnationalism challenges what Saskia Sassen (2005), drawing on Ulrich Beck, calls methodological nationalism which takes for granted "the nation as container category" and thus fails to account for "the proliferation of transboundary dynamics and formations" (158). Some scholars in these fields tend to romanticize globalization and transnationalism as offering routes to freedom from the constraints of the nation-state (e.g. Appadurai 2005; Pollock, Bhabha, Breckenridge, and Chakrabarty 2002). In contrast, other academics point to the structural limitations imposed on people through the increasingly rapid and intensely globalizing reach of transnational capitalism (e.g. McMichael 2005) or point out that "the nationstate" has not yet lost its authority as an organizing force in social life (e.g. Nixon 1997). Aiming to avoid completely polarizing images of globalization's impacts, some scholars argue that globalizing processes simultaneously enable and constrain the potential actions and mobilities of social actors (Balibar 2006; Burman 2010; Comaroff and Comaroff 2001; Ong 1999, 2006; Sassen 2005). For instance, much of the public discourse justifying increasing transnational military and corporate links across what some scholars call Fortress North America (Bhandar 2004) is framed in terms of national security and economy (Dobrowolsky 2007). Similarly, while the emergence of 
transnational governing bodies such as the European Union seems to erode borders between nation-states, it involves complex processes which make such borders more permeable for some people at the cost of immobilizing others (see Fortier 2006). Finally, Sassen (2005) points out that while "global cities are the sites for the overvalorization of corporate capital and the devalorization of disadvantaged workers... they are also the sites for new types of politics that allow the latter to emerge as political subjects" (161, emphasis added). Thus, the production of transnational linkages, sensibilities, and economies exists alongside rather than displaces the (re)production of nation-states (Sassen 2005) which have not lost their holds on people's imaginations and lives (Dauvergne 2007; Dirlik 2002; Mudimbe-Boyi 2002). For my project, it is thus important to consider how research participants' imaginations and lives continue to be shaped by multi-scalar and multidimensional discourses which also shape them as political subjects. As Arif Dirlik (2002) suggests, concepts such as transnational citizenship and diaspora identity have "an undeniable appeal" as routes for critiquing "assumptions of national cultural homogeneity" (94). He warns, however, that "diasporic notions of culture" ought not to be "employed without due regard to the social and political complexities of so-called diasporic populations" (95; see also Habib 2004). When used uncritically, Dirlik (2002) argues, "the idea of diaspora" erases "differences between Chinese Americans and Chinese elsewhere (including in China)," for example (97). His point is that the reification produced by the concept of "diasporic identity ... does not overcome the racial prejudices of earlier assumptions of national cultural homogeneity but in many ways follows a similar logic, now at the level not of nations but of offground 'transnations"' (97). Dirlik suggests that "what is important is to enable people to 
feel at home where they live. This does not," he continues, "require that people abandon their legacies, only that they recognize the historicity of their cultural identities and that those identities are subject to change in the course of historical encounters" (115).

In calling for careful and reflexive use of the concepts of transnationalism and diaspora, Dirlik's work converges with that of Burman (2010), Fortier (2006), Ong (2006), and Sassen (2005). These scholars argue that it is necessary to pay attention to the multiple scales at which various socio-political discourses and historical processes take place without losing track of the specificities involved in their (re)production at local scales. For me, this means I cannot assume that Arab Canadians living in Ottawa all come to share a common sense of identity with one another and with Arabs in other parts of the world. Yet, I also cannot deny the histories they share in common with each other, with other Arabs, and with other Canadians. Following from this, it is necessary to investigate how various claims to shared national identities (as Arab, Canadian, and Arab Canadian) are experienced, mobilized, accepted, and contested in often unpredictable ways by social actors. An important methodological and political implication of the argument I make is that an analytic lens that focuses first at the immediate experiential scale while tracing its thorough imbrications in other temporal and geographic scales is a fruitful way to undertake such an investigation. More specifically, such an analytic lens highlights the inseparability of socio-political structures and histories, socio-cultural interactions, and the very categories of thought that simultaneously limit the ways we can (and do) live our lives and make living our lives possible. This inseparability is the main point I take from Mahmood's (2001) definition of agency as a set of capacities produced by the discourses that shape people's subjectivities. 
Below I explore how some scholars draw on the above-discussed insights to theorize Canadian national identity discourses. My main focus is on scholarly engagements with the interrelationships between Canadian national identity discourses and liberal teleological narratives about changes in immigration and citizenship laws. There are two reasons for this. First, such narratives came up often during fieldwork. Second, many scholars whose work I discuss below convincingly argue for these liberal national discourses' centrality and mutual reinforcement in "official" definitions of Canadian national identity and nation-building projects.

\subsection{Canadian National Identity Discourses and Nation-Building Projects}

Based on analyses of various institutional discourses and nation-building projects, numerous scholars conceptualize the dominant Canadian "model of nationhood" as a liberal one centred on the principle of individual equality in relation to the ideals of “"citizenship', civil and legal rights, political rights and duties, and socioeconomic rights" (Mackey 1999:157; see also, e.g., Bannerji 2000; Day 2000; Goldberg 2002; Handler 1988; Howard-Hassman 1999; Kymlicka 1988, 1989, 1995; Taylor 1995). Since this model relies on and valorizes liberal political philosophy, and given the variety of ways liberalism can be taken up, I want to say a few words about the term before proceeding to discuss how it has figured and continues to figure in Canadian national(ist) discourses, policies, and legislation. As Whitehead, Bannerji, and Mojab (2001) point out, there are certain dangers in outright dismissing everything associated with liberalism and modernity - including the notion of equality. Rather than dismiss all liberal ideals, my aim here is to point to the ways liberalism can be used to deflect attention from historical and present socio-economic and political inequalities in the name of an abstract equality. 
Despite their variations, liberal political philosophies share some tenets: a focus on autonomy and freedom of the individual as a universal, abstract, and undifferentiated figure; a valorization of notions of (individual) equality of opportunity; an understanding of government as simultaneously a "good" which ought to protect freedom and property and a "necessary evil" which involves rule by others rather than unfettered individual autonomy; and a separation between "public" and "private" spheres as an avenue for ensuring individual freedom from state interference into matters such as religious practice and accumulation of capital (Bealey and Johnson 1999; Goldberg 1993, 2002). Liberal philosophers also discursively construct liberalism as representing rational progression away from autocratic rule and despotic government toward a more just mode of (national) governance. In line with the above, liberal political thought is popularly characterized as signifying the abandonment of racist policies and adoption of (ostensibly) "non-racialist" modes of governance (Goldberg 1998, 2002; Thobani 2007).

As David Theo Goldberg (2002) convincingly argues, however, while liberal thinkers generally reject "naturalist" arguments of (bourgeois) white, European racial superiority, they tend to accept and reproduce "historicist" arguments according to which white European political, social, and cultural thought and institutions (including liberal political philosophies) are the most "civilized" and progressive in the world. Following from this, and as suggested in my earlier discussion of McClintock's work (1995), liberal discourses were, and continue to be, used to justify (racialized) paternalistic colonial policies ostensibly aimed at "modernizing" various peoples and places (see also Brown 2006; Bhabha 1991; Chatterjee 1991, 1993). Yet the uses to which liberal political thought is put in governing strategies and rationalities are flexible and vary with socio- 
political context. Multidimensional analyses of Canadian immigration and citizenship laws, which complicate straightforward narratives of "progress" wherein racism is a relic of the past that was gradually removed from state policies and conceptions of Canadian national identity, highlight such flexibility.

In its earliest formulations, Canadian immigration policy had the explicit objective of keeping Canada a "white man's country" (Knowles 2006; Kobayashi 2007; Mackey 1999; Thobani 2007). Some pieces of legislation directly named specific populations as targets of exclusion. For example, once Chinese labourers had built the Canadian Pacific Railway which joined British Columbia with the Dominion of Canada, the Chinese Immigration Act 1885 set a $\$ 50$ "head tax" which, as the name implies, anyone immigrating to Canada from China had to pay (Dua 2003; Knowles 2006; Ng 1993; Thobani 2007). The amount was raised to $\$ 100$ by 1900 and to $\$ 500$ by 1903 to further limit the number of Chinese people coming to Canada (Knowles 2006). Yet, a multidimensional analysis of the uses and application of this Act illustrates that Chinese merchants were exempt from paying this head tax and allowed to bring their families with them to Canada (Li 1990; $\mathrm{Ng} 1993) .{ }^{13}$

A multidimensional and multi-scalar analysis of early immigration policies also shows forms of racialized exclusion were sometimes enacted through pieces of legislation that did not directly name a specified group of people. The Continuous Passage Act 1908, for example, prohibited the entry into Canada of anyone who did not arrive at a Canadian port of entry by direct continuous journey from their country of birth

\footnotetext{
${ }^{13}$ Similarly, one way Indigenous people could become enfranchised was through obtaining an education in law or science (Dua 2003), a process which required a certain amount of capital in the first place.
} 
or citizenship (CIC 2008a; Dua 2003). ${ }^{14}$ Although this act did not explicitly name a specific group of people, Enakshi Dua (2003) illustrates that its intended target was people from the Indian subcontinent. Dua's analysis illustrates the multidimensional and multi-scalar power relations involved in the Act's insidious approach to the exclusion of Indians: British imperial policy, racism, capitalist enterprise, European conceptions of state sovereignty, and nationalist assumptions about the idealness of a homogeneous national body. British Imperial law technically granted to Indians, as subjects of the British Empire, free entry into, exit from, and right to settle in any part in the empire. Consequently, Canadian policy makers could not explicitly exclude Indians without contradicting Imperial rules or embarrassing the British Empire. The Continuous Passage Act thus offered a way to surreptitiously circumvent Imperial policy. Furthermore, as Dua suggests, the Act's effective exclusion of its targeted population relied on the CPR ceasing its direct journeys from Calcutta to Canada, under direct order from the government of Canada (52).

Under the Immigration Act 1910, the government of the Dominion of Canada combined the Continuous Passage Act with other restrictive immigration laws. More specifically, Section 38c of the Immigration Act 1910 provided legislation to "prohibit for a stated period, or permanently" entry into Canada of "immigrants belonging to any race deemed unsuited to the climate or requirements of Canada" (Dominion of Canada 1910: 38c; CCR 2000a; Berger 1966; Knowles 2003). Framed through explicit references

\footnotetext{
${ }^{14}$ Along with other Asian exclusion immigration laws passed around the same time, the Continuous Journey Act was partly fuelled by the Anti-Asian Vancouver Riot of 1907, largely organized by the Asiatic Exclusion League (see Lee 2007). Erika Lee (2007) argues convincingly that such legislations are best understood as part of a "transnational anti-Asian racism" (538) ascendant at the time.
} 
to race, these policies were also discursively rationalized through "scientific knowledge" according to which "Asiatic" and/or "Negro" races would have difficulty adapting to Canada's "cold northern climate" (Berger 1966; see Chapter Five). Such a rationale (re)presents processes of racialized exclusion as both "objectively" necessary and benevolently concerned with the welfare of those deemed "unfit" for entry.

Yet, the Immigration Act 1910 did not have a single, undifferentiated and exclusionary impact in the lives of all people considered to belong to the same "racial" group. For instance, Aboud (2000) and Abu-Laban (1980) both argue this act was used to exclude Arabs from entry into Canada. Aboud (2000) also illustrates, however, that the legislation's application to Arabs (particularly those from the Fertile Crescent region) was often a matter for the discretion of individual immigration officers working at various ports of entry. Using archival research, he further shows that some Arabs were able to petition local politicians to bring family members into Canada during periods of Asian exclusion. Thus, at least where Arab immigration is concerned, immigration legislation did not have a singular effect, a finding which reinforces the notion discussed in Chapter One that there are sometimes unpredictable elements which factor into how various national discourses and institutional practices play out at localized experiential scales. Possibly, immigration officers' discretion was tied in to how they read the bodies of would-be immigrants in relation to vernacular understandings of "race." I suggest this because, as Suad Joseph (1999) demonstrates in relation to legal cases challenging the exclusion of Arabs from access to American citizenship, one judge allowed that Arabs could be considered white when the appellant was a man from the Fertile Crescent region (which is close to the Mediterranean) - although the judge designated this same man as 
not "that particular" type of white person intended by Congress (Naber 2000: 39). In another case where the appellant was from the Arabian Desert region, the judge involved rejected altogether that Arabs could be considered white (Joseph 1999).

Based on the above, the discourses used to justify early immigration policies in Canada seem to be about producing and protecting the interests of a "white," Western European, and bourgeois national body - such that the permeability of national borders to negatively racialized and/or impoverished others was often linked to the labour needs of a white bourgeois elite who formulated such policies (Arat-Koç 1989, 1999, 2005; Armstrong and $\mathrm{Ng} 2005)$. The foregoing also suggests racialized in/exclusion was complex: (1) references to "race" were not always explicit (e.g. the Continuous Passage Act), (2) negative racialization was not always a sufficient basis for exclusion (e.g. Chinese merchants were exempt from Chinese exclusion measures), and (3) such policies were not applied in a uniform manner, likely because the meanings of "race" are themselves variable (Frankenburg 2001; Gilroy 2004, 2005). It is also notable that the Immigration Act 1910 included seemingly more restrictive and explicitly racialized regulations than the preceding one passed in 1906. Taken together, these points complicate simple understandings of racialized in/exclusion and narratives of liberal progress according to which racism was slowly removed from Canadian legislation.

\subsubsection{Postwar Citizenship and Liberalizing Immigration Policy}

Teleological narratives of liberal progress also inadequately depict changes in immigration and citizenship legislation following the Second World War. The Canadian Citizenship Act 1947 - which was part of a broad post-war nation-building project aimed at producing a distinct, unified sense of Canadian national identity - coincided with the 
ascendancy of Keynesian economic ideals (Jenson 1999) and Marshallian conceptions of citizenship (Brodie 2002; Smith 2007). From a Keynesian perspective, citizens pay taxes to a state which, in turn, ensures their well-being by providing a social safety network in the form unemployment insurance and retirement pensions, for example (Bakker and Scott 1997; Jenson 1999; Salter and Salter 1997). Ideally, a welfare state's social services ensure a minimum standard of living, provide a social support network to mitigate some of the negative impacts of a capitalist economy, and see citizens through "difficult economic times" (Bakker and Scott 1997; Jenson 1999; Salter and Salter 1997).

British sociologist, T.H. Marshall, reinforced such ideals in his expansion of the concept of citizenship to include social rights guaranteed by a strong welfare nation-state (Brodie 2002; Isin and Turner 2007). According to Marshall, citizenship as an institution should play not only a legal, but also a social role which "overcomes, mitigates and reduces the impact of economic inequalities that have their origin in the market place" (Turner 1997: 11). Contemporary scholars in citizenship studies critique Marshall's work for reinforcing the boundedness of the nation-state and aim to expand the notion of citizenship in ways that are transnational (e.g. Isin and Turner 2007; Turner 1997). Nevertheless, Marshall's understanding of citizenship as "as a collection of rights and obligations which give individuals a formal legal identity" (Turner 1997: 5) and produce social solidarity continues to be usefully drawn upon and to shape some academic, legislative, and vernacular understandings of citizenship.

Given their conceptual overlaps and temporal coincidence, policy makers unsurprisingly drew on Keynesian and Marshallian ideals to frame the (necessity of) introducing a distinctly Canadian citizenship. For instance, reflecting on the importance 
of the Canadian Citizenship Act 1947 (Canada 1947), Paul Martin Senior (1993) argues that he considered it necessary once he visited the graves of soldiers from Canada who had gone to Europe to fight with Allied Forces in World War Two but were buried under disparate national affiliations (e.g. Irish, British, or Ukrainian) instead of the same banner of "Canadian." Interestingly, Martin also discusses this Act's relationship to the war through a language of liberal progress and social justice: "The country... was not in the struggle just to preserve the imperfections of past decades but was striving to achieve a more equitable and decent society" (73). He thus represents the introduction of Canadian citizenship legislation as a moment when Canada began to move toward (a necessary and desirable) congruence between nation-state-territory (Agamben 1996; Arendt 1951; Brah 1996; Brodie 2002; Gellner 1983; Malkki 1992, 1995, 1996; Strong-Boag 2002).

In the 1960s' global context of increasing social justice activism and anti-colonial nationalisms, the Canadian government applied some of these ideals to "liberalize" its immigration policies (Thobani 2007; see also Arat-Koç 1999; Mackey 1999). In 1962, it replaced explicitly race-based criteria for inadmissibility to Canada with a purportedly race-neutral point system whereby immigrants' admissibility to Canada and access to Canadian citizenship became based on such things as education level, ability to speak either English or French, and availability of capital for investment - a process intended to address a shortage of labour in Canada and concerns about demographic trends that suggested future labour shortages would be even more acutely felt (Canadian Council for Refugees 2000b; Mackey 1999; Thobani 2007; Walsh 2008). In keeping with liberal 
discourses and concepts of social welfare, in 1971 the Canadian government also framed its policy of multiculturalism as a matter of liberalizing national identity. ${ }^{15}$

As mentioned above, in its process of "liberalizing" immigration policies, the Canadian government ceased explicitly to rely on "race" to determine the (un)desirability and (in)admissibility of immigrants. A common, liberal interpretation of these changes is that they reflected commitments to equality and human rights wherein "race" ought not to factor into (exclusionary) definitions of national identity. ${ }^{16}$ From this perspective, Canadian national identity progressively became inclusive because - in keeping with Anthony Smith's (1989) definition of "civic nationalism" - it was (re)built on "rationality," law, or democracy to emphasize "historic territory, legal-political community, and common civic culture and ideology" (11). ${ }^{17}$

The idealization of "civic nationalism" as a route to inclusiveness (perhaps unintentionally) dismisses critical legal and critical race scholars' argument (see Chapter One) that states continue to use legal channels to enact social exclusions within their national, administrative territory. Moreover, in the context of settler-nations like Canada, civic nationalism's legal discourses and practices naturalize a purportedly Canadian

\footnotetext{
${ }^{15}$ Although I discuss multiculturalism in Chapter Six, here I want to note that its links to immigration and citizenship were made explicit in the government's 2008 relocation of the Department of Multiculturalism from Canadian Heritage to Citizenship and Immigration Canada. It is presently managed as part of the portfolio of the Minister of Citizenship, Immigration, and Multiculturalism, Jason Kenney.

${ }^{16}$ As Ruth Frankenberg (2001) points out for the American case, dominant discourses of Canadian national identity are used in ways that implicitly racialize it as "white" while also making it difficult to recognize historically and spatially distinct and shifting meanings of whiteness.

${ }^{17}$ Smith (1989) also elides that legislation within "civic" nations usually links rights to citizenship to the same "communities of birth" and "familial relations" he associates with ethnic nationalism - i.e. jus soli laws whereby citizenship is acquired through birth in a particular territorial community and jus sanguinis laws according to which parents can pass on citizenship to their children.
} 
"historic territory, legal-political community, and common civic culture and ideology" (Smith 1989: 11) through erasing or containing the previous presence and rights of Indigenous peoples. Similar problems pervade the narratives forwarded by scholars such as Will Kymlicka $(1988,1989,1995)$ and Charles Taylor (1997) who represent Canadian national identity as having "evolved" to be increasingly liberal, humanist, and inclusive. These scholars (re)present institutionalized discrimination as a matter of individual bigotry or a relic of an unjust past requiring only the updating of national laws to make them "truly" liberal: racism, for instance, is an aberration in an otherwise inclusive civic nation which can be fixed through further liberalizing "the law."

Scholars who are critical of liberal nationalist discourses, on the other hand, argue that teleological narratives of Canadian national identity and history (a) reproduce "the state's" version of Canada, (b) deny pervasive social inequalities, and (c) reproduce masculinist, Eurocentric, and bourgeois conceptions of a unified national identity (e.g. Bannerji 1993, 1995, 2000; Lawrence 2004; Mackey 1999; Ng 1993; Razack 1998, 2002; Stasiulis and Bakan 1997, 2005; Thobani 2007; Vukov 2003; Walcott 2001, 2003). As succinctly summarized by Himani Bannerji (1993a), these scholars theorize gender, "race," and class as intersecting relations of ruling that inform the legal and governing apparatuses liberal scholars idealize as "neutral" avenues for eliminating inequality. Thus, they argue, the liberalization of Canadian immigration and citizenship laws that followed World War Two - popularly and institutionally constructed as evidence of commitments to social justice and rejection of racism - was not the logical endpoint of liberal political thought. Instead, it reflected changes in global political economy, a need for cheap labour given declining birth rates in Canada, and the untenability of explicitly 
racist policies following the horrors of the Nazi eugenically framed genocide and Canada's involvement in the United Nations (Mackey 1999; Thobani 2007). The point system was first legislated in 1962 following this particular historical juncture.

\subsection{2 (Neo)Liberalizing Immigration Policy}

With the exception of two people, almost everyone I met during the course of fieldwork entered Canada under the point system in the 1960s or under the Immigration Act 1976 (Canada 1976). Legislative changes underway since the 1990s mean many research participants could not immigrate to Canada today in the same way they did in the $60 \mathrm{~s}$ or $70 \mathrm{~s}$ - although this is not to suggest they could not do so at all today. For instance, when my family fled Lebanon during a civil war, we could only get travel visas to the United States from the American embassy in Damascus, but could not get travel visas to Canada. We thus claimed refugee status at the Canada-U.S. border and were returned to the U.S. to wait the processing of our application. The route we took reflects the policies in force at the specific time when we arrived at the Canada-U.S. border in October 1988: it was almost eight months after legislative provisions were passed requiring "refugee claimants arriving from the U.S. ... to wait for processing" there and shortly after (failed) attempts to include regulations in Bill C-55 to exclude refugee claimants who traveled to Canada via "safe third countries," which were resurrected in the early 2000s (CCR 2000b). Thus, had we arrived the previous year, we would have entered Canada immediately. Thirteen years later, under the auspices of the Canada-U.S. Safe Third Country Agreement which came into effect in December 2004, our application would not have been processes at all. 


\section{Canada and the United States signed the Canada-U.S. Safe Third Country}

Agreement in December 2002, requiring refugee claimants coming to Canada through the United States to seek protection in the U.S.A. and vice versa, unless they qualify for one of three categories of exception under the agreement. ${ }^{18}$ According to the Canada Border Services Agency (CBSA 2009) the agreement "allows the governments of both countries to share the responsibility of providing protection to those in need, enhance the orderly handling of refugee claims, strengthen public confidence in the integrity of the Canadian and the United States refugee systems, and reduce abuse of both countries' refugee programs" ( $\$ 22$, emphasis added). CBSA thus frames the agreement through discourses of dangerous abuses of state benevolence ascendant since the 1990s (see below) which (re)produce common-sense images of "real" refugees as necessarily undiscerning - i.e. "if they really need to get away, the final destination would not matter."

This discursive framework, Peter Nyers (2003) argues, simultaneously casts asylum seekers "as the objects of securitised fears and anxieties, possessing either an unsavoury agency (i.e. they are identity-frauds, queue jumpers, people who undermine consent in the polity) or a dangerous agency (i.e. they are criminals, terrorists, agents of insecurity)" (1070). Such discourses reflect the specific socio-political and historical context within which the two countries undertook the agreement while echoing earlier eras' discursive construction of (racialized and impoverished) immigrants as threatening to national unity. My point here is that the specific historical moment when immigrants or refugees arrive in Canada plays a pivotal role in their immigration experiences because

\footnotetext{
${ }^{18}$ These categories include family member exception, unaccompanied minors exception, and document holder exception.
} 
they likely encounter national and global discourses and legislation which, even if continuous with earlier periods, are specific to that time period. In the remainder of this section, I review legislative changes the Canadian federal government and (some) academics interpret as reflecting a liberalizing immigration policy in the $1960 \mathrm{~s}$ and 70 s, as well as changes signifying increasingly neoliberal approaches to governance (since the 1980s) and discourses of national (in)security (through the 1990s and into the present). Throughout, I point to the (dis)continuities between these eras of immigration policy.

The point system formed the basis of the Immigration Act 1976 which introduced four routes to immigration: family class, independent class, humanitarian class, and assisted relatives class (Canada 1976; CCR 2000b; Knowles 2006). ${ }^{19}$ As will become clear in this section, some elements of these designations continue to be included in the Immigration and Refugee Protection Act which replaced Canada's Immigration Act in 2001. There are, however, differences to which I draw readers' attention below.

Family Class regulations were first introduced with the Immigration Act 1976, but changed several times since then. In 1988, for example, the government removed age limits for sponsoring a child but reintroduced them in 1992, setting an age limit of nineteen years (CCR 2000b). Presently, under Family Class immigration, Canadian citizens or permanent residents may sponsor one of the following: a spouse (including common-law or conjugal partner); a child who is unmarried or a full time student, is childless, and is under the age of 22 or "dependent" due to disability; a parent or grandparent; or an orphaned and unmarried sibling, niece, nephew, or grandchild (CIC

\footnotetext{
${ }^{19}$ The Assisted Relatives Class was cancelled in 1993. Today, potential immigrants who do not qualify as family class but have relatives who are Canadian citizens or permanent residents get five "bonus points" if they apply under the federal skilled worker category of independent class ("Assisted Relatives" 2000).
} 
2007c). Since 1976, sponsors must undertake "a 10-year sponsorship agreement with the Canadian government" whereby they assume "the provision of accommodation, care and maintenance for [sponsored] family member[s]" (Arat-Koç 1999: 37). Thus, family class immigrants are not entitled to claim many social services available to other Canadian citizens even after they obtain citizenship - suggesting citizenship rights are not universal, as mythologized, but differentiated (Thobani 2007).

Independent classes include business class immigrants (entrepreneurs, investors, or self-employed persons) or skilled workers (CIC 2010b). The latter of these are selected in accordance with the point system - being accorded points for education, work experience, and proficiency in English and/or French. While prearranged employment was once something for which an applicant received extra points, today a skilled worker or professional immigrant is required to have pre-arranged employment in Canada or at least one year of work experience in an occupation on a specified list (CIC 2011c). Since the introduction of IRPA, there has also been a proliferation of types of independent class immigration. For example, skilled and professional workers can apply under federal regulations or as Québec-selected skilled workers or provincial/territorial nominees (Canada 2001; CIC 2010b). In the latter two cases, the province or territory where an applicant plans to live determines the occupational skills needed, evaluates the application, and selects immigrants who then submit their application for processing by CIC (CIC 2011a). An additional category of Canadian Experience Class has also been created for skilled workers who have recently worked in Canada for two years or graduated from a Canadian post-secondary institution and have one year of work experience in Canada (CIC 2008b). Investors, entrepreneurs, or self-employed persons 
are "expected to make a $\mathbf{C} \$ 800,000$ investment or to own and manage businesses in Canada, and must meet certain experience and/or net worth criteria" (CIC 2010c). The Canadian government has steadily raised the required financial commitment since the 1990s, doubling it in the fall of in 2010 with changes that require "a personal net worth of $\$ 1.6$ million" and "an investment of $\$ 800,000 "$ "(CIC 2010a).

Finally, Humanitarian Class immigration, which includes people recognized as refugees according to the United Nations 1951 Convention Relating to the Status of Refugees, is now called Refugee Class (Canada 2001). On CIC's website, this category is framed as "in keeping with [Canada's] humanitarian tradition and international obligation" (CIC 2011b). Refugees may apply for permanent resident status in three ways: (1) make claims from within Canada; (2) be recommended for resettlement in Canada by "United Nations High Commissioner for Refugees (UNHCR), other referral organizations and private sponsorship groups" subject to approval by "a Canadian visa officer" (CIC 2007b); or (3) be sponsored (a) privately by groups of five or more permanent residents or Canadian citizens, (b) privately by a community organization, or (c) jointly by CIC and a private, incorporated organization (CIC 2010d, 2010e). Private sponsors must provide "financial settlement assistance ... for refugees once they arrive in Canada ... [and] emotional and significant settlement assistance for the duration of the sponsorship period" (2007a) of one year. In the case of joint sponsorship, sponsoring organizations sign an agreement with the Minister of Citizenship, Immigration, and Multiculturalism agreeing to provide twenty-four months of assistance: "CIC provides financial assistance to cover the cost of food, shelter, clothing and essential household 
goods" while the organization offers "help to refugees adjusting to life in Canada, significant settlement assistance and emotional support" (2010d).

Since the 1980s, there have been notable shifts in the percentage of immigrants who enter Canada under each of the above categories. In 1984, the distribution by category of immigrants who gained permanent resident status was as follows: $50.4 \%$ Family Class, $29.5 \%$ Economic Immigrants, $17.4 \%$ Refugees, and $2.6 \%$ Other Immigrants (CIC 2009). While Family Class and Refugee immigrants have steadily declined as proportions of immigrants granted permanent resident status, economic immigration has increased. Thus, in 2008, the distribution was dramatically different: 26.5\% Family Class, $60.3 \%$ Economic Immigrants, $8.8 \%$ Refugees, and $4.3 \%$ Other Immigrants (CIC 2009). These shifts to a much higher percentage of economic migrants reflect instituted changes in the (im)permeability of Canada's national borders to various immigrant bodies and increasingly neoliberal approaches to the governance of nationstates in general which have been underway since the 1980s (Arat-Koç 1999; Dobrowolsky 2007; Macklin 2007).

As Wendy Larner (2000) explains, academics conceptualize neoliberalism as a policy, ideology, or governmentality. While these approaches are not identical, they share an understanding of neoliberalism as co-constitutive with governing paradigms which make community groups and citizens increasingly responsible for their own social, economic, physical, and psychological well-being. Various governmental agencies have used neoliberal discourses to expound on the dangers of "dependency" and, concomitantly, to frame state spending on social services as fiscally irresponsible (in part) because it breeds dependence on the state rather than individuals' and groups' 
accountability for their own (and their family's) welfare (Brodie 1996; Brown 1995;

Jenson 1999; Rose 1996). The doubling of economic immigration and halving humanitarian and family class immigration must be understood within this context. In a neoliberal climate, it is unsurprising that successive federal governments continue to increase the amount of money business class immigrants must invest in Canada, require family members to be responsible for the economic and social wellbeing of those they sponsor, and shift the costs of resettling refugees onto private sponsors. Indeed, such policies are in keeping with neoliberal discourses which valorize decreasing government spending and privatizing citizens' social well-being as a personal responsibility.

Such discourses have explicitly pervaded Canadian immigration policies since the introduction of IRPA under the Liberal government of Paul Martin, junior. While Martin's father, as discussed above, introduced Canadian citizenship legislation through a discursive framing that drew on conceptions of social justice and human rights, IRPA's discursive framing focuses on "protecting" the state and "Canadians" from those who would take advantage of their generosity (Dobrowolsky 2007). Consider, for example, the following stated objectives in section 3(1) of IRPA:

(g) to facilitate the entry of visitors, students and temporary workers for purposes such as trade, commerce, tourism, international understanding and cultural, educational and scientific activities;

(h) to protect the health and safety of Canadians and to maintain the security of Canadian society;

(i) to promote international justice and security by fostering respect for human rights and by denying access to Canadian territory to persons who are criminals or security risks. (Canada 2001, emphasis added) 
These objectives are not surprising given that work on IRPA began in the 1990s, a time that saw an "explosive mixture of concerns about what [came] to be known... as 'system abuse"' (Pratt and Valverde 2002: 136; see also Arat-Koç 1999; Dobrowolsky 2007).

As Anna Pratt and Mariana Valverde (2002) point out, "the threatening figures of the international terrorist and the organized criminal were joined in the $1980 \mathrm{~s}$ by that of the 'bogus refugee,' an unscrupulous, queue-jumping economic migrant also tainted with the suspicion of criminality." In this context, public images of persons who claim "administrative state benefits (whether of refugee protection or of social services) ... merged with the threatening figure of the criminal immigrant" in a discursive process whereby 'the 'deserving victim' of international human rights law came to be replaced by the fraudulent or downright criminal "bogus refugee/welfare cheat"" (138). Reflecting on the use of such discourses in depictions of Somali refugees in a report produced by the Department of Immigration and cited by Canadian politicians and journalists, Pratt and Valverde suggest that Somali refugees would not have been described as "'masters of confusion'... in the 1970s, when immigration and refugee policies were being liberalized" (138). Their arguments, along with legislative developments such as IRPA and the Canada-U.S. Safe Third Country Agreement, call into question liberal national discourses officially used to define Canada as having "progressed" away from racist immigration policies toward ones based in universal notions of human rights and social justice.

In the $2000 \mathrm{~s}$ - and with the added weight of the attacks on the Twin Towers and Pentagon on September 11" 2001 and the "War on Terrorism"- neoliberal discourses are tightly articulated with a security agenda which explicitly re-criminalizes immigrants and refugees in ways that echo pre-War immigration policies (Bhandar 2004; Kinsman 
and Gentile 2010; Macklin 2002; Pratt 2005; Pratt and Valverde 2002). ${ }^{20}$ This convergence of neoliberal and national security discourses is materializing in several ways: the use of refugee detention centres in Toronto, purportedly to minimize security threats posed by bogus refugees (see Pratt 2005); increasing connections between Canada Border Services Agency, Public Safety, and Citizenship and Immigration Canada (CIC); and the constitution of Canadian citizenship in CIC's newest citizenship test study guide, Discover Canada (2010f), in terms of "securing" liberty via European legal traditions.

In this latter document, those studying to become Canadian citizens are told Canadian laws "secure for Canadians an 800-year-old tradition of ordered liberty, which dates back to the signing of Magna Carta in 1215 in England (also known as the Great Charter of Freedoms)" (CIC 2010f:8). Readers are also told that "in Canada, men and women are equal under the law. Canada's openness and generosity do not extend to barbaric cultural practices that tolerate spousal abuse, 'honour killings,' female genital mutilation or other gender-based violence. Those guilty of these crimes are severely punished under Canada's criminal laws" ( 9 , emphasis added). This phrasing constitutes citizenship, not as a right to be claimed, but as a generous gift bestowed or denied in accordance with benevolent European legal traditions. Aside from the Eurocentric depiction of law and order, the practices named as barbaric are ones that have been discursively defined as African, Muslim, South Asian, Arab, and/or Middle Eastern. Thus, this passage points to an explicit process of racialized in/exclusion. I read this particular passage in several interrelated ways: it (1) represents Canada as a place where

\footnotetext{
${ }^{20}$ These convergences are not entirely new. For instance, in 1993, under the Conservative government of Kim Campbell CIC was transferred to the Department of Public Security before being moved again in the same year to Citizenship and Immigration Canada (CCR 2000b).
} 
there is no (legal) gender inequity; (2) constitutes certain (racialized) practices as representing the only potential (and criminalized) source of gendered violence/inequity within Canada; (3) is silent about the (legally-sanctioned) violence of gendered pay inequities and socioeconomic injustices enacted (by corporations and employers) throughout Canada; (4) represents the process of becoming Canadian as simultaneously a process of (Western and Christian) Europeanization that inherently civilizes "barbaric" peoples through law; and (5) suggests that only those whose "origin" includes some combination of British, French, and/or Christian ancestry can be wholly Canadian since others must learn to leave behind their "barbaric" and criminal cultural traditions.

\subsection{Conclusion}

Again, the above-cited passage from CIC's Discover Canada points to an explicit resurfacing of criminalizing discourses about the dangers of immigration that are represented within liberal discourses of national progress as relics of an earlier, racist phase in Canadian history which began to end with the liberalization of immigration law. Yet, the above-discussed legislative changes suggest that Canadian immigration policies and national identity discourses never ceased to be racialized, classed, and gendered. As some academics (whose work I discussed above) and groups such as the Canadian Council for Refugees argue, the removal of overt references to "race" cannot be equated with the end of institutionalized racism in Canadian immigration law (CCR 2000c).

For example, while "race" ceased to explicitly determine admissibility, Canadian visa posts remain more highly concentrated in Europe than in Africa (CCR 2000c: 7). This geographic distribution effectively makes it easier for those who live in Europe or have the economic means to travel to an embassy distant from their place of residence to 
access Canadian visa and immigration applications. The Canadian government's introduction, in the 1990s, of a "right of landing fee" to be paid by immigrants upon receipt of their immigration papers has similarly differentiated effects (Dobrowolsky 2007). Like some scholars and immigrant rights organizations (Arat-Koç 1999; CCR 2000c), a research participant evoked earlier explicitly racist laws by referring to this landing fee as "a head tax." In analyzing this legislation, he pointed out that people who are economically underprivileged or who live in countries where the average annual income is less than $\$ 1000$ (mostly in Africa, Asia, and Eastern Europe), likely have difficulty coming up this amount of money.

Ultimately, then, although the liberalization of immigration laws means the same "rules" were in place for all individuals, the immigration system (as an institution) continues to be fraught with racialized and economic marginalization and exclusion. In this context, it is clear that liberalism's aim to guarantee universal equality by applying the same rules to abstract individuals is compatible with institutionalized racism. It is also evident that liberalization has not eradicated discourses defining racialized Others as national threats. I think this leaves us in a socio-historical and political context where explicitly racist, liberal, and neoliberal discourses co-exist, sometimes reinforcing one another while other times contradicting one another. One way to make sense of the continuities between early and more recent immigration policies is through Anibal Quijano's concept of the coloniality of power which I discuss in the next chapter in relation to global discourses about Arab and Arab Canadian identities. ${ }^{21}$

\footnotetext{
${ }^{21}$ I am particularly indebted to Gabrielle Etcheverry for introducing me to the concept of coloniality.
} 


\section{Chapter: Coloniality, Orientalism, and Arab Canadians}

In the 1980s and 90s, under the heading of post-colonial theory and often inspired by Edward Said's (1994) Orientalism, anti-colonial scholars directed provocative and insightful criticisms at colonialist knowledge and modes of knowledge production (e.g., Ashcroft, Griffiths, and Tiffin 1989; Barker, Hulme, and Iverson 1994; Blunt and Rose 1994; Chakrabarty 1992; Gregory 2001; Loomba 1998; McClintock, Shohat, and Mufti 1997; Prakash 1992; Young 2003). Some of these same scholars quickly began to question whether the term "post-colonial" may prematurely suggest an end to colonialism (for example, McClintock 1992; Shohat 1992) and/or homogenize various histories under a singular Eurocentric teleological narrative (McClintock 1992). Concomitantly, critics charged postcolonial theorists with being elitist academics from the Third World who pay little (if any) attention to international relations of capital thereby occluding a trenchant continuation of imperial power relations (Ahmad 1992; Bannerji 2001; Dirlik 1994).

Following these critiques of postcolonial theory, Anibal Quijano (2000) and other Latin American anti-colonial scholars (e.g. Mignolo 2000a, 2000b) began to write about the concept of the "coloniality of power." As Linda Martin Alcoff (2007) explains, the concept of coloniality of power [allows] us to think through how the colonized were subjected not simply to a rapacious exploitation of all their resources but also to a hegemony of Eurocentric knowledge systems. It allows us to understand the constitutive relationship between the historical a priori of European thought and its off-shore adventures. It also allows us to think through the Anglo- and Eurocentric structure of thought and representation that continues to dominate much of the world today, whether or not, in a given place and time, formal national liberation has been won. (83-4, emphasis added)

The concept thus refers to the continuing discursive and material effects of colonization and highlights that even where formal independence from colonial rule is won, the modes 
of knowledge production and power relations set in motion by colonization do not suddenly dissipate with the withdrawal of colonial administrators and armies.

Concerns that the term "postcolonial" may conceal how "colonial norms and forms extend into the present" (Gregory 2001:84-85) are trenchant in settler nations such as Canada for at least three reasons which illustrate the multidimensionality of colonial power relations and the differences in how they play out at various scales of governance. First, Indigenous peoples continue to struggle for self-determination within the confines of the Canadian colonial states' legal system, even as they have successfully used this same legal system to change the ways they are governed at specific jurisdictional scales (Lawrence 2004; Valverde 2010). Second, many people immigrate to Canada from parts of the world formerly colonized by the same British and French Empires which colonized North America and formed the juridico-political system of governance which now defines access to Canadian citizenship (Anderson 2000; Walcott 1999). When granted access to Canadian citizenship (even if, as some scholars argue, it is conditional and tentative) these same migrants from formerly or presently colonized parts of the world become immigrant-settlers in Canada (Thobani 2007). Third, current forms of governance in Canada continue to resurrect (in flexible form) racist and colonialist discourses commonly thought, as discussed in the previous chapter, to have been phased out through the liberalization of Canadian citizenship and immigration laws. In this context, the coloniality of contemporary global, national, and local power relations, institutions, mobilities, and identity discourses is undeniable.

In the previous chapter, I discussed Canadian immigration policies and nationalist discourses' relationships to racialized, classed, and gendered dimensions of (colonialist) 
discourses wherein a civic nationalism - based in legal tradition - is idealized as a teleological end-point of nation-building projects. In that context, the coloniality of contemporary power relations is evident in continued distinctions between those who are "deserving" and "undeserving" of access to citizenship, which constitute Canadian national borders' variably permeability to potential immigrants based on racialized, classed, and gendered discourses. In some cases, access to Canadian citizenship is denied through racialized discourses which criminalize would-be citizens as potential terrorists (Thobani 2007) or welfare cheats (Pratt and Valverde 2002) who threaten the Canadian nation-state. As I also explained in the previous chapter, colonialist discourses that many people think were phased out by liberal progress toward civic nationalism are presently being resurrected as would-be citizens are subjected to tests on Canada's " 800 -year-old tradition of ordered liberty" which - in opposition to "barbaric" cultural traditions ensures that "in Canada, men and women are equal under the law" (CIC 2010f:8-9).

In this chapter, my focus is on the coloniality of power relations that factor into discursive definitions of Arab and Arab Canadian identities. This is important for my overall argument because my research is with people who identify as Arab Canadian. In other words, their subjectivity and agency are not delimited by discourses of Canadian national identity, but also shaped by discourses of Arab (pan)national identity. Thus, to understand their narratives of the relationships between their immigration experiences and their senses of national identity requires taking into account the history of discourses defining Arab (pan)national identities. As will become apparent in my analysis chapters, the histories and discourses explored in this chapter have implications not only for how 
research participants conceptualize their sense of identity as Arabs, but also for how they engage Canadian national discourses and policies.

In the next section, I offer an overview of Arab (pan)national identity discourses which, as I show, are interconnected with histories of colonialism - something research participants often highlighted to lament national divisions between Arabs as products of histories of colonization (see Chapter Eight). I go on to discuss Edward Said's Orientalism, which scholars continue to invoke in critiques of dominant Eurocentric representations Arabs as "primitive" and barbaric. I follow this with a discussion of the ways in which variations of such racialized colonialist discourses (the specific content of which has shifted) are still used to frame international and national policies in Canada (and the United States) in ways that criminalize Arab Canadians (and Americans) as potential threats to Canada's (and America's) liberal democratic legal tradition and national body. I conclude the chapter by reflecting on the implications of the arguments made in this and the previous chapter for my methodological approach to my project.

\subsection{Defining Arab (Pan)National Identity}

The term Arab does not have a self-evident, fixed meaning or reference point. Indeed, questions of who or what is Arab "were hotly debated in the formative period of the modern Arab nation states during the first half of the twentieth century and continue to generate a great deal of discussion" (Haddad 2004:14). Scholars with divergent interpretations nevertheless tend to agree that the meanings of Arab identity have emerged out of and been (re)shaped by particular historic, socio-cultural, and political contexts (Aboud 2000; Haddad 2004; Haeri 2000; Hafez 2011; Khalidi 1991; Salameh 2011; Suleiman 1994; Suleiman 1999). In its historical and present-day contexts, the term 
Arab is discursively constituted as designating linguistic, cultural, anti-colonial, and/or political forms of identification.

Scholars writing about the topic in North America agree that "an Arab nationalist identity" was first used to designate "all who speak the Arabic language and identify with Arab history" (Haddad 2004:14; see also Hafez 2011; Khalidi 1999; Salameh 2011; Suleiman 1999). As the term suggests, Arab identity has been (and most commonly continues to be) associated with speakers of the Arabic language. Significantly, the Arabic language entered into use through parts of the Middle East and North Africa especially as an "official" language of bureaucracy - with the spread of Islam from the Arabian Peninsula (Abu-Laban 1980; Salameh 2011; Suleiman 1994). Yet, processes of Arabization and Islamacization in the region were not identical with one another. In other words, not everyone who came to speak Arabic or identify as an Arab converted to Islam. In keeping with this distinction between Arabs and Muslims, some historians suggest the term Arab first emerged as a "multi-religious identity ... promoted primarily by Jews and Christians" who spoke Arabic, were living under Ottoman rule, and wanted "to carve out a national identity" as religious minorities (Haddad 2004:15). During this period, "Arabic-speaking Muslims opposing the Young Turks who were seeking to 'Turkify' all ethnic and tribal groups ... in the Ottoman Empire" (15) also began to identify as Arabs. With the demise of the Ottoman Empire at the end of the First World War, the former territory of the Ottomans came under the rule of (British, French, and Spanish) European empires by mandate of the League of Nations. During and following this period, the term Arab came to denote a shared (pan)national identity opposed to the regional (national) divisions exacerbated by European administrators (Haddad 2004; 
Hafez 2011; Khalidi 1991; Salameh 2011; Suleiman 1994; Suleiman 1999). Thus, the term Arab came to denote a shared politico-cultural and anti-colonial identity related to resisting inter-Arab national divisions reified by colonial (including Ottoman and European) rule and building a "modern" Arab nation-state(s) as a secular, national alternative(s) to religious identifications.

Given all of the above, it is to be expected that "today, several ... meanings [which map on to the histories discussed above] may be given to the word "Arab" (Haddad 2004: 15). For example, some people use the term to distinguish between people from the Arabian Peninsula and what Yvonne Yazbeck Haddad (2000) calls the "'Arabized' northern tier (Iraq, Lebanon, Syria, Jordan, Palestine, Egypt, and North Africa)" - usually referred to as the Fertile Crescent and the Maghreb (15). Such distinctions between Arabs and those who have been Arabized are related to the above-discussed linguistic identifications. They gesture, in other words, to the historical spread of the Arabic language into these latter regions beginning in $633 \mathrm{AD}$ (Abu-Laban 1980: 14).

Another common contemporary usage of the word Arab is to signify "citizenship in any of the twenty-two Arab states that are members of the Arab League" (Haddad 2004:15). Here, I suggest, there is an uneasy tension between two forms of identification that are both shaped by colonial processes. On the one hand, the twenty-two Arab states were established and their boundaries drawn roughly in accordance with European colonial rule and the ascendancy of "the nation-state" as an ideal way to organize communities. On the other hand, to use the (pan)national term "Arab" rather than a specific national identifier (e.g. Egyptian) associated with a specific nation-state (e.g. 
Egypt) is to insist on continued affiliation between the members of the nation-states "carved up" by the League of Nations following the break-up of the Ottoman empire.

Yet, to define Arabs as citizens of particular Arab states technical exclusion of Palestinian refugees who self-identify as Arab but are stateless, holding United Nations refugee status papers rather than official Palestinian citizenship. Indeed, most Palestinians have lived in exile or under Israeli military occupation since 1948 or 1967 (Bornstein 2002; Bowman 1994; Hammer 2005; Habib 2004; Jean-Klein 2001; Nazzal 1978; Said 1986,1994 a, 1997; Tamari 1980). ${ }^{22}$ Despite their dispersal to several spatially incongruous territories and the absence of a Palestinian state, most Palestinians think of themselves both as Arab and as forming a nation (Cox and Connell 2003; Kanaaneh 2002; Khalidi 1997; Lindholm Schulz and Hammer 2003; Nassar 2006; Peteet 2005; Said 1994a, 1997; Swedenburg 1990, 1995).

Within institutionalized Israeli discourses and folk-histories, on the other hand, pre-Partition Palestinians are represented as a collection of tribes, clans, and villages with no understanding of themselves as a cohesive nation and Palestinians are discursively

\footnotetext{
22 In 1947, the United Nations adopted Resolution 181 which would partition the land of Mandate Palestine into two states, one Israeli and one Palestinian (Gregory 2004, Kanaaneh 2002, Khalidi 1997. Peteet 2005, Swedenburg 1995). When the British Mandate government began to withdraw from the area at the end of 1947, violence broke out between Israeli Jews (who had a more organized and technologically reinforced army) and Palestinian Arabs (who were reinforced by troops from neighbouring Arab countries) and, at the end of the war, the state of Israel was formed, declaring its independence on May 14, 1948, and including more land than was allocated in the Partition Plan. The new border, known as the armistice line of 1949, became the general border of Israel while Jordan and Egypt effectively took over control of the West Bank and the Gaza Strip, respectively. In 1967, Israel undertook a pre-emptive strike framed as necessary for the defence of its existence as a nation-state during which it took control of the West Bank and the Gaza Strip, whose inhabitants continue to live under Israeli military rule and, in the case of Gaza, under an almost complete military blockade since 2008 (Bornstein 2002; Gregory 2004; Kanaaneh 2002; Khalidi 1997; Mamdani 2004; Nazzal 1978; Parmenter 1994; Piterberg 2001; Rabinowitz 1997; Said 1994a, 1997b; Slyomovics 1988; Swedenburg 1995).
} 
represented as nomadic Arabs who can, therefore, be (re)absorbed into the surrounding Arab nations (Rabinowitz 1997; see also Gregory 2004; Parmenter 1994; Piterberg 2001; Slyomovics 1988). ${ }^{23}$ In keeping with this, Israeli laws and policies refer to Palestinians who remained within the territory of the state of Israel upon its formation in 1948 - and became citizens of the newly formed nation-state - as Arab Israelis. ${ }^{24}$ This terminology has been central to some Israeli politicians' denials of Palestinian claims to nationhood and suggestions that resettlement within the surrounding Arab states is the most logical solution to the "problem" of Palestinian refugees. In this context, Palestinian citizens of Israel might understand the national identifier of Palestinian as anti-colonial (and specifically anti-Zionist). Ultimately, then, to define the term Arab in reference to citizens of Arab states exclude citizens of Israel who identify as both Arab and Palestinian as well as Palestinian refugees who are technically stateless.

Perhaps due to some of these problems with the definition of Arabs as citizens of member nations of the Arab League, other scholars suggest the term more "properly" applies to citizens of "the Arabic-speaking countries [which] today include Algeria, Bahrain, Egypt, Iraq, Jordan, Kuwait, Lebanon, Libya, Mauritania, Morocco, Oman, pre-

\footnotetext{
${ }^{23}$ Despite United Nations Resolution 194 (passed December $11^{\text {th }}, 1948$ ), which essentially grants Palestinian refugees the option of return to their homes or compensation for their loss, neither option has been forthcoming: most Palestinians continue to live as refugees in exile from their homes.

${ }^{24}$ Some scholars suggest that the term "Arab Israelis" denies the coloniality of Israeli nation-building and (re)enforces the image of Israel as a multicultural society and "the only democracy" in the Middle East (Kanaaneh 2002; Rabinowitz 1997, 2001a, 2001b). Many also argue that the dominant representation of Israel as a final destination/solution in a long history of suffering often means criticisms of the state and its policies toward Palestinians, as well as claims to Palestinian identity, are incorporated into and represented within a discourse that dismisses them as essentially anti-Semitic or anti-democratic, and thus, as threatening the very existence of the state of Israel (Bornstein 2002; Gregory 2004; Mamdani 2004; Said 1986, 1994a, 1994b, 1994c, 1997; Semmerling 2004; Shohat 1997; Swedenburg 1995).
} 
1948 Palestine and the Palestinians, Qatar, Saudi Arabia, Sudan, Syria, Tunisia, United Arab Emirates, and Yemen" (Suleiman 1999:1, emphasis added). From this perspective, those countries are to be distinguished from "Somalia and Djibouti [which] are also members of The League of Arab States and have some Arabic-speaking populations," but many of whose members are not as likely to identify as Arab (1).

Yet, defining certain nations as "Arabic-speaking," and their inhabitants as ipso facto Arab, discursively denies the cultural and political membership of linguistic "minorities" in these nations, even in cases where they are not so minor. For example, such a discourse implicitly erases the linguistic and cultural centrality of Berber in Morocco (Sadiqi 1997) and negates many Lebanese people's self-identification as Phoenician rather than Arab - an identity discourse itself tied in with various colonialist histories (Hage 1992, 2009). Similarly, many citizens of Iraq identify as Kurds rather than Arabs and have struggled to claim and maintain this sense of identity against a great deal of state repression (Mojab 2001; O'Leary 2002). To use the appellation "Arab" in reference to them may reproduce the state violence against which they have struggled even if most of them speak Arabic as well as Kurdish.

Moreover, while many emphasize linguistic ties in definitions of Arab identity, there are variations in the Arabic language. As Haeri (2000) points out, "Classical Arabic coexists with such national vernaculars as Egyptian, Syrian, Jordanian, and so on. The first is the language of writing, education, and administration, while the latter are the media of oral exchanges, nonprint media, poetry, and plays" (63) - although there is an increasing, but informal, tendency to use the Arabic alphabet to write in national vernaculars. Consequently, while readers/writers of Arabic generally do share a linguistic 
medium of communication in the form of Classical Arabic, those who only use and know the language as an oral medium of communication most likely know a specific, localized, vernacular form (or a few of these) and may, thus, be unable to communicate orally with speakers of other Arabic vernaculars even if they consider themselves Arabs.

Following all of the above, I want to draw out three points about the complexities and contradictions that emerge in attempts to provide a homogenous, all-encompassing definition of the term Arab. First, while some people use the term "Arab" as if it is a selfevident category of "ethnic" identification, its application to any group of people must be contextualized; it may encompass more than one meaning within the same historical era and geographic location. In this same vein, even the designation as Arab of an ostensibly homogenously linguistic community has been problematized. Second, some uses of the term "Arab" implicitly or explicitly rely on discourses embedded within hierarchical notions of "authentic" Arab-ness. For example, the above-discussed distinction between Arabs as people who are descendents of the inhabitants of the Arabian Peninsula and "Arabized" peoples from the Fertile Crescent or North Africa implies that the latter have come to take on an Arab identity but are not as "authentically" Arab as the former. Third, the broad use of the term "Arab" has been discursively framed as resisting (colonial) attempts to divide (and conquer) inhabitants of the region from the Atlantic shores of Morocco to the Persian Gulf, a form of resistance sometimes referred to as pan-Arab nationalism (or pan-Arabism). It has, however, also been linked to Zionist discourses denying the possibility of a meaningful Palestinian national identity.

Taken together, the above three points reinforce the idea that Arab identity discourses developed, and continue to develop, in complex and uneven ways. Thus, a 
thorough understanding of the meaning(s) of Arab identity requires taking into account the constitutive relationships between various regions in "the Arab world," the Ottoman empire, European political thought and rule (including the veneration of the nation-state as the most ideal socio-political unit), as well as religious and local affiliations (which continue to intersect with and shape people's identifications as Arab). Historically, Rashid Khalidi (1991) argues,

Arab nationalism represented both a revival of old traditions and loyalties and a creation of new myths based on them... Thus, as Arab nationalism took hold, what had been described for thirteen centuries as the glories of Islamic civilization came to be called the glories of Arab civilization; the language and literature of the Arabs, always revered and cherished, took on a new and heightened importance; and a sense of pride in Arabism that had... long been dormant was consciously revived and actively fostered.... [E]arly in the twentieth century, at the end of this process of synthesis ... the idea was widespread throughout the 'Arab world' (itself a concept born of the rise of Arab nationalism) that anyone who spoke Arabic, looked back on the history of the Arabs with pride, and considered himself or herself to be an Arab was one, and that this sense of shared identity should in some measure find political expression. (1365, emphasis added)

Khalidi adds that "local patriotisms" form alternate loci of identification which "mounted ... challenge[s] to Arab nationalism" (1365). Thus, he suggests, "it is not the case that Arab nationalism was or is necessarily synonymous with pan-Arabism, that is, with the idea that all Arabs should live in a single great Arab nation-state" (1365). ${ }^{25}$

What I take from Khalidi's discussion is that there continues to be a variety of Arab nationalisms and identities, some of which are more localized than the nation-states in which they emerged, that circulate alongside the identity discourses associated with those nation-states as well as (pan)national Arab identity discourses. Moreover, claiming

\footnotetext{
${ }^{25}$ For varying assessments of the concept of pan-Arabism, refer to Karsh and Karsh (1996), Kramer (1993), and Reiser (1983).
} 
a specific national identity, such as Jordanian, is neither necessarily synonymous with nor entirely divergent from claiming a broader pan-Arab identity. This suggests that the meanings associated with Arab identities shift in accordance with various historical and geographic scales of analysis. It also suggests pan-Arab national identity discourses have not been entirely eclipsed by those of specific Arab nation-states. Ultimately, then, "Arab national identity," like "Canadian national identity," has been and continues to be a site of struggle among those who identify as Arab. As I explain in the next section, globalized colonialist discourses which define Arab identities from the outside often obscure and elide the multiple, contested meanings of the term Arab. These globalized discourses are important in the context of my dissertation because research participants often referred to them as forming the kind of "misinformation" about Arabs they encountered in Canada.

\subsection{Colonialism and Orientalist Conceptualizations of Arabs}

Edward Said (1994b) coined the term Orientalism in reference to British and French academic scholarship which gained much of its authority from, and was used to rationalize, administrative and military imperialist incursions into a geographic region broadly referred to as "the Orient" - a region broad enough to encompass the Middle East, China, and the Indian sub-continent. Specifically, Said uses the term Orientalism to refer to a discourse which reinforces a particular homogenizing "style of thought" about "the Orient" within academic scholarship and colonial policies. According to Said, Orientalist discourses produced a binary opposition between two ostensibly mutually exclusive subject positions. Within Orientalist discourse, this is to say, active, selfpossessing, detached (Western European) Occidentals are capable of speaking objectively and, thus, expertly about/for the Orient while Orientals' knowledge about/for the Orient 
is dismissed as tainted by their subject positions. Said argues that Orientalist discourses define the latter, including Arabs, as technologically backward, barbaric, and irrational.

Said's concern is not about the "truth" value of Orientalist discourses as such. Instead, he aims to illustrate that such literary and academic discourses matter, that discourses (Orientalist or not) have material effects in people's lives because they are tied in to power/knowledge and consequently enter into and shape, even as they are shaped by, governing relations (see also Said 1993). He illustrates this by examining the justifications and homogenizing identity discourses Orientalist scholars produced for colonial administrative and military interventions (defined as civilizing missions).

The main critique of Orientalism (1994b) and Culture and Imperialism (1993) is that Said presents a totalizing argument which does not take into account historical changes in Eurocentric and colonialist discourses and delimits the possible subject positions that could be produced within its context. The most comprehensive of such critiques comes from Aijaz Ahmad (1992), who argues that Said's argument remains firmly within the world-view he criticizes and thus reproduces a vision of a "unified European/western identity which is at the origin of history and which has shaped this history through its thought and its texts" (100). Ultimately, Ahmad says, Said leaves little room for theorizing historical changes in or differences between how discourses play out (based on material relations) in specific geographic locations, thereby conceptualizing "Western" knowledge as both homogenous and all-encompassing.

Said addresses these critiques in the afterword to the 1994 edition of Orientalism in two interrelated ways. First, he clarifies, he does not use the concept of Orientalism as a synecdoche for all "Western" or "European" thought, but as a way of naming a specific 
set of Othering discourses prevalent in a particular body of scholarship defined by its ties to colonial administration and imperial capitalist ventures. Such a (re)formulation, he suggests, leaves room for alternative conceptions of "the Orient" written by and for European thinkers as well as by people who live(d) in "the Orient" (who are, after all, capable of representing themselves). In this regard, Said asserts, his argument is that although there are alternate formulations, scholarly works framed through Orientalist discourse came to have the status of "expert" knowledge within colonial government circles precisely because of their usefulness for colonial administrators. Said's second response to his critics is to highlight his decidedly anti-essentialist understanding of identity and to deny any claims of a singular Occident which produces a singular Orient for all times. Instead, he says, his point is that a particular construction of the first, which was tied into "the struggle for control over territory" (Said 1994b: 331), relied on an equally specific construction of the latter. Thus, he insists, "no one person, authority, or institution has total control over [the] definition" of any identity (332).

While I think Said's response begins to address some concerns raised by critics, it does not entirely undo the potential homogenizations that may be enacted by the terminology of Orientalism. Yet, Said's work continues to be central in academic analyses of colonialist discursive constructions of Arabs, which shape foreign and domestic European and North American state policies (e.g. Abu-Lughod 2001; Haldrup, Koefoed, and Simonsen 2006; Gregory 1995a, 2000, 2004). This centrality reflects the continued pertinence of Said's arguments in Orientalism (1994b) and other books (e.g. 1993, 1994a, 1997a, 2000) for analyses of the lives of Arabs throughout the world. In the contemporary socio-political context, Samuel Huntington's (1996) The Clash of 
Civilizations and the Remaking of the World Order - based on Bernard Lewis's "The Roots of Muslim Rage" - has become a best-seller (Obituary 2008; Said 2001). Moreover, some of the discourses Said identifies as Orientalist presently factor into the formation and framing of policies involved in the "War on Terror," including the sexual torture of prisoners in Iraq's Abu-Ghraib prison (McClintock 2009; Puar 2004). Within such gendered discourses, Arab and Muslim men (often conflated into one category) emerge as hypermasculine, particularly homophobic, highly authoritarian, irrational, and motivated by concerns about "honour" above all else. The image of Arab and Muslim women (again conflated into a single category) produced through these same discourses is of demure, silent, meek, and oppressed victims in need of liberation from the excessive patriarchy of Arab and Muslim men (Abu-Lughod 1989, 2001, 2002).

In the next section, I illustrate the ongoing legacy of such discourses, the specific content of which has been continuously (re)shaped through their intersections with other discourses. Given concerns over the totalizing or homogenizing potentials of the term, rather than referring to these discourses as Orientalist, I focus on their particular content and the ways in which they reflect the coloniality of specific power relations. As I argue below, Americans and Canadians who have immigrated from or claim ancestry in the Arab world are frequently required to confront colonial discourses according to which they are depicted as primitive, illiberal, and (potentially) dangerous "outsiders" within the U.S and Canada respectively.

\subsection{Coloniality and Representations of Arab Americans and Canadians}

In his work on representations of Arabs in Hollywood films, Jack Shaheen (2001, 2003,2007 ) analyzes over 900 feature films (dating from 1896 into the 2000s) and finds 
that only five percent (just more than fifty) of those films portray Arabs in roles other than as villains. The other ninety-five percent of the films, he argues, rely on and reproduce images of Arabs as "brutal, heartless, uncivilized religious fanatics and moneymad cultural 'others' bent on terrorizing civilized Westerners" (2003: 172). Such images are in keeping with representations of "the Orient" Said first described in 1979.

Despite such continuities between early and more recent Hollywood films, the specifics of gendered and (hetero)sexualized representations of Arabs have shifted over time. Thus, as Shaheen illustrates, while Arab men continue to be represented as barbaric despots, earlier images of hedonistic, greedy sheiks intent on killing Western European men and seducing Western European women have been replaced by images of equally violent Arab "terrorists" intent on generally oppressing women and killing Western Europeans, North Americans, and Israelis. Shaheen $(1980,1984,2001,2003,2007)$ argues convincingly that such films cannot be dismissed as "merely" cultural representations (see also Shohat and Stam 2004). For instance, some of these films were/are funded and/or made with the help of the American Department of Homeland Security - which has recently enlisted the help of scholars like Bernard Lewis, the colonialist elements of whose work Said illustrates in Orientalism, in drawing their Middle East policies and outlining their rationale in the "War on Terror" (Said 2007: 3). In other words, while "the Arab world" is no longer composed of British, French, and Spanish colonies or mandates, elements of discourses which gained much of their expert status under their colonial rule continue to factor into contemporary institutionalized discourses and imperialist policies wherein "Arabs" are defined as dangerous Others. 
Such discourses have also figured centrally in several policies and government operations in the U.S. since the early 1970s. For example, Operation Boulder, "launched in 1972 by the Nixon administration after the massacre of Israeli athletes at Munich" (Haddad 2004:21; Naber 2008) and lasting into 1975, was founded on discursive constructions (and fear) of Arabs as terrorists. Under this security operation, organizations which formed in the U.S. to combat racist representations of Arabs and defend Arab Americans' civil rights - in response to media images of Arabs as dangerous which followed war of 1967 wherein Israel took control of the Gaza Strip and the West Bank - came under FBI surveillance: their phones were tapped, their mail was intercepted, and undercover FBI agents gathered information about Arab Americans to track their ostensibly dangerous political ideals. Operation Boulder also initiated "the deportation of hundreds on technical irregularities" and led to restrictions on "immigration from the Arab world" (Haddad: 21). ${ }^{26}$

Given all of the above, perhaps it is not surprising that "utilizing the Freedom of Information Act, the Arab community learned that in 1986 the American administration was considering the use of two military compounds in the South for the possible internment of Arabs and Iranians" (Haddad 2004: 21; see also Joseph 1999; Naber 2008; Ono 2005). While the FBI and Immigration and Naturalization Services did not follow through on these contingency plans for internment, the consideration of such a policy

\footnotetext{
${ }^{26}$ In another FBI operation, ABSCAM (Arab Scam), undercover FBI agents offered bribes to US Senators with the stated aim of tracking corruption in American government (Haddad 2004:21; see also Naber 2008; Shaheen 1980, 1984). As part of this operation, two FBI agents posed as Arab sheiks/oil barons: one purported to be from Oman (and went by the non-Arab name of Kambir) and the other from Lebanon (a country which has neither oil nor sheiks). Thus, the rationale and design of the operation presupposed and relied on senators' familiarity with and acceptance of homogenizing discourses wherein the Arab world is a place inhabited by greedy, corrupt oil barons (see Shaheen 1984).
} 
over thirty years after the internment of Japanese Americans (and Canadians) during World War Two, at a time that is discursively constructed as post-racial (Goldberg 2002) and post-colonial, highlights the continuation of racist and colonialist logics infusing forms of contemporary governance. The above-discussed policies and operations are, as I illustrate, founded on racialized nationalist discursive logics wherein those constituted as fundamentally foreign to an otherwise homogenous nation are feared as disloyal and dangerous "outsiders." In this context, their political citizenship might be (re)presented as "accidental" and their social citizenship denied (Nyers 2006).

In Canada, during the first Gulf War in 1991, similar racialized discourses within which Arab Canadians were defined as potentially dangerous threats also infused security logics. At that time, the Canadian Security Intelligence Services (CSIS) and the Royal Canadian Mounted Police (RCMP) undertook a large operation, The National Emergency Operations Plan, which involved intense surveillance of and interviews with hundreds of Arab Canadians about their political views and support for the war (Kashmeri 1991: 59). During this time, some Canadian politicians and representatives of the RCMP and CSIS consistently appeared in national media outlets calling on Canadians to be vigilant about potential threats to Canada's national security and encouraging them to report any "suspicious" behaviour. As Zuheir Kashmeri (1991) illustrates, some people took up this call for vigilance in such ways that the RCMP received and often followed through on "tips" from callers who had overheard a group of people they thought to be Arab Canadians discussing the war, which many Canadians (Arab or not) were likely discussing at the time (108). According to Kashmeri, RCMP and CSIS interviewers often entered people's homes without warrants and interviewed them without lawyers present. 
Concerns about such practices led the Canadian Arab Federation (CAF, a national association which operates out of Toronto, Ontario) to produce and distribute a brochure called "When CSIS Calls" to inform Arab Canadians of their legal rights and provide telephone numbers to call for advice (Kashmeri 1991: 105).

During this time (i.e. 1991), CSIS representatives questioned Arab Canadians about their political views and explicitly and publicly questioned their "loyalty" to Canada (see Kashmeri 1991), an approach that resonates with earlier legislation within Canada. For example, it echoes racialized "national security" logic of The War Measures Act 1914, which was used, among other things, to suppress labour activism (often through deporting activists who had immigrated or whose parents had immigrated to Canada from Eastern European countries deemed to be the source of "socialist propaganda") and to intern those people (mostly Ukrainian Canadians) defined as "foreign" or "enemy aliens" during the First World War (Kealey 1992). During the Second World War, this same act was used to deport Japanese Canadians and/or intern them in labour camps, again under the auspices that they were "enemy aliens" (Kobayashi 1990). In both cases, based on homogenizing racialized discourses, certain people were (re)defined as dangerous and "disloyal" outsiders within Canada's national borders. Similarly, in the context of the Gulf War, Arab Canadians were seen as a potentially imminent threat to be managed and intercepted precisely because they were identified as Arab and thus potentially "disloyal" to the Canadian nation-state.

As discussed in Chapter Two, such racialized institutionalized discourses also infuse(d) Canadian immigration laws. Recall, for example, that Canadian immigration legislations included "Asiatic exclusion" laws (e.g. the Chinese Head Tax and the 
Continuous Passage Act) which were in place until 1967 (Aboud 2000; Dua 2003;

Knowles 2006). As powerful administrative tools used to produce a specific national body, such immigration policies were framed through racist discourses and aimed to keep Canada "a white man's country." Although explicitly racial language was removed with the liberalization of immigration policies, as mentioned in the previous chapter, some scholars represent this removal as the result of Canadian labour market needs and the impossibility of using explicitly racist language following the horrors of the Holocaust rather a reflection of newfound anti-racist commitments (Mackey 1999; Thobani 2007).

Following from this, some scholars suggest that earlier references to race have been superseded by a "culturalist" language that operates according to similar logics (Mamdani 2002; Razack 2008; Thobani 2007). Like Said's argument that "Orientalist" discourses produced images of "Orientals" as forever tainted by their associations with "the Orient," these scholars argue that in an era where racism is defined as a form of discrimination based on external, phenotypic traits, contemporary racializing vernaculars rely on culturalist discourses in attempts to side-step accusations of racism (see also Gilroy 1987). Mahmood Mamdani (2002) calls such vernaculars "culture talk":

On the one hand, cultural explanations of political outcomes tend to avoid history and issues. By equating political tendencies with entire communities defined in nonhistorical cultural terms, such explanations encourage collective discipline and punishment - a practice characteristic of colonial encounters... On the other hand, culture talk tends to think of individuals (from 'traditional' cultures) in authentic and original terms, as if their identities are shaped entirely by the supposedly unchanging culture into which they are born. In so doing, it dehistoricizes the construction of political identities. (767, emphasis original)

Mamdani makes this argument in relation to discursive representations of Muslims following the September $11^{\text {th }}, 2001$ attacks on the Twin Towers and the Pentagon. He suggests that as journalists, "terrorism experts," and politicians rushed to explain the 
attacks, they relied on a distinction between "modern" and "premodern" cultures: in the first case "culture stands for creativity, for what being human is all about" while in the latter case it "stands for habit, for some kind of instinctive activity whose rules are inscribed in early founding texts" (767). Accordingly, he says, Muslims are represented as being "incapable of transforming their culture" such that "their salvation lies... in being saved from the outside" (767).

Mamdani's arguments can be extended beyond discursive constructions of Muslims to those of other cultures that are defined as "premodern" such as Arabs. Indeed, as Joseph, D'Harlingue, and Ka Hin Wong (2008) illustrate, journalists tend to use the terms Muslims and Arabs interchangeable such that Pakistani Muslims are represented as Arabs in the New York Times. The main point I want to draw out from Mamdani's work in relation to the arguments I make in this section is that the use of "culture talk" enacts similar homogenizations as earlier explicitly "race"-based discourses which infused colonial policies and justified imperial capitalist ventures as civilizing missions. From this perspective, people whose cultures are defined as "premodern" are depicted as essentially driven by the authority they impute to their "cultures" and consequently forever fixed in (extremist) modes of thought others have long since moved beyond. They are, in other words, represented as driven by a variation of "ethnic" nationalism (see Chapter Two) rather than a (post-racial) liberal "civic" nationalism ostensibly built on a non-cultural rule of law. These discourses form an important part of the socio-political environment faced by the people who participated in this research project.

\subsection{Conclusion}


By way of concluding this chapter, I want to gesture toward my forthcoming analysis by highlighting key elements of the literature I reviewed in this and the previous chapters. First, the foregoing literature review complicates dominant understandings of liberalism as something which guarantees social equality and justice by focussing on an abstract individual. A focus on an abstract individual (who is located in a present moment that is somehow beyond and free of past injustices) cannot ensure equality because it occludes how past injustices continue to shape contemporary thought and institutions. This is part of the point made by anti-colonial scholars who insist that present-day power relations and modes of production are necessarily colonial in some respects.

Following from the above point, it is impossible to separate institutional and individual understandings and representations of national identities and the in/exclusions such understandings may be used to enact. Thus, while it is important to pay attention to institutionalized discourses, it is also necessary to develop empirically-based analyses that illustrate how and why such discourses are or are not embraced by everyone they aim to constitute. Indeed, it is difficult to imagine arguing that Arab Canadians embrace discourses defining Arabs as threatening the security of Canada. In this same vein, it is unlikely that they all accept discourses defining Canada as having moved into an antiracist present. This is not to suggest that individuals' senses of themselves are entirely independent of the broader socio-political and historical contexts and discourses in which they exist. Instead, it is a call for analyses that take seriously the idea that citizens and subjects may not, and often do not, literally and directly take up the underlying frameworks and assumptions of state policies and institutionalized national discourses. 
This latter point is especially important in terms of how I approach this project. While studying the production and circulation of state-sanctioned discourses at the institutional level is important - and, indeed, my project is difficult to imagine without such analyses - if we aim to draw conclusions about the impacts of such discourses on people's senses of self, I argue, it is equally essential to pay attention to what happens as people interact with these discourses, as I do in this dissertation. Moreover, the moments and sites where a person interacts with a particular institutionalized discourse are important components of the circulation of such a discourse. At these points of interaction, people may challenge discourses in various ways and, often, such challenges exist (perhaps uneasily) alongside acceptance of certain components of a discourse. Thus, as I explained in Chapter One, my aim is to build on analyses of institutionalized discourses of national identity through a methodological framework that highlights the inseparability of intersecting discourses, socio-political structures, and research participants' subjective agency - i.e. an agency that is inseparable from the processes that produce subjectivity. I take up these and other methodological considerations that frame my project in the next chapter. 


\section{Chapter: Methodology and Multiplicity}

I conceptualize this project as a critical, interpretive ethnography. Below, I explain my methodological approach to this project. As a way of entering into this explanation, I begin with an informal conversation I had during fieldwork which reinforced the importance of this approach for me.

Amal was always full of energy, projected a contagious sense of confidence, and I felt an instant connection with her - likely because she reminded me of one of my aunts. Shortly after we met, I bumped into her in the west end of Ottawa and she invited me to her house to speak with her, her husband, and their children (whose ages range from late teens to early twenties) about my research. Explaining that she thought my research would be an interesting topic of conversation, she asked me to bring along my interview questions (see Appendix D) to show her husband, Majed, and their children. I agreed and Amal and Majed drove me to their house while he and I talked about the Lebanese village from which he emigrated and the one where my father's parents lived before moving to a suburb of Beirut. When we arrived, Amal placed a large spread of fruits, vegetables, dips, nacho chips, nuts, and pizza in the den and suggested I take notes as we spoke.

Over the next few hours, I showed Amal, her husband, and their two sons, Adam and Tariq, my list of interview questions and the two young men took turns answering questions related to their conceptions of Arab and Canadian identities. Adam, who was the older of the two young men (both of whom were born in Canada), presented a linear narrative about his sense of national identity wherein he shifted from feeling Arab to feeling Canadian. Starting this narrative with his childhood, he suggested that, at the time, he experienced his sense of national identity vicariously through his parents. Thus, 
he said, he had not thought of Canada as his home because it was not that of his parents. This puzzled me a little at first because I interpreted previous conversations with Amal to mean that she felt quite at home in Canada, and particularly in Ottawa. As the conversation went on, I began to think many of Adam's comments were about his perception of Majed's sense of (dis)placement in Canada and Majed soon began to display signs of frustration at Adam's narrative.

Despite understanding himself as an Arab child, Adam continued, he often felt that other Arabs and Arab Canadians did not consider him a "real" Arab because he was born in Canada rather than Lebanon. Hyper-aware of and sensitive toward what he perceived as an attitude that dismissed his identification as Arab, he would tell other Arabs and Arab Canadians that he was born in Lebanon hoping this might lead to greater acceptance from them. At the same time, Adam felt he did not "fit in" as a Muslim Arab with his Catholic, non Arab Canadian classmates at the Catholic elementary school he attended. Considering this feeling of non-belonging aloud, Adam wondered if it resulted from not partaking in rituals, like the taking of the Eucharist, with his classmates and said his sense of non-belonging diminished once he transferred to a public school.

As he developed friendships with his new non Arab Canadian classmates, felt a sense of acceptance from them, and began to feel more independent of his parents, his understanding of his national identity shifted. At the time of our discussion, a few years after completing high school, he said he felt more Canadian than Arab. He added that he did not voluntarily tell people he was "Middle Eastern" but that if someone were to ask, he would identify as "a Canadian with an Arab background." In this sense, he seemed to suggest, any Arab national affiliation he might express was still about its connection to 
his parents' life histories. Yet, because his own formative experiences and relationships had all taken place in Canada, Adam concluded, he was Canadian.

By now Adam's younger brother, Tariq, had finished eating his lunch and joined our conversation to explain that he thought the entire question of national identity was misplaced. Offering this as advice for my research project, he argued I would need to keep in mind that nobody is the same in every social interaction: "If I'm talking to one person," he said, "and then talking to someone else, I'm not the same in both conversations. That's not just about being Arab or Canadian. It's about relating differently to different people." While Adam seemed to struggle with his sense of national identity and to understand it as having to be somewhat fixed, Tariq (to whom Amal referred as "my little philosopher") seemed to be comfortable shifting between various senses of identity (national or otherwise) and to understand identity as necessarily contextual rather than an expression of some core, unchanging feeling or sense of self. As our conversation moved on, the two young men eventually began asking me questions about myself: how long I had lived in Canada, how I would respond to some of the questions they had just answered, and what I liked to do in my spare time. Toward the end of this conversation, Adam turned to his brother and asked "So you still think she's really Arab?" Surprised by the comment, I asked what he meant and he responded with "You are definitely not Arab. You're not like other Arab women." When I questioned him about what he thought "Arab women" were like, all I could get in response was "Not like you!" His father, Majed, interjected here, insisting Adam was wrong: "Samah is very proud of being Arab." He elaborated on this by explaining that he saw me as a proud 
Arab woman who "knows the importance of her roots." For her part, Amal said she did not think being an Arab woman and a Canadian woman had to be mutually exclusive.

Amal's view was certainly in keeping with what I knew of her and the sense of "cosmopolitan" identity she seemed to project. A Muslim Arab, Amal grew up in Lebanon where she had attended a French Christian school - an experience she spoke of in positive terms, never suggesting that she felt out of place among her teachers and classmates. She met her husband when he was visiting Lebanon (where he had been born) and moved to Ottawa upon her marriage to him, where she eventually started her own business. In conversations, she often and easily switched between Arabic, English, and French (the three most commonly spoken languages in Ottawa) and always had a kind word of encouragement if I seemed self-conscious about my role as a researcher.

Although I would have liked to continue the discussion with Amal and her family, she and Majed had an appointment so we quickly said our goodbyes. After parting ways with Amal and her family, I reflected on our encounter: we all took part in the same interaction, yet each of them had a different interpretation of me, all of which hinged on their definitions of the relationships between two (pan)national identity categories, namely Arab and Canadian. Methodologically, it seemed clear that analyzing differences in their interpretations required considering the interconnections between national identity discourses, those related to age and gender, each person's life history, and the familial dynamics of the interaction.

Majed, for example, had left Lebanon for Canada in the 1960s. It is likely that his view of life in Lebanon or other Arab countries was based on his experiences there prior to immigrating to Canada. Amal, who was younger than her husband by more than five 
years, and who had lived in Lebanon well beyond the time he had spent there, had different experiences in the country, reflecting a different era. Their sons, on the other hand, had neither lived in Lebanon nor spent much time there; their interpretations of Arab identity were based on stories they heard from their parents, their parents' friends, and various media representations of Arabs.

Indeed, although I knew that Amal had once loved to go out dancing with her friends in Lebanon and Canada, Adam's interpretation of me seemed to shift from "Arab" to "Canadian" upon his learning that one of my favourite things to do was to go out dancing with my friends: at this point, his eyes widened and he turned to Tariq to ask if he still considered me "really Arab." That my love of dancing began during my childhood in Lebanon, and was nourished by summer evening parties on the beaches of Beirut with my parents and their friends, was not something he could have known. He also could not have known that when I now visit my cousins in Lebanon and the United Arab Emirates, we dance at clubs until all hours of the morning. To him, it seemed, "Arab women" do not dance!

Interestingly, during the conversation in their living room, Amal told me they had Arab Canadian friends over the previous evening and that her husband had been surprised to learn their friends' daughter regularly goes out dancing at night clubs. Perhaps, then, Adam's surprise reflected his interpretation of his dad's conception of what being Arab, young, and female means - or should mean. Yet, while his father might have been surprised about my "clubbing" activities, my knowledge of various villages in the south of Lebanon, my willingness to discuss "Arab politics," and my research interest in Arab identities seemed to denote certain "pride" that factored into his interpretation of my 
national identification(s). In other words, my intellectual engagements with the places and politics of "the Arab world" seemed to be the most salient factor for him.

From my perspective, some of the tensions pervading the above interaction were not only about divergent interpretations of Arab and Canadian national identities but, at a localized familial scale, they also reflected a father's frustrations with feeling that his son had little interest in learning about or respect for a form of national identification he felt defined much of who he is as a person. He also seemed exasperated by what I think he interpreted as his son's (perhaps wilful) rejection of his "roots," at one point drawing on elements of institutionalized discourses of Canadian multiculturalism in an attempt to convince Adam that he was missing out "on the opportunity to learn from multiple cultures." Adam, on the other hand, seemed to suggest that rather than a wilful rejection, his sense of not being (able to identify as) "Arab" was the result of feelings of exclusion and marginalization he encountered in his interactions with people he defined as Arab and Arab Canadian, of feeling he could not be "Arab enough" for them - a marginalization which eventually severed his expressed childhood longing to sediment any (seemingly vicarious) connection to Arab identity. Indeed, I got a clear sense that my invitation to their home to discuss my research was, in part, motivated by Amal's desire to open up a space for Adam and his father to discuss these issues.

Analyzing only institutionalized forms of discourse(s) of multiculturalism or gendered national distinctions between Arab and Canadian women would not allow me to say much about the ways such discourses may map onto, shape, and be agentively used in localized interpersonal and familial dynamics such as those depicted above. For instance, had Adam not so adamantly insisted that he is Canadian, his father might not have 
evoked elements of multicultural discourse in an attempt to convince him that embracing an "Arab identity" might be an avenue "to learn from multiple cultures."

Over the course of fieldwork, I had many interactions where people disagreed on the meanings and "signs" of Arab and Canadian national identities - or professed surprise at "discovering" that I identify as Arab. Like the conversation with Amal and her family, such instances continuously (re)directed my focus toward the multiple dimensions of the struggles over the meaning(s) associated with various (national) identity categories and scales at which such struggles play out. Methodologically and analytically, I became quite interested in the ways day-to-day encounters with multidimensional discourses of national identity provide a particularly salient avenue for understanding the uses to which such discourses can or cannot be put in producing different subjectivities and agencies.

I was also continually reminded that differences in people's interpretations of their immigration experiences, national identity discourses, and the relationships between the two are just as important as overlaps because they point to the ways people's interpretations of the multiple discourses and experiences that intersect in their lives permeate and shape one another. Indeed, I began to notice that research participants' narratives of their immigration experiences highlighted the ways their engagements with identity discourses seemed to be reshaped as they navigated certain legal channels, undertook searches for employment, or adjusted their familial and social interactions, for instance. In the rest of this chapter, I explain how such concerns shaped the methods I used to collect and analyze data as well as my rationales for doing so.

I begin the next section of this chapter with a statement of my methodological approach and the aims which motivate it. I then explain the reasons for my choice of 
Ottawa as my research site and go on to outline the methods I used to develop and design this project, including the details of my sampling and data collection methods. In the following section, I discuss how some of my interactions with members of the Arab Canadian community shaped the form this project has taken, particularly in terms of my choice to avoid using a "post-9/11" framework. I then offer a brief overview of Ottawa's Arab Canadian population in numeric terms and explain the limitations of such "numbers games" for my project. I conclude by reviewing my methodological rationale and introducing the first analysis chapter.

\subsection{Methodological Approach}

I am guided by an interpretive approach to the process of knowledge production which is founded on the premise that researchers can never present a full, objective description of social life (Abu-Lughod 1986, 1989, 1993; Clifford 1988; Clifford and Marcus 1986; Geertz 1973; Marcus 1995, 1998). Such an epistemological approach to ethnographic writing - first associated with the work of Clifford Geertz (1973) developed into a broad critique of the distinctions often drawn between anthropological researchers (as people who engage in the act of interpreting "cultures") and research participants (as objects of study who "do culture" without consciously reflecting on or interpreting the activities in which they are engaged). Similar critiques of ostensibly objectivist knowledge production have been taken up in multiple disciplines under the umbrellas of a "crisis of representation" (Abu-Lughod 1986, 1989, 1993; Appadurai 1988; Asad 1997; Blunt and Rose 1994; Clifford 1988; Clifford and Marcus 1986; Fabian 1983; Gupta and Ferguson 1992), a "linguistic turn" in analysis (Bhabha 2002; Butler 1990, 1992, 1993; Spivak 1988; 1999), and the impossibility of objectivity (Haraway 
1989, 1991, 2004; Harding 1983). As suggested above, writing under these headings, scholars argue it is impossible to reflect an essentially unmediated "truth" of social experience in academic writing - ethnographic or otherwise (see especially Scott 1991).

Following from these critiques, I conceptualize my project as a critical ethnography. As such, a major component of my analytic focus is on "the contingent way in which all social categories emerge, become naturalized, and intersect in people's conception of themselves and their world, and ... an emphasis on how these categories are produced through everyday practice" (Rofel 1994:703, emphasis added). I do, however, heed an important point of caution in relation to this task: to avoid romanticizing "everyday life" as something which "automatically jump[s] into our texts to give them validity, authenticity, political relevance, or critical edge" (Valverde 2003: 91). In order to avoid such romanticization, it is necessary to conceptualize the concept of "everyday practice" as inseparable from the broad social structures and power relations that simultaneously constrain and enable every element of our socio-cultural interactions (Valverde 2003). I build on these points in the remainder of this section as I outline the three main aims motivating the critical ethnographic approach that frames this project.

A critical ethnographic approach is in keeping with Suad Mahmood's (2001) critique of academic tendencies to (re)produce definitions agency built on an implicit valorization of a remnant, pre-discursive self which acts "against the weight of custom, tradition, ... or other obstacles" (206). Importantly, I specifically sought out analyses like Mahmood's, along with the literature on scalar politics and multidimensionality, due to my sense that much of the available academic writing on Canadian national identity tends to focus almost exclusively on the production and circulation of institutionalized 
(inter)national discourse and pays little attention to when, where, and how people encounter and engage such discourses. Thus, while I entered this project well-versed in and convinced by academic arguments that Canadian national(ist) discourses and policies, such as multiculturalism, buttress and reproduce an exclusionary, racialized, and/or hierarchical version of national identity (Bannerji 1993, 1995, 2000; Dua 2003; Mackey 1997, 1999; Razack 1998, 2002, 2004, 2008; Thobani 2007; Vukov 2003), I found little methodological guidance for analyzing relationships between such discourses and research participants' subjectivities and agencies. ${ }^{27}$

To interpret all instances where research participants drew on such discourses exclusively through the lens of these arguments, I feared, might lead me to conclude they had a sense of "false consciousness" or had uncritically embraced institutionalized national identity discourses (e.g. Malhi and Boon 2007), a conclusion that would be grossly unfair and theoretically untenable. Aside from not doing justice to research participants' analytic capacities, such a conclusion would be (implicitly) based on the assumption that, as a researcher, I can somehow stand outside the reach of such institutionalized national (identity) discourses to interpret research participants' engagements with them as evidence of their "false consciousness." As Mariana Valverde (2003) argues, however, "false-consciousness theories... [fail] to explain how [a researcher's] own position is theoretically possible" (90). Consequently, academic

\footnotetext{
${ }^{27}$ My point is not to dismiss these works. As I discuss in Chapters One and Two, these scholars' work has been ground-breaking as they sought to and succeeded in exposing the insidious ways dominant Canadian national identity discourses tend to draw on and reproduce hierarchical and racist discourses. In so doing, they challenged earlier work which assumed that there was a single, coherent, uncontested, and selfevidently "liberal" meaning to Canadian identity. Further, the work of these scholars has been highly inspiring and paved the way for many of us who are interested in anti-racist theorizing in Canada.
} 
interpretations built on the notion of false consciousness deny that I am also shaped by circulating discourses (including those produced within academe).

These concerns, reinforced throughout fieldwork by finding that "social categories" do not always and necessarily become "naturalized" in the same ways in all people's lives and senses of self, produced the first two interrelated methodological aims which shape my approach to this research project. First, I aim to highlight the inseparability of socio-political discourses and structures, socio-cultural interactions, and the very categories of thought that simultaneously limit the ways we can (and do) live our lives and make living our lives possible. This aim echoes Mahmood's (2001) definition of agency as "a capacity for action" enabled and created by spatially and temporally located power relations (203; see also Asad 2000) and informs my second methodological aim: to illustrate that many research participants did not necessarily assume the "naturalness" of various socio-political structures and discourses, even when they drew on them to narrate the relationships between their immigration experiences and senses of national identity. These two aims shape my project insofar as - as mentioned above - I do not consider socio-political structures and discourses (institutionalized at national and global scales) "as ontological categories, [or] distinct spheres" (Valverde 2003: 91) of social life from research participants' subjectivities and agencies (experienced and enacted at localized (inter)personal scales).

The third aim motivating my framing this project as a critical ethnography is to avoid "ontologizing" Arab Canadians in Ottawa as a homogenous, fixed cultural group with identical beliefs, values, and practices. I do not, in other words, conceptualize my task as one of producing a definitive textual representation of a singular, territorially and 
culturally delimited community whose members are essentially and wholly defined by shared "ethnic" or "cultural" identifications. While I do speak of an Arab Canadian community in Ottawa, I also continuously foreground differences in research participants' interpretations of their processes of immigration, national identifications, and feelings of in/exclusion. Pointing to such differences might, I hope, begin to undo some of the homogenizing "culture talk" (Mamdani 2002; Razack 2004, 2008; Thobani 2007) used to suggest that Arabs are constituted by a singular "premodern" culture they are somehow unable to escape. I empirically highlight such differences throughout my analysis by juxtaposing research participants' divergent interpretations of certain elements of their immigration experiences, lives in Canada, and expressions of their sense of identity. Following Saukko (2003: 70-3), I analyze such juxtapositions to illustrate how differences in interpretation emerge out of the multidimensionality of research participants' life histories and attendant encounters with (non)national identity discourses which produce their (subjective) agencies.

While I do not understand my dissertation as a geographically multi-sited ethnography (Marcus 1995), the above considerations led me to examine research participants' engagements with national identity discourses at multiple points of encounter. These include their interactions with national policies and laws (Canadian or otherwise), media outlets (radio, television, newspapers), local "identity-based" community events, and other people. Some of the sites in question are particular events I attended in Ottawa and discussed with research participants. This was the case, for example, with lectures organized by the Arab Canadian University Graduates Association or a play put on by the Syrian Canadian Students' Association, the latter of which was 
followed by a trip to a shawarma restaurant in Ottawa where I discussed the play with several members of the association. ${ }^{28}$ In other instances, the sites in question are not events or places. Media representations of Arab Canadians are a good example here since they may be thought of as specific sites where a person encounters discourses defining various versions of and relationships between Arab, Canadian, and Arab Canadian (national) identities; interactions with these sites of discourse (re)production involve coming into contact with and engaging national identity discourses.

While I address a variety of sites where research participants encounter identity discourses, I do not assume the separateness, primacy, or dominance of any of these sites of interaction in their engagements with discourses of national identity and interpretations of their immigration experiences. Instead, keeping in mind the concepts of scalar politics and multidimensionality, I try not to impose a singular lens which might prematurely circumscribe my analysis (Marcus 1998; Passaro 1997). I also analyze the narratives presented by research participants, and particularly interviewees, for answers to the questions of when, where, and how they encountered national identity discourses throughout the process of immigration. Bringing this together with the above-discussed methodological aims, my overarching methodological objective is to show the nuances involved in research participants' interpretations of national identity discourses, the multidirectional circulation of these discourse, and the (un)predictability of their effects.

\footnotetext{
28 "Shawarma is a fast food that consists of meat slices layered alternately with slabs of fat onto a vertical rotisserie. As the outer surface cooks, small pieces are carved off and served in pita bread" (Obeidat 2002: 12), usually with pickles, tahini sauce, and tomatoes (along with some other fresh vegetables).
} 


\subsection{Why Ottawa}

When I first planned to conduct doctoral research in Ottawa, it was not with the present project in mind. Instead, I was interested in how being located in the National Capital Region might shape some of the programs and policies of immigrant services organization operating in the city. My research interests shifted once I arrived in the city, however. While friends of my parents who had lived in Ottawa approximately twenty years ago had spoken of its large Arab Canadian population, I was still surprised by how much this presence shaped my experience of the city. When I first moved to Ottawa, I constantly overheard Arabic language conversations in the streets, in stores, and in restaurants. When I travelled by taxi, my conversations with many taxi drivers began in English and ended in Arabic once they learned I could speak the language.

I was also amazed, walking down an eight block stretch of Bank Street (between Cooper St. and Wellington St.), to pass three shawarma restaurants in such close proximity to one another. As I got to know the city, shawarma restaurants soon seemed ubiquitous. Indeed, an internet search for the terms "shawarma" and "Ottawa" using Google Maps' Canadian search engine yields 365 hits. ${ }^{29}$ By comparison, a search for "McDonald's Restaurants" and “Ottawa" yields 348 results ${ }^{30}$ and one for "Tim Horton's" and "Ottawa" yields 516 results. ${ }^{31}$ Most recently, the ubiquity of shawarma in the

\footnotetext{
${ }^{29}$ See http://maps.google.ca/maps?q=shawarma+ottawa\&hl=en\&s $1 /=49.891235$, $97.15369 \&$ sspn $=25.897616,56.513672 \& z=12$.

${ }^{30}$ See http://maps.google.ca/maps? q=MCDonald's+Restaurants, +Ottawa,+Ontario\&hl=en\&s sll=45.410667.$75.695916 \&$ sspn $=0.027476,0.055189 \& z=12$

${ }^{31}$ See http://maps.google.ca/maps?q=Tim+Hortons, +Ottawa,+Ontario\&hl=en\&s $11=45.402038$,$75.707477 \&$ sspn $=0.109922,0.220757 \& z=11$
} 
National Capital Region was highlighted in a classroom discussion when a student who was born and grew up in Ottawa (and who is not Arab Canadian) told me that when a friend's partner visited the city for the first time, they took her to a shawarma restaurant to make sure she got what he called "the real Ottawa experience." While this student's definition of shawarma as part of how he imagines "the real Ottawa experience" might point to the ease of incorporating commodifiable elements of "culture" into the cityscape in a capitalist society, the presence of restaurants offering foods I associate with my childhood in Lebanon, along with my sudden ability to converse in Arabic at a rate I had not experienced since that same childhood, shaped my understanding of the city in a profound way. I thus began to wonder if this might be the case for others who identify as Arab Canadian. Thinking, at first, that this may be an interesting side project, I began to look into the make-up of the city's Arab Canadian population.

Based on the 2001 Census, I found that "Canadians of Arab origin make up one of the largest non-European ethnic group in Canada... representing $1.2 \%$ of the total Canadian population," a number which "is growing considerably faster than the overall population" (Colin 2001a: 9). As I searched available census data, I also found that "in $2001, \ldots$ people of Arab descent made up ... $4 \%$ of the population of Ottawa," a percentage comparable only to Montreal's and double Toronto's (10), which tend to be imagined as major urban destinations for immigrants to Canada. ${ }^{32}$

\footnotetext{
${ }^{32}$ In another Statistics Canada "community profile" study, I also read that "Lebanese people account for a larger share of the population of Ottawa than that of any other census metropolitan area across the country" such that "in 2001, people of Lebanese origin made up $2 \%$ of the total population of the national capital region" (Colin 2001b: 10). Statistics Canada is the government association responsible for producing the census questionnaire and collecting the census data.
} 
Although I now knew (or confirmed) that there were large numbers of people who live in Ottawa and identify as Arab Canadian, these numbers told me nothing about if and how any of these people thought of themselves as forming a community. This is because an Arab Canadian community is not an automatic by-product of these people's living in close proximity to one another and sharing (pan)national or "ethnic" identification. Instead, senses of community develop through processes of building and maintaining relationships with others for whom identifying as Arab or Arab Canadian forms an element of their sense of self and a meaningful basis - amongst others - for social relations and intimacy. ${ }^{33}$

I thus began to search for and read whatever scholarship I could find about Arab Canadians' experiences of life in Canada (and Ottawa) and quickly realized there was little qualitative research on the topic. One major study about Arab Canadians, which focuses mostly on Arab history and the history of Arab immigration to Canada, is Baha Abu-Laban's (1980) An Olive Branch on the Family Tree, sponsored as part of a Multiculturalism Directorate by the Canadian Department of the Secretary of State. Aside from this book, there have been a few other studies of specific Arab communities in Canada (Abu Rabia 1997; Barclay 1968; Collin 2001a, 2001b; Eid 2007; Fathi 1973;

\footnotetext{
${ }^{33}$ This understanding of community parallels critiques of (some versions of) diaspora theory discussed in Chapter Two. As Jasmin Habib (2004) suggests, it only makes sense to describe "people who live away from a place once or presently defined as their historical, traditional, or indigenous homeland as a diaspora" if they "have maintained a relationship to home, define their present identities in relation to their past home, or would return home if given the chance" (16). To do otherwise is to reproduce the territorializing, national(ist) structures diaspora scholars aim challenge. From this perspective, diaspora is (re)conceptualized as a process through which socio-cultural, spatial, and historical relations are lived out rather than a thing or state of being. Similarly, to avoiding the homogenizations enacted through "culture talk" requires that unless people maintain relations with one another that, at least in part, revolve around their shared identifications as Arab Canadian, they do not automatically become an Arab Canadian community by virtue of living within the territorial bounds of the same city.
} 
Hamdan 2007; Jabbra 1983, 1997; Karim 1991; Kashmeri 1991; Khouri 2003; Murphy and McDermott 2002; Ohan and Ibrahim 1993), one historiography of Arab immigration to the United States, Canada, and Australia (Aboud 2000), and several autobiographical accounts and anthologies of Arab Canadian writing and art (Dahab 2002; Ghulam 2006; Kadi 1994; Kaouk and Bourque 2004; Rostom 1989). I could only find two studies, both M.A. theses completed at Carleton University, about the Arab Canadians in Ottawa (Friedman 2000; Oliphant 2005).

Not only were the above-cited studies few, but none focused on the relationships between people's interpretations of their immigration experiences and their senses of national identity using a multi-scalar and multidimensional analytic framework as I do in this project. Eventually, these realizations, along with my interest in learning more about the degree to which Arabs and Arab Canadians in Ottawa form and maintain community connections and how they interpret and experience their senses of national identity, led me to undertake the present study. In the next section of this chapter, I explain the details of how I went about collecting data for the study.

\subsection{Research Methods}

When I began this project, I lacked any connection to other Arab Canadians in Ottawa and did not know how to go about forming them. I thus began my research by looking up Arab community organizations. Immediately, I realized there are many such associations in the city. For example, on the website of the Lebanese and Arab Social Services Agency I found a listing for 34 clubs and associations. These varied from those based on church membership (e.g. Parish Council of St. Elias Orthodox Church), to village association (e.g. Kfarmichky Association), to university affiliation (e.g. Alumni 
Association of the American University of Beirut), to national affiliations (e.g. Egyptian Canadian Cultural Association of Ottawa), to gender identity (Arab Canadian Women's Association), to student status (Club du Liban Carleton University), to religious membership (Canadian Druze Federation), to business associations (e.g. Canadian Lebanese Business and Professional Association). Members of these organizations have different reasons for joining (cultural, social, and/or political) and each association has its own aims which reflect a range of interests and priorities.

I added myself to several mailing lists to learn about upcoming events I could attend and I started listening to CHIN Radio's Arabic language programming. ${ }^{34}$ Through these two avenues, I learned that Ottawa's Arab communities are highly active socially, culturally, and politically. I had a broad range of events that I could attend, such as academic lectures, dinners, festivals, trips, and galas. There were so many events that I sometimes had to choose between ones taking place on the same day or evening.

When I started attending events (at first mostly "cultural festivals"), I would try to meet and speak with some of the people in attendance, but given that most were already there with groups of friends and/or family members, I often found it difficult to start indepth conversations where I could broach the subject of my research. When I managed to do so, it seemed to be a quick way to end what had been a pleasant conversation about the festivities. At this early stage, I found the most I could do was speak to people about the entertainment or food at a particular festival. I was having a lot of fun at these events,

\footnotetext{
${ }^{34}$ Arabic language programming airs on 97.9FM, Monday to Friday $1 \mathrm{pm}$ to $6 \mathrm{pm}$, and Sundays $1 \mathrm{pm}$ to $4 \mathrm{pm}$.
} 
which included a daytrip to Montreal with the Arab Canadian Women's Association, but was also being demoralized about my ability to conduct fieldwork.

Eventually, through several avenues, I met some people who were instrumental in helping me get my work started. In particular, two people helped me a great deal by letting me know about meetings for associations whose major focus can be broadly described as "community building." By this time, I was interested to understand how research participants engage national identity discourses and the relationships between their immigration experiences and such engagements.

In August 2008, I started to put together a document outlining my research interests (Appendix A). By then I had received ethics approval for the project and put together a letter of information (Appendix B), a letter of invitation to participate in the project (Appendix C), and an interview guide (Appendix D) for in-depth, semi-structured interviews. I sent electronic copies of these to a woman who expressed interest in the project and who seemed supportive of my research, asking her for feedback about the project as I conceptualized it. I got an encouraging response (with minor typographic errors corrected) and was invited to attend meetings of two "community building" associations where I presented my project and distributed several copies (to each attendee) of the documents I put together in order to seek formal interviews. At both meetings, those present showed interest in my work, asked engaging questions, gave me advice for research, and at one of these meetings pointed out that my data about Ottawa's Arab Canadian population was outdated since Statistics Canada had just released the results of the 2006 Census. Starting from here and using snowball sampling, I conducted a total of fourteen in-depth semi-structured interviews while continuing to attend 
community events where I engaged in participant observation and informal conversations about my research. As I began to develop relationships with people during participant observation, I soon began to learn about community events through phone calls, personal e-mails, and Facebook messages as well as through the listservs I joined.

It is important to note here that while I draw extensively on these formal interviews in my analysis, my project was also shaped by data collected in other settings. For example, the conversation with Amal and her family with which I began this chapter was central in shaping my analysis, not least because most fieldwork interactions involved similar disagreements about the meanings of being Arab Canadian - as well as the meanings of immigration. This was also the case with Hala, for example, who asked me to get my notebook and a pen to take notes as she related some of her experiences with immigration to Canada. Yet, I do not count such conversations in the number of formal interviews cited above. Specifically, even when such conversations centred on the topics covered by (and followed the structure of) my interview guide, unless I went through the exact protocols described below (on the basis of which I received ethics approval for interviews), I do not count them as "interviews."

When someone agreed to participate in a formal interview, I provided her/him with the interview guide in advance to ensure s/he knew as much as possible about interviews before making her/his decision about whether or not to take part in them. In some cases, this meant someone who agreed to take part in a formal interview would change her/his mind after seeing the guide, feeling uncomfortable with divulging so much personal information, but would continue to discuss some elements of her/his immigration experience and/or sense of national identity with me informally. I asked 
interviewees to choose a place where they would feel comfortable discussing their immigration experiences and senses of identity. The interviews took place at coffee shops (six), at interviewees' places of employment (six), or in their homes (two). When I arrived at interviews, I reminded research participants that they could stop the interview at any time or could refrain from answering any of the questions I posed. I also asked them if they preferred for me to audio record the interview or take notes as we spoke. In five cases, interviewees chose not to have the interview recorded; these interviewees often paused as they spoke to make sure I had written down what they said. During my interview with Farida, she spoke in Arabic while I spoke in English. All other interviews were conducted in English.

In cases where I collected data through informal conversations or participant observation, I have either left the person's name out of all field notes, or asked for or supplied a pseudonym to maintain anonymity (as with Amal and her family, for instance). I began formal interviews by asking research participants to fill out a coversheet which included a pseudonym I would use when I referred to them in any notes, throughout my dissertation, and in any published work. On the coversheet, I also asked about and recorded each research participant's age, gender, sexual orientation, marital status, if and how many children they had, field of employment, whether they came to Canada as immigrants or refugees, the length of time they lived in Canada, and whether they had any family in Canada. Altogether I interviewed nine women and five men. Everyone I interviewed identified as heterosexual, three were single, two were divorced, and nine were married. Four interviewees did not have children, two had one child each, seven had two children each, and one had three children. Three interviewees 
were employed in the field of social service provision, two worked in healthcare, two identified their line of work as community building, three were government employees, one was a student, one worked in banking, one worked in post-secondary education, and one was retired. Interviewees ranged in age between twenty-six and sixty five years and had immigrated to Canada between 1966 and 2004. Finally, all interviewees had family members in Canada, although one specified that she had no immediate family in the country. One interviewee came to Canada as a refugee while the rest came as immigrants.

Once the coversheet was filled out, I began by asking interviewees the first question on the interview guide about their reasons for immigrating to Canada. In the first interview I conducted, Omaima pointed out that because she had immigrated as a child, she was not involved in the decision-making process. Following her advice, I began other interviews with people who had immigrated at young ages by asking if felt they could answer the first set of questions about the decision to immigrate to Canada and knowledge of the country before immigrating. Dina chose to answer these questions because, she had immigrated at the age of 16 , could remember some aspects of her mother's decision-making process, and knew some things about Canada before immigrating. Eddie answered some of these questions because although he was one year old when he immigrated to Canada with his parents, he explained, he heard the story enough times that "it feels like [he has] a memory of it." Aladdin, Nousayba, and Amira (who immigrated at the ages of six, eight, and seven respectively) responded to the first of these questions by speaking about their parents' reasons for immigrating. Aladdin and Amira both said they had spoken with their parent about what they knew about Canada before immigrating, so they also answered this question. Nousayba did not know this 
aspect of her parents' experience but was able to tell me what role the presence of family in Canada played in her parents' decision to immigrate to the country.

Interviews lasted between forty-five minutes and three hours. After I asked all the questions on the interview guide (or, when interviews were wholly conversational, once we covered all the questions over the course of the conversation), I asked interviewees if there was anything else they wanted to add or if there was something important about which I had not asked. Nouhad used this as an opportunity to question me about the working title of the project and to discuss some of the theoretical literatures to which I referred in answering her question while Omaima asked me to clarify the purpose of my research once more. In three cases, once the tape recorder was turned off interviewees asked about my own sense of identity and how I came to be interested in my research topic. I ended interviews by providing other copies of my Letter of Information and Letter of Invitation and asking interviewees to pass them along to anyone they knew who fit the research criteria and might participate in a formal interview. Once I transcribed interviews, I emailed or gave hard copies of the transcripts to interviewees for their approval. Five interviewees edited the transcripts I sent them: four (Monzer, Wafaa, Sam, and Nousayba) did so to clarify some of their comments, one (Lias) deleted segments of the interview transcript to ensure further anonymity, and another (Aladdin) asked me to not to include certain identifying elements of the transcript in the final written version or any published work. I also sent portions of the final dissertation to interviewees in order to show them how I was using their interviews and to ask again for approval. These chapters prompted different replies, from updates on interviewees' lives (e.g. Rana's recent marriage), to encouragement and requests for the final version once it has passed 
defence (e.g. Monzer), to updates on children (e.g. Sam), and corrections of typographic errors (e.g. Wafaa).

During this time, I continued to attend community events, engage in participant observation, and speak "informally" with other attendees (some of whom had participated in formal interviews) about their immigration experiences, senses of national identity, and reflections on the event we were attending. There were also "impromptu" and unexpected encounters that made it into my field notes. This was the case with conversations with taxi drivers in Ottawa. Almost every time I travelled by taxi in the city, the driver would ask me what I do. My explanation of my research often prompted engaging discussions with Arab Canadian taxi drivers about their own immigration experiences and reflections on life in Canada. In four such instances, the taxi driver in question gave me permission to use these discussions as part of my research. In these cases, I supplied a pseudonym and removed any identifying information to maintain the anonymity of the person in question. As with other "informal" conversations, I did not count these as interviews since I had not followed the full ethics protocol and had not supplied an interview guide in advance. Although I gave these taxi drivers my card and asked them to contact me if they would consider participating in a formal interview, none of them took me up on this offer.

Before concluding this section of the chapter, I want to address the number of formal interviews I conducted, which may seem small. Following the qualitative epistemological rationales framing this project, I do not take this number as a measure of the rigor or validity of my project. Indeed, to consider as rigorous and valid only those qualitative studies which meet numerical evaluative criteria aimed at producing a 
representative sample is to impose quantitative epistemologies to measure qualitative research (Cannella and Lincoln 2004; Denzin and Giardina 2008; LeGreco and Tracy 2009). Where qualitative research is concerned, non-quantitative evaluative criteria are more in keeping with feminist and anti-colonial scholars' concerns about the coloniality involved in valorizing modes of knowledge production with ostensible claims to universality and "objectivity" (Smith 1999; Bhattacharya 2009). Thus, more flexible criteria for evaluating qualitative research are part and parcel of a broad methodological project aimed at resisting and "parochializing" (potentially colonizing, masculinist, and homogenizing) insistences that our research methods and findings be universally representative (Asad 1993; Chakrabarty 1992; Mahmood 1996).

Resisting this insistence begins with the recognition that since a "multiplicity of goals" may motivate qualitative inquiries, we need to make room for "multiplicity in standards of evaluation as well" (Bochner 2000: 268). Thus, each qualitative inquiry must be framed and judged "in terms of its own necessities" (269) as dictated by the research objectives. In the case of the present study, these objectives shifted as I began to conduct fieldwork and, with them, so did my approach to data collection and analysis. I started off the project aiming for fifty interviews and thinking this number, along with participant observation at various events, would provide me with sufficient data to be able to speak with some sense of authority about Ottawa's Arab Canadian community.

As I began to conduct fieldwork and fill pages with data from participant observation, I started to doubt the necessity or usefulness of meeting the "magic number" I had set for myself. My doubt was solidified when I conducted my first formal interview with Omaima, which lasted three hours, wherein she offered and reflected on a rich life 
history that intersected in interesting ways with some of the participant observation I had already done. This experience set in motion a serious challenge to the methodological assumptions with which I had begun. As I transcribed and reflected on this and other interviews, I realized that using fewer interviews and triangulating these with government documents and institutionalized discourses would allow me to offer a more in-depth, multi-scalar analysis of research participants' multidimensional engagements with national identity discourses.

Further, as I took on methodological commitments to undo some of the homogenizing "culture talk" surrounding Arabs and Arab Canadians, I realized it would be necessary to highlight some of the differences in research participants' experiences, but to do so in a way that neither dismissed their commonalities nor produced images of entirely individualized Arab Canadians with no connections to one another. Effectively, this meant doing away with my "magic number" and offering an in-depth, multidimensional analysis of fewer narratives. In the end, while the number of formal interviews ended up being fourteen, I had equally in-depth but informal participant observation experiences (including attending monthly meetings with one organization) and conversations with other members of the Arab Canadian community in Ottawa who generously shared a great deal of their (reflections on their) life experiences with me both on and off the record. As I illustrate in the next two sections, informal conversations and participant observation greatly shaped my approach to this project.

\subsection{The Elephant in the Room: Post 9/11}

St. Elias Centre and Banquet Facility, located at Ridgewood Ave. and Riverside Dr. across from Mooney's Bay, is a central location for celebratory Arab Canadian 
community events, particularly those which involve dinners and dancing. I attended several fetes at this hall, including the Arab Canadian Women's Association's (ACWA) gala in November 2008, an annual event held in honour an Arab Canadian woman from the Ottawa community which was a springboard for meeting several friends and research participants. I also continue to attend Ottawa's annual Lebanese Festival there, which celebrated its $21^{\text {st }}$ year in July 2011. By spring 2009, when I headed to the hall to celebrate Syria's National Day, I had been engaged in participant observation for several months and attended seven monthly meetings of one network and two meetings of the Arab Communities' Roundtable - where representatives of different organizations meet to discuss upcoming events and/or any difficulties community members might be facing.

Prior to heading over to the hall, I made my way over to two friends' apartment, sisters who lived in the south end of Ottawa not far from me. I met the older of the two, who was the same age as me and always immaculately dressed, at the ACWA gala in November 2008 where we spent much of the evening speaking with one another. A few months later, when her sister moved to Ottawa from Syria, we discovered that we also got along well. Her sister had an amazing archival memory of Arab pop culture, knew the writings of most Arab feminists thoroughly, and could quote the poetry of Mahmood Darwish at length. The first time I came to their apartment for dinner, she made a play list of Arabic music with which she rightly assumed I would be familiar given the year I had emigrated from Lebanon. When we heard about the Syrian National Day party, we made plans to get ready at their apartment and drive to the St. Elias hall together.

Because I had met mostly Lebanese, Palestinian, and Egyptian Arab Canadians during fieldwork, I did not expect to see other people I knew at the hall. I was wrong, 
however. As soon as I entered the hall, I saw several people I knew - some of whom were Lebanese and Palestinian Canadians who had come with Syrian Canadian friends or partners. At some point during the evening, I made my way outside to have a cigarette. While I was out there speaking with two people I had met that evening, two men - one in his forties, the other in his fifties - whom I had seen at several other events and who knew about my research project approached us. They asked about my research and the older of the two men told me he thought this was a perfect time to do research on immigration because in the political atmosphere of "the current financial crisis" overt expressions of anti-immigrant sentiments were likely to increase. He elaborated on this with a Marxist-inspired analysis and concluded with the following words: "Make sure you pay attention, Samah. There is nothing like a financial crisis and high rates of unemployment to bring to the surface the racism inherent in capitalism. Capitalism thrives on racism." His analysis was welcome, but not surprising to me; I assumed, given his age, he was likely familiar with the Marxist anti-colonial nationalisms that pervaded Arab (and global) politics in the 1960s and 70s.

As we continued discussing the relationships between immigration, racism, and capitalism, I asked if he might be willing to have a longer discussion about the topic as part of a formal interview. He immediately thanked me and declined participating in an interview. Given the passion with which he had offered his analysis, I did not hide my surprise at his refusal. At this point, the other man jumped in to offer an explanation:

Samah, this is not a reflection on your research. A lot of us think your work is important and want you to do well, but that's different from doing an interview. I know you will be very careful with your data. I know you will try to make sure everyone stays anonymous, but you can't really have full control over that. You don't know what is going to happen with your research. Even if you have the best intentions, your research can be dangerous in the wrong hands. 
My immediate reaction to these words about the potential danger of my research was to conceptualize them as part of a broad climate of fear resulting from increasing state security logics and surveillance since September 11, 2001. As I conducted further research, however, I concluded that a multidimensional analysis requires resisting the urge to paint all such expressions with a "post-9/11" framework.

In recent years, academic analyses of national security, identity, and law have increasingly framed institutionalized forms of racism that affect the lives of Arabs in Canada and the United States through a post-9/11 rubric (e.g. Bayoumi 2008; Jamal and Naber 2008; Khouri 2003; Salaita 2006; Shaheen 2007). I do not want to do away with (parts of) the analyses offered by these scholars, but I am thoroughly convinced that use of this framework in an all-encompassing way or as a self-evident short-hand for institutionalized valorization of "national security" may lose track of important historical and spatial connections we ought to be highlighting.

My line of reasoning here follows critiques of the language of postcolonialism as potentially signifying a temporal break and concealing relationships between contemporary institutionalized power relations and historical colonial scholarship and administration. Recall that in Chapter Three I used the concept of coloniality to historicize relations between contemporary representations and state surveillance of Arabs (and Muslims) and colonial discourse, scholarship, and policies. Similarly, in Chapter Two, I suggested many (rationales for) changes in immigration policies, grouped together under the rhetoric (critical or otherwise) of a post-9/11 "national security" legislative environment, predated the attacks on the World Trade Centre and the Pentagon which occurred on September $11^{\text {th }}, 2001$. Institutionalized security discourses, 
founded on racist, colonialist imaginaries, were certainly (re)justified in the context of those attacks, which continue to be used to validate the supposedly "self-evident truth" of images of Arabs (often conflated with Muslims, Middle Easterners, and South Asians) as barbaric, "freedom hating," and violent "terrorists."

Yet, pre- and post-9/11 discursive constructions of Arabs share much in common as American (e.g. Operation Boulder) and Canadian (e.g. the massive "security operation" during the first Gulf War) state surveillance projects attest. We cannot lose track of these histories in our analyses because despite any claims to the contrary, we are not in an entirely new world that suddenly came into being and began to impact the lives of Arabs and Arab Canadians (among many others) on September $12^{\text {th }}, 2001 .{ }^{35}$ Indeed, to challenge such discourses in state legislation, we must account for their histories and continuities with earlier, explicitly racist policies. Moreover, researchers who want to understand the impacts of such discourses and legislations in the lives of Arab Canadian research participants ought not to impose a singular lens on all their words and actions.

For instance, the man who told me that despite supporting my project he would be uneasy participating in an interview may have also been signalling something beyond a national Canadian spatial and temporal scale. I only considered this possibility, however, when I contemplated his comments alongside those of an Arab Canadian taxi driver I call Jean (whose immigration experiences in Canada I discuss in Chapter Six). At the end of a thought-provoking discussion about immigrating to Canada, I handed my card to Jean,

\footnotetext{
${ }^{35}$ I do not mean to deny that the events of September $11^{\text {th }}, 2001$ had a large impact on the lives of many Arab Canadians. My point is simply that the attacks amplified racist and colonialist attitudes already present prior to that date. For specific statistics on the increase in hate crimes immediately following September $11^{\text {th }}, 2001$ refer to Silver, Mihorean, and Tayolor (2004).
} 
told him I would love to learn more about his experiences, and asked if he might consider participating in a formal interview. As soon as the words left my mouth, Jean looked visibly shaken. "No, I will not do an interview," he said emphatically.

Jean had just asked me to make sure to include his words as part of my research. I was unsure why he seemed upset by my request, but I did not have to ask because he immediately explained his rationale: "When I arrived in Canada, Samah, my head was like this," he began, putting his hands out several inches from his head. "It was almost two times the size you see now. You know why? Because I was brought in for 'an interview' in Lebanon. I came here as a refugee after that because I had to escape. I could not take another interview."

In this context, I began to consider concerns about participating in my research project in a formal way to reflect much more than fears about the security apparatuses of the Canadian state. Instead, I thought, these fears were equally about some people's past experiences with (state and non-state) security regimes in the contexts of civil wars, for instance. Thus, while some elements of the lives of Arabs and Arab Canadians are shaped by dominant racialized discourses which (re)produce them as dangerous, internal Others, their lives are equally shaped by their past experiences in Arab or non Arab countries.

Of course, these are not entirely separate so that the overlaps between Canadian and Arab security apparatuses are important. For instance, the extraordinary rendition to Syria of Maher Arar - a Canadian citizen who had immigrated to Canada from Syria which a recent inquiry revealed took place with the full knowledge of Canadian security and intelligence agents, can certainly be understood as enabled by the racialized security discourses used to (re)produce Arabs and Arab Canadians as dangerous Others, but his 
torture was enacted by agents of Syrian security forces (Canada 2006a, 2006b, 2006c). It is thus likely that some (potential) research participants feared not only what would happen within Canada, but how elements of Canadian security agencies were working with those in Arab countries. Put differently, these instances called into question the promise of safety from the violence of state and non-state actors in Arab countries which seeking asylum in Canada may have previously held for refugees like Jean.

To rely exclusively on a post-9/11 framework may unintentionally converge with the racializing discourses I aim to challenge by continually (re)centering this particular moment and (re)producing certain cases associated with it as representative of the lives of all Arabs or Arab Canadians. While analyses of the extraordinary rendition of Maher Arar to Syria, where he was tortured for two years, are necessary, care must be taken not to make his case entirely representative of "the" Arab Canadian experience. Otherwise, critical analyses may homogenize and essentialize people's varied encounters and engagements with the discursive association of Arabs with terrorism and slip into making such cases and, thus, the concept of "terrorism" the overarching framework for thinking about Arab Canadians' lives. It is also important to recall here that all four majorly publicised cases of extraordinary rendition of Canadian citizens involved Muslim men, and Muslims account for less than half of all Arab Canadians (Colin 2001a: 12). Thus, some non-Muslim Arab Canadians might have distanced themselves from the Arar case by reading it as concerning religious affiliation. I also could not assume a singular way the discourses surrounding such cases manifest in the lives of all Arab Canadians.

Moreover, research participants often expressed concerns about the continual redrawing of links between Arab Canadians and terrorism in corporate Canadian media 
forums. They expressed desires to see and hear the lives of Arabs and Arab Canadians discussed outside of this context/framework. Nouhad, for instance, complained that Canadian media "only talk about Arabs when it has to do with Maher Arar" and Dina explained that "you never see Arab families picnicking." These references to and negations of such cases and discourses about terrorism and security, in part suggest such discourses form a key component of the exclusionary national(ist) discourses research participants encounter, but they also illustrate a desire to change the limitations imposed by (re)centering such discourses. Given how often I heard this desire, I felt it was important not to frame my dissertation exclusively through such discourses and potentially collude with over-determining research participants' lives through them.

In this context, my conversation with the two men outside St. Elias Hall at Syria's National Day celebrations also reminded me not to assume what events/incidents were likely to impact Arab Canadians' experiences in Canada. For example, one of the men referred to "the financial crisis" that was the centre of much media attention in 2008/9 as potentially impacting the lives of all immigrants and racialized people in Canada. His reference reminded me that I had to leave open to question the specific instances when research participants felt they encountered, and how they engaged, (exclusionary) national identity discourses. Issues around racializing national security discourses certainly came up in participant observation and interviews, but not only and not always in relation to September $11^{\text {th }}, 2001$. Indeed, the 2006 war in Lebanon between Israel and Hezbollah came up just as often. In December 2008 and January 2009, Israel's military assault on Gaza and the Canadian governments' condoning of this assault became the prime reference point in most informal conversations about representations of Arabs in 
corporate Canadian media and state policies. Had I continuously asked research participants how "9/11" had changed their lives, my framework may have erased these politically charged moments, which I discuss in Chapter Eight, from my analysis.

\subsection{The Math Doesn't Always Add Up}

In October 2008, a woman I had recently met invited me to an Arab Communities Roundtable meeting - held every few months for members of various Arab Canadian organizations in Ottawa to meet and share information about upcoming events and discuss any pertinent issues facing members of the community. I was invited to present my research project and recruit interviewees. During my presentation, I framed the above-mentioned lack of research about Ottawa's Arab Canadian communities as surprising given that four percent of Ottawa's population identified their "ethnic origins" as Arab on Canada's national census. The question period that followed my presentation, turned into the kind of lively discussion I witnessed at many events.

During this discussion, a woman in the audience asked me for the source of my statistics and I explained that it was from a Statistics Canada study (Colin 2010a). Surprised, she and other audience members asked me for further details about the study. When I explained that it was a "Community Profiles" study based on the 2001 Census, someone jumped in to say "Oh, well, that's the problem." As I looked around the room, I saw that others were nodding in agreement. Statistics Canada, it seemed, had recently released the data from the 2006 Census. The woman who had started this round of questions now explained that "according to the latest Census data, Arabic is the third most commonly spoken language in Ottawa, after English and French." When I went home, I looked up the newest figures and realized the audience members were correct. 
While such statistics do not help me to understand the relationships between immigrant Arab Canadians' interpretations of their immigration experiences and senses of national identity, they were clearly important to those present at the roundtable, who were immediately familiar with the numbers. In later discussions of this incident with two research participants, both explained to me that these figures were important because they are the basis for claiming a sizeable Arab Canadian community in Ottawa when applying for government and nongovernment funding for Arabic language social service programs (e.g. counselling services) to be offered in Arabic (especially for seniors). Since these figures are important for efforts to obtain funding for social services, I think it is important to include them here. Yet, I also want to address some of the difficulties in calculating the number of Arabs or Arab Canadians living in Ottawa. To begin with, those of us doing research in Canada must first decide the basis on which to count people as "Arabs" or "Arab Canadians" " because census forms include three questions where

\footnotetext{
${ }^{36}$ By contrast, Arab Americans are counted in the racial category "White" or "Caucasian" in U.S. census data. Respondents who mark themselves as "Other" and write "Arab" in the space provided are recategorized by census employees as "White" (Abdulrahim 2008; Haddad 2004; Naber 2008). Scholars argue this process erases Arab identity from official census data even as Arab Americans continue to come under surveillance (Abdulrahim 2008; Jamal 2008; Joseph 1999; Naber 2008; Shryock 2008). Ironically, in the 1800 s and 1900 s, Arabs were denied access to U.S. citizenship because only "Caucasians" could qualify for naturalization. Their fight for political inclusion as citizens relied on "anthropological evidence" that they are "white" (Caincar 2008; Haddad 2004; Joseph 1999; Naber 2008). Lawyers representing Arabs in their struggles for citizenship argued that their clients were more akin to "Mediterranean" Europeans than Asians and, therefore, (1) Asian exclusion rules should not be used to prevent them from immigrating and (2) they were white and should qualify for "naturalization." While this argument worked in some cases that came under judicial review, in one recorded case the judge declared that Arabs were not "that particular type of free white person" referred to in naturalization statutes (Joseph 1999:257) and thus could not be "naturalized."
} 
respondents can report such identifications: ancestral origins, mother-tongue, and membership in "visible minority" groups in Canada. ${ }^{37}$

According to projections from the 2006 Long Census forms, which twenty percent of the population answer while the other eighty percent answer a shorter version, 45,245 people (approximately $4.1 \%$ ) of people living in Ottawa-Gatineau would identify "Arab" as their "ethnic origin" (Statistics Canada 2009b). In addition, 24,525 people would identify Lebanese as their "ethnic origin" - approximately 2.2\% (Statistics Canada $2009 \mathrm{~b}) .^{38}$ It is impossible to know whether those who identified specifically as Lebanese did so because they do not identify as Arab or if they understand Lebanese as a subcategory of Arab. Two things are important to note here. First, while "Arab" was not one of the listed examples on the 2006 Census form, Lebanese was. Thus, some people may have responded with "Lebanese" instead of "Arab" because they read its being offered as an example to suggest that Arab was too general a response. Second, unless 500 or more people wrote down a response, it was not included in calculated data. This means some respondents may have listed other categories that might count under the heading "Arab" (e.g. Iraqi), but were not numerous enough to be included in the numbers provided.

Another way to sketch out a numerical profile of Arabs and Arab Canadians in Ottawa-Gatineau is according to the Census question concerning "visible minority

\footnotetext{
${ }^{37}$ Statistics Canada (2009a) defines ethnic origins "as the ethnic or cultural origins of the respondent's ancestors," adding the qualifier that "an ancestor is someone from whom a person is descended and is usually more distant than a grandparent." Following the Employment Equity Act, "visible minorities" are "'persons, other than Aboriginal peoples, who are non-Caucasian in race or non-white in colour"" (Statistics Canada 2009c). Finally, mother tongue is the "first language learned at home in childhood and still understood by the individual at the time of the census" (Statistics Canada 2010a).

${ }^{38}$ Interestingly, the data for Montreal does not include a separate Lebanese category, but does include a Maghrebi category (Statistics Canada 2009b).
} 
populations." The data on "visible minority populations" are based on a Long-form Census question where respondents circle one of eleven listed responses - again, the Long-form Census is answered by twenty percent of the populations and the figures are used to project calculations for the entire population (Statistics Canada 2009c). Possible responses "include Chinese, South Asian, Black, Filipino, Latin American, Southeast Asian, Arab, West Asian, Korean, Japanese, Visible minority n.i.e. ('n.i.e.' means 'not included elsewhere'), Multiple visible minority, and Not a visible minority" (Statistics Canada 2009c). The number of people in the National Capital Region who would identify with the category of Arab as denoting a visible minority status is projected at 28,194approximately $2.5 \%$ (Statistics Canada 2010c). Thus, many people who identify as Arab in terms of "ethnic origin," do not seem to understand themselves as visible minorities.

Yet, the difference in numbers might also result from the methods of calculation used by Statistics Canada. For example, if a person selects both "white" and "Arab," s/he is not included in the category Arab as a visible minority in the tabulated results (Statistics Canada 2009c). Similarly, anyone who identifies as "black" and writes another term in the "n.i.e." category is counted as black. This means someone who is Sudanese, for instance, who identifies as black and writes "Sudanese" would be counted in the category of black rather than Arab.

Finally, if the size of the Arab population in Ottawa-Gatineau is calculated according to "mother tongue," the estimated result is 28,405 people - approximately $2.5 \%$ of the total population and the third most common response after English and French (2010b). Statistics Canada calculates this number based on those who put in a single response. This means they include anyone who reported Arabic and English, 
Arabic and French, or Arabic, English, and French in the categories "English and nonofficial language," "French and non-official language," or "English, French, and nonofficial language" respectively - a move which reinforces the dominance of English and French as Canada's two official languages.

As the discussion of each of the above ways of "sketching" an Arab Canadian community suggests, census data clearly has its limitations (see also Abu-Laban 1980). How, for example, would I decide whether to include as "Arab" or "Arab Canadian" someone who lists "Moroccan" as her/his "ethnic origins"? Do I take this person's use of a more strictly national category to mean that he or she does not identify with a broad, pan-national category of "Arab"? Maybe s/he identifies as Berber? Using the category of "mother tongue" also has its limitations. If I categorized "Arabs" as those who list Arabic as their mother tongue, I would exclude from my numbers those who do not speak the language, but who do identify as Arab. Indeed, I met several people through the course of fieldwork who would thus be excluded although they adamantly identified as Arab Canadian. This method of "counting" would also include those who may speak Arabic but who do not identify as Arabs, such as some Somali Canadians.

These figures also tell me nothing about why respondents chose the categories they did on the census form or how they came to identify as they do. Furthermore, I cannot know if the figures are self-reported since Statistics Canada sends one census form to each household and one person may fill it out for all the inhabitants of a house. What the figures do indicate, as audience members at the above-discussed meeting pointed out, is that Arabic was recorded as the third most commonly spoken mothertongue in the city after English and French on the 2006 Census. While it is difficult to 
claim an exact size for an Arab Canadian community in Ottawa, perhaps this figure might suffice to procure funding for Arabic language social service programs.

\subsection{Conclusion}

Critique was something with which I was continuously surrounded in Lebanon. I grew up in a household where history, politics, and the present-day acts of governments across the world were regular topics of conversation in which I was encouraged to take part even as a child. For my parents and their friends, these discussions presented opportunities for me not only to learn about history (including the history of the colonization of Lebanon first by the Ottoman Empire and later by the French in the guise of tutelage instituted by the Mandate of the League of Nations), but also to learn how to think critically and question what seemed most taken-for-granted around me. I would hear similar discussions about politics on the streets, in restaurants, in coffee shops. I was continuously immersed in conversations that rarely included academic voices - but which often drew on poetry and music - whose central feature was engaging with what I would now call nationalist discourses and global political economy.

I remember distinctly waking up early with my father to watch coverage of the American presidential elections in 1984, at the age of five, and discussing the results with students and teachers at school, many of whom had hypotheses about their implications for politics in the Middle East. It is perhaps an understatement to say few people living in Lebanon, or the Middle East in general, were (or are) privileged enough not to care about global politics or imperialism, both past and present. They pervaded our lives and formed the topics of some of the most popular music and plays since the 1960s. 
Spending time with research participants in Ottawa, I was reminded of my childhood world of rigorous and passionate argumentation about politics. Whenever I attended a lecture organized by one of the Arab Canadian organizations in Ottawa, the lecture would be followed by intense, passionate debate about the topic of the evening, be it commerce or "Arab thought." Even outside these debates, people often engaged me in astute critiques of current political events. Such political engagement was evident in many other events I attended, including a performance of Samah Sabawi's stage adaptation of Deborah Ellis's (2006) Three Wishes: Palestinian and Israeli Children Speak, which I discuss in Chapter Eight.

My research methods and methodological rationale, which I have outlined in this chapter, were informed by these experiences. As explained, I approach research participants' engagements with (national) identity discourses through a critical interpretive lens that is not dismissive of their own theorizations of these processes. In other words, I try to keep in mind that theorizing the social world is not the limited purview of academics. Although I recognize that as a researcher I have "the final say" in what I write, throughout my fieldwork, analysis, and writing I attempt to bring together academic literature, my own analysis, and research participants' narratives and interpretations of their own and others' lives into productive conversation and tension with one another. I begin to do so in the next chapter where I discuss research participants' first encounters with discourses of Canadian national identity which predated their immigration to Canada. I do so because, as I was reminded during fieldwork, research participants' encounters with institutionalized discourses of Canadian national identity did not begin with their arrival in Canada. Moreover, as I illustrate in the 
next chapter, understanding the ways in which they engaged such discourses - which certainly seemed to shape their subjectivities - requires a multi-scalar and multidimensional analysis which takes into account how their previous life experiences also shaped their interpretations of such discourses. 


\section{Chapter: Getting (T)here/First Encounters}

As suggested in Chapter One, the focus of most scholars writing about Canadian nation-building projects and modes of governance has been on the institutionalized forms of national identity discourses rather than on how people (other than the scholars in question) encounter and engage such discourses at an experiential scale. Similarly, in The House of Difference, Eva Mackey (1999) shows how various "national mythologies" are (re)produced through Canadian nation-building projects. Taking her analysis one step further, Mackey draws on ethnographic fieldwork to show how "Canadian-Canadians" experience and engage such mythologies in ways that authorize them to act and speak as daily managers of national space and national difference. While my focus in this chapter, and throughout this dissertation, is on such experiential encounters, I do not explore how dominant "Canadian-Canadians," experience and mobilize national/state discourses to create and defend their position as managers of social space. Instead, I focus on how people who define themselves as Arab and Canadian, people who in theory are much more subordinate as racialized immigrants and refugees within Canada, mobilize such discourses. I thereby bring into view distinctly different relationships between power, subjectivity, and national identity.

My focus on experiential encounters is particularly important as an avenue for demystifying "the nation-state" by teasing out where and how people interact with and experience "it." Part of this demystification must come from considerations of the globally dispersed, but experientially encountered power relations of "the state." For these reasons, below I explore how research participants encountered and experienced what I call the Canadian extra-national state "as a social subject" (see below) prior to 
immigrating to Canada; I show how nation-building projects, and the national discourses they (re)produce, extend outside of Canada's geographic borders and how some potential immigrant/citizens encounter and engage them. In this way, I hope to bring into sharp focus the experiential sites and interactions where the nation-state's governmental rationalities are (re)produced and/or challenged by social actors.

Between August 2008 and November 2009, I attended several public lectures sponsored by the Arab Canadian University Graduates' Association (ACUGA). I found out about these lectures, which took place at various locations across the city, both by word of mouth and through a listserv called Lebanese in Ottawa. ${ }^{39}$ After these lectures, audience members and presenters usually stood around discussing the topic of the lecture as they drank coffee and tea and nibbled on snacks provided by the association. They usually approached these discussions as serious intellectual arguments, presenting, critiquing, and defending their positions with great passion and precision, but with jokes and laughter thrown in for good measure. The lectures also offered opportunities for association members to catch up with one another, plan other engagements, and/or announce upcoming events.

At the end of one lecture, held in the basement of Sts. Peter and Paul Melkite Catholic Church, I stood chatting with Hala, whom I had known for a few weeks and with whom I was beginning to develop a friendship. As other audience members walked by, Hala would wave them over and introduce me. If I did not mention my research, she

\footnotetext{
${ }^{39}$ Although the listserv is called Lebanese in Ottawa, it is used by Arab associations whose membership is not exclusively Lebanese. For instance, I have received information through this list about a play organized the Syrian Students' Association, a lecture organized by the Ottawa Muslim Women's Association, and a trip organized by the Arab Canadian Women's Association.
} 
urged me to do so with the words "tell so-and-so about your work." She made sure few people left the event without an invitation to participate in a formal interview.

It was at this lecture that I met Monzer, a sixty-year-old civil servant who had been living in Canada for almost thirty years. He seemed somewhat sceptical about the idea of a formal interview, but he took the documents I offered: a Letter of Information, a Letter of Invitation, an Interview Guide, and a three page summary of the rationale and aims of my research. Because I had interpreted his scepticism as a lack of interest, I was surprised when he called me the next day to say he had read over the documents, thought my project was a worth-while endeavour, and wanted to help. Our phone conversation ended with us agreeing to meet that afternoon at a coffee shop near my apartment.

When Monzer arrived, he had read the materials I gave him the previous evening thoroughly enough to have picked out and corrected several typographic errors I missed during numerous proof-reads. "This will give you a sense of what type of person I am," he said, laughing as he handed me the documents with the errors underlined so I could correct them before distributing more summaries and letters. ${ }^{40}$ Amid the din of background conversations and clanging cups, we ordered our hot drinks, found a small table with two chairs, and sat down in the busy coffee shop in Ottawa's south end. Over

\footnotetext{
${ }^{40}$ Monzer is a person who, when he commits to something, does so completely. He is also a very kind and generous individual. He drove me home after the interview and told me, sincerely, that if I needed anything at all, I should not hesitate to contact him. Since I had no family living with me in Ottawa, he said, I was to consider him as an uncle. This act of kindness is certainly reflective of Monzer's personality. For some scholars, however, it might just as accurately reflect the cultural importance of hospitality for Arabs (Rabinowitz 2000; Shryock 2004, 2009; Sweedenburg 1989). Many research participants would likely agree with this assessment. Indeed, during fieldwork research participants often made me feel quite weicome to call on them for anything I may need, usually framing their offers in terms of Arab "culture."
} 
the next ninety minutes Monzer recounted various struggles and joys related to the process of immigrating to Canada and to his sense of national identity.

Monzer is a Palestinian refugee who has been exiled from Gaza since the 1967 War, a battle that tends to be represented as one of several incisive moments in the history Palestine/Israel (Bornstein 2002; Khalidi 1997; Swedenburg 1995; Tamari 1980). During this war, Israel annexed the Sinai Peninsula (which Egypt reclaimed six years later), the West Bank, and the Gaza Strip. ${ }^{41}$ At the time, Monzer was completing his education outside of Gaza and could not return. Since then, he has repeatedly made requests to the Israeli administration to be reunited with his family members in Gaza, all of which have been denied. Following his exile, he spent approximately ten years as a stateless person without a passport living from one temporary work permit to another in several Arab countries across the Middle East and North Africa before immigrating to Canada toward the end of the 1970 s. ${ }^{42}$ Monzer's interpretation of his experiences in Canada cannot be understood outside of this individual, national (as a Palestinian), and deeply globalized context. It is, in other words, related to multi-scalar histories.

Monzer interpreted his experience of immigrating to and living in Canada contrapuntally (Chowdhry 2007; Said 1993, 2000), evaluating it alongside his life

\footnotetext{
${ }^{41}$ Since the Six Day War, the Gaza Strip and the West Bank - generally known as The Occupied Territories - have been under Israeli military and administrative rule, with the Israeli Defence Forces imposing a blockade on the entry/exit of most goods and people into Gaza since November 2008 and engaging in an intensive military assault on the strip in December 2008 and January 2009 (Haas 2009; Roy 2009; "The Siege" 2010). The continued building of Israeli settlements and demolition of Palestinian homes throughout the Occupied Territories have made them a central focus for Palestinian and Israeli peace activists and left-wing academics (Halper 2008).

${ }^{42}$ For a discussion of the various laws surrounding the lives of Palestinian refugees in Arab countries, refer to Hammer (2005); Lindholm Shultz and Hammer (2003); Khalidi (1997); Peteet (2005); Sayigh (1994).
} 
with(in) Palestine/Israel and several Arab countries. ${ }^{43}$ For example, he explained that since entering Canada he has not had to worry about renewing residency permits:

I celebrated, actually celebrated, one time the fact that I forgot to renew my [Canadian] passport because it expired and I didn't know. While I was living in the Arab world, the expiry date of my visa and permit was tattooed in my brain while here I was more important than that paper... For a Palestinian, that's very significant. It's a type of feeling that is familiar to all Palestinians in the diaspora. The feeling of always needing a permit everywhere you go ... ended with getting Canadian citizenship. (original emphasis)

Thus, for Monzer, the ability to forget his passport's expiry date is a noteworthy symbol of his social citizenship and its recognition by the Canadian state; not having to continually (re)seek permission from officials "to stay in one place" - as he was required to do for ten years in several Arab countries - substantiated this legal state recognition. Against the backdrop of his above-discussed life history, Monzer interpreted the process of immigration to Canada as the culmination of a long trek during which he lived in exile from and was denied access to a national homeland, only allowed to remain in any national space temporarily, and constantly required to re-seek permission for these temporary forays. At the same time, he represented immigrating to Canada as a starting point for a new type of life (especially for his child) which (1) was marked by a sense of being permanently placed and (2) symbolized and produced a renewed sense of (national) belonging. He emphasized the meaningfulness of this sense of permanence for him, saying "my life has changed significantly positively to the better since becoming a Canadian citizen" (emphasis original). While Monzer discussed his sense of permanence

\footnotetext{
${ }^{43}$ The term contrapuntal was introduced into social science literature through the work of Edward Said (1993; 2000). Said adapts the term from musicology to refer to the ways in which several distinct experiences may enter into our interpretations of any given phenomenon in ways that highlight the simultaneity and interdependence of such experiences.
} 
as a Canadian as a vast improvement on his previous position as an internationally stateless refugee (and a temporary voyager and noncitizen of the world), as I discuss in Chapter Six, he did not suggest that his life in Canada has been without difficulties.

As Monzer pointed out, his experiences of exile, temporary permits, and permanent residence and citizenship were produced by specifically located (inter)national state policies. He interpreted differences between these experiences as resulting from the actions and decisions of various "officials" within different (national) political systems and spaces. Because such officials seem to produce and/or enact state legislations, their actions and decisions stand in for "their" states' denials or authorizations of Monzer's senses of national belonging - which are, in turn, symbolized by his exile from his place of birth, his always temporary position in several Arab nations, and his socio-political and geographic location as a Canadian citizen. What I find most clear in Monzer's interpretation of his exile and immigration experiences is that his senses of national in/exclusion and identity are, to a large degree, produced by the impacts of national laws (including citizenship legislation) on his life and sense of agency. His feeling that his life improved once he became a Canadian citizen should direct our attention to the continued significance of nation-states not only in the production of our subjectivities, but also our senses of agency. As a stateless Palestinian refugee with no official citizenship, for example, Monzer's capacity to travel was severely limited, as a Canadian citizen it is far less so (even though he still cannot enter Gaza).

As I illustrate in this chapter, like Monzer's account of his immigration experiences and senses of national identity, those of other research participants suggest that some of their engagements with discourses of Canadian national identity occurred 
through encounters with the policies and/or representatives of the Canadian nation-state which predated their immigrating to the country. In other words, their encounters with discourses of Canadian national identity have been neither territorially bound by Canada's internationally recognized geographic borders nor temporally bound by the date of their arrivals in the country. Not only did research participants (at least those who immigrated to Canada as adults) encounter such discourses prior to immigrating to Canada and through interactions with people positioned as representatives of the Canadian nation-state (see below), they tended to interpret (their encounters with) these discourses contrapuntally through their convergences with and divergences from their experiences of/in other nation-states. Bringing these two points together, in the rest of this chapter I argue that many research participants were first introduced to discourses of Canadian national identity through experiential encounters with an extra-national and multi-scalar Canadian state (i.e. one whose actions and discourses extend outside its internationally recognized geographic borders) prior to immigrating. ${ }^{44}$

I make this argument in four sections. I begin the next section by discussing governmentality scholars' theorization of the concept of the state as encompassing spatially dispersed rationalities through which multiple actors enact, reproduce, and/or challenge various power relations. This conceptualization forms an entry point for asking (1) when, where, and how research participants first experientially encountered the Canadian nation-state, (2) what national identity discourses were articulated in such encounters, and (3) how they engaged these discourses. Focussing on research

\footnotetext{
44 I would like to thank Julie Gregory and Jasmin Habib for pushing me to consider where "preimmigration" narratives fit into my overarching project and Eva Mackey for suggesting I think of the ideas presented here in terms of an "extra-national state."
} 
participants' pre-immigration narratives, I then offer an overview of their encounters and engagements with two national identity discourses defining Canada according to (1) its climate and (2) its ostensibly humanitarian attitude to immigration which discursively locates it as a liberal nation-state committed to social justice. Next, I explore how the Canadian nation-state engages in extra-national "pedagogies of patriotism" (Mackey 1999) aimed at (re)producing and solidifying specific images and expectations of (life in)

Canada for immigrants. I conclude the chapter by discussing the implications of these encounters for research participants' later engagements with national identity discourses.

\subsection{Academic Representations and Representatives of Nation-States}

When I asked Monzer if there was anything he found particularly difficult or easy about immigration, he told me that "the whole thing was easy":

I was living in [an Arab country]. My [sibling] applied to sponsor me and the Canadian Embassy in [a European country] contacted me to see if I wanted to continue with this application... When the time came for an interview, they actually sent a representative from the embassy [... to the country where I was living]. We went and met with him in his hotel room....Canada, one of the best countries in the world, [sent] one of its representatives [from one country to another] to interview me. Now, if I had wanted to come $10 \%$, it jumped to $99 \%$; I was being treated as a human being, with respect. ${ }^{45}$

This experience, one of Monzer's first encounters with Canada, preceded his immigration to the country and was central to consolidating his decision to immigrate.

From my perspective, understanding fully the impact of the above interaction on Monzer's sense of national belonging and identity requires a multi-scalar lens. More specifically, the above interaction produced Monzer's sense of having a respected (future) place in Canada at a local experiential scale through a global contrast of different

\footnotetext{
${ }^{45}$ Monzer's sibling could sponsor him at the time under the Assisted Relatives Class. As mentioned in Chapter Two, sponsoring a sibling has not been permitted since 1993.
} 
national policies. For example, the representative of the embassy travelled across continents to meet with Monzer based on a sponsorship application his brother submitted. Monzer interpreted the representatives' travelling internationally to interview him as evidence that the Canadian nation-state was treating him humanely. Contrasted with his experiences with other nation-state's policies, the state official's travels are particularly striking: while the Israeli administration continued to reject Monzer's applications to be reunited with his family members in Gaza, Canadian immigration officials not only accepted his brother's application to have Monzer (and his wife and child) join him in Canada, they even sent an employee across continents to conduct the interview required to complete the application. Informed by this contrast, Monzer began to interpret Canada as a liberal and just nation-state prior to arriving in the country.

As suggested above, although this meeting took place outside Canada's internationally recognized borders, I think it is best analyzed as an encounter between a potential immigrant-citizen and (a representative of) Canada as a nation-state. In his role as an immigration official, the man who traveled from Europe to meet Monzer is officially authorised to make decisions about who may (not) enter the geographic borders of Canada. In this sense, his position entails managing (the permeability of) the borders of "the nation" through his state-sanctioned authority to grant or deny access to the national body and territory. While this man may not think of himself as a gate-keeper to the national body and territory, as someone who enacts (his interpretation of) immigration law, he mediates state legislation.

My understanding of this man as mediating state legislation by interpreting and enacting immigration law follows from the work of critical legal scholars who challenge 
liberal interpretations of "the law" as an objective social structure which ensures individual equality (see Chapter One). Instead, as critical legal scholars illustrate, while laws (such as immigration legislation) might be written (and dominantly conceptualized) as if they guarantee individual equality by always producing the same results, they are enacted "on the ground" by subjective social actors whose interpretations give meaning, and thus social life, to these structures. In other words, I refer to this immigration official as a state representative because in this encounter Monzer experiences him as embodying immigration law which, in turn, comes to have a social life through this man's interpretations and actions.

Interestingly, Monzer also explained that during this encounter "the representative from the embassy" gave him advice on what to expect in Canada, telling him, for example, that what he currently considered "winter clothes" would be "useless" against Canada's cold climate - advice which, as I explain below, is woven into workshops offered to immigrants as part of CIC's Canadian Orientation Abroad (COA) seminars. In this way, this state representative (re)produces certain expectations of what life in Canada will encompass both through what he says (in terms of appropriate attire for Canadian winters, for example) and through his making a trip to the country where Monzer resided (something that, for Monzer, signifies "being treated as a human being"). In doing so, he animates discourses about Canada's "national character" - i.e. it is defined by cold weather and a commitment to liberal humanism.

I therefore conceptualize this interaction as one way in which Monzer experiences the Canadian nation-state as a "social subject in [his] everyday life" (Aretxaga 2003: 395). I take this terminology from Bagoña Aretxaga (2003) who argues that while the 
state is not a physically locatable, unitary, ontological centre of power, "the fictional reality of the state is socially powerful" (401). For Aretxaga, theorizing the social power of the state requires scholars to "focus not only on those discourses and practices that produce [the] state form as real but also on the actual social and subjective life of this formation we call the state" (401). The state's subjective component, she suggests, is about the ways in which people experience certain elements of their lives (e.g. the impacts a person understands as resulting from state laws) as the effects of the state. In other words, she asks us to consider in what ways the idea of the state materializes in people's lives. Given scholarly critiques of ideas of the state, the nation, and any selfevident relationship between them, in the rest of this section I explain why I draw on the concept of the nation-state in my above analysis and throughout the rest of the chapter.

In the last twenty years, numerous scholars worked to complicate normative understandings of "the state" (Aretxaga 2003; Brown 1995; Das and Poole 2004; Dean 1999; Foucault 1991; Kanaaneh 2002; Linke 2006; Rose 2001, 1996; Rose, O’Malley, and Valverde 2006; Shore and Wright 1997; Vukov 2003). They contend that reifications of "the state" as a singular, coherent ontological entity confound various power relations that ought to be analyzed and explained. Such power relations, they argue, (re)produce and are (re)produced by the socio-political phenomena represented by the term "the state." For example, Wendy Brown (1995:174) points out that while there is an "almost unavoidable tendency to speak of the sate as an 'it', the domain we call the state is not a thing, system, or subject, but a significantly unbounded terrain of powers and techniques, an ensemble of discourses, rules and practices cohabiting in limiting, tension ridden, often contradictory relation to each other." 
Brown's conceptualization of "the state" is in keeping with that of scholars who build on the work of Michel Foucault (1991; also Foucault 1979; 1980; 1990a; 1990b). Foucault developed a framework to illustrate that modes of governance are not solely about overtly repressive prohibitions against particular actions, that the state is not as centralized as some scholars suggest, and that the achievement of desired behaviours among members of governed populations relies on more than (the threat of) violence. ${ }^{46}$ Using this framework, he argued that the (re)production of discourses which define (un)desirable ways of thinking and acting, and which are based in particular bodies of knowledge/power, constitute techniques of governance. He pointed out, however, that governmental bodies and the discourses they (re)produce sometimes contradict one another and sometimes work in concert to reinforce certain notions of (un)desirability. From this perspective, governmental discourses shape people's subjectivities thereby producing populations whose members self-govern in accordance with these discourses.

Following from Foucault's work, scholars working with this understanding of governmentality represent "the state," not as a singular unified entity, but as a dispersed group of multifarious governmental agencies (e.g. educational, military, legal, economic, and medical institutions) that rely on and reproduce particular forms of knowledge/power and discourses which shape people's senses of self and produce self-disciplining populations (Dean 1999; Rose 1996, 2001; Rose, O'Malley, and Valverde 2006; Shore and Wright 1997). At the same time, they argue, governing agencies can never guarantee

\footnotetext{
${ }^{46}$ In "Governmentality," Foucault (1991: 93-96) breaks down these ideas by outlining four characteristics of government: (1) its object is the management of people, things, and the relationships between them; (2) it aims to achieve particular ends; (3) it attempts to achieve these ends by managing "dispositions," or the ways in which people think about and understand their own and others' actions; and (4) it is based on knowledge of the things, people, and relationships to be governed.
} 
the production of such populations because people might "act and [...] think in a variety of ways [...] not foreseen by authorities" (Dean 1999:12). Thus, governance is connected to "relations of power and authority" as well as "issues of self and identity" (17; see also Rose, O’Malley, and Valverde 2006; Sabra 2008b).

Notwithstanding such analyses, even if "the state" is a kind of "collective illusion" (Aretxaga 2003:401), my above analysis suggests it is experienced as a material reality in the form of immigration laws, for example, which may differentially affect people's abilities to access national spaces, identity discourses, and/or resources (Agamben 1996, Honig 2001, Rancière 2004). As I argued in Chapter Two such legislations, generally represented as state laws meant to protect the nation, (re)produce and rely on various power relations that constitute and locate multiple actors, including those who participated in this study and the representative from the embassy, in relation to one another, to material resources, and to national spaces and identities (Bhabha 1990a; Das and Poole 2003; Hall 1999; Mackey 1999; Macklin 2001; McClintock 1997; Shore and Wright 1997; Smith 2007; Yuval Davis 1997).

In the Canadian context, scholars who study Canadian nation-building projects highlight the necessity of focusing analytic attention on "the state" and its role in the production of social structures (e.g. Bannerji 1993a, 1995, 2000; Mackey 1999; Razack 1998, 2002, 2004; Thobani 2007; Vukov 2003). Scholars such as Eva Mackey (1999), Sherene Razack (2002, 2004), and Sunera Thobani (2007), for example, illustrate the extent to which "the state" has aimed to define and (re)produce discourses of a distinctly Canadian national identity and to manage differences within the supposedly coherent "national body" thereby producing (the image of) coherence: their work demonstrates the 
fruitfulness of examining the (production of a) link between "nation" and "state." More specifically, these scholars have shown that "the desiring, making and reinforcing of national identity $[. .$.$] are an essential feature of the Canadian nation building project, and$ [...] the site of immense state intervention and funding" (Mackey 1999:89; see also Kinsman and Gentile 2010). Illustrating the state's desire and attempt to produce an image of a unified nation, these scholars demonstrate the importance of paying attention to the relations between government, power and authority, and self and identity, something I do throughout the rest of this chapter. I begin to do so in the net section by considering the discourses of Canadian national identity which research participants encountered prior to immigrating to Canada.

\subsection{Circulating Discourses of Canadian Nationhood and National Identity}

In both informal conversations and interviews, research participants most commonly said they knew little about Canada before making their decision to immigrate. For example, Nouhad, a fifty-three year old female who has been in Canada since 1987, told me "I knew where it was located, but otherwise I did not know anything specifically about it." Wafaa, a 65 year-old woman, similarly told me she "knew a little bit from [her] geography classes in middle school." Like Nouhad and Wafaa, Lias, a man in his forties, explained that he knew Canada's geographic location and "names of the major cities." In these and other cases, research participants' explanations of "the little" they knew tended to include discourses in which several scholars have suggested the Canadian state has heavily invested (either historically or presently). Most commonly, research participants referred to Canada's cold climate and its reputation as welcoming to immigrants. 


\subsubsection{Canada as Defined by a Cold Climate}

Discourses constructing a distinctly Canadian identity have stressed its "cold Northern climate." Carl Berger (1966) outlines the use of such discourses by members of the Canada First Movement during the late 1800s. He demonstrates their racialized use of the idea of a Northern climate to assert an identity as a ruddy, resilient, white, Northern European Canadian "race" which was naturally hard-working, democratic, and capable of self-rule. According to such discourses, Canada's "cold, northern climate" ensured only the most stalwart and resolute people would make up the country's population and distinguished Canada from the United States whose southern climate made its population indolent and feeble. Thus, members of this movement argued Canada's cold weather would "protect" it from having a "negro problem" like the United States. Ultimately, Berger illustrates the long racialized history of the use of discourses about Canada's cold climate to construct a "distinct" Canadian national character (see also Berland 1999).

In keeping with this history, would-be-immigrants were barred from entering Canada under the Immigration Act 1910 if they were categorized as belonging to a "race" deemed climatically unsuitable to the country (Mackey 1999: 33). While references to "climatic unsuitability" are no longer enshrined in immigration laws, as suggested in Chapter Two, other racialized discourses (focused especially around notions of "culture" and criminality) continue to pervade present day legislation. In Chapters Seven and Eight I take up the question of how such racialized discourses impacted research participants' experiences in Canada. In this chapter, my focus again is only on research participants' interpretations of discourses they encountered prior to immigrating to Canada. 
Although research participants referred to Canada's cold climate when telling me what they knew about the country before immigrating, they did not represent them as central to their understandings of Canadian national identity. Instead, their references to the weather were banal. For example, Lias said prior to immigrating, and based on conversations with Canadian coworkers and faculty members at the university he attended in Lebanon, he expected Canada to be "a very hospitable place." Almost as an afterthought, he added, he "knew it was going to be cold though." Thus, through conversations with Canadians in Lebanon, Lias encountered discourses defining Canada according to its warm hospitality (see below) and cold climate.

Monzer encountered discourses about Canada's cold climate in two ways. He explained that, at first, "the only thing [he] knew" was that his sibling lived in Canada. Once his sibling put in a family reunification application to sponsor him, Monzer began to buy and read books about Canada while on work-related trips to the United Kingdom. Through this reading, he said, he "found out that, in Canada, they don't speak Canadian, they speak English in most of the country and French in some parts." He added that before starting this reading, he "knew it was cold, but ... thought it was all snow." Thus, for Monzer, Canada's climate seemed to be part of a series of "basics" that define the country (e.g. official languages spoken), which he learned while reading to prepare for immigration. In addition to this, as mentioned above, a representative from a Canadian embassy further warned Monzer about Canada's cold winters. Yet, while Monzer seemed to understand these basics as defining features of the country, his explanation that he had erroneously thought "it was all snow" prior to this reading also implies that he imagined the details about Canada's climate through stereotypical (mis)representations. 
In this context of stereotypical (mis)representations, Wafaa's explanation of what she knew about Canada before immigrating was particularly interesting and critical: "in the same sense that when we first came here from Egypt everybody was asking us about the Pyramids and camels, from my perspective I knew Canada as Niagara Falls and cold." In this way, she interpreted images of Canada as defined by a cold climate at a global scale by drawing parallels between standardized, homogenizing depictions of Egypt as "Pyramids and camels" and those of Canada as "Niagara Falls and cold." In doing so, Wafaa interpreted both of these stereotypical images as clichéd and trite, almost not worth engaging. For Wafaa, there are, of course, Pyramids and camels in (some parts of) Egypt and Niagara Falls and cold (in some parts/seasons in) Canada. She suggested, however, that these features do not define either country or the people who live in them. The above references to the weather are reminiscent of what Michael Billig (1995:6) calls banal nationalism, ways in which "daily, the nation is indicated, or 'flagged', in the lives of its citizenry." Billig's idea of banal nationalism is intended to highlight how people are continuously reminded of the meanings they ought to attribute to the nation whose "body" they make up. "Consequently," he argues, "an identity is ... found in the embodied habits of social life [... and, thus, to] have a national identity is to possess ways of talking about nationhood" (8-9). Billig concludes that studies of nationalism should not only focus on "exotic and passionate exemplars" but include "the routine and familiar forms of nationalism" (9), such as talk about the weather.

In the above excerpts from interviews, some research participants suggested their expectations about life in Canada were in part produced through the idea that Canada is defined by "cold weather." In accordance with Billig's work, these encounters with 
images of Canada's cold climate might be interpreted as "forgotten reminders" of Canadian national identity which gesture toward (future) "embodied habits" (e.g. dressing a certain way to protect against the cold) which people may not consciously think of as being about nationhood. This is the case, for example, in the excerpt at the beginning of this chapter where a representative from the embassy warns Monzer that what he currently considered to be winter clothes would be "useless" against Canada's cold climate thereby implying that the process of joining the Canadian national body requires reconsidering Monzer's habitual conceptions of winter clothes.

Yet, research participants engaged such banal discourses in varying ways. Reflecting back on their encounters with this image, Monzer and Wafaa respectively challenged the details and centrality of Canada's climate to definitions of the country. In Monzer's case, the books he read presented a challenge to what he suggested was a stereotypical (mis)representation of Canada's weather. While he still expected it to be cold (and, again, this expectation was reinforced by the representative from the embassy), he no longer thought the country would be "all snow." Wafaa, on the other hand, deconstructed these "forgotten reminders" of national identity precisely by highlighting their banality and suggesting it was somewhat ridiculous to think of them as defining Canada and/or Canadian identity.

Similarly, Nouhad told me that although people kept "talking about the weather," when she first arrived in Canada, she had so many other concerns that "the weather [was] the last thing [she worried] about." For her, the process of immigrating came with many other changes that had a greater impact on her life so that Canada's cold winters did not define her experience. Lias talked about how he thought Vancouver might have been a 
better choice of destination given its mild weather. References to Vancouver, which several other research participants also made, are particularly interesting because at the same time as they are framed within banal discourses which (re)centre "the cold" as a defining experience of life in Canada, as reminders that "Canada's" climate varies across geographic location, they simultaneously challenge such discourses.

Drawing on the above examples, the point I wish to make here is that while discourses of Canada's climate seem ubiquitous enough that every interviewee who immigrated to Canada as an adult (Monzer, Lias, Sam, Wafaa, Nouhad) brought them up, they did so in slightly varying ways that suggest they do not necessarily and unquestioningly accept them as centrally defining characteristics of the country. For Wafaa, for example, the weather is not a forgotten reminder but a stereotypically misdirected focus. For Nouhad, moving to a new country involved so many adjustments that warnings about the weather similarly seemed misplaced. These women do not, as Billig's framework of banal nationalism would imply, forget or fail to notice these "reminders" of Canadian life. Instead, they question how central they should be to definitions of the nation and their experiences in it.

\subsubsection{Canada as Welcoming to Immigrants and Refugees}

Before immigrating to Canada, most research participants (including those who did not participate in formal interviews) were familiar with discourses according to which Canada is defined as particularly welcoming to immigrants. Much as participants engaged discourses about Canada's cold climate in varying ways, their interpretations of discourses about Canada's welcoming attitude to immigrants were also multidimensional. In other words, their interpretations of this latter discourse emerged out of its 
intersections with other experiences and discourses, including those distinguishing a feminized Canada from a masculinised United States.

As mentioned above, Lias said that based on conversations with Canadian faculty members at the Lebanese university he had attended and co-workers in Lebanon, he "had some idea [he was] coming to a very hospitable place." While notions of hospitality can have varying meanings, they necessarily imply a relationship between people who are defined as hosts and others who are defined as guests. To a certain degree, a hospitable "host" makes "guests" feel welcome and "at home." Yet, when they are mediated through (immigration) law, relations of hospitality also place certain conditions on "guests" thereby reiterating that the nation-state is someone else's home (see below). With this in mind, I want to say a few words about Lias's use of the term "hospitable" in this context.

Jacques Derrida (2005) argues that under the present liberal politics of state sovereignty immigration laws enshrine a conditional hospitality: immigrants are welcome only if their presence does not (appear to) challenge state sovereignty. According to Derrida, such conditional hospitality is necessarily contradictory insofar as it maintains and reproduces a certain tension between what ought to be a gesture of infinite welcoming (and here his main focus is the case of offering asylum to refugees) and the limitation imposed on that possibility by the notion of sovereignty which recognizes "the host" as a "master" who can decide whether or not to be hospitable, to whom, and under what circumstances. Consequently, he suggests, under liberal legal principles, hospitality necessarily reproduces an asymmetrical power relationship which valorizes the position of those defined as hosts and owners of national space. In this sense, "the welcoming of the [immigrant] other within the limits of law is possible on the condition that the host, 
the owner of the home, the one who accepts, remains the master of the home and thereby retains his/her authority in that place" (Yegenoglu 2003: \15).

While Lias might not have used the word "hospitable" with the above deconstruction in mind, in all my interactions with him (including the formal interview from which this excerpt is taken) I got the sense he continued to struggle against the feeling that "Canadian-Canadians" - discursively positioned as managers of national space (Mackey 1999) - might understand him as no more than a guest in their country. He often suggested that despite having "an emotional stake in what happens in the country," Arab Canadians are "treated like second-class citizens" in Canada. More than once, he told me he and his wife were "doing everything [they] can to make sure [their] kids will be well established in the country," namely by ensuring their kids are fluent in both English and French, and that they complete their post-secondary education in Canada so they will not have difficulty finding work. I thus got the sense that Lias felt he and his wife were still "guests" in Canada, that the limits on their welcome were still determined by others, but hoped their children would feel and be felt by others to be hosts. Indeed, I often heard first-generation immigrant Arab Canadians express this hope that their children will not face the same (especially economic) hardships they had.

Unlike Lias, Sam did not use the language of hospitality. In reflecting back on what he knew about Canada before immigrating to the country, Sam instead tended to interpret discourses defining Canada as welcoming to immigrants in relation to those distinguishing it from the United States. For instance, he explained that before immigrating he "always had a good image of Canada" as "an accepting society." When I asked him to elaborate, Sam told me he had known Canada to be "a gentler form of the 
U.S. society in a way, which [he was] familiar with through the Hollywood movies" and other forms of media. Thus, rather than interpreting the discourse about Canada being welcoming to immigrants through a lens of "hospitality" (with its relationships of hosts and guests), he drew on another long-established discourse according to which Canada is defined by its difference(s) from the United States (Mackey 1999).

To understand Sam's use of this discourse of Canada's distinctiveness from the U.S.A., it is important to know that his regular conversations with siblings who have lived in the United States with their partners and children for decades formed an important element of his life experiences. He often spoke with these family members about the differences in their experiences of immigration and their lives in Canada and the United States. Sam told me that while he felt he could say "I am Canadian," his siblings did not have the same level of comfort in claiming an American national identity. He interpreted these differences as being about Canadian and American attitudes toward immigration, pointing specifically to Canadian multicultural policies as central in producing these differences. I return to Sam's discussion of these differences and of multiculturalism in Chapter Seven. Here, I simply want to suggest that his retrospective interpretation of discourses according to which Canada is "an accepting society" hinged on its distinctions from the United States in part because of differences he and his siblings perceived between their immigration experiences. Thus, while his use of this discourse might be interpreted as an acceptance of dominant mythologies of the nation, it was also mediated and complicated in other ways by specific familial experiences.

Indeed, Sam also questioned this discourse about Canada's "national character" being defined by an accepting attitude toward immigrant "others" when he told me about 
a conversation he had with his nieces and nephews who were born and lived their entire lives in Canada. Sam explained that he was surprised to discover these nieces and nephews did not feel they could confidently claim a national identity as Canadians:

My follow-up question was 'Well, what is a real Canadian?' And they looked at it as a real Canadian is, you know, somebody who's white, somebody who's from an Irish background. You know, his family was born here and he may have longer ties. And it makes you wonder if that's, I mean it has to be coming as a reflection from the mainstream society.

Likely, Sam concluded his nieces' and nephews' sense that they are not "real" Canadians was "a reflection from the mainstream society" because he firmly believes, as he reminded me after reviewing his interview transcript, "your identity is shaped according to your experiences." Thus, if his nieces and nephews did not have a sense of themselves as "real" Canadians, this indicated to him that they had experiences wherein they were made to feel this way. Sam's conclusions about this conversation opened up room for fissures in discourses defining Canada as "welcoming to immigrants," precisely by pointing out that some second-generation (Canadian-born) Arab Canadians experience a process of negative racialization that constitutes them as "guests" rather than "hosts."

Scale is particularly important in analyzing the differences between the two ways Sam engaged discourses about Canada's "welcoming" and "accepting" nature. At an (inter)national scale, the primary dimension of his engagement with these discourses was the difference between his and his siblings' respective experiences in Canada and the United States. In this context, the major factor distinguishing their experiences from one another is the country in which each resides. When Sam's interpretive scale shifted to a national level, however, focussing exclusively on Canada, differences between Canada and the United States no longer applied. In this context, he seemed to suggest, the 
production of his nieces' and nephews' senses of non-belonging must be located within Canada's national boundaries given that their life experiences have (mostly) taken place in the country. Sam's feeling that he is accepted in Canada was also produced through a distinction with his prior experiences of political and economic exclusion as a stateless Palestinian refugee in Jordan, which I discuss below. ${ }^{47}$

The discursively constituted relationship between Canada's distinctiveness from the United States and its being welcoming to immigrants was also evident in Farida's narrative about her decision to immigrate to Canada. Farida is a fifty-year-old Palestinian refugee who immigrated to Canada via the United States in the fall of 2001. Prior to this time, she and her husband, also a Palestinian refugee, lived in an Arab Gulf county with their children on temporary residency permits conditional on their participation in paid labour. They had to renew these permits at regular intervals and knew their children would become unauthorized to remain in the country with them upon completion of high school - i.e. once they ceased to be considered their dependents. The only way around this was to find a sponsor for each child and pay a considerable annual fee toward this sponsorship as their children went on to post-secondary education.

Hoping to find what might be, to paraphrase Monzer, a sense of permanence in their lives, Farida and her husband first looked to the United States: they travelled to the country with their children, found employment, and immediately applied for work

\footnotetext{
"97 Other research participants' explanations that they "knew" Canada to be welcoming to immigrants prior to immigrating also relied on discourses distinguishing Canada from the United States. Most research participants who immigrated to Canada as young children (between one and six years of age) drew on these latter discourses in describing what being Canadian meant to them. I take up their use of such tropes in Chapter Seven where I discuss engagements with discourses of Canadian national identity encountered in Canada.
} 
permits. Farida's husband then returned to the Gulf to cancel their residency permits and submit their letters of resignation to their places of employment. While he was there, Farida said, "the attacks of September $11^{\text {th }}$ happened" and when her husband tried to rejoin her and their children in the United States the following month, "they cancelled the entry visa they had given him and said 'bye bye." Because their residency permits had also been cancelled, Farida and her children were unable to return to the Gulf. Looking for advice on how to reunite her family, she met with several immigration lawyers in the U.S.A. who explained to her that it would likely take "around 3 or 4 years until they [American immigration officials] let [her husband] back into the country." At this point, "a lot of people" (including these immigration lawyers in the United States) advised her that Canada would be her "only option" for family reunification. Thus, like Lias and Sam, Farida also encountered discourses according to which Canada is "welcoming to immigrants and refugees" prior to immigrating to the country. As in Sam's case, this discourse was (re)produced for (and by) Farida by differentiating Canada from the United States (a distinction drawn in the United States).

As Farida explained, although she "didn't know much about [...] the conditions" of life in Canada, based on these conversations, she knew it had a reputation as "a good place for immigration." Motivated by suggestions that "Canada" would "understand [her] situation" as a Palestinian refugee, Farida applied for refugee status at the AmericanCanadian border. Significantly, Farida's ability to do so reflects the time at which she made this application - i.e. before the signing of the Safe Third Country Agreement between Canada and the United States. As discussed in Chapter Two, since this agreement came into effect in 2004, refugees who arrive in the United States before 
Canada are usually required to seek asylum in the U.S. and vice versa. Thus, if she were in the same situation today, Farida would not be able to apply for asylum in Canada.

As with other research participants, Farida's engagement with and interpretation of discourses defining Canada as welcoming to immigrants was refracted through her previous experiences and other discourses with which she was familiar. More specifically, Farida is a Palestinian refugee, as are her siblings and her parents. In the absence of a Palestinian nation-state, and due to the impacts of constantly changing policies defining Palestinians' rights to residence in different Arab countries, she and her siblings and parents have not been able to live in the same nationally defined territory for long. They also had difficulty traveling to see one another prior to her acquisition of Canadian citizenship. Having been denied access to a familial homeland for most of her adult life, Farida placed great value on the possibility of family reunification, which many other people are entitled to experience as a taken-for-granted right because they have national citizenship. Against this backdrop, she interpreted American lawyers' claims that Canada was her "one option" for family reunification as evidence of its humanitarian commitments which make it welcoming toward immigrants.

Perhaps for these same reasons, familial imagery also pervaded Farida's narrative of her arrival at the Canadian border. Describing this arrival, she said Canadian officials were "of course [...] very welcoming. I found that it was like the nurturing mother who was holding me" (emphasis added). In drawing on mothering discourses, Farida reiterated a (feminized) image of Canada's (maternal) compassion. Through this image of being welcomed with open arms by representatives of a caring mother(land), Farida represented her entry into Canada as a home-coming into a loving and accepting 
Canadian national family. Her gendered use of familial imagery was also intertwined with discursively constituted distinctions between Canada and the United States. More specifically, she presented a narrative wherein Canada (as a caring mother) not only welcomed, but comfortingly held her while the U.S.A. denied her husband entry despite his willingness to engage in paid labour (recall they had both already found employment in the United States). The comparison brings to mind images of a disciplinary and (overly) authoritarian father: in contrast to Canada, the caring mother who welcomed her based only on humanitarian motivations, the United States emerged as an overly authoritarian father who could not even recognize the potential value of her husband's immigrant labour. Thus, as in Sam's above description, Canada emerged in Farida's narrative as "gentler" (i.e. more femininely coded) than the United States.

As suggested above, Farida first encountered such discursive distinctions in her interactions with American immigration lawyers in the United States - professionals who are socially defined as experts in the field of immigration law - who advised her that it would take a longer time for her husband to rejoin her and their children in the United States than for her to apply for refugee status and family reunification in Canada. Aside from its expert status, Farida interpreted these lawyers' advice in relation to a distant relative's (also a Palestinian refugee) success in having her/his refugee claim recognized by Canadian immigration officials. She called this relative who reiterated what these lawyers and several friends in the United States had said: Canada was committed to humanitarianism and, thus, welcoming to refugees. In other words, for Farida, several elements (familial, national, and global) came together at an experiential scale which 
reinforced the intertwining of feminizing discourses according to which Canada is (1) welcoming to immigrants, (2) committed to humanitarianism, (3) distinct from the U.S. That this latter discourse (i.e. Canada as distinct from the United States) infused the knowledge claims of American immigration lawyers, Farida's distant (Canadian) relative, and her American friends with whom she discussed her situation is to be expected. Indeed, it is a long-established institutionalized discourse, some versions of which permeate the works of prominent Canadian authors (for example, Atwood 1972; Frye 1971) and several government documents aimed at defining Canadian national identity/character. For example, the authors of the Massey Commission on National Development in the Arts, Letters and Sciences (Canada 1949), the Fowler Commission on Broadcasting (Canada 1955), and the O'Leary Commission on Publications (Canada 1962) all go to great lengths distinguish Canada's identity from that of the United States. ${ }^{48}$ The reports of these commissioners also make recommendations for how to maintain this distinction through state-spending on such things as a Canadian national broadcasting corporation or Canadian publishing firms, for example. Furthermore, since the late 1800 s, Canada has been represented using feminine tropes which distinguish it from a dangerous, menacing, and masculinized United States (Wood 2001; see also Clarke 1997; Mackey 1999).

Variations of these distinctions between Canada and the United States were central to Sam and Farida's interpretations of Canada as particularly welcoming to

\footnotetext{
${ }^{48}$ Given that several other scholars have documented this trend with great care, I do not elaborate on the details of these reports here. For thorough outlines and discussions of the development of these themes by Canadian authors, nationalist movements, and government documents, refer to Berger (1966), Bumstead (1992), or Mackey (1999).
} 
immigrants. They did not, however, come up in my discussion with Lias. As I show above, these differences in Lias, Sam, and Farida's encounters with and interpretations of this latter discourse are multidimensional: their interpretations of this discourse depended on its intersections with specific life experiences or other discourses with which they were familiar. Thus, Lias's feelings that discursively legitimized members of the Canadian national body (generally white, Anglo-Saxon, bourgeois Canadians) fail to recognize his emotional investment and sense of ownership in of the country translated this discourse through a language of hospitality which positions him as a guest in their home. For Sam, on the other hand, his siblings' experiences in the United States as compared to his own (but not those of his second-generation Arab Canadian nieces and nephews) in Canada refracted the discourse defining Canada as "an accepting society" at an international scale such that he depicted it as a "gentler form" of American society. Finally, the value Farida placed on having a familial national home intersected with advice she received from American immigration lawyers, family, and friends, gendered conceptions of nurturing, as well as Canada's definition as welcoming to immigrants such that she depicted her arrival in the country in terms of a warm, motherly embrace.

Before moving on to a discussion of the ways in which some versions of the above discourses are institutionalized by a Canadian extra-national-state, I want to very briefly address two other references I interpret as (perhaps indirectly) linked with discourses defining Canada as welcoming to immigrants. Nouhad and Monzer both mentioned knowing of Pierre Eliot Trudeau before immigrating to Canada. ${ }^{49}$ In

\footnotetext{
49 Pierre Elliot Trudeau was Canada's Liberal Prime Minister from 1968 to 1979, served as the Leader of the Opposition until 1980, and was again Prime Minister from 1980 to 1984
} 
Nouhad's case, she said she "knew that he was a handsome Prime Minister." Monzer, on the other hand, said he knew Trudeau "wanted Canada to be a just society."

To some degree, these references gesture toward the times at which Monzer and Nouhad immigrated to Canada, namely at the end of the 1970 s and mid 1980 s. This temporal context is important because during these time periods, particularly in Anglophone Canadian discourses, Trudeau's "legacy" came to be respectively linked with multiculturalism and the Canadian Charter of Rights and Freedoms. Indeed, the images of Trudeau Nouhad and Monzer reference were also highlighted in my high school's Canadian history class in Etobicoke, Ontario in the mid-1990s: it was an image of Trudeau that perfectly matched the Canadian Broadcasting Corporation's (CBC) description of him as a "charismatic prime minister" (CBC 2009:ף1) with a "vision of a unified, bilingual, multicultural 'just society"” (CBC 2009:ף1).

This particular image of Pierre Trudeau resonates with and, thus, indirectly reinforces other narratives of Canadian nationhood through his association with the era of the liberalization of immigration policy - necessitated by a need for cheap (immigrant) labour but discursively framed as evidence of Canada's uniquely "tolerant" nature (see Chapter Two) - and the repatriation of the Canadian constitution in the form of the Canadian Charter of Rights and Freedoms within which several individual and group rights were enshrined (see Chapter Seven). His vision may have come out of struggles to "manage" difference within Canada's geographic borders (see Mackey 1999; Thobani 2007), but through liberal discourses it was officially designated as a vision of what Trudeau himself called a "just society." In other words, through his association with the production of these two pieces of legislation, Trudeau has come to symbolize a particular 
time in Canadian history when nation-building projects were discursively constituted through liberal notions of justice and institutionally linked with efforts to define a distinctly Canadian national identity and a need for increased immigration. Thus, Nouhad and Monzer's references to Trudeau are partially, even if indirectly, linked to discourses defining Canada as committed to liberal humanism and social justice, both of which reinforce its image as welcoming to immigrants.

It is also noteworthy that Monzer mentioned he "knew there were outstanding land claims and disputes with Aboriginals and that there was injustice there" prior to immigrating to Canada. He was one of only two research participants to mention Indigenous peoples, even briefly, over the sixteen month period during which I conducted fieldwork. The other research participant, Eddie, mentioned Indigenous peoples when he said he hyphenates his identity because "referring to yourself as Canadian, as a pure Canadian, unhyphenated, is to say you're a native, Aboriginal and, even at that, saying you're Canadian is to admit colonization or defeat to the country of Canada." Consequently, he suggested, to identify as Arab-Canadian is to recognize, his "heritage," his "residency," and his non-indigeneity. I take up Eddie's reference again Chapters Seven. Here, I want to suggest that the general absence of references to Indigenous peoples reflects the coloniality involved in the circulation liberal Canadian national identity discourses and the silencing of narratives which trouble such discourses. As I illustrate in the next section, the Canadian state continues to play a role in the international circulation of the discourses research participants encountered prior to immigrating to Canada. 


\subsection{Official Canadians and State Representatives}

So far in this chapter, I have outlined some of the discourses research participants encountered before immigrating to Canada. As I explain above, these discourses have been used to define Canada and a distinct Canadian national character across a variety of nation-building projects since the late 1800s. I interpreted research participants' encounters with these discourses prior to immigrating to Canada to mean such national identity discourses transcend Canada's (inter)national borders. In this section of the chapter, I want to build on this argument. More specifically, I argue that the Canadian state plays a role in the extra-national circulations of the discourses I discussed above, namely those defining Canada according to its climate and its liberal humanist commitments to immigration and justice.

In some cases, the people who (re)produced these discourses for research participants were not necessarily officially authorized by the Canadian nation-state to do so. Rather, it is their places of employment that positioned them, in their interactions with research participants (and other would-be immigrants), as representatives of the Canadian nation-state or as "experts" in Canadian national identity and/or law. Again, this argument relies on the idea that the nation-state does not necessarily exist as an ontologically material entity, but does materialize in specific interactions where a person might immediately experience its impacts (e.g. the meanings of a particular legislation) in her/his life. In such encounters, a person might experience someone who officially conveys these impacts as a representative of or stand-in for the state. Recall, for example, Monzer's meeting with a representative of a Canadian embassy which occurred before he immigrated to Canada. Monzer explicitly referred to this man as a representative of 
Canada, suggesting that he experienced this as a meeting with Canada as a nation-state which, for him, was embodied by this man in this specific instance.

Rana's extra-national encounter with the Canadian nation-state was different and illustrates the Canadian state's more direct role in the continued circulation of discourses defining Canada according to its climate and commitments to liberal humanism and immigration. Of all the people I met during the course of fieldwork, Rana was the most recent immigrant having immigrated to Canada in 2004. After her application to immigrate to Canada as a skilled worker was accepted, Rana was invited to take part in a three-day course at the Canadian embassy in Lebanon:

When they grant you approval to come to Canada, they do a kind of three day orientation. So what I was told in that orientation is that Canada is a totally multicultural place, that all the cultures are respected evenly, that no one is allowed by law to discriminate [against you]... for example, for your sex, for your age, for your origin, for anything. So there's no discrimination at all in Canada [laughing]. ...I was told 'Ok. Wow. Rana, you are a math teacher. You are gonna be starting at least with $\$ 45,000$ and it's going to be easy for you to find a job and, at the same time, it's a beautiful place. ... You can see all of the seasons. You can see spring, winter, summer [laughing]. So you will enjoy nature and everything.' ... What else? Yeah. 'It's an open country. You can say your opinion freely. It's a democratic country.' So you come with an optimistic [outlook ...]. Oh, yeah. [They also said] 'You are offered health insurance. You don't have to pay anything. Just, you go to the doctor, you see the doctor.' [...] So [they said] 'You are totally insured. Schools, like, the public schools are better than the private schools but you don't have to pay anything' [laughing]. So it's like showing Canada as heaven. (emphasis added)

Rana was referring to seminars offered as part of the Canadian Orientation Abroad (COA) initiative. The experience she depicted thus points to extra-nationally dispersed governmental rationalities of the Canadian state.

"Implemented in 1998," the COA initiative is "the responsibility of the Settlement Division of Citizenship and Immigration Canada" and involves one- or two-day orientations which are "delivered abroad on behalf of CIC by the International 
Organization for Migration (IOM)" (CIC 2005). The IOM contacts convention refugees, skilled workers, and live-in care-givers - and, in fewer cases, family class immigrants by phone about the voluntary seminars when their visas are approved or by sending them flyers with their visas. The COA programme is intended to "provide future immigrants and refugees with an idea of what life in Canada is like" (CIC 2005).

The rationale behind the seminars is that it will provide immigrants "with a more realistic view of life in Canada" which leaves them "better prepared to face the initial demands of adaptation and settlement and to integrate into Canadian society more easily" (CIC 2005). In keeping with this rationale, the IOM's website includes the following statement about the need for the seminars:

New immigrants to Canada typically may have unrealistic expectations and limited understanding of Canadian culture and society. In some cases, future immigrants may have no information or could have been misinformed. Many may not have considered the rights and responsibilities that are essential for life in Canada. These possible factors can make adjustment more difficult for the immigrants and hamper their successful settlement in Canada. (IOM n.d. emphasis added)

Although the seminars are offered to skilled workers, live-in care-givers, family class immigrants, and convention refugees, CIC's 2005 Evaluation Report makes clear that much of the focus is on "orienting" convention refugees. ${ }^{50}$ The logic behind focusing on convention refugees is that skilled workers "tend to be much more familiar with the challenges of life in Western societies" and family class immigrants and live-in caregivers "have support from their sponsors" in adjusting to life in Canada (CIC 2005). That skilled workers are less targeted for these seminars because they are believed to be

\footnotetext{
${ }^{50}$ At the same time, the report makes clear that COAs have not been meeting their targets because, while the main focus is on orienting refugees, there has been a "decrease in the number of [convention refugee] cases processed ... compared with targets" (CIC 2005).
} 
"familiar with the challenges of life in Western societies" reinforces the above-mentioned ideas that the seminars are intended to teach participants about "Canadian culture and society." This logic also reproduces a dichotomy between "the West and the Rest" (Hall 2007; Mahmood 1996) of the world, placing Canada firmly in the former category.

Citizenship and Immigration Canada produced the guide used by seminar facilitators when the COA first began (in 1998). The guide contains thirteen modules amongst which facilitators are to choose depending on the length of the seminar: Transit (15 pages); Culture Shock (28 pages); Employment (69 pages); Rights and Responsibilities (60 pages); Climate (10 pages); Finding a Place to Live (8 pages); Living in a Multicultural Society (13 pages); The Cost of Living in Canada (12 pages); What is Social Welfare (39 pages); Family Life in Canada (26 pages); Communications (3 pages); Education in Canada ( 9 pages); Adjusting to Canada (10 pages) (CIC n.d.a). A thorough analysis of these documents would produce an entire dissertation. Consequently, I present only brief discussions of the modules on climate and multiculturalism which I hope will suffice to give readers an impression of the Canadian state's extra-national involvement in reproducing Canadian national identity discourses.

The module on climate lists three objectives. As Rana mentioned, participants in the seminar are taught that, in Canada, they "will be able to see all [four] seasons." The other two objectives of this module, however, shift from a four-seasonal focus to a focus on Canadian winters. Thus, seminar facilitators teach participants "how to prepare for winter" and "to identify measures for keeping warm in the winter" (CIC. N.d.b: 1). While three, two, and one bullet point(s) follow the headings of Spring, Summer, and Autumn, respectively (2), there are eleven bullet points under the heading of Winter (3). These 
bullet points are further followed by a note that Canadian weather forecasts may include terms such as "'a nice day', a 'sunny day', or 'a warm day' when talking about weather in the winter. The unspoken words '...for a winter day' are understood by Canadians, but not always by newcomers" (3). It is, of course, practical to offer participants who are unfamiliar with Canadian (or generally cold) winter weather a sense of what to expect. The module goes beyond simply informing seminar participants about the weather, however, by directly linking winter weather and "Canadian culture." Two of the bullet points under the "Winter" heading make this most clear. Seminar participants are told "the seasonal variations in climate greatly affect the Canadian experience and contribute to Canada's culture" and that "the weather offers an endless source of conversational material. It is common that people talk about the weather when they exchange greetings" (CIC n.d.b: 3 emphasis added). Moreover, the module suggests activities such as asking participants how they feel about Canada's winter (4), how they "think Canadians keep warm" (4), and "interpreting Canadian weather forecasts" (5).

These elements of the module work to define life in Canada and Canadian national identity through an almost obsessive focus on winter weather. Immigrants who attend this seminar are taught that becoming Canadian involves learning to understand weather reporters' "unspoken words" and to "talk about the weather [endlessly] when exchanging greetings." My point is not that people do not talk about the weather - in Canada or elsewhere. Instead, my point is that the module is set up in such a way that "talking about the weather" emerges as a central element of "Canadian culture." In other words, the module is pervaded by banal nationalist discourses which govern Canadian national identity through teaching "embodied daily habits." From a governmentality 
perspective, this module - produced by CIC and facilitated by IOM employees discursively constitutes a particular subjectivity (focused on winter weather) as authentically Canadian.

The module on Living in a Multicultural Society opens with the following two sentences: "Canada can be compared to a 'mixed salad' containing many individual ingredients with distinctive characteristics, yet all mixed together. Immigrants and refugees who resettle in Canada join millions of others who have come before them in search of freedom, human rights and a better life" (CIC n.d.c: 1 emphasis added). These two sentences immediately link multiculturalism with immigration and human rights, defining Canada as a nation of immigrants. Moreover, participants are also taught that only Indigenous peoples are not "immigrants to Canada, or descendents of immigrants," a framing which recognizes Indigeneity but erases the violent histories of settler colonialism. Participants are also told that "to participate fully in Canadian life, every person must speak at least one of the two official languages, English or French" (2) revealing the continued dominance of settler colonial languages.

Also significant in this context of a simultaneous denial and recognition of the dominance of traditions which arrived in Canada via colonization, participants are told "there are representatives of virtually every faith in Canada," "The Charter of Rights and Freedoms protects the freedom of religious expression," and people whose "culture" does not include "tolerance" for other religious traditions may have difficulty "adjusting to life in Canada" (CIC n.d.c: 2). Yet, in one of the activities where participants are asked to compare their own values with "Canadian Urbanized Values," the latter are described as Christian rather than multi-faith or secular, for instance (9). While the module does 
mention the existence of racism in Canada, it does not address systemic racism, suggesting instead that "some Canadians may make you feel unwelcome. However, the majority of Canadians are fair-minded. They will accept and respect anyone who accepts and respects them" (2). Aside from presenting racism as only a matter of individual bigotry, this phrasing places the onus on seminar participants if they encounter racism in Canada. It does so by implying that if they face such racism on a regular basis, it may be because they have not shown acceptance and respect first since, as the module instructs, most Canadians "will accept and respect anyone who accepts and respects them."

Again, while I do not have space here to get into a thorough analysis of the entire module, there are a few points I want to draw out briefly. First, the ideas presented in this module of the COA seminar discursively link Canada's policy of multiculturalism with immigration and human rights. Second, the module links multiculturalism with religious freedom through the Canadian Charter of Rights and Freedoms. Third, within this document, multiculturalism is presented as a defining feature of life in Canada even as English and French remain the dominant linguistic frameworks and Christianity remains the dominant religious framework (see Chapter Seven; see also Mackey 1999). Fourth, participants are told that "tolerance" - a liberal discourse scholars have deconstructed as preserving asymmetrical power relations (see Chapter Seven; see also Brown 2006; Mackey 1999; Thobani 2007) - is a defining element of developing a distinctly Canadian sensibility. These ideas are reinforced in the module on Rights and Responsibilities (CIC n.d.c), which focuses specifically on the Charter of Rights and Freedoms and Canadian laws as guaranteeing freedom from discrimination and requiring respect for the freedom of others from this same discrimination. 
The main focus in the Multiculturalism and Rights and Responsibilities modules is on teaching would-be citizens that Canadian national identity is defined through liberal discourses of "tolerance" and individual notions of equality. Thus, like the module on Climate, these two modules also illustrate a form of governance aimed at producing particular embodied habits and desirable ways of thinking that are framed as distinctly Canadian. Mackey (1999) refers to such forms of governance as "pedagogies of patriotism" to denote their focus on teaching "about the nation, its relationship to the world, and one's role as a citizen and national subject" (58). She traces the (re)production (albeit in shifting and flexible form) and intertwining of discourses defining Canadian national identity according to its cold weather, "northern wilderness," and liberal pluralism from the late 1800 s to the state-sponsored celebrations of Canadian Confederation's $125^{\text {th }}$ anniversary in 1992. She illustrates that such "stories of the nation" are "designed to promote national identity" by highlighting "Canada's pluralism within a linear narrative of Canada's past, present and future" (71).

The modules used to structure the COA seminars show that Canadian state agencies continue to engage in such pedagogies of patriotism well beyond the celebrations Mackey discusses. Moreover, the modules also demonstrate that the Canadian state's pedagogical practices, and thus "the Canadian state" itself, are multiscalar and multidimensional. The IOM, whose employees run the COA seminars, is a global organization which takes on a pedagogical role for CIC (a nationally defined state agency) in relation to would-be citizens outside Canada's national borders. Yet, the IOM's pedagogical role is nationally defined since $\mathrm{CIC}$ produced the seminar modules to reach future national subjects/citizens. In other words, CIC tasks the IOM with the role of 
governing would-be citizens (like Rana) as national subjects through Canadian national identity discourses before they enter Canada's national borders and, likely, with the hope they will become part of a self-governing population within Canada.

Reflecting on the COA seminars, however, Rana did not accept and embody the national identity discourses she encountered therein. While she was at first excited by these discourses, she retrospectively found them laughable. Indeed, she continually laughed as she (re)presented the COA discourses. When I asked if she learned "anything new" about Canada after immigrating, Rana further dismissed these discourses as lies:

I want to tell you I'm a very positive person... and that's what made me survive. ... I'm trying to focus on finding something positive, shockingly positive. Really, I can't. I'm unable to find something. Like, really, what shocked me was that I discovered the reality, I discovered that everything that had been told to me was not right.

More specifically, and as I illustrate in the next chapter, Rana's immigration experience did not match up with discourses about Canada's liberal humanism that purportedly legally guarantees individual equality. Rather than interpreting her encounters with racism through a liberal focus on individual bigotry, she challenged these discourses, insisting that systemic racism pervades Canada's labour market and that the content of dominant discourses is generally untrue.

Rana's interpretation reinforces the pivotal importance of focussing our academic analyses on more than the national and institutional realm of discourse production. For me, it shows that while COA seminars may be designed to constitute a particular national subjectivity, their ability to do so is not guaranteed. Indeed, Rana's encounter with Canadian national identity discourses actually produced her capacity to challenge them: the discrepancy between the state-sponsored discourses she encountered prior to 
immigrating to Canada and her experiences once she arrived in the country opened up fissures in, and spaces for questioning, these discourses. Interpreted through her experiences in Canada, Rana's encounter with these discourses played a role in producing her agency and not the specific national subjectivity CIC may have desired.

\subsection{Conclusion}

In this chapter, I have illustrated that "getting here" involves encounters with Canadian national identity discourses at multiple, sometimes extra-national, contactzones (Linke 2006). I conceptualized these encounters as ones where research participants experience an extra-national Canadian nation-state as a social subject in their lives because such moments involve more than the introduction of potential immigrants to Canadian "national identity." Instead, I have suggested, these extra-national encounters may point us to the ways the Canadian state transcends its nationally defined borders in attempts to govern future national subjects through discourses defining an ostensibly authentic and desirable national subjectivity. I also illustrated that a multi-scalar and multidimensional analysis of how research participants - as future national subjects experience and interpret such encounters allows us to go beyond institutionalized forms of Canadian national identity discourses to understand some of the factors that may shape engagements with such discourses. This latter point is particularly important for considering how the same discourses used in attempts to govern national subjectivities may, as I have illustrated, simultaneously open up fissures that lead people to question the mythologies and identities the discourses are aimed at producing.

The examples I used above also illustrate that national identity discourses shape people's agency. These discourses, in other words, produce and enable people's capacity 
for "agentive action" (Mahmood 2000) which was not always opposed to the discursive traditions of the Canadian nation-state, as is clear from the above multidimensional and multi-scalar analyses of Monzer and Rana's narratives. Both research participants' encounters and familiarity with institutionalized discourses according to which Canada is welcoming to immigrants and committed to social justice shaped their desires to immigrate to the country and their interpretations of their multidimensional life experiences. In Monzer's case, these discourses enabled his capacity to confirm and insist on his sense of worth as a human and national citizen-subject which had been denied in other state's national policies which he encountered throughout his global travels as a stateless Palestinian refugee. As I illustrate in the next chapter, on the other hand, Rana's familiarity with these discourses provided her with a specific institutionalized national representation against which to measure her experiences in the country and to suggest that such a representation is an outright lie used to seduce potential labourers to immigrate to the country.

My point in this chapter has not been to suggest that research participants' first encounters with the Canadian nation-state produced fixed interpretive lenses for all experiences within Canada. Instead, as I illustrate in the next chapter, research participants' narratives were continuously and retrospectively (re)formed through their daily experiences in Canada following immigration. In the next chapter, I begin to consider research participants' interpretations of their first few years in Canada. 


\section{Chapter: Multidimensionality and "the Canadian Experience"}

In November of 2008, invited by a woman I met during the initial stages of fieldwork, I headed to an Ottawa elementary school where Arabic language classes are held. Although I did not know this in advance, the day I chose to spend at the school coincided with a visit by the Syrian ambassador. Recording the visit for a Syrian satellite television program, a camera crew accompanied the ambassador - who casually stopped and chatted with people at the school - and several embassy staff as they toured the school which was abuzz with activity as teachers, students, and parents were slightly distracted by the excitement.

I arrived during the lunch break and entered the front doors feeling a little ambivalent. There I was, at twenty-nine years old, wandering the halls of a school where weekend Arabic classes were held. Years earlier, in Etobicoke, Ontario, I had begged my parents not to make me spend weekends at language school. My brother and I hated these classes and did not last a full year in them. When we stopped attending, we felt victorious, certain our whining had paid off. In retrospect, we likely stopped attending altogether because our parents' work schedules made our attendance sporadic at best. Almost twenty years had passed and I found myself spending a Saturday wandering the hallways of just such a school, grateful the school existed, excited at the opportunity to expand my research networks, but nevertheless feeling out of place. I held my breath as I walked through the halls, afraid of what parents or teachers might say if they discovered that some of the ten-year-old students could write Arabic better than I could.

When I recognized Amal, I felt a rush of relief and took the opportunity to enter one of the empty classrooms to speak with her. We talked for a few minutes about her 
children, why she was at the school, and how my research was coming along. ${ }^{51}$ Several minutes later, I left the room feeling more at ease and then met Rana for the first time. Although we did not yet know each other, she smiled in my direction and said hello. I introduced myself and through the course of our conversation explained why I was at the school. When I told Rana about my dissertation, her interest seemed piqued and she immediately agreed to participate in a formal interview. Given both of our schedules, however, we knew this was unlikely to happen for some time.

Two months and several email exchanges later, during the OC Transpo bus strike, I borrowed a friend's car and drove to the building where Rana worked. ${ }^{52}$ I asked for her at the reception desk and she soon stepped out of an office and walked toward me smiling, as usual. We expressed relief to have access to vehicles during the bus strike as Rana led me into her office and asked if I would like a hot drink. Thankful for the chance to warm up, I said yes and she left the office as I took off my coat and got my pencil, notebook, and digital recorder out of my bag. Shortly after, she returned with two cups of tea which we drank as we exchanged small-talk before starting a "formal" interview.

As I mentioned in the last chapter, Rana immigrated to Canada in her early thirties as a skilled worker. She is a Palestinian refugee who was born and grew up in Lebanon where she worked as a teacher. Despite having been promoted to a position

\footnotetext{
${ }^{51}$ I came to expect questions about my research in such conversations as more people learned about and took an interest in my work. In some cases, people wanted to know what I was finding, asked questions about "the community," offered "off-the-record" bits of information, or suggested some analytical tool for me to consider. In other cases, people less directly interested in the research than in helping young woman develop her career. Others, still, offered to help me recruit more interviewees.

${ }^{52}$ On December 10, 2008, the union representing the drivers, mechanics, and dispatchers who worked for Ottawa's public transport system (OC Transpo) followed through on a strike mandate. The strike lasted fifty-one days.
} 
where she supervised several other teachers, she left Lebanon in 2004 because "the struggle there with being a Palestinian refugee... was really stressful.” Rana explained that in Lebanon she lacked "even minimal rights" and had experienced "a lot of discrimination... since childhood. ${ }^{, 53}$ In Canada for almost five years, Rana still had not found employment in the field of education. She explained her difficulty finding work in her field in terms of systemic discrimination implicit in the requirement of "Canadian experience." For Rana, meeting this requirement meant finding time to volunteer in Canadian classrooms, even as the necessity of paying for rent and food required her to work full time. She expressed frustration at being caught in this paradoxical situation: because she had to work, she was unable to volunteer at a school but needed to do so to find work she wanted. Looking for a way out of this bind, Rana had left Canada to work abroad for a year so she could save money to make time to volunteer in schools in Ottawa. Laughing at the absurdity of her present situation, Rana told me "you keep hearing things about Canada that are positive, like that there's no discrimination and stuff like that. So you hear a lot of positive things before, [she interrupted her narrative with a laugh] before you come" (emphasis original).

As I explained in the previous chapter, Rana had heard such "positive things" in the COA seminars she attended prior to immigrating to Canada. Trying to make sense of the discrepancies between the discourses she encountered at the COA seminar and the material realities of her life in Canada became one of several intersecting elements of Rana's "Canadian experience." This experience deeply affected her individual sense of

\footnotetext{
${ }^{53}$ For an overview of the position of Palestinian refugees in Lebanon, please refer to Rosemary Sayigh (1994) and Julie Peteet (2005).
} 
identity as well as her engagements with dominant Canadian (nationalist) discourses especially images of Canada as a liberal democracy committed to equality and particularly welcoming to immigrants. Rana's depiction of her early days in Canada is highly instructive in this regard:

[You find you are] missing people, missing your background, missing your friends and, at the same time, missing yourself because you are not yourself anymore. You are doing something that you really don't like, but you are doing it because you need to survive and you want to learn about the culture and about the people, and you need to gain references here in Canada because they need what they call 'the Canadian experience,' which is, I don't know, with the internet now, with the phone lines... you can call any place, you can ask any person in any organization about my experience. So you can trust the references from outside [Canada]... So, to me, it was like this is an excuse ... I started saying ' $\mathrm{OK}$. So the idea that was given to me is just a logo that's used to attract people from outside and it's not the truth, it's not the reality,' and I started feeling... discriminated [against].

In this way, Rana interpreted her personal struggles by relating them to her past and present social contexts, engaging in an analysis wherein she underscored the multidimensionality of her "Canadian experience" as an immigrant-citizen.

I want to highlight two points from Rana's above depiction of her first years in Canada which often came up in research participants' immigration narratives and which point to the importance of a multidimensional analysis of their experiences. First, in recounting her first years in Canada, Rana said she was missing herself; the changes in geographic and social location accompanying her move from Beirut to Ottawa had repercussions for her self-perception and sense of identity. Second, as was the case with other research participants, the kinds of adjustments often academically and governmentally subsumed under the concept of settlement - i.e. as matters of socioeconomic and cultural adaptation and "integration" - were intricately intertwined both with Rana's personal struggles and with her interpretations of Canadian national identity 
discourses. Indeed, Rana interpreted her "Canadian experience" in a way that highlighted a disjuncture expressed by many, but certainly not all, research participants between institutionalized Canadian national identity discourses - what Rana referred to as a logo and their experiences in/of the country. Together, these points suggest research participants experienced the economic, political, and social realms as deeply interconnected dimensions (rather than separate spheres) of immigration which then played a role in (re)shaping their senses of (national) identity.

Building on this, and focusing on research participants' settlement narratives, in this chapter I argue that changes in their familial and social networks as well as their experiences in the labour market shaped multiple dimensions of their senses of identity, including their interpretations of and engagements with Canadian (national) identity discourses. In the last chapter, I illustrated the importance of multi-scalar analyses for theorizing the relationships between people's subjectivity, agency, and engagements with Canadian national identity discourses. In this chapter, my aim is to highlight the importance of multidimensional analyses for theorizing these same relationships.

As I show in the next section of this chapter, much of the literature on immigrants' socio-economic "settlement" or "integration" tends to elide the multidimensional impacts of these experiences, including those for immigrants' engagements with images of Canadian national identity that are reproduced in (neo)liberal governmental discourses which imply that immigrants are responsible for their own social and economic welfare. Below, I suggest that processes of "settlement" and "integration" not only involve practical adjustment to a physical and cultural relocation, but also are related to governing rationalities that are intertwined with 
conceptions of national and individual identity. Next, I offer an overview of the similarities and differences in four research participants' (Dina, Rana, Wafaa, and Monzer) narratives of their settlement experiences, focusing on the implications of their entries into the Canadian labour market for their (re)interpretations of previously takenfor-granted senses of identity. In the following section, I narrow my focus to analyze the relationships between these settlement narratives and research participants' engagements with (neo)liberal discourses of Canadian national identity. I conclude the chapter by examining how some research participants rejected dominant (neo)liberal discourses about Canada's national character precisely as a result of the fissures they experienced between these discourses and their lives in the country.

\subsection{Immigration and Identity}

Recall from Chapter One that from an anti-essentialist and multidimensional perspective, identity is conceptualized as "contingent, fragile and incomplete and thus ... amenable to reconstitution" (du Gay, Evans and Redman 2009: 2). It is continuously (re)produced through encounters with multiple socio-cultural discourses that enter into definitions of particular categories with which people may (not) identify. From an antiessentialist and multidimensional perspective, identity is interrelated with subjectivity and agency, and movements in space/time are accompanied by encounters with changing socio-cultural discourses. Such encounters shape a person's social experiences, interpretations of those experiences, and, thus, the ways s/he identifies. In other words, people's senses of identity are continuously (re)shaped by their encounters with discourses related to multiple social axes - e.g. ethnicity, gender, age, class, (dis)ability, and/or race - but no axis universally takes precedence over the others. Instead, the 
seeming salience of any axis of identity in a specific context suggests that processes of identification are necessarily complex and context-specific. Following from the above, since immigrating to a new country is accompanied by changes in socio-cultural, geographical, and political contexts, it has multiple implications for a person's sense of identity, nationally or otherwise defined.

Yet, the immediate changes migrants face upon arrival in a new national space tend to be subsumed in academic literature on immigration under the rubric of "settlement" or "integration" with little attention to what this means for their interpretations of institutionalized national identity discourses. As used in government documents and literature about immigration, "settlement" refers to "the process by which the newcomer, during his or her initial years, acquires the basic information, knowledge, and skills that are required to function in a self-sufficient manner" (George and Chaze 2009: 394). The latter term (i.e. integration), "often adopted when studying immigrants and their settlement process," implies "a desirable outcome" whereby "newcomers become members of the receiving society" (Li 2003: 316). Through such uses, settlement and integration emerge as related concepts. The explicit focus in policy and academic discussions of settlement and integration in Canada tends to be on immigrants' access to housing, employment, and English or French language training, all of which are practical necessities of life in Canada as a bilingual, capitalist society. Underlying this focus, however, is a subtext on what constitutes desirable and undesirable behaviour in Canada. At a global scale, the idealization of the self-sufficiency of individual immigrantcitizens certainly reflects neoliberal valorization of individualism, consumerism, and financial independence as the most ideal characteristics to develop if one is to be 
considered a "contributing" member of any society. As suggested in Chapter Two, such globalized discourses also shaped changes in Canadian immigration legislation which began in the 1990s and were framed in terms of a need to protect the Canadian (welfare) state from fraudulent immigrants who would take advantage of its welcoming and benevolent nature, thereby overburdening the tax-paying authentic national body. Thus, from this same perspective, the ideal immigrant is one who becomes economically and socially "integrated" into the Canadian national body as an English/French speaking, taxpaying, consumer-labourer-citizen as quickly and efficiently as possible. In this way, the concept of integration, as used in "policy statements, immigration debates, and academic writings," can be conceptualized as a governmental discourse that "clearly upholds the normative expectation of conformity" to "nationally" defined ideals "as the desirable outcome of immigrant integration" ( $\mathrm{Li}$ 2003: 316). In defining a normative, desirable outcome of the process of settlement, I suggest that discourses of integration are implicitly about governing newly arrived immigrants' incorporation into an ostensibly "cohesive" Canadian national body; they are as much about discourses of Canadian national identity as they are about the socio-economic well-being of immigrants.

For example, the use of institutionalized discourses of Canadian national identity in the governance of "immigrants" through discourses of integration emerges clearly a speech given by then Liberal Party Federal Minister of Citizenship and Immigration, Joe Volpe, at the May 2005 "Progressive Seminar on Migration, Integration, and Diversity" in Toronto, Ontario. Volpe frames his address to the audience in terms of a "collective need" to "find new approaches to managing global migration, and new ways of helping newcomers ... quickly adapt to their new lives without requiring that they completely 
abandon their own customs or traditions." Beginning in this way, Volpe defines "integration" as a concern for global governance through a liberal pluralist framing of the role of the state. He immediately adds, however, that there is an equally urgent need "to develop mechanisms or policies that help and encourage all to become fully participating members of our communities and share in our national growth," thereby shifting to a national scale of governance focused on building national communities and economies.

Having shifted to a national scale, Volpe offers a (dominant, institutionalized) narrative of Canada's immigration history according to which "embracing newcomers and celebrating diversity in one form or another have always been core to our [Canadian] identity as a nation, and vital to our future prosperity, cohesiveness and growth. The model is singular to our history and environment." Volpe thus erases the long history of unwelcoming, racist immigration legislation (see Chapter Two) and genocidal colonial violence toward Indigenous peoples by (re)defining the "core" of Canada's "national identity" through discourses according to which it has "always" welcomed immigrants and celebrated diversity. After offering this narrative, Volpe suggests that the need for "strong integration programs" in Canada revolves around managing a tension between "diversity" and unity: "the wide range of backgrounds, skills, cultures, interests, languages, religions, myths and general narratives that each group brings to Canada today presents policy makers with a new set of challenges. How, for example, do we foster social cohesion and a sense of national identity?" (Volpe 2005, emphasis added).

Four years later, Canada's current Conservative Party of Canada Federal Minister of Citizenship, Immigration, and Multiculturalism, Jason Kenney (2009) echoes this same question in a speech titled "Good Citizenship: The Duty to Integrate," which he 
gave in London, Ontario. Addressing a university audience, Kenney defines his federal role through the following two questions: "How can a country that maintains such a high level of immigration while embracing the diversity that it brings, maintain a sense of social cohesion, a common purpose and of national identity? And what more can we do to strengthen the ties that bind us together as Canadians?" (emphasis added). Thus, like Volpe, four years earlier, Kenney suggests that part of his role as Minister of Citizenship, Immigration, and Multiculturalism is to produce and enact legislation to manage tensions between "embracing diversity" and ensuring "social cohesion" and "national identity" through integration - something he insists immigrants have a duty to do if they are to become (considered) good citizens.

My point in discussing these two speeches is most emphatically not to dismiss the importance of or need for settlement programs. Indeed, the availability of governmentfunded English/French language classes, workshops about the recognition of foreign credentials, or assistance in finding housing, for instance, are absolutely invaluable for many immigrants and refugees who would otherwise be unable to afford them. Given the difficulties many immigrants and refugees face trying to enter the Canadian labour market, it is essential that funding for such programs continue, although they would be more effective if they were accompanied by commitments to finding and funding ways to address the systemic racism that continues to pervade Canada. My point, however, is that the concepts of integration and settlement may be - and, as in the above speeches, sometimes are - used in ways that aim to govern the behaviours and values of those coded as immigrants by defining them as threatening to Canadian national identity unless and until they are able (economically and linguistically) to conform to and perform in 
ways said to maintain social cohesion through shared national values. Within such governmental discourses, the analytic focus shifts away from segments of the population in Canada who are economically marginalized and socially excluded as a result of institutionalized racism, toward individual "bad" immigrant-citizens who threaten Canadian national identity because they have not fulfilled a "duty to integrate." Yet, scholars writing about immigration in Canada rarely explicitly take up the relationships between questions of settlement/integration and national identity. On the one hand, under the rubric of settlement/integration some scholars discuss the impact of racist, classist, and/or gendered discourses on the economic marginalization of (racialized) immigrant-Canadians in the labour or housing markets, for instance, which perhaps implicitly challenges dominant liberal discourses of Canadian national identity as welcoming to immigrants (e.g. Anisef, Sweet, and Frempong 2004; Bauder 2003; Bloom, Grenier, and Gunderson 1995; Dalgleish 2008; Fong 2009; Hiebert 1999; Liladrie 2010; Liu 2007; Man 2004; Omidvar and Richmond 2005; Pratt 1999; Reitz 2001a, 2001b; Salaff and Geve 2003; Teelucksingh and Galabuzi 2005). On the other hand, scholars take up immigrant-Canadians' senses of socio-cultural in/exclusion or the ostensible tensions they experience between ethno-nationally defined identities, paying little direct attention to the relationship(s) between their "settlement" experiences - including those in the labour market - and interpretations of and engagements with national identity discourses (e.g. Berry 1997, 2001; Boski 1991; Ley and Hiebert 2001; Magat 1999). In other words, scholars tend to study either (1) how those coded as "immigrants" may be institutionally marginalized in the labour or housing markets or (2) how "ethnicity" or cultural identity discourses shape processes of national identification and sense of 
belonging. While both foci are important, few scholars engage multidimensional analyses of their co-constitution in immigrants' experiences of "resettlement." An exception to this disjuncture is work on im/migrant labour and citizenship wherein scholars highlight the interconnectedness of the economic, political, and social experiences of immigrants or immigrant-citizens (e.g. Stasiulis and Bakan 1997, 2005).

As I illustrate in the rest of this chapter, the "settlement" difficulties research participants faced during their first few years in Canada had implications for multiple dimensions of their senses of identity, including how they interpreted national identity discourses. For instance, over the course of dinners, meetings in coffee shops, and outings at Arab Canadian community events, Sara told me she felt that other people's perceptions of her "personality" were different in her first year in Canada than they were in Syria. In her early thirties, Sara had lived in Canada for more than ten years. When she first arrived in the country she had a basic comprehension of English and took two courses at a local college to prepare for studying at a Canadian university, an education she hoped would facilitate her entry into the Canadian labour market. She went to every class, could not comprehend the lectures, and would return home to read the assigned text-books with a dictionary in hand to translate almost every word she came across. Sara told me one of the things she found difficult about this situation was the change in how people she met seemed to perceive her personality.

As she explained, prior to immigrating to Canada she thought of herself and was perceived by her peers as outspoken, social, and humorous. Unable to understand or contribute to the English language conversations around her, Sara was perceived by those she first met in Canada as shy, quiet, and submissive. This "personality change" was 
related to the linguistic element of the change in "national culture" that accompanied her geographic relocation, but part of what Sara worried about was that she was being read by others as a demure, silent Arab woman when she had always taken pride in being a strong-willed, outspoken, and independent thinker. It is thus necessary to approach Sara's narrative using a multidimensional analysis of the "resettlement" aspects of her immigration experience that takes into account the intersection of (globalized) discourses defining the relationship between gender, Arab identity, and Canadian identity.

Similarly, Rana's above interpretation of her struggles with acquiring "Canadian experience" was not only about difficulties in finding work, but also about how such experiences shaped her sense of self, ability to maintain a meaningful identity, and interpretations of Canadian national identity discourses. Indeed, Rana represented her struggles with trying to find employment and her sense of social isolation as intricately interconnected with feeling that her identity was being reconstituted through immigration. She also represented these struggles as leading her to reinterpret the Canadian national identity discourses she had encountered as a false logo used to attract immigrants by "showing Canada as a heaven." As I illustrate in the next section of this chapter, Rana was not the only research participant to discuss resettlement as related to multiple dimensions of her senses of identity.

\subsection{Lost and Found}

In narrating their first few months or years in Canada, research participants who played a primary role in the decision to immigrate highlighted the relationships between their geographic relocation, social relations (including those based on friendships, romantic affiliations, kinship circles, and labour), and senses of identity. Many of them 
suggested that feeling disconnected from their social surroundings and relations had immediate impacts on (previously taken-for-granted) dimensions of their senses of identity. Research participants who said they found immigration "easy" focused on the relative continuity in their social relations and surroundings throughout the process of "settlement." In both scenarios, research participants interpreted their social relations as important elements of their settlement experiences which played a role in shifting or maintaining some dimensions of their senses of identity.

For instance, Rana spoke of missing the physical familiarity of the neighbourhood where she lived in Lebanon as well as of the people (including family members) she associated with the place. According to Rana, when she first arrived in Canada, she felt "a big difference [from Lebanon] ... is the way people interact with you" - something both Nouhad and Farida also discussed in terms of missing "the warmth" of social interactions with neighbours and friends they had left behind. ${ }^{54}$ Elaborating, Rana reminded me that at the age of thirty-two she left a neighbourhood in Lebanon where everyone knew her and neighbours would drop in on a regular basis just to say hello. "I had a life there," she continued, "I had a lot of friends, I had a lot of activities I was doing there, so I missed that part in my life."

At the same time, Rana said, she developed relationships with extended family members whose presence in Ottawa encouraged her choice of the city as her final

\footnotetext{
${ }^{54}$ Nouhad said she often heard people complain that "they are not friends with their neighbours" in Canada. She explained that upon arrival in Canada, people who are used to daily the interactions with their neighbours in Lebanon, "would expect to see their neighbours every day or talk with them every day or eat at their place or have them at their place every day." Farida also said that the pace and price of life in Canada required a focus on and long hours of work that left little time for maintaining new friendships through frequent social interactions, which left her and (especially) her husband missing "the warmth" of their more frequent social interactions with friends in the Gulf.
} 
destination and who offered help as she adjusted to her relocation. Referring to the unofficial role these family members played as "settlement counsellors" who explained how to apply to a social insurance number, for example, Rana described them as her personal "community centre." 55 Despite being able to develop these familial relationships, as mentioned above, Rana said she missed herself (as defined by regular interactions at an immediately localized scale of her neighbourhood). This turn of phrase (i.e. missing herself) suggests she could not continue to think of herself as a welcoming neighbour, sociable friend, and community-oriented person in the absence of experiences which might confirm, and thus reproduce, these dimensions of her sense of identity.

The most consistent focus in Rana's narrative of her settlement experience was her continuing struggle to find employment as a teacher. Rana explained that her expectations of finding work in the field of education were neither unrealistic nor unfounded; she had researched and confirmed claims that there was a shortage of teachers in her subject area in Canada. When she arrived in Ottawa, she immediately set out to acquire her provincial (Ontario) teaching certification, which she expected to take some time. Meanwhile, in need of a source of income to pay for rent and build credit, she took a job at a large department store. Rana spoke of this job as something required by the need to become "self-reliant," a notion which, as discussed above, pervades governmental discourses of integration in Canada. For Rana, as is likely for many migrants, this desire did not emerge once she immigrated to Canada. Instead, as the sole economic provider for her mother (who remained in Lebanon), her desire for what she

\footnotetext{
${ }^{55}$ Everyone I spoke with who had family members present in Canada when they immigrated echoed this sentiment about their role in the settlement process.
} 
called self-reliance preceded her arrival in and exceeded the geographic boundaries of Canada. Rana's desire to meet this familial (and now transnational) responsibility, which was an extension of her conception of her role as a daughter, motivated her decision to immigrate to Canada as an independent skilled worker. It also shaped her (gendered) sense of identity as an economically independent working woman who could make such a decision and take on such a responsibility.

In Canada, Rana found the switch from having a career in education, which had been central to her sense of identity, to a job in retail extremely difficult because she conceptualized teaching as a vocation to which she felt particularly drawn and wellsuited, something she considered highly rewarding outside of monetary compensation. Working in a department store instead of a classroom, Rana said she could find no personal fulfillment in "putting clothes on a rack" and consistently asked herself "What's this doing for humanity?" Troubled to find herself working only for monetary compensation, and feeling increasingly alienated from herself as a worker, Rana explained, she considered returning to Lebanon "every minute" and constantly worried about "wasting" her life working in retail just to make ends meet. Rana thus related what she experienced as a disconcerting shift from working and identifying as a teacher who could "see [herself] in [her students'] eyes" to working in a department store where she put clothes on a rack, and wondered what purpose her labour served besides fuelling consumerism and meeting monetary necessity. Her struggles with feeling like a worker whose labour does not matter beyond capitalist accumulation shaped Rana's critique of Canada as a consumerist society, which I take up in the next section of this chapter. Indeed, her "resettlement" experiences also shaped her interpretation of (life in) Canada 
such that she often told her friends in Lebanon that "the worst things" about Lebanon were better than "the best things" about Canada.

Like Rana, Dina spoke of the ways her sense of identity changed during her first few years in Canada. When she moved to Canada with her mother at the age of sixteen, one of the most difficult things for Dina was a sense of isolation both from the people around her and from her previously meaningful sense of identity, which she interpreted as partly precipitated by a change in her class position that accompanied the move. Dina and her mom came to Canada in the 1980s, during the civil war in Lebanon, assuming they would return in a few months. More than twenty years later, Dina recalled her feelings toward the move in this way:

Coming at that age, knowing the country before [when I had visited as a tourist], I was excited... And then ... I had to change class... [In] Lebanon, where we were comfortable, I was going to a very recognizable private school, French system, never worked in my life... So it was a big change for me. I used to live in a big, big home and suddenly l'm living in an apartment that is as big as one room in my house. I had to stop studying because we had to work and my first job in Ottawa was at McDonald's. So imagine coming from, I would say, an elitist life to the lowest working class.

This change in class position was accompanied by changes in how Dina and her mother experienced and lived out their familial relations with relatives who already lived in Ottawa. She interpreted the necessity for these adjustments in familial relations as resulting from "the lifestyle" in Canada, which required a lot of time to be spent engaging in paid labour, adding that the effect was that "[her] place within the same group ... change[d]. It's not that I'm saying it's bad. I think it's just a different dynamic."

Prior to immigrating, Dina had visited these relatives in Ottawa who had also gone to Lebanon for visits. When Dina and her mother were in Canada "as tourists," the relationship between them and their relatives was "central" to their daily (and 
entertaining) experiences of the city as their relatives took them to visit various sites or to go shopping. No longer identified as tourists upon immigration, Dina and her mom had to learn their own way around as they settled into the city, and could not spend much time "having fun" with their relatives who were busy with work. Dina thus felt she no longer had the same "connection [with] the people who [were] supposed to be [her] relatives... because [she was] lost" and did not know "how to interpret" this unfamiliar dynamic although she knew that she "[didn't] hate them. They [didn't] hate [her]."

Dina's feelings of being socially "lost" as she tried to settle into her unfamiliar class position and familial relationships in Canada, were compounded by changes in her relationships with her friends in Lebanon:

I felt, as a teenager, all my friends were [still in Lebanon and] I was writing letters like crazy, on a daily basis sending letters, and, of course, you expect others to reciprocate and they don't because nobody else is feeling this isolation. So, for them, writing a letter once every three months is enough. ${ }^{56}$

To counter her feelings of isolation, Dina explained, her "immediate needs of communicating" had to be met through "watching television or even just accepting the people who [were] around [her] that normally [she] wouldn't get along with just because of necessity." Dina said that although there were many Arab Canadians in Ottawa (although she added that their presence and numbers were not as noticeable to her in the 1980s), she could not easily build relationships based in a shared sense of Arab identity with those of them she met because she found their definitions of this (pan)national identity to be "backward and traditional."

\footnotetext{
${ }^{56}$ Dina further suggested that current technologies of communication, such as e-mail, Facebook, or even phone cards likely would have made it easier for her to remain in closer, more constant contact with the friends she had left behind in Lebanon.
} 
Although I take up discussions of differing discourses used to define Arab identity in Chapter Eight, I briefly want to address the multiple dimensions which likely produced the differences between Dina's interpretation of Arab identity and the one she encountered in Ottawa. Dina lived an urban, upper-class lifestyle in Lebanon. When she arrived in Ottawa in the 1980s, she said, the Arab community she encountered was not quite as large as it is today and she often met people who had lived in rural communities in Lebanon and immigrated to Canada long before she and her mother did so. In calling their conceptualization of what it means to be Arab "backward," Dina was likely pointing class-based and urban-rural dimensions of definitions of Arab (pan)national identity as well as a sense that they imagined Arab identity in accordance with memories of different times/places. In speaking more directly of Lebanese Canadians she met upon arriving in Ottawa, Dina also complained of factionalism she interpreted as reflecting conflicting, politicized discourses of Lebanese national identity that had precipitated the civil war in Lebanon and which she and her mother had hoped to leave behind in Lebanon. There were thus multiple dimensions to the difference between her understanding of Arab identity and the one(s) she encountered in Ottawa which, in effect, made it difficult to build immediate relationships with Arab Canadians in the city on the basis of a sense of shared (pan)national identity.

Furthermore, Dina's above narrative suggests that immigration and settlement shaped her (in)ability to embody certain dimensions of a sense of identity that was coconstituted by the relationships between discourses defining an "appropriate" teleological trajectory for someone of her age and class position in Lebanon. Given the age at which she immigrated to Canada, Dina's shift in "class" position - from someone who was 
"elite" to what she described as "the lowest working class" - materialized in having to leave behind her studies (at a French private school in Lebanon) to become a worker (at McDonald's in Canada). This shift produced the spatial distance between her and her friends in Lebanon as a classed, national social difference as they were able to "[go] on with their lives... at least in terms of education" while she could not follow this same trajectory due to the (class-based) requirement that she work in Canada.

There is also an important (gendered, familial) dimension to Dina's specific experience of settlement: her mother went from having the support of Dina's grandparents in Lebanon and a large house in which to live to being a single mother who needed income to pay for rent. Her mother's position as a working-class single parent in Canada meant Dina had to enter the workforce, essentially taking on the role of a dualearner for her family. The need for a dual earner was further intensified by their desire to sponsor Dina's aunt who lived with a disability in Lebanon and was, thus, unlikely to be accepted if she applied to immigrate to Canada without a sponsor. While Dina took on this position as a worker partly with the aim of bridging a geographic distance between her and this aunt, doing so increased the social distance with her relatives in Ottawa as it left her with little time for socializing.

Like Rana, then, Dina's narrative underscored the process of immigration as a transnational spatial relocation which mapped onto a multidimensional socio-economic relocation. For both women, this is to say, the process of settlement was thoroughly multidimensional, involving changes in familial relations, class position, and/or employment, for instance, which (re)shaped their interpretations of their social relations 
and senses of identity. In this context, Dina and Rana's interpretations of their

"settlement" experiences are aptly summed up in Dina's following words:

It was finding out your identity, reconsidering your identity again. Do you maintain it? And you're maintaining it among factors and conditions that are very much different than the ones that you left. And these conditions here did not allow the same closeness or social organization or individuality that you had before.

In contrast to Rana and Dina's narratives, Wafaa's did not contain this same element of "reconsidering [her] identity." Wafaa, who was retired at the time I interviewed her, had first travelled to Canada with her husband on student visas in the late 1960s, planning to remain in the country only for the duration of their studies and therefore leaving a child in Egypt in the care of family members. Wafaa represented this separation from their child as the only difficult part of their early years in Canada, particularly during the 1973 war when Egypt reclaimed the Sinai Peninsula which had been annexed by Israel in 1967. Otherwise, she said, the process of settlement was "easy" and attributed this ease to the consistency she experienced across three interrelated and mutually reinforcing aspects of her early days in Canada: her social location as a student, her immediate social relations, and her sense that her life was unfolding according to a teleological trajectory from student to professional.

Wafaa interpreted the salience of her sense of identity as a student to have facilitated her relocation from Egypt to Canada. Although she and her husband moved to a new country, she explained, they lived in a city that "was built around the university" which "made it easy to get along" because they "jumped from an academic environment in Egypt to an academic environment here [in Canada]." Thus, Wafaa experienced the local space of the city where she first lived (with her partner) not as representative of an 
entirely new national space into which she permanently had to resettle, but of a familiar academic environment which she temporarily needed to navigate.

Wafaa also interpreted the continuity in familiar social relations across her initial relocation from Egypt to Canada as adding to the "ease" of her settlement experience. More specifically, she travelled together with her partner to attend a university where some of their "student colleagues" from Egypt had already been studying for approximately one year. Thus, not only did her senses of identity as a student and a wife both continue, but Wafaa also explained that she and her partner were able to rely on their colleagues in finding a place to live, "familiarization with the university environment," and "facilitating things logistically and emotionally." In part, she suggested, this emotional and logistic facilitation was enhanced by the ability to maintain meaningful friendships because they "saw each other every week" - something which was, again, partly related to their shared positions as students at the same university.

This is an important difference from Rana and Dina's depictions of their settlement experiences. For example, Rana spoke of missing herself as she could not rely on friendships or work for daily interactions through which her sense of identity could be (re)produced. Similarly, Dina said she felt "lost" during her early days in Canada as she struggled to (re)interpret familial relations in Canada and primary friendships in Lebanon and had to leave school to enter the workforce. On the other hand, the continuity Wafaa felt in her social relations and location meant she did not experience the same senses of isolation and loss. Again, it is important in this context that Wafaa did not consider any immediate changes she experienced as permanent. 
Instead, she represented her and her partner's remaining in Canada as an initially unplanned but logical decision brought about by a series of almost serendipitous events. When Wafaa and her partner arrived in Canada, she explained, "the officials" at the airport suggested they "change [their] status from student visa to immigration visa."

Although they agreed to do so, they expected to return to Egypt upon graduation. As Wafaa explained, they eventually decided "not to immigrate, but to stay" in the country:

At the time we had one [child] and we got very good scholarships... We felt that we were doing very good work and were rewarded for it by the scholarships... so we decided we would use up our scholarship time. At the end of our scholarship time, each of us was offered a very nice job so it became almost like a given [that we would stay in Canada]. That's how it worked out in the end and, once our [child] was in school and with friends ... we felt that we should really keep [our child] in the environment [s/he] was in since [s/he] was happy and the rest is history. We became more and more attached to our work and we continued to be here.

Wafaa further explained that "how [she and her partner] acquired equipment to do [their] research ... was a whole lot easier here, and life was easier." Consequently, returning to Egypt would have involved its own (difficult) process of resettlement in terms of work.

Wafaa's immigration narrative suggests that she interpreted her and her partner's settlement experiences in Canada to have developed easily, chronologically, and in accordance with an academic/labour system based on meritocracy: they did good work, were given scholarships, did more good work, and were offered excellent jobs. For them, settlement was an unintentional and spontaneous process driven by acquiring meaningful employment and developing professional identities in Canada. These experiences, along

\footnotetext{
${ }^{57}$ Although Wafaa did not mention this, given that they immigrated prior to 1974 and were married, Canadian immigration policy at the time would have required that her husband be the primary applicant and she his dependent (Arat-Koç 1999: 37) regardless of their immigrating together to undertake the same degree at the same university.
} 
with their (monetarily rewarded) success in their research/work in Canada meant resettling in Egypt would have required a large degree of planning and work-related adjustments not required by remaining in Canada.

Two additional points are important for understanding how Wafaa experienced the process of settlement in Canada. First, she told me that "seeing how easily the Arabs were defeated" during the 1967 War with Israel left her and her spouse feeling disenchanted with (pan)Arab nationalism and counteracted any political commitment to live in Egypt. Wafaa's statement implied that had this war played out differently, they might have returned to Egypt due to political commitments to a (pan)Arab nationalism aimed at thwarting the effects of centuries of European colonization by (re)building strong Arab nation-state(s) through education and technological and economic "progress." Thus, at an immediate experiential scale, their decision to remain settled in Canada was driven by the above-discussed series of nationally delimited and careerrelated events in Canada and by the impact of the internationally spatialized events the 1967/Six Days War in the Middle East on their political, national commitments.

Second, Wafaa added that she and her husband "didn't have a lot of difficulties" with settlement in Canada because, as students, they did not "encounter what a regular person [with foreign credentials] who's looking for a job does." Her addition of this qualification suggests she thought the ease of her settlement experience was likely facilitated by studying for and receiving her degree from a Canadian institution. In gesturing toward the importance of having studied in Canada, Wafaa hinted at one of the (potential) limits of the narrative of meritocracy she used to frame her work-related experiences in the country. This qualification points back to Rana's account of how 
discourses about the necessity of "Canadian experience" may be used as common-sense justifications for excluding immigrant Canadians from segments of the labour market.

In keeping with Wafaa's above suggestion that her settlement experience was particularly easy because she did not have to look for work as someone with nonCanadian education/experience, Monzer depicted "the difficulty in finding a job" as "the only negative" element of settlement: "When I first came, I was very excited," he said. "I have a place now... where I can stay in and live as an equal human being, but then that excitement changed because I wanted to find a job."

Before immigrating to Canada, Monzer was "the financial manager of a multinational ... company with $\$ 3 / 4$ billion worth of projects." Laughing, he said,

I thought I was a big shot... When I started looking for work, I looked at the big ads... that took up a quarter of a page... I would send in my application and my résumé ... and they wouldn't even respond. Then, as the ad size got smaller, I eventually started to receive the standard rejection letter. 'Dear applicant. We have received your application. You are not suitable for us at this time, but we will keep your application on file for six months.' ... The first of these letters was good news. At least I was receiving something.

While Monzer depicted his experiences with immigration officials prior to immigrating to Canada - and upon arrival at the airport in Halifax where the immigration officer welcomed him "home"- as symbolizing his being treated "with respect," his experience of trying to enter the Canadian labour force was not pervaded by this same sense. Instead, he went from perceiving himself as "a big shot," to prospective employers ignoring his résumé, to being happy that his potential as a worker was acknowledged by a rejection letter for a job for which he was probably over-qualified.

The impact of the above experience on Monzer is perhaps most evident in his ability, almost thirty years later, to recite the exact "three or four small lines" of the "ad 
in the Ottawa Citizen" that finally led to his finding employment. Rather than send in his résumé by mail, Monzer went to the company in person and persisted in seeing one of the people in charge of hiring for the position. Told he was "overqualified," he offered to "work in the company for six months for free" to prove his abilities because, he said, he "was that desperate" but also "that confident" that "once they saw [his] work, they would want to keep [him]." At the end of this conversation Monzer was hired - with pay - in a junior position at a "place [, which] was about one tenth the size of the company" he had worked at prior to immigrating to Canada.

Although Monzer's long struggle to enter the Canadian labour force impacted his sense of himself as "a big shot," he did not interpret the difficulty he faced finding work in Canada as representative of life in the country. Instead, he turned to his more recent experience of applying for and being given a job as a civil servant, as well as to his encounters with Canadian immigration officials, to explain his interpretation of what he saw as an authentically Canadian national identity based in liberal ideals. In other words, in immigrating to Canada, Monzer experienced his newfound access to citizenship, a passport, voting rights, and (inter)national mobility, all of which he was denied for most of his adult life as an internationally stateless refugee, as the most salient and defining elements of his settlement experience. For him, the elements of his settlement experience which were in keeping with the liberal national identity discourses that defined a shift in his political subject position from an internationally stateless Palestinian refugee to a Palestinian Canadian citizen were most representative of (his life in) Canada. 


\subsection{The "Canadian Experience"}

My aim in the previous section of this chapter was to show that the process of (socio-economic) settlement shaped research participants' abilities to continue to identify in previously meaningful ways and, thus, shaped their subjectivities and senses of agency. In this section, illustrate more directly how these same experiences shaped their interpretations of what constitutes nationally-defined ways of behaving. More specifically, my focus here is on the similarities and differences in their engagements with socio-cultural discourses they read as defining Canadian identity. During interviews, all research participants who remembered the process of "settlement" drew on liberal discourses in defining Canadian national identity as built on tolerance and respect for difference, order, and the law. While they depicted their settlement experiences as encompassing a gradual process whereby they came to identify with these discourses, there were also important differences in how they engaged them.

Many research participants said they relied on their everyday social interactions, particularly at work, to "learn" what they depicted as characteristically Canadian ways of behaving. For example, Rana retrospectively interpreted her retail job both as a way to acquire enough income "to survive" and as a key avenue "to learn about the culture and about the people" in Canada. She described a conscious "learning" process based on observing the behaviour of those around her: "At the beginning ... you're kind of an observer more than an initiator... because you don't want to initiate something that is not acceptable in the culture... You learn a lot by observing people." Eventually, she added, through her social interactions with people at work, she started "discovering that we are 
not different and we can interact with each other." In this way, she represented her work experiences almost as an anthropological study of "Canadian culture."

Through these observations, she said, she learned the following:

The good thing about Canada, something that is positive, is that people do accept each other. There's a kind of openness in a way, like, 'OK. You believe in this, I believe in your right to believe in this.' So ... it makes you feel easygoing about yourself and very open to talking about anything you believe in because the other person will respect that you believe in this thing. So this was, like, something I discovered when I worked. I found that people... are very friendly. They like... to tell you stories about themselves and they appreciate if you are a good listener.

Based on this experience, Rana said she advised new immigrants she met to "just go start working because this will put you in society" and, thus, become an avenue for learning about the behaviour of Canadians and coming to observe "many positive things."

Similarly, a research participant who worked in an immigrant services agency said she consistently told clients to volunteer or take any type of employment they could get in order to interact with people and learn about Canadian life and social expectations. Nouhad concurred with this suggestion, telling me she considered three aspects of her settlement experiences, namely entering the labour force, taking courses at university, and volunteering at a women's shelter, as key avenues for learning what Canadians consider acceptable behaviour. Learning about these expectations, she said, hinged on looking for subtle cues or observing other people's interactions with one another because Canadians were too "respectful" to tell her outright that she had behaved in a (nationally) inappropriate way. She elaborated,

For example, Lebanese [people] have the tendency to interrupt [during conversations] while here it's impolite. But nobody, for example, at the beginning, I don't think I ever felt that people were perhaps, how should I say it? They did not like this from me, but they don't tell you. ... [It's] living with the Canadians and working with them, this is how you learn how they think and 
how they do things... [They] don't feel they have the right to tell you 'You are doing something wrong.' So you learn it, uh, bit by bit.

Thus, while Rana suggested that social interactions in Canada were guided by a respect for differences of opinion, Nouhad argued that Canadians were "tolerant," withholding overt condemnation even when they did not like a particular behaviour.

Both of their interpretations of ostensibly "Canadian" characteristics echo longstanding discourses defining Canadians as nice, respectful, and tolerant (Clarke 1997:5; see also Mackey 1997; Maloney 2001; Thobani 2007; Wagner 2006/7). Although I return to research participants' critiques of these (and other) liberal (nationalist) discourses in the next chapter, in this context, I want to highlight that both women interpreted these characteristics as defining an ostensibly singular, liberal Canadian national character embodied by those who make up the national body. That they spoke of observing social interactions between those they understood to embody these characteristics to learn how to behave appropriately suggests they began to discipline their own behaviour in accordance with these "national characteristics." Nevertheless, each woman identified with these liberal discourses of Canadian national identity in her own complex way, indicating that they were not simply and directly reproducing Canadian national mythologies, but interpreting them at an experiential scale through a multi-scalar lens that was a product of multidimensional elements of their senses of identity.

Although Rana suggested those who make up the Canadian national body embody a liberal national character, as I suggested earlier, she depicted Canadian national institutions as failing to live up to liberal notions of equality. She also represented kindness and respect as elements of Canadian national identity that were worthy of embodiment because they resonated with "the roots of Arab ethics" which dictate 
"respect... of your beliefs, [and] of you as a human person." While she said she "loved" being Canadian because it encompasses "respect for the human," she valued this respect as representative of Arab ethics. In doing so, she (re)defined liberal humanist ideals, not as uniquely Canadian (or "Western") but as simultaneously Arab.

Nouhad, on the other hand, did not interpret these liberal ideals as overlapping across Arab and Canadian national identities. She distinguished Arab and Canadian national spaces and identities in two ways. First, she represented being Canadian as involving having "integrity [and] opportunities," particularly for her as a woman engaged in paid labour. Unlike Rana, who experienced greater career fulfilment and opportunities in Lebanon than in Canada, Nouhad interpreted her ability to enter into and advance within the labour force in Canada as confirming gendered discourses according to which Canada is to be distinguished from Arab (and other Middle Eastern) nations by the availability of employment equality for women in the former.

The second distinction Nouhad drew between Canadian and Arab national characteristics was more implicit. She depicted Canadians as people who are generous, humble, and "feel the pain of others." When I asked Nouhad to elaborate on these points, she said the pervasiveness of "charitable campaigns for the poor" in Canada taught her to feel "much better giving one hundred dollars... for a charity than buying clothes for [herself]." Nouhad interpreted such (neo)liberal charity as a particularly Canadian characteristic: "I don't think I would have had ... this view if I stayed living in Lebanon. I think I'm learning a lot living here," she added, "I think I'm becoming a better person." Although Nouhad also described generosity as something associated with the warmth of social interactions in the mountains of Lebanon, she interpreted the institutionalization of 
"generosity" though charitable work funded by the monetary donations of private citizens to be distinctly Canadian. In this way, she interpreted (neo)liberal generosity as worth embodying as a form of national moral capital (Valverde 1994): it made her both Canadian and "a better person" to embody such a (neo)liberal ideal of private charity. The idea that characteristically Canadian ways of behaving are both liberal and distinct from typically Arab ways of behaving also pervaded Dina's discussion of what she learned about Canadian national identity. According to Dina, she "only knew that [she] learned things in Canada when [she] went back to Lebanon, comparatively: order, waiting in line, being respected when you ... do any kind of government application or paperwork, equality... [and] that work is not shameful, any kind of work." Dina explained that she felt "valued for who [she] was [in Canada]. It ... mattered if you worked here or not, it didn't matter what you do... Everybody starts at McDonalds... That's your own work. It doesn't make you a person that's lesser. You start to empathize with others and you see there's possibility rather than fixity." Dina said she struggled throughout the settlement process because she felt she had lost her sense of individuality, but that the same process taught her that she "represented only [herself]."

Dina's narrative suggested that she developed a subjectivity shaped by what she understood as a Canadian respect for her as an economically independent worker. She depicted settlement as a process through which she learned to identify with liberal discourses about the necessity and value of paid labour ("it mattered here if you worked"), order ("waiting in line"), respect, and individual equality, incorporating discourses about the value of self-sufficiency into her sense of self. She also retrospectively framed these discourses, which shaped her subjectivity and agency, as 
worth embodying because she conceptualized them as avenues for regaining a sense of "individuality" she had lost. Their role in shaping her subjectivity and agency was evident in the pride Dina took in her sense of individual identity as a worker, which became an avenue for not feeling ashamed about the shift in her subject position from an "elite" Lebanese student to a working class (immigrant) Arab Canadian. In other words, Dina experienced her shift in class position as intersecting with and mapping onto her geographic movement from one national space to another. Indeed, when I asked Dina if she thought that ideas about (some types of) work being shameful was an Arab cultural ideal or something which had to do with socio-economic class, she said she couldn't say it was "one thing or the other" because "in Lebanon, if ... a 16 year old child is working, it's because you need it and, therefore, you belong to a lower class or you're not in good health." By contrast, in Canada she thought it was considered more morally reprehensible, and thus shameful, not to engage in paid labour (i.e. to rely on social assistance) than to be join the ranks of the working poor.

Farida also spoke about the importance of paid labour. As a Palestinian refugee living in the Arab Gulf on the basis of her paid labour, however, work was a necessity for her prior to immigrating to Canada. For Farida, the main distinguishing characteristic of Canadian national culture is the value of law and order in the country which, she said, meant "you know one thing follows from another: you do something wrong, you're going to get punished." She concluded this depiction by telling me she wanted "to teach [her] children" the importance of systematic order and that living in Canada facilitated her ability to do so. Interestingly, while she used this "law and order" discourse to define Canadian national culture, she did not conceptualize it as something she had to learn to 
embody upon arrival in the country. Instead, Farida said being organized and respecting "law and order" were things she already considered worthy of embodying as values taught to her by her father. Perhaps to confirm this interpretation, she added that her "husband always tells [her], 'Canada fits well ... with [her] need for order and [her] way of doing things." Thus, Farida experienced her desire to (continue to) identify with this liberal discourse as produced by the intersections of familial and national values.

To explain what he called the "cultural changes" he experienced as accompanying the process of settlement, Monzer related the following anecdotal story which tied together all the above liberal discourse of Canadian national identity:

My brother was living on the seventeenth floor of an apartment building ... A few days after I arrived in Canada, I was standing on the balcony overlooking the street ... and I just stood out there watching... There was a car approaching [a] traffic light ... [which] was red for this car, and this driver, to my surprise, actually stops. I was on the balcony observing this 'idiot' stop at a red light at 10:30 at night with no cars coming... Coming from the Arab world it was funny. It was a joke. He or she, carefully, like the typical Canadian gentlemen or lady, stopped and then drove when the light was green. This was one indication that I was no longer where I had been. Then, a few months later, while driving my brother's car ... at the same traffic light, around the same time of night, I stopped at the red light with no cars coming and I actually smiled to myself at the change that had happened within me after living in a civilized place where rules are respected regardless of the competing interests.

With this anecdote, Monzer summed up his seemingly unconscious embodiment of discourses defining Canada as a "civilized," liberal nation, which he framed in terms of taking on a Canadian "national character" (Handler 1984, 1988).

As with Dina, Nouhad, Rana, and Farida, the way Monzer imagined Canada and Canadian national character was in keeping liberal discourses according to which it is a place where individuals are respected and laws are obeyed. In Monzer's anecdote, these two ostensibly national characteristics maintain order within Canada's geographic 
boundaries thereby preserving civilization/civility. His depiction of Canada as a place where rules are respected "regardless of the competing interests" further suggests he conceptualized Canadian rules/laws as aimed at guaranteeing the rights/interests of an abstract individual rather than shaped by the desires of any one social group. At the same time, in referring to law and conceptions of civilization, Monzer's depiction also evokes the limits of liberalism's ostensible respect for difference.

What was particularly interesting to me in Monzer's anecdote is his suggestion that he went from conceiving the behaviours he associated with such characteristics as laughable to considering them desirable and worthy of emulating. Yet, he represented these characteristics as somehow seeping into and (pleasantly) surprising him by producing the behaviour of "the typical Canadian gentleman or lady." Given Monzer's desire for a national space, state, and citizenship denied to him as an internationally stateless refugee, he unsurprisingly said that his conscious desire to make Canada "home" was fostered upon his arrival at the airport in Halifax by an immigration official's words of "Welcome home." Perhaps this desire facilitated a process whereby Monzer began to discipline his behaviour to match what he interpreted as "typically" Canadian.

On the other hand, Monzer also said that he gradually came to consider Canada his national home when he engaged in socio-political acts such as voting in national elections which tend to be conceptualized as evidence of democratic citizenship. In other words, it was not only the national discourses he encountered and personal experiences he had in Canada that produced his desire for citizenship. As I have illustrated, Monzer's desires for a national state, space, and citizenship cannot be understood without considering the stark contrast between his experiences of exile and those of being granted 
citizenship. Here, I want to add that his desire for citizenship was transformed into a sense of national belonging in Canada precisely at the point where he felt enabled to enact his citizenship through acts such as voting, which are globally defined as evidence of democratic citizenship. This was not the case, as I illustrate in the next section, for all research participants.

\subsection{It's Just a Logo}

All research participants depicted certain ways of behaving as typically Canadian. Given their dominance in institutionalized definitions of Canadian identity, it makes sense that most participants drew on liberal discourses in defining characteristically Canadian behaviours. Those whose narratives I have discussed thus far in this chapter, spoke of the process of settlement as being as much about socio-economic adjustments as about learning and coming to embody these nationally defined behaviours. While they conceptualized liberal national characteristics (e.g. tolerance and respect for difference, the valuing of law and order) as worthy of embodiment, their justifications for valuing those characteristics varied greatly and emerged out of the intersections of multiple dimensions of their lives and settlement experiences. While these liberal discourses seemed to shape their (nationally defined) subjectivities, these and other life experiences played a role in how they interpreted and engaged such discourses.

In some cases, research participants' interpretations of their settlement experiences led them to question and reject some elements of the liberal national identity discourses discussed so far in this chapter. For instance, although Rana constructed Canadians' respect for difference as both intersecting with Arab ethics and worthy of embodying, her settlement experiences simultaneously led her to reject another 
characteristic she interpreted as defining life in Canada, namely a consumerist materialism aimed at the accumulation of capital and commodities. Moreover, as mentioned in the introduction to this chapter, Rana also questioned the image of Canada as a liberal democratic nation where there is no discrimination and every person's rights are respected which had been presented to her at the COA seminars prior to immigrating.

Based on her settlement experiences, Rana (re)conceptualized this image as "a logo used to attract people" to Canada. She elaborated on this, explaining that she feels the Canadian government needs to tell

the truth to the people that are coming here. So don't, just because you have an aim of increasing the population and increasing the economy ... or whatever, don't lie to people. The truth, the truth, the truth, that's what we want. Because we've all suffered from the same thing, we've all undergone the same thing... [There is] this promise of, of heaven, whereas you come here and you don't find anything that is promised to you. You can't find a family doctor. You go there, you wait for two hours... So, just ... tell people the truth.

Not only did Rana interpret the image of Canada she encountered at COA seminars as an outright lie, she suggested such false promises are purposely used by representatives of the Canadian nation-state to attract immigrants in order to increase the population and fuel the economy. In this sense, rather than a liberal democratic nation that is welcoming to immigrants, she represented Canada as characterized by institutionalized governmental mandates that are dishonest and unfair to (potential) immigrants.

This perspective was most adamantly articulated to me by Jean, an Arab Canadian taxi driver whom I briefly introduced in Chapter Four and who had immigrated to Ottawa from a village in the north of Lebanon. Late one night in March 2008, Jean drove me and some friends home. After dropping my friends off along the way, Jean and I began chatting. I mentioned that I was a graduate student at Carleton University doing research 
"about people's immigration experiences in Canada." Upon hearing this, Jean exclaimed "Oh, then you have to be talking to taxi drivers." When I asked him to elaborate, he said I "should" speak with taxi drivers because they "know about immigration in Canada." This was the beginning of one of the most scathing critiques of liberal discourses of Canadian national identity I heard throughout my fieldwork.

Jean told me that when he arrived at the airport in Ottawa, "they stamp[ed his] passport and [said] 'Welcome to Canada, sir."” Before immigrating, he had "never heard of Canada." Needing to escape the war in Lebanon, he decided to leave for Canada when he "heard that people can come here... But I came and I had to figure things out the hard way," he said, "all I got was a 'Welcome to Canada.' I didn't know what to do when I came here. I didn't know anything." He continued,

What do I do now? How do things work here? What do I do? And they just say 'Welcome to Canada' and that's it... There's a lot about the culture that you don't know when you come here... things that you do that are different here so you need to learn them. I'll give you an example. I'm used to, in Lebanon, we don't line up for things. So, I come here and I need to go to the bank. I didn't know this thing about lining up. In Lebanon you walk in, you put your hand up like this [showing me, he puts his hand up in the air and with his palm partially folded as if something is in it] and you wave at them with some money in your hand and then you go over, they wave you over. So, I go to the bank here: I walk in, I put my hand up like this and walk up to the counter and the woman gets mad at me, she tells me there's a line-up and I have to wait my turn. How am I supposed to know this? You get here and they say 'Welcome to Canada' and that's it. You're on your own.

Rather than constructing this "lining up" as a more orderly or civilized way of doing things, Jean represented it as simply a different way of doing things.

Jean also subverted (dominant) liberal national(ist) discourses constituting Canada as a place where law and order are respected and used to guarantee the rights of all individual citizens. Instead, he argued that "what [Canada has] is a police system" : 
I mean you come here and you live your whole life doing exactly what you're supposed to do. You do everything right, you're really good, and the system doesn't know you. You know when the system knows you? As soon as you do ... something you're not supposed to do, all of a sudden the system knows you. I've been here 19 years, Samah, and in 19 years, nothing! I didn't even get a letter, or anything. The system doesn't know me. They don't care ... as long as I pay my taxes and do what they want... I didn't even get a single letter in 19 years saying 'How are you doing, Jean?' Not a single letter asking how I'm liking Canada, how I'm finding it, if I need anything. Nothing asking 'How are you liking this country? How did you find it here? Did you like it? Did you hate it?...' You know, this is very frustrating.

Jean clarified that his frustrations with his life in Canada were not about financial

limitations. Rather, he felt that Canada, as a country, had "absorbed [him] financially." At this point, the car was stopped at a red light. Perhaps for added emphasis, Jean turned around to face me. Looking me in the eyes, he said, "even as a taxi driver it absorbed me financially, but it failed, and failed with a capital F - make sure you write this down, it's important - it Failed to absorb me emotionally."

Jean and I continued speaking about his immigration experiences as he drove me to my apartment. When we arrived, I remained in the car a while longer as we finished our conversation and Jean offered his most excoriating critique of Canada and, more specifically, its point-based immigration system. He suggested, however, that he was not alone in offering this assessment. "Do you know," he asked me, "what the taxi drivers call immigration system here? They call it 'Slavery 2000.' Do you know what I mean when I say that?" I replied that I did not know, so Jean explained:

It's like slavery in the 2000s. This means that, you know, a long time ago, when they wanted to get slaves, they would go to Africa, and they picked the one who looked the strongest, who looked like they can do the most menial work, can carry a lot... Now, they say they have immigration. But you know what happens? They have this point system and they say, "We need engineers, so we take you, Jean, because we need engineers." And I think this is great. But then I come here and, well, there's not work for engineers. They want people to come here to work as taxi driver, dishwasher, but they don't say that. They want slaves, they 
want people who do the work they don't want to do, for as little money as possible, but they don't say that. They want educated people, they want educated slaves to come here and do this work. So they say we need engineers and they make them work as taxi drivers. This is what "Slavery 2000" means... It's a bad system. It's a police system and it's a slave system. Don't go with what they [those in government] say. Talk to taxi drivers. We can tell you about immigration here.

In this way, Jean made it clear that, like Rana, he did not think nationalist discourses according to which Canada is a welcoming "heaven" for immigrants are true. Jean was familiar with these discourses, but rejected them not only as untrue, but as oppressive lies used to enslave immigrants.

Jean's representation of the point system is in keeping with scholarly depictions of the liberalization of Canadian national identity I reviewed in Chapter Two. As I discussed, anti-racist critics of Canadian national identity argue that the crisis of whiteness that ensued with the rise of anti-colonial movements, the civil rights movement, anti-Vietnam war protests, and the discrediting of "scientific racism," Canada and the United States (along with European nation-states more generally) could no longer (legitimately) justify explicitly race-based immigration policies. From this perspective, the introduction of the point system was necessitated by the need for a larger workforce and the global unacceptability of drawing on "racial types" to determine (un)desirability and (in)admissibility. For example, Sunera Thobani (2007) argues that the introduction of the point system and multiculturalism were used to (re)define Canadian national character and reinscribe (white) superiority through notions of tolerant and benevolent liberalism (143-50). At the same time, she represents these liberal discourses as ways of duping "immigrants" into subservience through their emotional attachments to and identifications with such discourses. As Rana's and Jean's comments illustrate, however, 
liberal national identity discourses may have unintended results. I take this point up in the next chapter by focussing on research participants' interpretations of Canadian national(ist) discourses of multiculturalism.

In this chapter I have illustrated that research participants' "settlement experiences" shaped their senses of self in complex, multidimensional ways which, in turn, shaped their interpretations of institutionalized Canadian national identity discourses. Their narratives of their immigration experiences highlighted the inseparability of the economic, political, and social realms as deeply interconnected dimensions of their lives which impacted their interpretations of the Canadian national identity discourses they encountered throughout the process of "settlement." At the same time, these interpretations emerged out of the multiscalar comparisons they made between their pre- and post-immigration experiences. In other words, research participants' encounters with Canadian liberal national identity discourses were not the only dimensions of their life experiences which shaped their subjectivities and agency.

Again, however, there was not a single, unidirectional relationship between the (neo)liberal governing rationalities that pervade institutionalized discourses about "the duty to integrate," research participants' interpretations of Canadian national identity discourses, and their representations of their senses of self as Canadian national citizens and workers. In some cases, for example, research participants reproduced some elements of liberal national discourses while also suggesting that the specificity of their experiences meant they were able to experience settlement in the particular way they did - as with Wafaa representing her settlement experiences through a liberal discourse of meritocracy while also highlighting that "a regular person who is looking for a job" 
would likely have different experiences. In other cases, the vast differences between research participants' settlement experiences and liberal national discourses led them to reject these discourses as no more than seductive lies used by a self-serving Canadian national state - as with Rana's depiction of liberalism as "a logo" and Jean's representation of Canada's immigration system as a contemporary form of slavery. In all of the examples I used in this chapter, liberal national discourses infused research participants' interpretations of their settlement experiences.

While this commonality might point us to the role of such discourses in the production of national subjectivities, the differences among their interpretations should redirect our focus to the ways in which their agency also emerges at the intersection of such discourses and their life experiences. To make this argument is not to oppose subjectivity and agency. It is, instead, to suggest, as Mahmood (2001) argues, that any discourse which shapes our subjectivity by definition also produces the possibility of our existence as political subjects and, thus, also shapes our agency. This process may end in us accepting, challenging, modifying, or rejecting the very discourses which have shaped us in the first place. The complexities of research participants' engagements with discourses of Canadian national identity are particularly evident in the analysis I undertake in the next chapter. 


\section{Chapter: 'Let's all fit into this multi-culture anyway'}

I went Omaima's home in November 2008 to conduct the first formal interview for this project. I got off the bus near a busy shopping mall and picked up a box of chocolates to bring with me, hoping the process of handing it over would distract from my nervousness. Since this was my first formal interview, I was expectantly anxious. What did it mean that I was going to Omaima's home "as a researcher"? I was not entirely comfortable with this designation and, based on conversations with fellow graduate students and professors, I was convinced all the readings I had done about methods and methodology had not prepared me for what lay ahead.

I had other worries: What if I couldn't figure out how to work the digital recorder? Omaima might think I was incompetent. I reminded myself that I had practiced using the recorder for hours the previous evening, read the "trouble-shooting guide" that came with it four times, and packed extra batteries. Trying to calm my nerves was an exercise in futility, however. As I assuaged thought after thought of all the things that might go wrong, I took a deep breath and knocked on the door. When Omaima answered with a warm, welcoming smile on her face, my worries dissipated. I might be here as a researcher, I thought, but this designation did not have to entirely determine the interaction that was about to take place.

I liked Omaima and the few exchanges we'd had were pleasant and relaxed. We met only two weeks prior to this day but I felt at ease in her presence. Although we had both immigrated to Canada at young ages, more than twenty years separated the time she had done so at the end of the 1960s - which, she reminded me, was just the beginning of "the immigrant movement" and Canadian multiculturalism as an official state policy - 
and the time I did so in 1989, shortly after the introduction of the Multiculturalism Act 1988 (Canada 1988). I therefore interpreted my comfort around Omaima as having less to do with our "shared immigration experience" than with her personality and way of dealing with people. She was kind, outspoken, cheerful, calm, and unassuming. If we approached a topic from opposing perspectives, we could have long conversations during which I never felt my opinion was dismissed. In social settings, she always listened attentively to other people's ideas on a subject while not holding back her own views.

As I entered her home, I presented her with the chocolates. "I just wanted to bring something small to thank you for having me in your home," I explained, sounding more sheepish than I intended. She smiled, took the chocolates from me, thanked me, and quickly added, "You know, Samah, you are a student. If you bring 'a little something' to every interview or to home you enter, you'll quickly go broke." I agreed with the sentiment. Still, I was glad I had brought the chocolates.

My coat hanging in the closet and my boots abandoned at the front entrance, Omaima led me through the hall and into the living room. Once I sat down, she offered me juice, water, and tea. I opted for juice and she entered the kitchen and came back with a tray containing juice, popcorn, and chocolate. She settled on the couch opposite me and we exchanged pleasantries and asked about each other's families as I began to get out my interview guide and consent form.

Because Omaima had come to Canada as a child, she chose to skip the first part of the interview guide about the decision to immigrate. She also explained that since first immigrating to Canada, she had left and come back several times. Like Monzer and Farida, Omaima interpreted her experiences of living in several countries across four 
different continents contrapuntally (see Chapter Five). Indeed, Omaima's answer to the first question I asked - if she thinks of Canada as home - made this clear: "I do, especially because I've travelled all over the world, and I've lived in lots of places... and I've realized that I don't really fit in anywhere else," she said, laughing. "Even having lived in Egypt, which is the "homeland," she continued, "made it more clear that that's not home." While she "could live just about anywhere," Omaima concluded, where she sees herself "being at home is definitely Ottawa and Canada."

When I inquired about Omaima's feeling of "being at home" being particular to Ottawa, she explained that although she had lived in Montreal, she "never really enjoyed that" because there was "double the struggle [of] being an Arab [and] being an Anglophone." Omaima added that she would also have "an extra struggle ... with wearing the hijab, the headscarf, in Montreal. If you speak French," she continued, "at least you speak their language; if you don't dress like them you'll get away with it" more easily. I asked Omaima if she "feel[s] like [she has] issues with hijab here, in Ottawa" and her response made me immediately aware of how poorly I had framed my question: "I think [other] people have issues," she gently corrected me, "I don't have issues." Omaima thereby made it clear that "the problem" is not that she wears a hijab. The problem is, instead, other people's responses to her doing so. Answering in this way, Omaima challenged the terms of media and governmental debates about "the problem of immigration" or "the problem of diversity" (see Day 2000; Kernerman 2005) for national cohesiveness reproduced in Joe Volpe and Jason Kenney's speeches on integration 
discussed in the previous chapter. Instead, she reminded me, "the problem" is not one of immigration and difference, but of xenophobic responses to these. ${ }^{58}$

Like other research participants, Omaima interpreted interactions wherein she was constituted as "foreign" to the Canadian national body as both in keeping with long histories of racialization, xenophobia, and discrimination within Canada and as starting points for anti-racist education challenging the meanings of Canadian-ness and attendant social, legal, and economic rights. For example, after repeating that she doesn't "have issues" with the hijab, Omaima added, "to me, I just, I enjoy it ... because a lot of times people have so many preconceptions, and I know I can break those quite easily once they've met me." She added, however, that "even in the [countries] where hijab was and is [common], they're still struggling with it." In this vein, she conceptualized herself wearing hijab as a walking, embodied, potential anti-racist educational encounter for people who have wrong preconceptions. She also implicitly suggested that such education needs to exceed Canada's geographic boundaries and take place on a broad global scale since even in places where wearing the hijab is common, there are still public debates about the garment.

As we talked, I learned that Omaima was not suggesting that anti-racist education/training be approached only on an individual, person-to-person basis, nor that it is the individual responsibility of those who are (racially) excluded to correct others. While she often spoke of (individualized) instances of interpersonal racism and was adamant that we ought not to be "in denial" about the existence of racism and

\footnotetext{
${ }^{58}$ See Bonnie Honig's (2001) Democracy and the Foreigner for an astute discussion of how liberal democratic politics and theorizing are inherently tied in to ambivalence about the relationships between immigration, national identity, and citizenship.
} 
discrimination in Canada, she was also clear that "a lot of work needs to be done" in institutional settings such as media and public education. For her, it is not a matter of either individualizing or institutionalizing anti-racist education. At the same time, Omaima insisted that "we're on the right track" as a country which "laid out a foundation for multiculturalism" in its constitution. Asked if she feels accepted in Canada in her daily interactions with people, Omaima unhesitatingly replied, "Yeah. Totally." Thus, Omaima moved back and forth between discussing processes of (racialized) exclusion from, and a sense of belonging to, Canadian national identity discourses.

Omaima was not the only research participant to draw on institutionalized national discourses to articulate simultaneously what she saw as the contraction and expansion of (who can claim and define) Canadian-ness. Indeed, Sam, Wafaa, Aladdin, Lias, Amira, Eddie, Rana, and almost everyone with whom I had informal conversations about this topic echoed these sentiments, some focusing on a need to bring such training into the local police force and the RCMP. Following from this, my main aim in this chapter is to explore how research participants' engagements with liberal national and nationalist discourses I have discussed so far in this dissertation. I argue that their engagements implicitly provide evidence that simultaneously supports and challenges scholarly critiques of these same discourses. As I illustrate, they often discussed multiculturalism and peacekeeping together, as quintessentially representative of a Canadian "national character;" referring to these discourses as (inter)national extensions of respect for diversity and suggesting the Canadian nation-state has been and ought to remain committed (or return to its commitments) to liberal humanism. Throughout fieldwork, research participants tended to represent such liberal national discourses in 
complex and sometimes seemingly contradictory ways that highlighted the interrelationships between their senses of in/exclusion, a liberal humanist focus on individualism, and the need for a broad anti-racist agenda focused on reforming sociolegal and economic institutions.

I illustrate these points below. In the next section, I offer an overview of the entry of liberal discourses defining multiculturalism as a basis for building a homogeneous Canadian national identity into Canadian federal policies. Continuing with the example of multiculturalism, I then review scholarly critiques, defences, and counter-critiques of multiculturalism as a liberal nationalist project and governmental discourse aimed at producing docile bodies and particular national subjectivities. In the next section, I examine research participants' engagements with three interrelated liberal discourses which pervade institutionalized definitions of Canadian national identity: multiculturalism, individualism, and peacekeeping. Throughout the section, I show that the same discourses which seemed to play a role in shaping research participants' nationally defined subjectivities were simultaneously launching points for their critiques of Canadian national institutions. I conclude by considering how research participants' agency is produced by multiscalar discourses and political commitments.

\subsection{National Identity Discourses, Immigration, and Multiculturalism}

Multiculturalism was first introduced into Canadian federal legislation following the release of the fourth volume of a report on biculturalism and bilingualism the Canadian government commissioned in the 1960 s with the stated purpose of examining and responding to tensions between Anglo- and French-Canadians. The discursive shift from biculturalism to multiculturalism was set in motion when, during their investigative 
hearings, the commissioners heard (more than anticipated) from what they referred to as "the other ethnic groups" in Canada who identified as neither French nor British, but mostly as Ukrainian or German Canadians and explicitly rejected the constitutive discourse of biculturalism as further institutionalizing their social, legal, and economic exclusion in Canada (Abu-Laban and Gabriel 2002; Abu-Laban and Nieguth 2000; Kobayashi 2007; Mackey 1999; Mitchell 1993; Wood and Gilbert 2005).

Following these hearings, the commissioners recommended that federal and provincial governments enact "employment practices... or housing legislation prohibiting discrimination because of race, creed, colour, nationality, ancestry, or place of origin" and standardize "conditions for citizenship, the right to vote, and to stand for election to public office ... with no regard to ... country of origin" (Canada 1969:228). Although such recommendations were directed at reforming socio-economic institutions through antidiscriminatory legislation and practice, the federal government used the commissioners' report to frame what they termed a "cultural policy" aimed at "uniting" Canadians (Trudeau, quoted in Heritage Community Foundation 2010: \ 5; see Chapter Three). Indeed, in 1971, the Canadian federal government - under the Liberal Party of Canada and led by Pierre Trudeau - introduced into parliament a Policy of Multiculturalism within a Bilingual Framework framed as aiming to make individual Canadians less xenophobic and discriminatory as they became more confident in and proud of their own cultures (Fleras 2010). In doing so, I suggest, the government constituted the ostensibly insecure and threatened psyches of individual citizens as the main source of racial discrimination and the loci of social change, glossing over the necessity for (antidiscriminatory) institutional reform at the municipal, provincial, and federal levels. 
Close to a decade after its initial introduction, and again under the Liberal Party of Canada and led by Trudeau, multiculturalism was further enshrined in Section 27 of the Canadian Constitution 1982 (Canada 1982). More specifically, in response to the advocacy of groups such as the Canadian Ethnocultural Council the federal government included a clause on multiculturalism in the Charter (Abu-Laban and Nieguth 2000; Kobayashi 2007). According to this fairly vague clause (i.e. Section 27), the Charter of Freedoms must be "interpreted in a manner consistent with the preservation and enhancement of the multicultural heritage of Canadians" (Canadian Department of Justice 1982). At the behest of members of feminist, anti-racist, and disability movements, the charter also included anti-discriminatory clauses guaranteeing individual legal and equality rights (sections one to fifteen of the Charter). Yet, Section 33 of the Charter (commonly referred to as "the notwithstanding clause") allows provincial parliaments to pass legislation that temporarily overrides Sections 2 (fundamental freedoms) or 7-15 (legal and equality rights) of the Charter (Canadian Department of Justice 1982). The legislative exceptions to the use of the notwithstanding clause are the multiple sections on English and French language rights, Section 25 ("Aboriginal Rights and Freedoms"), Section 27 ("Multicultural Heritage"), and Section 28 ("Rights Guaranteed Equally to both Sexes").

Socio-legal scholars represent the enshrinement of multiculturalism in the constitution as a simultaneous win and loss for anti-racist organizing in Canada. On the one hand, Section 27 cannot be overridden by the notwithstanding clause. On the other hand, its wording is vague enough to make its use in litigation difficult at best (see especially Kobayashi 2007). This leads some scholars to conclude that the inclusion of 
multiculturalism in the Charter reflects a "merely symbolic" gesture meant to manage difference by equating multiculturalism with the "quaint" notion of heritage rather than the social rights of marginalized groups (Karim 1993; Kobayashi 2007). Other scholars interpret the Charter's individualization of ostensibly group-based social rights and dependence on Supreme Court Justices' interpretations of various clauses as inherently limiting for social justice advocacy (Bakan 1997) or reflecting the "Americanization" (used here as a stand-in for individualization) of Canadian politics (Mandel 1994). These latter critiques converge with long-standing nationalist discourses according to which Canadian national identity is distinct from American national identity (Bloemraad 2011). Toward the end of the 1980s, with the ascendancy of a (global) neoliberal focus on laissez faire capitalism (Harvey 2005) and entrepreneurial citizenship (Jenson 1999), the Canadian federal government started to (re)articulate multicultural policies in terms of their (global) economic potential (Abu-Laban and Gabriel 2002; Mackey 1999; Mitchell 1993). In particular, leading up to and beyond the adoption of the Multiculturalism Act 1988, multiculturalism discourses became increasingly institutionalized through corporate language as an avenue for Canada to build "export markets and increased trading opportunities" (Mitchell 1993: 281) through the "cultural contacts" of individual Canadians. In other words, multiculturalism was (re)presented as a route for enhancing Canadian capital through international "entrepreneurial" links. Reflecting on the above history of multiculturalism, Audrey Kobayashi (2007) argues that the kind of work multiculturalism can and does do depends on its broader sociopolitical contexts. For example, with the opening presented by the Commission on Biculturalism and Bilingualism, some groups were able to engage the state's attempt to 
govern through the notion of biculturalism in a way that produced a shift to multiculturalism - a process which left out Indigenous peoples as neither "multicultural" nor "founding nations." Similarly, the public consultations that led up to the production of the Charter opened up a (fleeting and perhaps tenuous) space in the production of governmental rationalities that members of various social movements could enter.

\subsection{Critiques, Defences, and Counter-critiques}

Since its introduction as a government policy, multiculturalism has been the topic of much academic debate and discussion in Canada. Bissoondath (2002), the most-often cited neo-conservative critic of the policy, laments its "ghettoization" of "minorities" as preventing their adoption of "mainstream values" and depriving Canadians of a unified national identity. While some centrist, liberal academics support the latter part of his critique (e.g. Brotz 1980; Clifton and Roberts 1982; Howard-Hassman 1999; Roberts and Clifton 1982), others reject such a characterization as "culturally imperialist" (Goonewardena and Kipfer 2005; Kymlicka 1988, 1989, 1995; Taylor 1997).

Liberal academics who defend multiculturalism argue it strengthens Canada's claim to liberal democratic rule and ought to be used to guarantee group rights (e.g. Burnett 1979; Dawson 1982; Kymlicka 1988, 1989, 1995; Taylor 1997). The most wellknown of these defenses come from Will Kymlicka $(1988,1989,1995)$ and Charles Taylor (1997) who further argue that "difference" can only be legally "accommodated" by the Canadian government if it neither threatens Canada's dissolution nor "interferes" with the rights of other groups/individuals. In other words, while these scholars reject entirely individualist interpretations of multiculturalism, they nevertheless insist that "we" cannot allow "illiberal" cultural practices which threaten "the core values" of 
Canada as a liberal-democratic state. In both cases, these authors take upon themselves the ability to designate certain practices as liberal or illiberal and constitute "difference" in relation to and as threatening to an ostensibly homogeneous Canadian national character defined by a Euro-Christian tradition of liberal democracy.

Indeed, in his defense of multiculturalism, Charles Taylor (1997) notes that "liberalism can't and shouldn't claim complete cultural neutrality." For Taylor, to espouse a liberal, secular philosophy is necessarily to claim (and privilege) a particular cultural position, one which he ironically identifies as both "Western" and Christian. In other words, Taylor argues, "liberalism is ... the political expression of one range of cultures, and quite incompatible with other ranges" $(95) .{ }^{59}$ Consequently, some scholars read liberal approaches to multiculturalism as pervaded by an ambivalent oscillation between a xenophillic approach to difference as a national asset and a xenophobic conceptualization of it as a threat to be managed (Kernerman 2005; Vukov 2003).

The most consistent critiques of liberal justifications of multiculturalism come from scholars who aim to challenge normative, institutionalized narratives of Canadian multiculturalism and national identity (Abu-Laban and Gabriel 2002; Bakan 1997; Bannerji 1993a, 1995, 2000; Day 2000; Kernerman 2005; Mackey 1991; Mitchell 1993; Moodley 1983; Razack 1998, 2002, 2001; Thobani 2007). Multiculturalism, they suggest, is a state-orchestrated nation-building project which aims to manage populations deemed

\footnotetext{
${ }^{59}$ Here, Taylor's example is "mainstream Islam," which he represents as essentially unable and unwilling to separate the cultural from the political, which by his account ought to be private and public respectively. For a different perspective on Islam's ability and willingness to make such a separation, refer to Tariq Ramadan's (2004) Western Muslims and the Future of Islam, written from a distinctly liberalIslamic philosophical perspective. For critiques of Taylor's position, specifically, refer to Bannerii (2000: 125-50), Kernerman (2005), and Razack (2008).
} 
threatening and maintains the status-quo ${ }^{60}$ From this perspective, multicultural policies designate such things as food and music as "safe" cultural practices precisely because they are economically viable and do not challenge the political, legal, and economic structures that underpin Canada's constitution as a capitalist settler-nation-state. For some of these critics, by shifting the focus to food and music as representative of "identity," multiculturalism aims to govern Canadians' subjectivities by distracting from (racialized) economic exclusion and injustice (see especially, Bannerji 1995, 2000; Thobani 2007).

These latter scholars outline several interrelated arguments about the multicultural discourses that pervade Canadian state policies and institutions. For some scholars, the policy shifts the focus from group rights and institutionalized discrimination toward individualized conceptions of "cultural" choices and discrimination by (re)constituting a supposed distinction between a "public" realm where a unified Canadian (liberal) political culture must reign and a "private" realm where cultural differences from European norms could be individually sold, consumed, or practiced (e.g. Mackey 1997; Thobani 2007). They also argue that in maintaining bilingualism as the framework for multiculturalism, the government further privileged position of Canadians "of British and French origin" as the two charter groups and "founding peoples" (Mackey 1997; Thobani 2007). In doing so, they suggest, the policy further enshrines colonialist discourses which erase the presence of Indigenous nations by reifying a foundational narrative whose heroes are British and French "discoverers" (Mackey 1999). Other scholars argue this same framing also has the impact of erasing the long histories of black Canadians in Canada by placing their "heritage" in extra-national geographic locations such as the

\footnotetext{
${ }^{60}$ For similar analyses within the Australian context see Hage 1998.
} 
Caribbean (Walcott 2001). Finally, and as suggested in Chapter Two, Sunera Thobani (2007) argues that multiculturalism - together with the liberalization of immigration policies - aims to make "immigrants" complicit in Canada's settler colonial project by seducing them through the offer of partial inclusion in Canadian national identity.

I want to elaborate on Thobani's work because I consider Exalted Subjects a valuable (and long-overdue) intervention in theorizing the racial categories implicit in Canadian national(ist) discourses and nation-building projects. Based in a historical, theoretical conversation with (nationally institutionalized) state discourses, Thobani argues that "racial difference, as a system of hierarchy within the Canadian socio-legal system, constitutes the national, the Indian, and the immigrant as different kinds of legal beings" such that "the relationality among them, [is] sedimented in state practices" ( 28 , emphasis added). Of particular interest to me is Chapter Four of Exalted Subjects, "Multiculturalism and the Liberalizing Nation," because this is where Thobani examines the Canadian state role in using multiculturalism as a liberal discourse to produce specific meanings of the figure of "the immigrant" and the category of "immigrant communities" (143-175). She argues that "the state's communalizing power" is evident in multiculturalism as a policy which reifies cultural, ethnic, and racial differences and constitutes "discrete ethnic, racial, and cultural groups" (149) whose members are both physically included (as a fetishized source of difference), within and symbolically excluded from the national body. Accordingly, she suggests, state policies constitute racialized others as immigrants "irrespective of their place of birth, their legal citizenship status, or the length of their residence within the country" (149). 
According to Thobani (2007), the constitution of "discrete ethnic, racial, and cultural groups" makes "cross-racial" alliances difficult and contains "demands for racial equality that sought to transform the very basis of economic, social, and political power" (160). Ultimately, she argues, "inclusion and integration [for racialized national subjects]... was to come at the cost of increased subservience, across generations, to the grand narrative of national supremacy" (149). Building on this claim, Thobani writes that immigrants, seduced by the prospect of inclusion through multiculturalism and "exalted" above Indigenous peoples into the position of (limited) national subjects, "tend to minimize or deny the racism that pervades their lives" (161).

Thobani's (2007) argument is thus about multicultural discourses as governmental rationalities aimed at producing an "immigrant" subjectivity that is subservient to "the state's" nation-building project. Yet, as discussed in Chapter Four, governmental agencies can never guarantee that populations will self-discipline in accordance with their rationalities because people might "act and [...] think in a variety of ways $[\ldots]$ not foreseen by authorities" (Dean 1999:12). I bring these two insights together in the remainder of this chapter as a way of adding to scholarly discussions of Canadian multiculturalism.

More specifically, my discussions so far in this dissertation, and my analysis in the rest of this chapter demonstrates that while most research participants interpreted liberal discourses as central to Canadian national identity, they also drew on them to launch their critiques of Canadian institutions as failing to live up to these national characteristics; they engaged liberal national(ist) discourses in ways that often opposed the governmental aims critical scholars (including Thobani) outline, drawing on these 
governmental discourses to argue for increased governance of Canadian national institutions. In other words, Canadian multicultural and liberal legal discourses and policies seemed simultaneously to produce research participants' nationally defined subjectivities and to "enable and create" their "capacity" for critiques of state institutions (Mahmood 2001: 203).

\section{3 (Re)Defining Canada and Canadian National Identity}

Explaining why Canada "feels like home," Amira (who emigrated from Egypt as a child) simultaneously drew on multiculturalism in ways that were consistent with liberal nationalist discourses and underscored the pervasiveness of racialized economic injustice in the country. She began by asserting that Canada is multicultural, which means she "can feel okay to practice [her] culture, okay to practice [her] religion, it's the safety, the freedom." Amira's parents had left Egypt because they felt they were unable to advance at work as Christians in a predominantly Muslim country and wanted to ensure their children would not face similar difficulties. Given her family's immigration history, it is perhaps unsurprising that when I asked her what being Canadian meant to her, she said, "for me, the biggest thing is just having freedom to practice religion." In contrast, she explained, to be Arab meant being "in touch with [her] roots and [her] culture, the food, the dancing, that type of thing."

Amira's distinction between what being Canadian and being Arab meant to her, her relegation of food and dancing to the latter, was in keeping with how critical scholars suggest multicultural discourses and policies aim to constitute "culture" as a matter of private, consumerist practices and distract from issues of economic (in)justice. Yet, she was clearly not distracted from these issues. When I asked if she felt accepted in Canada, 
Amira said that although she does, she thought "not having an accent helps a lot." She continued, "I think, too, ... my dad is darker than me... and he struggled a lot ... his whole life, but for me, no." She also added that "it would make a big difference if" she were a Muslim Arab woman who "had the hijab on," concluding that there are "still major employment barriers" for women who wear the hijab and that "[there] needs to be more" done in the areas of anti-racist education and anti-discrimination policies. Thus, Amira's interpretation of multiculturalism as a definitive characteristic of Canadianness did not preclude awareness of its limitations in dealing with prevalent racialized (and gendered) economic injustice. Instead, like other research participants, Amira provided nuanced accounts of her contradictory experiences in Canada. In other words, the governmental rationality of offering partial national inclusion through multiculturalism shaped Amira's national subjectivity but did suppress her awareness of processes of racialized exclusion.

Similarly, when I asked Nousayba what being Canadian meant, she said "respect for diversity, our freedoms, the Charter of Rights and Freedoms" before adding, "when you asked that, I also thought 'not American' for some reason." As I show below, Nousayba was not alone in thinking this. Indeed, in keeping with the work of critical scholars of Canadian national identity, most research participants defined Canada through combined references to its commitments to multiculturalism, human rights, and/or peacekeeping, often distinguishing these from images of the United States as a melting pot. ${ }^{61}$ In the rest of this section, I continue to complicate and build on the accounts of

\footnotetext{
${ }^{61}$ Some participants added images of hockey (Aladdin, Sam), charity/volunteering (Nouhad, Rana), official (legal) citizenship (Dina, Farida, Lias, Monzer, Sam), publically funded healthcare (Sam and Farida), and cold weather or snow (Sam and Aladdin). The only complete exception to this was Lias, who referred to none of these "typical" images of Canadianness. Instead, he said being Canadian meant "not just that we hold a passport," but also "that we have an emotional stake in what happens in the country." This was
} 
critical scholars discussed above by analyzing research participants' engagements with liberal national discourses. Again, I argue that research participants' experiences of institutionalized racism in Canada shaped their theorizations of Canadian liberalism and national identity thereby placing limits on the effects and effectiveness of national liberal discourses like multiculturalism on how they imagined Canada and their place in it. I illustrate these points below by taking up research participants' sometimes seemingly contradictory references to three interrelated national(ist) discourses defining Canada and Canadian identity: multiculturalism, individualism, and peacekeeping. I separate these into three sections for heuristic reasons. As will become clear, however, they are not entirely separate discourses but interlinked with one another through liberalism.

\subsubsection{Multiculturalism as Distinctly Canadian}

When I asked Eddie, a man in his thirties who had immigrated to Canada at the age of one, about the meaning of Canadian-ness, he told me the "image of the Canadian identity used to be [of] a very easy-going people [who] respected human rights and neutrality around the world." Eddie also identified with a Canadian "we ... [who] see ourselves as a diverse people [who] are accepting of other cultures and ... don't try to stifle other cultures." Finally, he distinguished this image from "the melting pot that the U.S. is" and told me he was glad he "didn't have to give up [his] Arab heritage. [He] can hang on to it and still be Canadian."

particularly important to note, he argued, because some "consider [Arab Canadians] as second-class citizens." Lias was not alone in having this sense. As I discuss in Chapter Eight, many research participants suggested that Arab Canadians (and other negatively racialized groups) are considered or treated as second-class citizens. Also noteworthy is that Rana and Farida used the term multicultural, not to refer to a policy or ideal that facilitated their sense of belonging, but to describe Ottawa's demographic make-up. 
At the same time, Eddie had clearly felt and reflected on his own sense of national belonging in Canada. ${ }^{62}$ As we sat at a small table in a coffee shop in Ottawa's south end one evening, Eddie told me both that he felt accepted in his daily interactions with other people in Canada and that he did not "fit in" in the country because he saw himself "as an Arab by birth, a Canadian by citizenship." "I see myself as an immigrant" he repeated before assertively declaring,

I'm definitely an immigrant, and anyone who was born in Canada, younger or older than me, will still view me as an immigrant. And I make that distinction, about younger or older, because somebody who's younger than me, who was born in Canada, has been in Canada less time than I have, yet I'm still the immigrant in their eyes, even though I feel that I've probably contributed more and been here longer. So I' $m$ an outsider to 'Canadians,' natural-born Canadians, and I'm also, to natural-born Arabs who are visiting here or who are studying here, they see me as Canadian because I've grown up here. So I'm in a weird limbo. That's how I define my, my place in this country.

Eddie also demonstrated a politicized and critical awareness of Canada's colonial history when, as I mentioned in Chapter Five, he challenged the very notion that anyone should identify as Canadian: "Referring to yourself as Canadian, as a pure Canadian, unhyphenated," he argued, "is to say you're a native Aboriginal." He qualified this by adding, "even at that, saying you're Canadian" is to take on a colonially imposed identity. While Eddie spoke of and identified with liberal discourses defining Canadian national identity in accordance with "respect for diversity" and accepted Canadian nationalist discourses' designation of him as an immigrant, he also considered what this meant in relation to Palestinian/Israeli politics, the history of European colonization in the Arab world and Canada, as well as his encounters with racism at his Ottawa

\footnotetext{
${ }^{62}$ Eddie's experiences, like those of Omaima, Aladdin, Amira, and Nousayba, fall somewhere between those of first generation Canadians who immigrated to Canada as adults and those of second-generation Canadians who were born and grew up in Canada.
} 
elementary school. These considerations led him to re-conceptualize questions about who is or is not an immigrant Canadian as misplaced because any answer rested on accepting the injustices of settler-colonialism. Although no other research participant made this latter point, it was an important one which posed a challenge to the question I had asked about the concept of Canadian national identity.

While Eddie was most vocal on this account, other research participants challenged liberal national discourse of Canadian identity in other ways. For instance, Omaima distinguished Canada's multicultural discourses from metaphors of the United States as a "melting pot." For Omaima, not being required to "melt in" implies there are "no strict guidelines on what you have to be to be Canadian. You can be... from just about anywhere and as long as you accept the general principles of what made Canada Canada, you're fine." When I asked what defines Canada, Omaima said that, having lived in other places, she felt Canada "gives us the ability" to be "proud ... to be from a different culture." Multiculturalism, she concluded, facilitates this ability by being an avenue for people to "start working together" and to "realize that we're not gonna be the same, we're destined to be different, and [so] let's all fit into this multiculture anyway."

Omaima was clear, however, that arriving at the point where people actually could "all fit into this multiculture" would need a lot of "work politically." What she celebrated about multiculturalism was her sense that it offered a potential avenue for "working together" under a shared acceptance of the inevitability of "difference." While at first Omaima's words might seem similar to the Canadian state's "unity in diversity" argument (Day 2000; Kernerman 2005), they were also in keeping with feminist theorizations of the necessity of coalition-building for social change (Mohanty 1991, 
2003; Reagon Johnson 2000). In other words, she did not conceptualize multiculturalism as a way to manage difference in the name of coherence, but as a matter of working across difference to fight injustices; "working together" implied not a unidirectional expectation that Arab Canadians adopt "Canadian values," but required (racially, religiously, and/or economically) privileged individuals and institutions to work to fit into a "multiculture" where difference would not be seen as threatening. For her, multiculturalism was a pedagogical tool for political strategizing and community building as well as something that shaped her life experiences in Canada.

Aladdin, who immigrated to Canada at the age of four and was in his twenties at the time of our interview, integrated critiques of multiculturalism into his definition of Canadian-ness. He said being Canadian "involves taking in the culture and the culture is so big: the education system, the political system. It's all around." He continued, I don't drink, but I understand that it's a form of social cohesion for people. Same thing with hockey: I don't play hockey, but I understand what it means to people. I understand it as a national sport. I appreciate that. I guess, also, many people view Canada as being peacekeepers. Not peacemakers, but peacekeepers. There's a difference. It's multicultural, it's tolerant - although there are problems with the idea of tolerance: it's not really the same as acceptance. It's still a more open society than other places. We project those values abroad. It's also snow. My dad still complains about the snow. He hates it, but ... I grew up with it and I like it. I like that it's also the time when people put up their Christmas lights. I like to be part of that. They're also an open society compared to other places. That's what it means to be Canadian.

Like others, then, Aladdin suggested that images of multiculturalism were part and parcel of definitions of Canada's national character.

In the above passage, Aladdin also switched between speaking about the way he thought "many people view Canada" (implicitly excluding himself), to identifying himself with the Canadian "we" that projects the values of openness and multiculturalism 
abroad, and finally speaking as a more individualized "I" who grew up with and liked snow and Christmas lights. He concluded by distancing himself from "what it means to be Canadian" by speaking of Canadians as a "they." The shifting subject positions that pervaded his narrative seemed to be in keeping with his ambiguity about his place in Canada where he simultaneously felt included and excluded.

Aladdin's qualifications of the image of Canada as a multicultural nation pointed to his critical engagements with liberal discourses. More specifically, Aladdin's suggestion that "there are problems with tolerance" was in keeping with the work of scholars such as Brown (2006), Mackey (1997), and Thobani (2007). Such scholars argue that tolerance (1) fails to challenge the power relations that underpin liberal democratic theory by maintaining the privilege of dominant groups whose members can define the (in)tolerable, (2) does not ask people to accept or understand, but simply to "put up with" something or someone they may not like, (3) constitutes some people as actively tolerating and others as mere objects to be tolerated, and (4) constitutes certain acts/people as beyond the limits of what is tolerable. Consequently, Brown (2006) concludes that tolerance is a governmental rationality which works to privilege particular subject positions through constituting others as (in)tolerable.

Aladdin's ideas about tolerance were tied in to his sense that Canadian national media outlets represent Muslim Arab Canadians as illiberal threats to Canadian national culture. Along with this, since getting to an age in high school when his friends who are not Muslim and Arab Canadians began to drink alcohol and he refrained from doing so, Aladdin has felt far less accepted by these friends than he previously thought he was. These two experiences shaped how Aladdin represented the limits of tolerance. He did 
not refer to tolerance as "a governmental rationality," but he conceptualized it as a condescending attitude of "putting up with" difference despite finding it distasteful, rather than working toward understanding and acceptance of difference.

Like Aladdin, Dina also qualified her reference to Canadians as "tolerant." She clearly struggled as she tried to answer my question about what being Canadian means. "I don't know if I can answer this," she responded honestly, "but I'm trying, I'm trying." Finally, Dina told me "it's not one thing or another. Being Canadian, it's holding a Canadian passport, being respected, being semi-intelligent, respecting the rights of others, being tolerant, being polite, um, I mean that's being Canadian." She quickly added, however, that she "believe[d] that other countries would say the same thing about themselves." Thus, although she offered a definition of what being Canadian means, Dina concluded with the concession that these are characteristics "other countries" would also claim and were, by extension, not so distinctly Canadian.

Moreover, Dina told me she thought non-Arab Canadians "understand [Arabs] ethnically... in terms of falafel and hummus and ... the Lebanese festival" because "there's no danger in knowing those." Similar to critical leftist scholars, this is to say, Dina argued that there is a limited understanding of "ethnicity" in terms of nonthreatening "fun, food, and festivals" or "saris, samosas, and steel bands" (Mullard 1982). Dina rationalized, on the one hand, that there is no "necessity to understand the culture ... because they treat you on a human level." She, thus, seemed to imply that humanism eliminates "a necessity" to understand culture beyond "falafel and hummus ... and the Lebanese festival." On the other hand, Dina complicated this assertion by adding that treating others "on a human level" does not necessarily indicate acceptance of difference. 
From this perspective, she argued, "the majority of the general public are still of the thought that... 'You wanna come here, you be like us,' but they don't speak it." In articulating the place of Arab-Canadians in Canada, Dina moved from suggesting they are understood "ethnically" in terms of food and festivals, to arguing this implies a lack of understanding of Arab culture, to claiming that humanism eliminates a need for such understanding, to asserting the pervasiveness of unspoken assimilationist attitudes.

Throughout the above excerpts, research participants drew on elements of multicultural discourse to define Canadian-ness and expressed their sense of belonging in ways that seemed to be in keeping with state discourses. Yet they simultaneously articulated the limits of these discourses. This tendency, I argue, indicates their struggles to make sense of the relationships between national discourses according to which multiculturalism is an inclusive policy and their experiences of inclusion and exclusion in their day-to-day lives in Canada. Given that processes of inclusion within modern states "are interconstitutive with and co-dependent upon ... traditions of exclusivity" (Goldberg 2002:256), it is perhaps to be expected that participants (re)defined multiculturalism as a limitedly inclusive national policy.

\subsubsection{Individualism, Institutions, and (Racialized) Exclusion}

Above, I argued that research participants' discussions of multiculturalism as expanding the boundaries of national belonging does not represent an uncritical acceptance and/or embodiment of this institutionalized liberal national discourses. Here I shift my focus to research participants' representations of another aspect of liberalism, namely its valorisation of the individual. More specifically, I argue that research participants represented individualism as integral to expanding the boundaries of national 
inclusion by guaranteeing individual legal rights while also representing processes of exclusion as simultaneously individualized and institutionalized.

For example, Farida told me that being Canadian meant she had "official identity" and "official rights" which were particularly protected in the areas of education and health care. ${ }^{63}$ Comparing this to her previously discussed experiences of living on temporary work permits in several Arab countries, she concluded that "here it's a lot better in that they respect the human." This comparison was simultaneously a comment on the denial of (citizenship) rights to Palestinian refugees by several Arab states and on her sense that she was granted these previously denied rights by the Canadian state.

Being a Palestinian refugee, Farida said, had "followed [her] in all the different Arab countries." I asked Farida "it didn't follow you to Canada?" Her response to this question clarified the basis for her understanding of the humanist discourses pervading Canadian laws as particularly fair:

Here it didn't follow me; it actually made things easier for me. The only country that the U.N. refugee status papers [watheeqa] benefitted me in my whole life is Canada because it made my application easier. As a refugee, when I entered, there are rules for how they accept refugees, and because I had no country to return to, they accepted me. Here, it made things easier for me. ${ }^{64}$

In other words, Farida drew her conclusion about the fairness of and individual equality guaranteed by Canadian law from her experience of immigration officials accepting that her United Nations-issued documents confirmed her claim for refugee status, a route for

\footnotetext{
${ }^{63}$ Although Farida answered most of my questions in Arabic, she used the English words "official identity" and "official rights." Another term she used in English was "culture."

${ }^{64}$ Similarly, Rana, who was adamant about the existence of institutionalized racism and discrimination in Canada, understood the ability to become an official citizen in Canada (as compared to Lebanon), as something that increased her sense of belonging and acceptance.
} 
finally gaining access to formal citizenship. This interpretation was in keeping with her conceptualization respect for "law and order" as definitively Canadian characteristics (see Chapter Six). In contrast to being the source of institutionalized exclusions, in Canada her United Nations-issued papers became an avenue for obtaining official citizenship of a national state and the first passport she ever held, by virtue of which she was finally able to travel to visit her mother in an Arab Gulf country with no trouble.

Yet, Farida also followed this comparison with the statement that "here, the things that sometimes bother a person is feeling that people have these assumptions ... that 'you are lesser than us, you don't understand things, you're irrational, you're inconsiderate, you weren't raised right.' Those sorts of things bother a person." ${ }^{.65}$ In this way, Farida championed Canada as a place where she was treated on an individual level "as a human" while also constituting it as a place where individual people's "assumptions" interfered with such institutionalized commitments to legal equality.

Although Farida began by individualizing her experience of racism, above, she also offered a broader conception of racialization. Telling me she wanted to "talk honestly about this subject," Farida explained that she felt

lots of other cultures here in Canada ... have to struggle a lot more than us [Arab Canadians] because a lot of people have assumptions about them. So when [other people] see the way they look, they have assumptions that this person should be in a particular job or thinks in a particular way. You know what I mean? So they have these assumptions about people. This really bothers me.

\footnotetext{
${ }^{65}$ If it had been spoken in English Farida's reference to an abstract "person" who is bothered by other's assumptions might be interpreted as her distancing of herself from these instances. Her words, however, are translated from the Arabic language where the use of the abstract person might just as accurately be interpreted as a generalization that suggests that these instances happen to more than just her.
} 
Farida thus extended her analysis beyond herself and other Arab Canadians, drawing on vernacular conceptions of "race" as a phenotypic characteristic to make "cross-racial" links which suggested she understood such "assumptions" as quite prevalent. Using legal terminology, Farida added that such incidents make "you feel like you're accused and have to prove your innocence. You know what I mean? It's not like you're innocent and if you make a mistake then they will deal with it." Farida thus drew on a liberally defined legal standard - i.e. the presumption of innocence - in her representation of daily interactions through which racialized exclusions are as morally reprehensible. When I asked Farida about the source of these "assumptions," she argued that media and family, as social institutions, teach and perpetuate cultural stereotypes. Thus, she interpreted the ostensibly individualized interpersonal instances of racism as inseparable from institutionalized racism since, on her account, the latter enabled the former. Notably, however, Farida attempted to resolve the co-existence of liberal discourses of equality and institutionally based racist attitudes by distinguishing legal institutions from educational/familial ones: she employed discourses defining legal liberal standards as non-racist to criticize educational, media, and familial institutions as exclusionary.

While Sam did not make this same separation, he also seemed to struggle to make sense of the contradictions between liberal national(ist) discourses and his experiences of racism, which he at first depicted as "more subtle" than in the United States. ${ }^{66}$ As mentioned in Chapter Five, Sam distinguished between the U.S. as a "melting pot" and Canadian multicultural policies, telling me that unlike his siblings who were still "not

\footnotetext{
${ }^{66}$ Recall from Chapter Three that before immigrating, Sam had an image of Canada as "a gentler form the U.S. society."
} 
comfortable saying 'I' $m$ an American'" after living in the U.S. for decades, he had a sense of national belonging as a Canadian. To illustrate his point, Sam related a story of being able to get information from Ottawa's City Hall in Arabic for a visiting relative which, he said, made him feel that he could say "Yes, I am Canadian." Thus, he concluded, "being Canadian doesn't mean I have to dump my background somewhere and become part of the melting pot."

In keeping with these distinctions, and with images of Canada's national character as involving "more respect" for cultural differences than the United States, Sam said he mostly experienced racism when he visited his siblings:

[R]eally, it's more on the American side that incidents happen, and you know, every time you travel, they say 'What's your citizenship?' and you say 'Canadian.' The next question then is 'Where were you born?' and once you say Jordan, they say 'Down you go.' [i.e. to be searched]

Yet, he immediately switched from these interactions with American state representatives to discussing racialized exclusions within Canada, describing them as something experienced through "a collective of things." As he said, "it's the looks you get. It's the way people talk to you. It's the media, the barrage of media... Reading The Ottawa Citizen should not be a traumatizing experience for Arabs in Ottawa. ${ }^{.67}$ Thus, while Sam began his above comments about racialized exclusions by distancing them from his life in Canada, he brought his discussion back to Canada, focusing on individualized and subtle "looks" as well as (traumatizing) institutionalized racism. His movements between the scales of institutions and individuals suggested their co-

\footnotetext{
${ }^{67}$ Sam was not alone in criticizing The Ottawa Citizen's representations of Arab-Canadians. Others who did so included Lias, Aladdin, Nouhad, Monzer, Omaima, and Eddie. Nousayba referred to The National Post as particularly racist.
} 
constitution of his experiences of racialized exclusion and, by extension, pointed to the importance of addressing both simultaneously in any anti-racist social justice agenda.

Omaima also moved between experiences of individualized and institutionalized racialized exclusion. For instance, she told me her "daughter who... was born in Ottawa... still gets the odd professor, the odd teacher, who's like 'Where were you born, where are you from?' And she's like 'The [Ottawa] Hospital."' Omaima began by depicting her daughter's encounters with "the odd professor" as seemingly individualized and sporadic occurrences, which her daughter challenged by naming not the foreign country, but the local hospital where she was born as her place of origin.

Yet, Omaima offered a scathing critique of Canadian educational institutions which began with her observation that her daughter's "whole education ... was very much from a Western-centric perspective... and that just kills her." Omaima explained that her daughter "reads a lot" of literature that is outside of the curriculum and was "finding very troubling" to "[watch] the [other] students in her program ... being formatted a certain way." For Omaima, such "formatting"

starts at elementary school, where, when they talk about Morocco, they show you a camel... I'm talking elementary school onward. So, when they cover world affairs or geography, they're bringing a Bedouin in a tent. I have yet to meet a Bedouin in a tent, and I've been all over the Arab world. I haven't seen that. Not one, not anywhere, not in the streets, not anywhere. And so, if that's all people have to educate them, there's something wrong, and I think this is what really makes school difficult for our kids is that ... the history that's being taught about them, ... someone else wrote it, and it's not a fair picture. And they're getting depicted this way and in class people look at them: 'Oh, you're from Morocco,' 'Oh, you're from Libya, look at that.' It's very painful. I knew this growing up. 
Thus, in outlining her daughter's experiences of racism, Omaima connected these to her own experiences of Canadian educational institutions beginning with elementary school and following through to post-secondary education.

Aladdin made a similar point. After telling me that he was sometimes in situations where he heard non-Arab-Canadians stop others who make racist jokes about Arabs, he added that at "other times [he finds] that people really homogenize [Arabs], like Edward Said says ... in Orientalism." When I asked Aladdin where he thought such homogenizing images came from, he told me that "part of it has to do with the education system. People get tangled into it at a young age. ... A lot of it, I think, has to do with reinforcing these stereotypes through the media, so it's a mixture of things." Aladdin concluded that "children are indoctrinated into it at a very young age. I'm a perfect example of it." In giving himself as "a perfect example" of someone who had been institutionally indoctrinated into racialized discourses, Aladdin was also referring to his sense (discussed above) that he once considered himself as fully accepted into and part of the Canadian national body, but was occasioned by recent experiences of racism to reconsider this sense. In other words, I interpret Aladdin as suggesting that in attempting to make sense of the contradictions between his experiences of racism and the liberal nationalist discourses which shape his subjectivity as a "Canadian," he began to reconsider the content of these discourses and the desires they produced within him.

Amira, whose children were in elementary school in Ottawa, brought up their experiences in school to explain how she thought processes of racialized exclusion occur: "my daughter, I know her teachers have asked her where she's from. I never thought it would start that early, but it's already started." Amira said her daughter has "probably 
been asked for the last two years ... because she has ... very dark, dark, brown hair ... [and] dark brown eyes." The result of two years of getting asked this question, she said, was that her "kids actually asked [her] the other day, 'Are we Canadian?" Concluding with her children's questioning whether they were Canadian, Amira linked individualized and institutionalized processes of racialized exclusion to the circumscription of the boundaries of Canadian identity. At the same time, in stating that she "never thought it would start this early," she suggested she expected her children to encounter such questions in school, thereby implying that racialized exclusionary discourses pervade Canadian educational institutions.

Nouhad, on the other hand, presented a different picture of Canadian educational institutions. When I asked her how she had learned things about Canada (see Chapter Six), she said she learned about "anti-racism and all those good things about Canada" through things her children brought home from school. Given her children's ages, they likely attended public school in Ontario at the end of the 1980s and the beginning of the 1990s, a very brief time period during which anti-racist education was being incorporated into the curriculum at some Ontario schools. In the mid-1990s, however, this was cut from the curriculum as Mike Harris's Progressive Conservatives clawed back funding for such initiatives (Wright 2000).

Considering the above excerpts from interviews together, I suggest research participants did not separate their day-to-day experiences and interactions with individuals from their interactions with Canadian institutions. Their tendency to begin by defining experiences of racialized exclusion in relation to individualized day-to-day interactions might be interpreted as a way of minimizing racism or (re)presenting it as a 
matter of individual bigotry. In almost every conversation, however, they linked these instances to Canadian national institutions - especially national media (which I take up in Chapter Eight) and educational spaces. Omaima, Eddie, Aladdin, and Amira, who had all attended Canadian educational institutions were most focussed on these institutional spaces as avenues for the reproduction of racist discourses. They encountered liberal discourses defining Canadian national identity as inclusive within these spaces while also coming up against exclusionary discourses. These contradictions became the starting points for their questioning national institutional commitments to racial inclusion. Thus, while research participants represented liberal individualism as expanding the boundaries of national inclusion, they also discussed processes of exclusion as institutionalized such that any end to these processes would require institutional change. As I have been arguing throughout this dissertation some of the complex nuances that emerge out of analyses of the experiential scale at which people encounter national identity discourses clarify the role of such discourses in shaping people's subjectivities and agency. The analysis of research participants' deployments of liberal discourses according to Canada is defined by its commitments to peacekeeping and (inter)national justice, which I present in the next section of this chapters, highlights how agency is shaped by multiscalar commitments and discourses.

\subsubsection{Peacekeeping and Shifting Images of Canadian National Identity}

Research participants' references to Canada's peacekeeping tended to (1) align it with issues of human rights, (2) discuss it as part of Canada's international "image," and/or (3) draw on it to articulate what they saw as a present shift within Canadian institutional discourses and policies. Taken together, their references to Canadian 
peacekeeping as a presently shifting symbol of Canada's commitments to human rights suggest both that research participants conceptualized national identity (discourses) as flexible and that (at least in these instances) they used discourses defining Canada's "national character" as inherently liberal in order to criticize current government policies. Moreover, these comments (based particularly on Canada's military presence in Afghanistan and the present government's defence of Israel's now three-year-long military siege of Gaza) point to the importance of socio-political and historical context for people's interpretations of national(ist) discourses and policies.

Telling me about her early days in Canada, Wafaa said she was surprised by "how influenced the country is by the United States" in terms of its "values and ethics." Despite such influences, Wafaa seemed to feel that embodying a distinctly Canadian subjectivity entailed a "responsibility" of "looking out not only for [her] own rights, but also the rights of others" as well as "belonging to a peaceful environment." Indeed, she said, the image of peacefulness was something she valued about Canada, specifically in terms of its contribution to "the peace forces and the U.N. Peace Corps." As a result, Wafaa told me, she found it "shocking, of course, to see the image changing, to be part of a war in Afghanistan. All that we learned about Canada as a... catalyst for peace is changing." She thus constructed Canadian-ness as integrally linked to human rights, for which all Canadians were responsible, and to peacekeeping as an expected national commitment and responsibility of the state, which the government was failing to uphold.

Rana expressed similar concerns. She said that given that "respect for ... humanity in general" was an integral part of Canadian identity, she was frustrated to see politicians acting "in a way that [negates] this fact... because I feel that this is not respecting me as a 
Canadian." Her frustration, she said, was also because she did not "like the idea of people seeing Canada as a place where we do not respect humanity." In contrast, Rana felt "proud ... whenever something happens around the world and there is a protest [in Canada] or ... people ... saying that this is wrong." This emotional investment in how Canada is represented outside its national borders, she explained, made her "feel [she is] Canadian." When I asked Rana if there were "specific instances where politicians have responded in a way" that made her feel Canadians were not respected, she gave the example of Israel's December 2008-January 2009 military assault on Gaza: "at the UN, Canada said there are no crimes against humanity ... [when] it's obvious, you can see on the T.V. that phosphorous bombs are used, you can see them." Rana concluded that she used to love "before that Canada didn't take such positions." Rana thus suggested that disapproval of the present government's stance was authentically Canadian, conceptualizing the state's actions as contradicting the desires and values of the national body and shifting the meanings attributed to Canadian-ness. In doing so, like Wafaa, Rana used liberal nationalist discourses to launch her critique of the state by constituting its actions as unCanadian. Importantly, Rana takes up a subject position as Canadian by defining Canadian national identity in a way that is simultaneously a critique of the Canadian state's actions as unCanadian.

Lias also articulated a shift in discourses about Canada as a peacekeeping nation. He told me he wants "to be Canadian in a peacekeeping Canada" and does not "like the direction Canada is [headed] in right now." Further, he argued, although "being Canadian means being held in high regard internationally," he felt that "the actions of the current government [were] tarnishing that." More specifically, he suggested, "the current 
government is very pro U.S." Linking this pro-U.S. stance to the Iraq war, Lias concluded that he wanted "to revert to a more even-handed Canada, but expressed concern this might be difficult because "some people don't think beyond the simple slogans and headlines." For him, however, "the fact is Canada is migrating away from being a neutral country." Lias called peacekeeping and even-handedness images, but implied they were important because "the slogans and headlines" play a role in how people (including Canadians) perceive Canada's national character. He thus linked state and media discourses with national identity while using discourses defining Canada as "neutral" and "peace-keeping" to suggest the state's actions were imitating an American national character and, thus, evidently in need of amendment.

Like Lias, Eddie represented Canada's present government as enacting a (globally perceived) shift toward "Americanness." According to him, "the world opinion is that we're slowly becoming the lapdogs of our American neighbours." To support this claim, he argued that "our stance in the world has become ... less focused on human rights, less about peace-keeping and more about war mongering." This was something over which he expressed concern as "affecting the people" by "dividing them and forcing people to want to give up their identities a bit more... It's creating a sense of fear." Consequently, he concluded, "the people that are targeted in these international conflicts that have immigrated here quickly feel the sense that this isn't the Canada that they grew up with living outside it." When I asked Eddie if he felt this way, he responded assertively: "I think it's definitely shifting away from the Canada I once knew."

In this way, Eddie argued that a present discursive and institutional shift away from "peacekeeping" had implications for his own and other people's engagements with 
multiculturalism as a distinctly Canadian identity discourse. Recall from above that Eddie distinguished Canada's multiculturalism from "the American melting-pot ideology." Here, he seemed to suggest that moving from "peacekeeping" to "warmongering" was accompanied by a move from a multicultural milieu (wherein people could "hold on to [their] heritage") to one where people wanted to "give up their identities." He thus combined discourses defining Canada's "national character" according to its distinction from the U. S. and liberal commitments to peacekeeping and multiculturalism and used these as the basis to criticize the actions of the present government as un-Canadian.

All four research participants (Rana, Wafaa, Lias, and Eddie) represented Canada's image as a peacekeeper as more authentic than its current involvement in Afghanistan. Despite representing peacekeeping as authentically Canadian, however, they suggested that commitments to peacekeeping and human rights are changeable. In doing so, they implicitly called attention to the relationships between institutional discourses, Canadians' subjectivities, and (inter)national politics. At the same time, they identified with and drew on liberal national discourses, which some scholars suggest have been institutionalized in ways that limit the possibility of critiquing the Canadian nationstate by representing it as non-racist, precisely in order to frame their critiques of the state. The way they did so complicates scholarly depictions of liberal national discourses which, as I have discussed, tend to focus on their role in the institutional aim to produce racialized immigrant subjectivities which would limit the challenges immigrant Canadians might otherwise pose to the Canadian nation-state and therefore buttress settler mythologies. As I have argued throughout this dissertation and illustrated in this section, the same discourses which shaped research participants' national subjectivities 
also produced their senses of agency. In the case of discourses about Canada's commitments to liberal humanism as evidenced in its peacekeeping practices, these discourses become avenues (among other possible ones) for critiquing the Canadian state.

\subsection{Conclusion}

Research participants represented liberal national discourses of Canadian identity as avenues for the production of their senses of belonging and non-belonging. Their interpretations of these discourses highlighted the relationships between individualized and institutionalized processes through which racialized exclusions are enacted. Their discussions of racism and discrimination as individualized did not necessarily imply denial of the ways in which they are also institutionalized, however. More specifically, their interpretations of these discourses as expanding the boundaries of inclusion within the Canadian national body implied neither denial of the ways in which exclusions are enacted in their lives, nor straightforward acceptance of state-orchestrated nation-building projects, nor claims that national character was concrete and unchangeable.

As we saw above, for example, research participants who drew on multiculturalism to define Canadian national identity were often aware of their (negative) racialization and of Canada's racialized (and gendered and classed) hierarchies of belonging and citizenship. Nevertheless, multicultural discourses provided an officially recognized, legal avenue through which they could insist on their rights to define - and thus play a role in managing - Canada as a more inclusive national space.

Furthermore, research participants represented institutional discourses of, and commitments to, peacekeeping as presently endangered. Yet their concerns did not indicate that institutionalized governmental rationalities had produced a subjectivity that 
was subservient to these national discourses. Instead, they (re)presented peacekeeping discourses as avenues for governing state actions.

These critiques were also multiscalar insofar as they were shaped by their connections to Arab national spaces such as Iraq and the Occupied Territories. For example, Sam said he did not think Arab Canadians "feel that they truly belong within the larger context of the Canadian society" due in large part to "the political atmosphere," the wars in Iraq and Afghanistan, and the situation in Palestine/Israel. The result of this political atmosphere, he said, was that "especially the Arabic people from a Muslim background... sense that they are targeted. They are attacked in different ways, whether it's culturally or politically." Sam argued that there is a reciprocal relationship between these events, senses of (non)belonging, and "internalized racism ... where we have heard it so much that we have come to believe that we're inferior to others" which "stems from the [European] colonization era" in the Arab world. Ultimately, he said, "the feeling of belonging seems to be influenced by the events that happen on the world stage." In other words, Sam drew transnational and historical links to offer a (temporally and spatially) multiscalar explanation of how he thought Arab Canadians' senses of national identity are (re)produced in Canada. In the next chapter, I take up research participants' interpretations of what it means to be Arab in a Canadian context, focusing specifically on their engagements with multiscalar and multidimensional discourses and political events shaping their senses of national identity. 


\section{Chapter: Mediating Arab (Pan)National Identity}

So far in this dissertation, I have argued that research participants' engagements with Canadian national identity discourses reflect multi-scalar and multi-dimensional processes which shape their subjectivities and, ipso facto, the conditions of possibility for their agency. To support this argument, I have illustrated that research participants' subjectivities and agency are shaped by their encounters with globally circulating discourses, those they encountered in various national spaces, and the intersections between these and other discourses they encountered in multiple dimensions of their lives. All of these encounters are important, I have shown, for how research participants interpret and embody their senses of Canadian national identity.

I have further argued that a multidimensional and multi-scalar analysis of these engagements illustrates that institutionalized discourses do not always shape people's subjectivities in simple, predictable ways. Indeed, to understand how institutionalized discourses of Canadian national identity shape immigrant nationals' subjectivities requires that we consider the relationships between their previous life experiences and their interpretations of these discourse. To elide those experiences in any analysis of immigrant national subjects' lives, even if unintentionally, frames their encounters with the institutionalized discourses of the Canadian nation-state as the most salient dimensions of their life experiences. Thus, broad discourse analyses might give us one reading of the governmental rationalities pervading dominant, institutionalized attempts to shape specific national subjectivities - such as those of people coded as "immigrants" - but they do not and cannot tell us if and how these rationalities play out in practice. To 
be able to speak to the experiential effects of these discourses in people's lives and on their senses of self requires the kind analysis I have offered thus far.

In each of the previous analysis chapters, I tended to focus more directly on one of the three elements of my argument at a time: the multi-scalar politics involved in encounters with or interpretations of national identity discourses, the multidimensionality of such discourses, or the place of these discourses in the co-constitution of subjectivity and agency. I felt that it was necessary to do so in order to clarify how each of these elements of my arguments shapes the analysis I offer. Having done so, I bring these elements together in this chapter.

Here, I want to highlight the inseparability between (1) the idea that identity discourses are multi-scalar and multidimensional and (2) my methodological argument that analyzing them as such gives us a window into understanding the complex coconstitution of subjectivity and agency. To do so, I examine how multiple discourses used to define Arab (pan)national identity intersect with one another in research participants' interpretations and enactments of the idea of "community." Based on fieldwork, I consider two sets of historically produced discourses used in self- and colonial-definitions of Arab identities which respectively emphasize (1) shared historical and linguistic knowledge and (2) Eurocentric notions of civilizational progress. Research participants drew on such globally circulated discourses in interpreting and enacting their ideas of identity and community. They did so in ways that show how these ideas emerged at the intersections between such global discourses and (3) the institutionalized liberal discourses of Canadian national identity I have referred to throughout this dissertation. 
Analyzed at a Canadian national scale, these institutionalized liberal discourses are central to what Thobani (2007) calls "the communalizing power of the state" (149). Specifically, Thobani conceptualizes multicultural discourses as key to the Canadian nation-state's power to "[constitute] communities as discrete racial, ethnic, and cultural groups existing within its territorial borders, yet outside the symbolic bounds of the nation" (149). She argues, and rightly I think, that processes "that seeks to homogenize ["cultural communities"] as natural social groupings" elide how they are changed "by the process of migration and dislocation" (149) and work to exclude them from institutionalized definitions of an ostensibly unmarked, and thus authentic, Canadian national identity. She defines the state's communalizing power as a governing modality that works in two ways. First, it continuously requires immigrant national subjects to perform fetishized cultural differences that definitively mark their communities as both homogeneous and distinctly "immigrant." Second, and as discussed in the previous chapter, it makes them subservient to "the nation" insofar as "real" nationals can point to this supposedly inherent cultural difference to (re)code "immigrants"" attempts to shape national identity or policy as a form of interference or evidence of their "lack" of understanding Canada's liberal national character. Thus, Thobani concludes, those coded as "immigrants" can only ever achieve a precarious and partial admittance into institutionalized conceptions of a liberal Canadian national body.

Thobani's argument about the institutionalized requirement of immigrant national subjects' subservience to "the nation" and the denial of their right to manage national space and/or identity is in keeping with analyses of how discursive definitions of terrorism are used as disciplinary mechanisms of national (Arat-Koç 2005) and global 
(Mamdani 2002, 2004) governance. For example, Arat-Koç (2005) argues that the precarious admittance of racialized immigrants into the Canadian national body is particularly clear in attempts, following $9 / 11$, to discipline immigrant national subjects into publically supporting (or else remaining silent about) state policies through discursive distinctions between "good" and "bad" immigrants. Similarly, Mamdani $(2002,2004)$ argues that there emerged a global discourse which defines as "good" Muslims those who remain silent about or accept and reproduce a supposedly singular, liberal, "Western" worldview according to which Muslims who criticise international policies or suggest any rationale for their rejection are "bad." For Thobani (2007), AratKoç (2005), and Mamdani $(2002,2004)$, it is clear that national and global power relations are central to the hegemonic institutionalization of disciplinary discourses and modalities of governance which aim to shape the subjectivities, and thus actions, of specific people - i.e. negatively racialized, non-Western Others - and produce homogeneously defined communities. These scholars do not investigate what occurs when people encounter such discourses at an experiential scale, nor is that their project.

It is my project, however, so I will say a few words about it by way of introducing the argument I make in this chapter. Since, at discussed in Chapter Five, governed people can "act and $[\ldots]$ think in a variety of ways $[. .$.$] not foreseen by authorities" (Dean$ 1999:12), the production of homogeneous, "immigrant" communities whose members will self-govern in accordance with the above-discussed discourses about "good" immigrants cannot be guaranteed. For example, in the above-discussed article, Arat-Koç (2005) shows how media pundits and politicians used such discourses in attempts to discipline the behaviour of Sunera Thobani by marking her as an "ungrateful," and thus 
bad, immigrant for daring publically to critique the colonial policies of "the West." As evident by Thobani's (2007) publication of Exalted Subjects six years after this media campaign to silence her, she has not stopped engaging in such critiques out of a desire to be considered a "good" immigrant national-subject and, thus, a precarious part of the Canadian national body. As I showed in the last chapter, the case was similar with research participants even if, unlike Thobani, they accepted parts of, and framed their critiques through, liberal discourses.

As I have continuously argued throughout this dissertation, research participants' immigration experiences and their encounters with discourses produced in other parts of the world than Canada clearly shaped their subjectivities and agency. My argument in this chapter is that the desires and commitments that emerged out of their encounters with discourses of Arab identity produced in "the Arab world" (re)shaped their subjectivities and agency, were simultaneously (re)shaped by their experiences in Canada, and played a role in how they interpreted and engaged discourses about Arabs that they encountered in Canada. Nowhere were these mutually reconstituting impacts of these discourses and their life experience more clear to me than in research participants' interpretations and enactments of community, which were more than products of the "communalizing power" of the Canadian state. Indeed, the multidimensional and multi-scalar analysis I offer below highlights some of the limits of that power and shows that most research participants considered themselves members of multiple, simultaneously existing communities in Ottawa, which were driven by senses of shared knowledge of specific histories and multi-scalar yearnings for and commitments to socio-political justice. Jenny Burman (2010) describes yearning as a form of "desire for change" (10) in the face of 
asymmetrical power relations which "is able to connect past and present to future" (12). While her interests are "in the point at which past- and future-oriented desires are transformed into spatial practices" (13), my interest here is how such desires, which I understand to be multi-scalar, shape research participants' conceptualizations and enactments of community.

For example, Wafaa told me that since moving to Ottawa she has come to consider members of Ottawa's Arab Canadian community "like a family." She enjoyed living in the city because it gave her a chance to share her appreciation for Arabic poetry, music, and literature, as avenues for maintaining "a very rich heritage." Although she said "it would be a shame for anybody to lose the language... [which is] about identity, hawiyyah, I guess, in Arabic," she did not speak of identity as fixed:

If we are in a gala for the Arab community, obviously, you will find the flavour being Arab, the music being Arab, and so on. But if you are thinking of the serious stuff, like ... if... there is a war between Gaza and Israel, I would feel Arab. I think it depends very much on the event or what's happening or the issue actually... As a Canadian, let's say, for example, there is an issue about human rights which affects Jews and Arabs as minority Canadians, I will align with [Jewish Canadians] to defend that issue.

Thus, Wafaa suggested that she experienced her sense of identity as contextually dependent on and related to specific social settings and issues of social justice. She also seemed to be employing liberal humanist discourses to respond to prevalent multi-scalar discourses used to define Arabs as anti-Semitic: she would align with Jewish Canadians to fight for the legal rights of "minority" Canadians.

The links Wafaa drew between concerns about social justice and identity-based coalitions also factored into her ideas about "community." Retired from paid labour, she volunteered with many organizations which focused on issues of social justice and 
defined themselves by their members' shared identifications as Arab or Arab Canadian, as residents of Ottawa, or as concerned global citizens. She described her volunteer work as an avenue for "building bridges as an expatriate first generation immigrant" who felt that "fitting in" should not require becoming "assimilated." To counteract notions about the necessity of assimilation, Wafaa asserted, she worked to produce a space for her Arab "heritage" in Canada through public education and community involvement. She thus framed the importance of community through the language of liberal discourses (in this case multiculturalism) to challenge assimilationist ideas. Similarly, she argued that Arab Canadians in Ottawa need to "unite" as a community to challenge the "skewed picture" and "unfair portrayals" of Arabs and Arab Canadians that emerge in Canadian national media. These unfair portrayals included the misconception that "all Arabs are Muslims and all Muslims are Arabs" and representations of Arabs as people who "look at everything in terms of honour and humiliation" which are evident in discussions of the Israeli-Palestinian conflict which fail to mention of "the land that was taken away." In this context, she suggested that too many Arab Canadian organizations in Ottawa work separately toward the same goal which "just scatters the energy and doesn't make it target the right thing at the right time." Despite this "scattering" of energy, Wafaa said, she saw evidence that Arab Canadians in Ottawa were "emotionally... very united" when she attended demonstrations at Parliament Hill - e.g. when the Canadian government did not immediately set out to return Lebanese Canadians from Lebanon during the 2006 war between Hezbollah and Israel. At some demonstrations, she said, she would get to parliament and "see 3000 people." She interpreted this "emotional unity" to 
mean Arab Canadians in Ottawa share a desire to challenge unfair portrayals of themselves and issues they consider important which pervade Canadian media.

Thus, while Wafaa discussed the importance of being part of an Arab Canadian community in Ottawa in terms of a shared "heritage" which related to language, for instance, she also framed community-building (ethnically based or not) as a necessary strategy for dealing with what she called "the important stuff" of social justice issues. Her argument that Arab Canadians in Ottawa need to overcome divisions in their community was something I heard in various guises time and again during formal interviews and informal conversations at community events I attended. In almost all cases, research participants framed "unity" as a requirement for challenging unfair media portrayals of Arabs, Arab Canadians, and issues they consider important - particularly the IsraeliPalestinian conflict. They also argued that undertaking such a challenge was important not only locally, for Arab Canadians living in Ottawa, but nationally and globally.

Following from this, and as mentioned above, in this chapter I argue that, like their interpretations of Canadian national identity, understanding research participants' interpretations and enactments of Arab national identity and Arab Canadian "community" requires a multidimensional and multi-scalar analysis which takes into account their past and present encounters with discourses defining Arab and Canadian national identities. I begin to make this argument in the next section of this chapter by demonstrating that research participants' expressed yearning for "unity" is best understood through a multiscalar and multi-dimensional analytic lens that takes into account (1) the history of European colonization in the Middle East and/or (2) the globally dispersed effects of the coloniality of contemporary representations of Arabs and Arab Canadians. Because most 
research participants depicted "unity" as a necessity for counteracting "unfair" media depictions of Arabs, in the following section I turn to their engagements with two interrelated discourses they suggested pervade Canadian national media: depictions of Arabs as terrorists and unfair representations of "the Arab-Israeli conflict." I go on to illustrate the enactments of multi-scalar and multidimensional conceptions of community at an event I attended to illustrate the nuanced connections between subjectivity and agency. I conclude the chapter by reflecting on the meaning of agency.

\subsection{Identity, Community and Anti-Colonial Politics}

In explaining what being Arab meant to them, most research participants spoke of the importance of knowing their "roots," which they defined in relation to two discourses of Arab identity discussed in Chapter Three according to which a shared Arab identity is based in knowledge of Arab history and/or the Arabic language. At a strictly Canadian national and presentist scale, this tendency resonates with liberal discourses of multiculturalism and seems to illustrate "the communalizing power of the state," particularly since they tended to draw on these two ways of conceptualizing Arab identity to argue for the necessity of overcoming "divisions" within the Arab Canadian community in Ottawa. Yet, as I show below, they simultaneously framed these divisions as products of a history of European colonization of the Arab world and/or barriers to building coalitions to counteract multi-dimensional and multi-scalar processes of marginalization. Thus, their desires for a unified Arab Canadian community are best understood through a multiscalar and multidimensional analytic lens. 


\subsubsection{Identity, Community, and Multi-scalar Desires}

Eddie's definition of Arab (pan)national identity highlighted the centrality research participants gave to history in their definitions of Arab identity during informal conversations and formal interviews. He told me "being Arab means understanding a long-standing historical tradition," "knowing where you came from, and the history that comes with that." For Eddie, as for most research participants, Arab national identity was routed in shared knowledge of history and cultural traditions or "heritage."

Yet, as with most other research participants, Eddie also suggested that such knowledge was important for the collective process of counteracting derogatory discursive definitions of Arabs in North American media: "if you believe anything that the media tells you, [Arabs] are a backwards culture, a backwards civilization that has yet to modernize." In contrast to such discourses, he argued, "anyone that knows Arab history knows that the Dark Ages in Europe were the Age of Enlightenment in the Arab world." Ultimately, Eddie said, being Arab was about "having a sense of entitlement to connecting with" this history. For him, Arab identity was about a shared knowledge of (and pride in) Arab history and contributions to bodies of (modern) philosophical, mathematical, and scientific knowledge which are often denied within racializing discourses according to which Arabs are "a backward culture."

Like Eddie, most community members spoke to me about the importance of this history of Arabs' contributions to globally valued bodies of knowledge, framing these as contributions to "civilization." In doing so, they drew on global discourses European administrators often used to re-signify colonial and imperial domination as benevolent civilizing missions which, as discussed in Chapter Two, would allow non-Europeans to 
"progress" toward European-style civilization. Research participants did not, however, use the concept of civilization in its Eurocentric, colonialist meaning. Instead, they challenged such Eurocentric conceptions by insisting that bodies of knowledge often depicted as evidence of Europe's "advanced" civilization relied and were built on the contributions of non-European peoples (such as Arabs). Thus, while they interpreted the meaning of Arab identity through the concept of "heritage" - which, in Canada, is associated with a national policy of multiculturalism - they also employed the terminology of globally-spatialized colonial discourses that have been used to deny the value of non-European knowledges. Their doing so suggests that such civilizational discourses are prevalent enough to have shaped research participants' subjectivities and, in so doing, enabled their (in this case resistant) agency. At an experiential scale of dayto-day interaction, this is to say, their familiarity with the civilizational discourses colonial administrators once used to justify imperialist ventures meant they were able to use the concept of civilization precisely to open up a space where Arab history might be (re)valued by challenging the Eurocentric content of such discourses.

Histories of European colonization were also central to research participants' depictions of the main problem plaguing Ottawa's Arab Canadian community: division or lack of unity. Again, Eddie's words are representative of the most common way research participants discussed this lack of unity: "there is an Arab community [in Ottawa], but it's still too fractured to be referred to as a unified community." Starting with the caveat that he was "generalizing," Eddie explained that he thinks "due to [European] colonization, we divided ourselves [in the Arab world] along those same lines that we were told to divide ourselves along." Many Arab Canadians in Ottawa, he said, 
continued to "divide themselves" in accordance with colonially produced national distinctions. In contrast, he did not claim to be "intrinsically Lebanese in any way" but identified as "an Arab, always, first" because he considered "the [national] divisions [between Arabs] ... foolish" reflections of colonial imperatives.

Nousayba and Monzer also rejected conceptions of intrinsic difference among the inhabitants of Arab nation-states and Palestinians. Nousayba did not associate her sense of Arab identity with a specific Arab nationality: "Being Arab is important," she said, "but what difference does it make ... what country you are from? I find those divisions a problem." Similarly, Monzer told me he used "Arab Canadian and Palestinian Canadian interchangeably" because "they are the same to [him]." Monzer explained this sense of the sameness of Palestinian and Arab identity by telling me he came "from a very committed background of the two being one and the same."

The "committed background" Monzer invoked referred to anti-colonial Arab (pan)national identity discourses which were ascendant throughout Arab nation-states in the 1950s and 60s. As discussed in Chapter Three, (pan)Arab nationalism has many articulations, not all of which share a commitment to building a singular Arab nationstate (Khalidi 1991). Variations on (pan)Arab nationalism do, however, share in common the anti-colonial and anti-imperial political discourse - on which Eddie, Monzer, and many research participants drew - according to which colonial power relations and administrative policies produced divisions between Arabs which continue to serve imperialist interests (Niva 1999).

For example, Gamal Abdel Nasser - who was the president of Egypt from 19561970 and whom many depict as the champion of (pan)Arab nationalism - represented 
acceptance of national and sectarian divisions among Arabs as products of "the forces of imperialism['s]... active attempts to alienate the hearts of the Arabs and to divide them artificially into countries, states, clans and parties, and to sow the seeds of discord and hatred among them" (Abdel Nasser, quoted in Niva 1999:161). In opposition to such "artificial" divisions, he argued, "Arab nationalism is union, unity, solidarity, which should be erected on the rights, the interests of the Arabs, and not on those of imperialism and its spheres of influence" (Abdel Nasser, quoted in Niva 1999: 164). Monzer's commitments to Arab unity and his interpretations of divisions among Arabs in the Arab world as problematic thus suggested the continued importance for him of (anti-colonial) ideals which shaped his sense of (pan)national Arab identity prior to immigrating to Canada - the same ideals with which Wafaa and her husband, like many other Arabs, became disenchanted during the 1967 War.

Importantly, research participants did not frame overcoming divisions in terms of the necessity of having a singular, homogeneous community which could receive state (financial) support to maintain Arab "heritage" - even if, as mentioned in Chapter Four, some did think it was important to get funding for social support services to be offered in Arabic. Sam, for example, said he considered "our communities [to be] lacking cohesion." While this made his desire to build a stronger Arab Canadian community in Ottawa "a source of struggle," he still thought it was essential to "force the change of how other people see" Arabs and Arab Canadians as well as to influence national and international policies that have negative impacts on Arabs in Canada and in the Arab world. For him, "the division that exists in our community" reflects those based in religious affiliations and national distinctions existing in the Arab world which he 
associated with the era of European colonization. His comments suggested that his yearning to foster greater unity among Arab Canadians in Ottawa, like that of other research participants, emerged as he reflected on the history of European colonization in the Arab world and considered the necessity of counteracting globalized discourses about Arabs - especially, as I illustrate later in this chapter, those defining Arabs as "backwards," violent, and anti-Semitic terrorists.

Other people with whom I spoke at community events also iterated such sentiments about the coloniality of nationally-based distinctions between Arabs and framed these divisions as a major problem within Ottawa's Arab Canadian community. While Eddie was an exception to this trend, the age at which research participants immigrated to Canada was an important dimension of the tendency to do so with those who immigrated as adults being more likely to frame divisions between Arab Canadians in Ottawa as reflecting colonially imposed distinctions than those who immigrated as children. This trend further highlights the importance of a multi-scalar and multidimensional analysis of research participants' depictions of Ottawa's Arab Canadian community. More specifically, I interpret this difference as signalling the more prominent role anti-colonial Arab identity discourses had in shaping the subjectivities of those research participants who immigrated as adults and, thus, had likely learned the history of European colonization as part of their education in Arab countries.

My point here is that a nationally-scaled analytic lens, which might inadvertently make research participants' current residence in Canada the most important dimension of their desires to form a unified Arab Canadian community, would be inadequate in explaining these desires. To theorize such yearning at a strictly national scale, as 
evidence of the Canadian nation-state's "communalizing power" (Thobani 2007), for example, would miss their connections to anti-colonial politics and thereby occlude the critique of colonial global power relations and multi-scalar politics involved in their (re)production in Ottawa. Taking these multi-scalar politics into account, such yearnings emerge as products of encounters with an anti-colonial Arab identity discourse which was produced in the Middle East in response to European imperialism in the region and which continues to shape the subjectivities of research participants.

The importance of a multi-scalar analysis of research participants' complaints about divisions within Ottawa's Arab Canadian community was also evident in cases where they did not refer to anti-colonial politics or (pan)Arab nationalism. For instance, Lias's desires for a more unified Arab Canadian community in Ottawa emerged out of a multi-scalar comparison: it emerged out of a globally spatialized comparison between his personal experiences within the national spaces of Lebanon and Canada. At an experiential scale of his day-to-day encounters as a Christian Lebanese Arab Canadian, Lias said he perceived more "rigid boundaries" in the Arab Canadian community in Ottawa than in Lebanon, where he had friends from various religious groups and Arab nationalities. In contrast, he said, he did not "run into Muslims at a lot of the cultural events" because national and religious divisions shaped who interacted with whom in Ottawa "more than in Lebanon, and that's unfortunate," he concluded, "but it's the truth." Thus, although Lias did not base his critique of such divisions in anti-colonial politics, his desires for greater interaction among Arab Canadians across national and religious differences were nevertheless formed through a globalized comparison between his experiences in Ottawa and Lebanon. As I illustrate in the next sub-section, a multi- 
dimensional and multi-scalar analysis is also necessary for understanding research participants' more localized foci on the implications of definitions of community.

\subsubsection{Language, Multidimensionality, and Community}

A few research participants focused on the local implications of divisions within Ottawa's Arab Canadian community, saying such divisions marginalize people who do not embody specific discourses of Arab identity. This was especially the case with discourses defining Arab identity in terms of (the ability to speak) a shared language. As discussed in Chapter Three, such discourses have a long history, but are also complicated by variations in national vernaculars of Arabic which may differ significantly.

Monzer, Wafaa, and Sam, who immigrated to Canada as adults, spoke of the Arabic language as an important and emotionally laden medium for their experiences of Arab identity. The three of them did not use this discourse to discipline the behaviour of others through notions of authenticity - and, at some events I heard them reject other people's exclusionary use of this discourse. On the other hand, I did meet several people during the course of fieldwork who considered the Arabic language as the defining characteristic of Arabs, often because they felt that language necessarily shapes culture.

The importance of the Arabic language came up at three of the meetings I attended with the two community-building associations in Ottawa. Usually, a person who was attending such a meeting for the first time would start a conversation about the relationships between identity, community, and the Arabic language by asking some version of the following question: "What makes this a meeting of an Arab association if we do not speak Arabic?" Those who regularly attended these meetings knew that a few of us (generally the youngest attendees) were either born in Canada or immigrated as 
children and either spoke no Arabic or spoke it only colloquially and to a limited degree, which meant we would understand neither professional terminology nor national dialects with which we were unfamiliar. When someone posed this question, other attendees who wanted to ensure we would continue to feel welcome to take part in meetings they understood as imperative for building and maintaining "community" - would respond in ways that defended our abilities to claim an Arab identity. Whether they agreed or disagreed with the idea that the Arabic language was a defining feature of Arab identity within Arab nation-states, they argued that language could not be applied as a measure of identity in Canada where many Arab Canadian youth did not speak the language but were no less Arab for it. In doing so, they supported their conclusion about the proceedings at these local events by drawing a globally spatialized comparison to highlight the differences in the meanings of Arab identity in "the Arab world" and in Canada.

These conversations reminded me of my interview with Dina who interpreted discourses defining Arab identity in terms of the Arabic language as ones people often used to enact a localized, exclusionary politics. Although Dina told me she felt privileged to be able to speak, read, and write Arabic, she also said,

When your children are born and then everybody is like 'Oh. They don't talk Arabic? You don't send them to Arabic school?' Well, I tried, and they hated it and I shouldn't force them... Why am I imposing it on them? If they want to learn it, that's one thing, and maybe it's because of my experience and my childhood and being a dork who studied all the time, and so many high expectations, [but] I refuse to do that to my children.

For Dina, to insist that her children learn the Arabic language would be to attempt to discipline them through other people's definitions of identity. She interpreted (some) people's criticisms of her children's not speaking Arabic to mean "if you don't fit the mould they have for you, then you're [defined as] bad." Thus, Dina suggested that some 
members of the community used language as a disciplinary form of moral regulation which produced exclusionary hierarchies of authenticity among Arab Canadians.

Perhaps as an extension of the above critique of defining Arab identity through language, Dina represented divisions within the Arab Canadian community as products of exclusionary ideas about authenticity. She argued that Arabs are "very discriminatory against each other" due to "some cultural belief that one Arab has a higher class than another." As our conversation went on, I asked her if she thought it was possible to speak of an Arab community in Ottawa. "Numerically, yeah... definitely," she said. "Whether they're all united? No. No. Oh, no," she continued, "Since I've been here - twenty-two years - I have never seen Arab communities working together for something that's greater than their own sectarian identity... We still have to see this in the Arab community." Dina considered it essential to recognize and overcome such sectarian divisions in order to counteract their marginalizing effects on her children and other young Arab Canadians in Ottawa.

Interestingly, the only exceptions to the conceptualization of divisions within Ottawa's Arab Canadian community either as prevalent or as problematic came from Aladdin and Omaima respectively. In both cases, understanding their representations of Ottawa's Arab Canadian community requires a multidimensional, localized scale of analysis that takes into account their interpretations of their day-to-day experiences in Ottawa. I discuss each of their experiences in turn in the remainder of this section. Aladdin told me he identified as Arab Canadian but felt marginal to what he considered a coherent community which he tried to join "too late" in his life because he grew up "in a white part of town" and therefore thought of himself as "white" while other 
Arab Canadians his age "had known each other since they were kids" and did not consider it "silly to be Arab." Recall from Chapter Seven that shortly before entering university, Aladdin began to feel less accepted by non Arab Canadians and to interrogate the limits of liberal discourses which valued Canadians' "tolerance" for difference: his experience of feeling only "tolerated" as a (Muslim) Arab Canadian led him to question his perception of his subject position as an accepted "white" Canadian and temporally coincided with his siblings introducing him to their Arab Canadian friends. Aladdin's desire for a sense of belonging, his feelings of non-belonging to a Canadian national body, and his experience of meeting new Arab Canadian friends thus intersected in ways that reshaped his subjectivity and produced a new desire to learn more about Arab identity and history. Having grown up thinking of himself as "white," however, Aladdin felt marginal within the new friendship circles to which he was introduced whose members seemed to him to have grown up together thinking of themselves as Arab Canadian. All these dimensions of Aladdin's localized experiences produced his sense that a coherent Arab Canadian community pre-existed his introduction to it.

Omaima, on the other hand, did not conceptualize the Arab Canadian community in Ottawa as coherent and unified, but neither did she consider divisions to be a cause for concern. Instead, she represented divisions within the community as reflecting the multidimensionality of Arab Canadians' senses of identity which meant not everyone who identified as Arab Canadian would necessarily give primacy to the Arab dimension of her/his identity. "People wanna put you into one box," she said, but there are many "distinct nations who are completely independent of each other, who speak and have different cultures ... So, although it sounds like one group, it's not. Not to mention ... 
[they are] divided into different faiths." Omaima added while "some people ... kick and scream, 'Oh, we're so ununited. Oh, we'll never get anything done,"' she felt community members would eventually learn to work toward the common purpose of challenging institutionalized derogatory discourses about Arabs and Arab Canadians in Canada.

Omaima framed her conceptualization of fissures between Arab Canadians as unproblematic in two ways. First, she said although "the first Arab Canadians" may have arrived in Canada "over a hundred years ago," "as a community," they were really young. She rationalized her conceptualization of the community as "young" in a way that was in keeping with scholarly representations of Arab immigration to North America as having involved two phases: a pre-World War Two migration which was sporadic and a second more concentrated migration which followed the Second World War in the context of the liberalization of Canadian immigration policies (Aboud 2000; Abu-Laban 1980). She did not arrive at this conclusion based on these scholarly depictions, however, but through reflecting on her own experience of immigrating to Canada in the mid-1960s.

Omaima explained that she arrived in Canada with her parents at a time when there was not a large Arab Canadian population. In this context, her parents "didn't really stress the Arab thing, not even the Egyptian thing," she said, because there was a small Arab Canadian population and because their focus was on being "Muslim Canadians or Canadian Muslims first." For Omaima's parents, the local context into which they immigrated facilitated building friendships around a shared religious identification as Muslims with people from "a variety" of ethno-national backgrounds rather than as Arabs. In keeping with this, she interpreted her identification as a "Muslim Canadian first" as reflecting another important dimension of her sense of identity as well as the 
time at which she and her parents immigrated to Canada, but not as dividing an Arab Canadian community of which she certainly considered herself a part. Thus, the second element framing Omaima's conceptualization of "divisions" within Ottawa's Arab Canadian community as presenting no cause for concern was her sense that they represented the multidimensionality of Arab Canadian's senses of identity. Like other research participants, however, Omaima thought Arab Canadians in Ottawa needed to work across national and religious differences to be better able to challenge racialized stereotypes of Arabs which pervade mainstream Canadian national media.

As I have shown in this section, those research participants who expressed concern over divisions within Ottawa's Arab Canadian community tended to articulate these in ways that underscore the importance of a multi-scalar analysis of their ideas about community. In such cases, they drew on discourses of Arab identity that have long histories in the Arab world to suggest that divisions among Arab Canadians problematically reinforce colonially imposed national distinctions or locally enact exclusionary politics of authenticity. Thus, their concerns do not simply reflect desires for or beliefs in essentialist notions of cultural identity that emerged out of their experiences within Canada and cannot be understood through an analysis of institutionalized Canadian national discourses. Regardless of how research participants depicted Ottawa's Arab Canadian community, almost every person with whom I spoke during fieldwork expressed a desire for Arab Canadians in the city to form cross-national and crosssectarian coalitions. As I illustrate in the next section of this chapter, research participants framed their yearning for unity among Arab Canadians in terms of the necessity of 
forming coalitions to respond to negative representations of Arabs and Arab Canadians as dangerous and anti-Semitic terrorists which pervade Canadian national media.

\subsection{Multi-scalar Disciplinary Discourses and the Politics of Community}

As I discussed in Chapter Three, within a North American context, those who identify or are identified as Arab must contend with colonialist, racializing discourses which presently articulate with those about national security and the cultural incompatibility of Middle Eastern and North American identities. Such discourses, I suggested, are multiscalar and multidimensional insofar as they are shaped by colonial and imperial power relations and used to justify policies within Canada and the United States as well as those in other parts of the world, including the valorization of the state of Israel as "part of a rampart for Europe against Asia... an outpost of civilization as opposed to barbarism" (Theodor Herzl, quoted in Gregory 2004: 79). In keeping with such discourses, I argued, Arab Canadians continue to be demonized in corporate North American media representations as "monolithic 'outsiders'... whose beliefs and customs are characterized as inferior, barbaric, ... and irrational" (Haddad 2004:15; see also Gana 2009; Shaheen 1980, 1984, 2001, 2003, 2007; Suleiman 1999). As I show in this section, research participants' encounters with such discourses played a central role in their articulations of their yearning for greater unity among Arab Canadians in Ottawa as a first step to counteracting negative and stereotypical portrayals of Arabs which pervade Canadian national media outlets. They also framed the potential impacts of counteracting these portrayals as extending beyond Canada.

Every single research participant I spoke with about Canadian national media gave some variation of Lias's assertion that "the media is very biased and unfair to us" or 
Nousayba's contention that Arabs are "always represented as terrorists... [and] never ... in a fair or positive way." Dina elaborated on this point, telling me she thought "there's a menace attached to being Arab and it's because of a global situation" (emphasis added). She would not deny some Arabs had committed atrocities, she added, but most media pundits "like to select" and use the negative images as representative of all Arabs. Consequently, she said, Arabs are homogenized in popular cultural representations in North America such that "regardless of whether Arabs are Druze, Jewish, Christian, atheists, whatever," the term "Arab has become equal to any kind of swear word." Dina summarized her depiction of media representations of Arabs by telling me that although she thought there were limitations to Edward Said's notion of Orientalism, "definitely, there are Orientalists within this nation." In the end, she added, there is a negative, stereotypical, "synchronized representation" of Arabs in Canada that is best understood as globally produced and circulated. In other words, Dina suggested that negatively racializing discourses used to represent Arabs as a threatening "menace" pervade Canadian national media but could not be understood at a national or presentist scale of analysis: they are global in scope and they have long histories.

While research participants said such "negative images" of Arabs were globally circulated, many also spoke of encountering them at the local site of Ottawa's daily newspaper, The Ottowa Citizen. Referring to this paper's coverage of the September $11^{\text {th }}$ attacks in the United States and the 2006 war in Lebanon between Hezbollah and Israel, they cited it as a particularly virulent localized example of broader tendencies in corporate Canadian (and American) media. Indeed, Sam called "reading The Ottawa Citizen ... a traumatizing experience." I therefore want to give readers a sense of the 
newspaper's coverage of these two incidents before returning to how research participants spoke of the discourses reproduced therein.

In the first few months following September $11^{\text {th }}, 2001$, The Ottawa Citizen consistently published articles wherein journalists drew on discourses defining Arabs as particularly anti-Semitic and illiberal (Nirenstein 2001; Warren 2001a, 2001b, 2001c). Articles often (1) included claims that "tolerance" of Arab and Muslim Canadians simply enabled them to remain illiberal under the guise of multiculturalism and (2) inaccurately claimed that Arab and Muslim Canadians had yet to condemn the attacks (Jonas 2001; Warren 2001a, 2001b). In a particularly flagrant use of colonialist language, the paper's long-time Opinion columnist, David Warren (2001c), proposed what he called a "civ to civ" mission (as if it were a completely novel idea) in response to the attacks of 9/11:

We are coming to terms... with a level of anti-Semitism in the politically nurtured [Arab] popular culture that is no less than what we faced in Nazi Germany; and with an anti-Americanism that is only slightly less virulent... I would propose a huge, 'civ to civ' propaganda effort, one that frankly started, 'Hi, this is the Christian-Crusader-Zionist West and we have some things to say to you.' ... We would tell them about the stinking corruption of their governments, the backwardness and dysfunction of their societies, and the mental imbalance of their religious leaders, with interludes of intensely danceable Arab pop music. Then contrast western values: Individualism. Liberty. Human rights. The rule of law. Equality before the law. Democracy. Constitutionalism. Free markets. The separation of mosque and state. And... Bacon sandwiches. Short skirts. (emphasis added)

Above, Warren not only conflates Muslims and Arabs (proposing, even if facetiously, that bacon sandwiches might "civilize" Arabs), he also draws clear lines demarcating a supposedly more evolved liberal, humanist, and democratic West from an ostensibly illiberal, anti-Semitic, patriarchal, and Muslim Arab world which, from this perspective, geographically includes but ideologically excludes Israel as a liberal Western state that happens to be located in (and thus threatened by) the region. 
The same journalist also criticized then-Prime Minister, Jean Chretien, for telling "Canadians at large to be more tolerant" (2001a) and then-British Prime Minister, Tony Blair, for being "the first Western head of government to shake Yasser Arafat's hand since the carnage of Sept. 11" (2001b). In doing so, he aligned the Palestinian-Israeli conflict with "The War on Terror." He also argued such instances illustrate "the gullibility" of what he called "the essential liberal worldview" (2001b) - the same worldview he, ironically, suggested using to "civilize" Arabs.

In the case of the evacuation of (Lebanese) Canadians who were in Lebanon during the summer of 2006, there seemed to be a concerted questioning of Lebanese Arab Canadians' senses of Canadian national identity in letters and articles published in the paper and in the discourses of Canadian politicians who constructed their citizenship as a matter of "convenience" (e.g. Andrew 2006; Lewis 2006; Lohnes 2006; "No Place Like Home" 2006; Tortola 2006; Turner 2006). Letters and articles about the evacuation continually made three claims: (1) Canada needed to re-examine its policy of allowing dual citizenship; (2) the people being evacuated were taking advantage of Canadian taxpayers and the generosity of the Canadian state while thinking of themselves as Lebanese rather than Canadian (Lewis 2006); and (3) those trapped in Lebanon were responsible for their own situation for traveling to a politically volatile part of the world. The unnamed writer of one item even suggested some of those s/he called "Canadians of convenience" had been living in Lebanon for years and "maybe even voted for Hezbollah in the last election" ("No Place Like Home" 2006). S/he thus moved beyond the simple suggestion that they were not "really" Canadian to the claim that they were responsible for the war. S/he did so by suggesting they had likely supported Hezbollah whose 
kidnapping of two Israeli soldiers Canadian Prime Minister Stephen Harper continually represented as the cause of a war wherein Israel was defending itself (Blanchfield 2006; Proudfoot 2006; Zabjek 2006).

Several of the discourses I discussed in Chapter Three run through these brief examples of some of The Ottawa Citizen's coverage of two incidents that often came up in my discussions with research participants. In these discourses, (1) Arabs (and/as Muslims) are fundamentally anti-Semitic, dangerous threats to world peace and security as evidenced in their ostensible refusal to recognize Israel, a liberal nation-state they ought to emulate; (2) there is an inherent civilizational difference between Arabs and Canadians; and (3) Arab Canadians are dangerous internal Others who threaten the security of the Canadian nation-state through their (inherently Arab) anti-Semitism and unwillingness to assimilate into a liberal national cultural milieu and who take advantage of the state's generous liberal policies.

While these discourses were reproduced at a localized scale in Ottawa's daily newspaper, they are multi-scalar and multidimensional since, as discussed in Chapter Three and as Dina suggested, they are based in long-standing and highly flexible colonial discourses according to which Arabs are a homogeneous, "savage" people inferior to "civilized," liberal Europeans. Read in this way, the discourse of the Arab terrorist is best understood as a re-articulation of the discourse of the Arab savage through the language of security. In the above examples, local media commentators and politicians employ such discourses to map globally spatialized distinctions onto the bodies of specific people they associated with nationally defined territories. In doing so, they reproduce the kind of "culture talk" (Mamdani 2002, 2004) that naturalizes differences between Arabs and 
(Euro-)Canadians and implies that unless the former assimilate into a (Euro-)Canadian cultural milieu, they will remain forever bogged down by an illiberal, premodern culture.

My aim here is not to provide a thorough analysis of the above-discussed media depictions but to illustrate that research participants represented the ideas that pervaded them as interconnected and as having multi-scalar implications. Indeed, most research participants outlined negative media portrayals of Arabs as containing the related images of them as terrorists and, as Aladdin put it, "screaming fanatics talking about killing Jews, Christians, Infidels." People I spoke with about the latter of these depictions usually framed them as (1) conflating Arabs and Muslims and (2) misrepresenting the Palestinian-Israeli conflict as a matter of Arabs being anti-Semitic.

Sam gave a particularly detailed explanation of such representations wherein he linked discursive constructions of Arabs as terrorists with September $11^{\text {th }}$, colonial power relations, and the Palestinian-Israeli conflict:

[Arabs'] biggest enemy, if I can use that term, is the media. I think we have been vilified a great, great deal and ... no matter how small the group is that ... is perpetrating an incident, they try... - I don't know if they try on purpose or not but it comes across that they are portraying the whole community as supporting this... I remember after September $11^{\text {th }}$ how many times - because I was involved in those community forums working in Ottawa - how many times ... the Arab associations were coming out and condemning the acts of September $11^{\text {th }}$ and all you hear in the media [is] 'They haven't done this. They have not condemned.' ... [W] e're looked at suspiciously [in media portrayals]... If you ask them about the Palestinians, the only thing they think about is the terrorist acts and the terrorist groups... It's always about ... the negative side and there's no balance in coverage that way. And I think ... we got to the point where we believe we're less of a people than others... [C]olonization is happening and interference from outside is happening, so we have a very complicated situation. I think it'll get better when the oil dries up because then they really wouldn't want anything to do with us and we'll be left alone, maybe.

Thus, Sam drew multiscalar and multidimensional connections between local media coverage of $9 / 11$, tendencies to exclude Arab Canadians from the Canadian national body 
by defining them as supporters of terrorism, the Palestinian-Israeli conflict, economic relations of global capitalism, and histories of European colonization.

In explaining his frustrations with media depictions of Palestinians and the Palestinian-Israeli conflict, Sam further connected these localized depictions with international politics which play out on a global scale and have a personal, embodied meaning for him. He began this explanation by telling me "the Palestinian issue is something special for us. It's [about] an identity... we have been denied." He elaborated:

This is a place where my grandfather was born and his grandparents were born, and my parents were born there and my parents became refugees twice, once in ' 48 and once in '67... It's memory. It's who we are. It is where my roots and ancestors are... The Jewish population came back to Palestine, which is now Israel and the Palestinian Territories, after a thousand years. Why should anybody expect us to forget in less than sixty years? It doesn't make any sense. The right of return is given to, this is the injustice I'm talking about, the right of return is given to every nation and every people in the world and they wanna take it away from the Palestinian people. It just, it makes no sense to me.

Sam thus critiqued the ways in which the Palestinian-Israeli conflict is depicted in Canadian national media outlets by paralleling the Palestinian Right of Return to Palestine as their ancestral homeland with the right of Jewish people to return to Israel as their ancestral homeland. He made this argument by relating the exile of Palestinians with his personal and familial history as well as with international laws - which, he illustrated, are applied inconsistently. Indeed, he further pointed out that the United States "went to war against Iraq because of a U.N. Resolutions. I can ... dig out some Resolutions from the U.N. about the Palestinian Territories," he continued, "Okay, then, let's implement them. Then that would be O.K. That would be fair." It was in recognizing and rejecting the unfair, because inconsistent, applications of international laws that research 
participants argued Arab Canadians in Ottawa have an emotional unity based in a shared frustration with global politics and media representations.

Sam's above analysis of media representations of Arabs as interrelated with global politics paralleled Dina's suggestion that "synchronized representations" go into the production of images of Arabs and Arab Canadians as dangerous Others who, in the perspectives presented in The Ottawa Citizen, must be disciplined through the imposition of "Western" liberalism. These arguments are representative of the multi-scalar and multidimensional inter-connections research participants drew between media depictions of Arabs and international politics. Such interconnections suggest that research participants' yearnings for greater unity among Arab Canadians in Ottawa must be understood as multiscalar: most represented this unity as purposive, its aim would be to challenge the discourses pervading media images of Arabs - the material effects of which extend beyond the scale of the city of Ottawa or the nation of Canada - and as something that would counteract colonially imposed national distinctions among Arabs.

The links research participants made between the material effects to colonial power relations and imperialism are important to note in any consideration of the ways in which their subjectivities and agency have been shaped by their encounters with discourses defining Arab, Canadian, and Arab-Canadian identities in Canada. It also illustrates how my arguments in this chapter build on analyses of how institutionalized security discourses aim to discipline the subjectivities of racialized immigrant national subjects in North America, analyses which do not, and indeed cannot, tell us how these people engage such disciplinary governmental rationalities. Recall from above, for example, Mamdani's $(2002,2004)$ and Arat-Koç's (2004) arguments that security 
discourses aim to discipline certain racialized populations into publically supporting state policies out of fear of being defined as terrorist threats or "bad" immigrants. My analysis so far suggests this is certainly an important part of how some people aim to use such discourses in institutional arenas as, for instance, with journalists continuously calling on Arab and Muslim Canadians to condemn the attacks of 9/11/2001.

There are, of course, some Arab Canadians who likely did and do refrain from critiquing state policies - Canadian or otherwise - for fear of being considered terrorist threats or out of a desire to be considered good immigrants. Yet, many Arab Canadians in Ottawa have not been disciplined into a silent complicity with institutionalized discourses and state policies as a result of yearning for national acceptance in Canada or fear of being incorrectly accused of being terrorists or supporters of terrorism. Instead, as I have illustrated above, in many cases, a "transnational yearning" (Burman 2010) for global political justice motivated their thoughts and actions. Extending on Burman's (2010) arguments, I suggest that research participants engaged such discourses in ways that reflect multi-scalar yearnings and subjectivities - i.e. ones that emerged at the intersections of multi-scalar discourses.

For instance, Sam was clearly aware of the consistently repeated calls for Arab and Muslim Canadians to condemn the attacks on the United States that took place on September $11^{\text {th }}, 2001$. He understood these calls as connected with multiple other discourses used to represent Arabs as illiberal and anti-Semitic violent terrorists. Rather than be disciplined by these discourses into silent complicity with discourses and material relations he understood as unjust, he rejected such discourses. To do so, he drew on personal, local, national, and global histories which were particularly meaningful to him 
and clearly shaped his subjectivity, sense of identity, and agency. Sam's above comments illustrate the complexity of these relationships and, for me, particularly of the processes through which agency is produced: while he rejects the implicit injunction to be silent about the Palestinian-Israeli conflict, for instance, he frames his critique through a liberal discourse of the fairness or equality before the (international) law. He also recognizes Jewish Israeli's right of return - codified in Israel through the Law of Return (Habib 2004) - and uses this recognition as a springboard for framing the denial of the same right to Palestinians. Thus, while his critique of global power relations goes "against the weight of [some] ... obstacles" (Mahmood 2001: 206) it is also in keeping with, reproduces, and is enabled by his capacity to draw certain liberal legal traditions.

Similarly, Prime Minister Stephen Harper's representation of the 2006 summer war between Israel and Hezbollah as matter of Israel defending itself against terrorist threats did not serve to discipline all Arab Canadians in the city into a silent acceptance of this official depiction. Instead, Ottawa's Coalition of Arab Canadian Professionals and Community Associations (CAPCA) organized a demonstration on Parliament Hill which "drew about 2,500 people" (Proudfoot 2006) where Bahija Reghai, CAPCA's president at the time, called on the Prime Minister to "read the real facts' and alter his position" (Proudfoot 2006). Regardless of whether they were members of CAPCA or not, many Arab Canadians I spoke with about the 2006 war represented the Canadian state's response as evidence of its failure to live up to its liberal national and international legal obligations to defend human rights. As I illustrate in the next section of this chapter, research participants also enacted community connections which opened up space for their critiques of corporate media depictions of global politics. 


\section{3 "Building Bridges" and Enacting Community}

When I attended community events, I often felt hyperaware of the complexity of Arab Canadians' negotiations of the multi-scalar discourses which factor into abovediscussed representations of Arabs as illiberal and anti-Semitic vis-à-vis the PalestinianIsraeli conflict. At such events, rather than be silenced by discursive equations between criticism of Israeli state policies, anti-Semitism, and support for terrorism, research participants often enacted ideas of community and employed liberal discourses in ways that enabled them to present their criticisms of state policies in public settings. Indeed, based on their commitments to "building bridges" and the importance they gave to finding a just resolution to the Israeli-Palestinian conflict, many research participants took part in public education initiatives they understood as working toward such a resolution. These commitments were particularly highlighted in the performance of the play Three Wishes which I attended on opening night at Ottawa's Gladstone Theatre and on which I focus in this section of my final analysis chapter.

I first heard about the play - which ran from December $2^{\text {nd }}$ to the $13^{\text {th }}, 2008$ - at a meeting of the Arab Communities Roundtable where the playwright, Samah Sabawi, was promoting the performance to members of Arab Canadian organizations. Three Wishes was sponsored by Potlucks for Peace (P4P), a group that Qais Ghanem - an Arab Canadian professor of medicine who immigrated to Canada from Yemen in $1970-$ started in 2003 as part of a commitment to "building bridges" and starting a process of dialogue about the Palestinian-Israeli conflict (Balint 2005: \ 3) in the city. The Ottawa group consists of Jewish and Arab Canadians who meet once a month to "share food, engage in dialogue and develop initiatives that, [they] hope, will contribute to the 
possibility of peace in the Middle East" (P4P 2009). To a certain degree, then, the group's framing of their project is in keeping with liberal multicultural discourses: group members would share in each other's food, respectfully hear each other's opinions, and demonstrate the possibilities such reciprocally respectful dialogue could open up for peace. Committed to extending their work beyond the group, in 2006, P4P members began to organize and/or sponsor public education events. Two years later, Samah asked them to sponsor a stage adaptation of Deborah Ellis's (2004) Three Wishes: Palestinian and Israeli Children Speak, a book that had elicited demands that it be censored.

Ellis, a Canadian writer of young adult literature, wrote the book based on interviews she conducted in 2002 with children living in Israel and the Occupied Territories. Her book, described by her publisher as one that "does not take sides" (Groundwood Books n.d.: ๆ4), consists of a brief introduction followed by the narratives of twenty children - ten Israeli, ten Palestinian - between the ages of eight and eighteen who represent a range of differing opinions. Upon publication, the book was praised for "trying to keep a balanced perspective" (Evans 2004: ๆ2) and recommended as "a good choice for school libraries" (Elton 2006: A10) by the Association of Jewish Libraries. It was also a book that Wafaa told me she gave to her grandchildren to teach them about the Israeli-Palestinian conflict.

When the book was nominated for an award by the Ontario Library Association (OLA), however, an elementary school teacher in the York District School Board, upset at what she read as a demonization of the Israeli army, filed a formal complaint (Kramer 2006; Van Luven 2006). She approached the Canadian Jewish Council which sent letters to the OLA asking them to remove the book from their award program and to Ontario 
school boards asking them to reconsider its availability in school libraries, especially to children in grades four through six. The letters cited concerns that the book was not ageappropriate and teachers lacked the necessary tools and background knowledge to teach it. When news of these concerns broke, media commentators had three general responses: they defended the book's use in schools (e.g. Côté 2006; Higgins 2006; J. Kay 2006; Van Luven 2006), insisted there were many problems with it (e.g. B. Kay 2006; Kramer 2006), or argued that parents need to decide whether their own children are "mature" enough to handle reading it ("Parents Best to Decide" 2006; "Censorship" 2006). Ellis also published a response wherein she argued that "if children are tough enough to be bombed and starved, then they are also tough enough to read about it" (Ellis 2006: A18). In this context, the book was soon declared "a catalyst for controversy" (Wilhelm 2006). As Samah explained to me, this controversy piqued her son's curiosity and, when he read the book, he put in "a public entry about why this book should not be banned." Due to her son's interest in the book, Samah also read it and, immediately, "could see both sides on the stage together telling these stories, talking to each other." She thought the book opened up a space for dialogue and a play based on it could be an educational, anti-war initiative aimed at reaching a wide audience. Samah did not shy away from the controversial book for fear of being considered a "bad," illiberal immigrant - nor did community members who performed in, spread information about, and/or attended the play. Instead, she drew on and reproduced liberal discourses within which dialogue and "balance" are valorised, cultural difference is fixed, and cultural communities are homogeneous to (1) negotiate discourses defining Arabs as essentially and culturally antiSemitic, illiberal, and violent and (2) enact multiple, simultaneous forms of community. 
For example, when I spoke with Samah about the play, she told me she approached P4P for sponsorship because she thought having the play "supported by a group of Palestinians and Jews" would help ensure it equally represented the concerns of both sides. The reason Samah gave for seeking P4P sponsorship was thus in keeping with liberal valorization of presenting "a balanced perspective" - something most research participants felt Canadian media outlets lacked - as defined by ensuring all parties to a dispute are permitted to state their views. She also told me that she asked Jewish members of P4P to choose the stories of Israeli children to include while she chose the stories of the Palestinian children. Her decision to do so seemed to reinforce discourses about the homogeneity of cultural communities according to which Palestinians and Jews have two distinct interpretations of what is important to their own groups such that having Jewish members choose these stories would somehow ensure Israeli authenticity. Yet, in a context where Arabs tend to be represented as anti-Semitic, her doing so can be understood as an avenue for ensuring that she, as a Palestinian Canadian, could not be accused of misrepresenting Israelis: the way in which she represented Israelis on stage was based on the words of Israeli children as chosen by Jewish Canadians.

When I attended the performance of Three Wishes, I arrived early. As I waited for the play to begin, I walked around the lobby and mingled with people I had met at other events during fieldwork. I also noticed a lot of people at the theatre I had not met before, not all of whom were Arab Canadians. Like many attendees with whom I spoke, I was excited to see the play and interested in how Samah would stage an adaptation of a book that, as mentioned above, had been dubbed a "catalyst for controversy" (Wilhelm 2006: A2) only two years earlier. I got an immediate glimpse at the answer when I walked from 
the lobby into the theatre and saw that the stage was divided down the middle by a wall with barbed wire around the top of it: this was clearly going to be a play where "controversial issues" were literally placed centre-stage, I thought, as my friend and I took our seats next to Monzer and his daughter who were already in the audience.

The central act of the play reinforced my initial reaction. In this act, audience members meet a Palestinian girl named Wafa whose home was demolished a total of five times and whose mother, traumatized by these demolitions, had stopped speaking and an Israeli girl named Talia who has recently returned from a visit to Europe's concentration camps and lost an acquaintance in a suicide bombing. In the performance, Talia's fear of suicide bombings was powerfully conveyed as she faced the audience and told them "you could be walking down the street and suddenly..." At this point, her words were suddenly interrupted by a loud explosion as the stage went entirely dark and a large television screen came on with scenes of the aftermath of a suicide bombing. The shock of this scene, the unexpectedness of the explosion, brought home with force the unpredictability of the violence of war. Just as importantly, however, the act was staged in a way that paralleled the unpredictability of the violence Talia described and that Wafa described in relation to curfews, checkpoints, and house demolitions. As Wafa described the demolition of her home, actors dressed as Israeli soldiers overtook the stage and began acting out her narrative, as they did so the stage suddenly darkened and images of home demolitions flashed across another screen that hung above the stage.

Several months after the performance, in a telephone conversation with Samah, I found out that she considered the juxtaposition between Wafa and Talia's stories "really important." Samah also told me, however, that some members of P4P had expressed 
concern about this particular act of the play. As Samah described the process of writing the stage adaptation, it seemed to me that her attachment to this act was about the importance she placed on enabling public discussion about the very issues often used in (corporate Canadian) media depictions in ways that foreclose such a possibility by defining Palestinians as violent terrorists and thereby implying that attempts to understand "the Palestinian side" of the conflict is equivalent to support for terrorism.

For instance, when Samah gave P4P members a copy of the stage adaptation, she said, "the Arabs in the group objected to [the above-discussed act] because at the end of it, [Wafa] says 'I want to kill an Israeli."” They were concerned these words might present Palestinians as irremediably violent toward Israelis which some people could use to reinforce representations of Palestinians as anti-Semitic. Similarly, a Jewish member of P4P worried the act "would reinforce the fear a lot of Jewish people have about the Palestinians." For Samah, on the other hand, the act had to be in the play precisely because it provided the context of the young girl's statement:

You get the whole story, you know, because she's really conflicted. She knows that the Israeli activists are helping her rebuild her house, but the Israeli soldiers are demolishing it... And she distinguishes between the Israeli soldiers who are demolishing her house and the ones who are helping. She says 'I want to kill an Israeli, but not the ones who are helping us, the ones who try to steal my land.'

For Samah, it was important to highlight the distinction Wafa makes between peace activists and soldiers. Thus, while her asking Jewish members of P4P seemed to suggest there is one authentically Jewish view of the conflict, she staged the play in such a way that the homogeneity of Israelis was nevertheless called into question by the presence of and distinction between peace activists and soldiers. This distinction emerged as a key to understanding the relationship between "peace" and not trying "to steal [Wafa's] land." 
Samah discussed her perspective with the group members who had expressed such concerns and they agreed to keep this act in the play.

According to Samah, however, "one person complained... that when we put both sides on stage together ... the Palestinian suffering seemed stronger and more immediate." Consequently, he had told her, the play “didn't seem balanced." As P4P members discussed this concern, Samah said, "other Jewish people in the group... said that maybe it's because you can't present a skewed situation in a balanced way." Reflecting on this incident, Samah told me she "gave both sides equal attention on stage," but in displaying the violence of occupation - including curfews, checkpoints, and home demolitions - "the play redefines what it means to be balanced. We were ... projecting a reality," she concluded, "it was as raw and as balanced as it can be."

I am particularly interested here in the way Samah (and some of the other P4P members) employed the liberal definition of "balance" (i.e. as a matter of giving all sides to a dispute the equal opportunity to tell "their side" of events) in order to illustrate their understanding of the Palestinian-Israeli conflict as one that is pervaded by structural imbalances. More specifically, she emphasized throughout our conversation that she respected and followed the liberal rules of balance and dialogue. Since she and other P4P members were "projecting a reality" and doing so in a balanced way, any remaining semblance of imbalance resided in that reality rather than in their depiction of it. Again, if we think of agency "as a capacity for action that historically specific relations of subordination enable and create" (Mahmood 2001: 203), then Samah and other P4P members' subordination to liberal definitions of balance produces their agency. It 
produces, in other words, their "capacity for action" which, in this case, is about articulating their perspective of the Palestinian-Israeli conflict as structurally imbalanced.

I want to conclude this section by speaking briefly to the relationships between yearning and community. As I have argued throughout this chapter, research participants' yearnings for greater unity among Arab Canadians in Ottawa are multidimensional and multi-scalar. They explained these desires in terms of anti-colonial discourses about (pan)Arab identity, the importance of not enacting a localized exclusionary politics of identity based on linguistic coherence, and the necessity of counteracting national depictions of Arabs as violent, illiberal terrorists. They also connected these national depictions to global politics as well as to the politics of the Palestinian-Israeli conflict.

Above, I spoke of their encounters with such discourses as shaping their yearnings for a more unified Arab Canadian community in Ottawa, arguing that these yearnings are about more than "the communalizing power" of the Canadian nation-state. The arguments I have presented in this section suggest that for some research participants, the multi-scalar character of such yearning also meant that they participated in and enacted community coalitions that were based in shared purposes that transcended the boundaries of Arab identity. For instance, as Wafaa said she would do, many "align[ed] with Jewish Canadians" to form senses of Arab-Jewish community based in a shared desire for greater public discussion of and a just resolution to the PalestinianIsraeli conflict. While participating in such initiatives, they did not cease to consider themselves members of an Arab Canadian community, but were members of both simultaneously. Within these contexts, they were able - at least at an experiential scale - 
to challenge the liberal discourses often used in attempts to silence them through accusations of illiberalism, but did so precisely by enacting liberal notions of community.

\subsection{Conclusion}

As I have shown in this chapter, research participants' yearnings for greater unity among Arab Canadians in Ottawa, which "challenge the depoliticizing impulses of both romanticism and hopelessness" (Burman 2010: 12), were products of their encounters with multi-scalar and multidimensional discourses. Some of these discourses are ones often used in attempts to discipline them into a silent acceptance of or support for policies they might consider unjust by governing them through fear of being considered illiberal, anti-Semitic, or supporters of terrorism. Aware of such discourses, research participants were also motivated by multi-scalar and multidimensional desires which allowed them to work within the possibilities opened up by the governmental rationalities of such disciplinary discourses. The relationships between the multiple discourses they encountered - including liberal ones pervading institutionalized definitions of Canadian national identity and derogatory representations of Arabs - and their subjectivity and agency is thus quite complex. As I have shown in this chapter, their willing acceptance of some elements of such discourses does not signify a lack of agency. 


\section{Chapter: Conclusion}

My aim in this project has been to highlight the complexity of the experiential processes through which research participants negotiate their senses of national identity and claim their positions as social and political actors in Canada. I have argued that national identity discourses are (1) reproduced through multi-scalar processes, (2) encountered and negotiated at a multidimensional experiential scale, and (3) simultaneously shape both subjectivity and agency in and through one another. In keeping with this broad theoretical argument, I have suggested that the meanings research participants attributed to their senses of national identity were shaped by multiple facets of their social experiences and the broad geographic, socio-historical, and political contexts in which they have lived in the past and live presently.

My analysis builds on critical scholarly literature in the field of Canadian Studies and critically engages with existing theorizations of the production and productivity of Canadian national identity discourses which tend to focus at the national scale of institutional discourse production through the analysis of state policies and news media, for example (Cf. Burman 2010; Kinsman and Gentile 2010; Mackey 1998, 1999; McKittrick 2006; Walcott 2000, 2001, 2003). It is also, as mentioned in Chapter One, inspired by the work of several scholars in the field whose analyses are multi-scalar (Burman 2010; McKittrick 2006; Walcott 2000, 2001, 2003), multi-dimensional (Kinsman and Gentile 2010; Mackey 1998, 1999), and qualitatively investigate how people experience and engage specific discourses in their day-to-day lives (Burman 2010; Kinsman and Gentile 2010; Mackey 1998, 1999). 
For example, like Mackey, I have considered research participants' engagements with Canadian national identity discourses. My focus, however, has been on Arab Canadians' engagements with these discourses which differ significantly from those of Mackey's participants. While Mackey's “Canadian-Canadian" research participants tended to represent multiculturalism as a state-imposed policy that threatens national unity, the Arab Canadians with whom I spoke generally interpreted it as a policy that opens up space from which they can insist on their right to claim national belonging and citizenship. As I have shown, they go beyond insisting on this right to enacting it sometimes through small daily gestures (as in Omaima's daughter telling teachers that her "origin" is the local hospital) and other times in larger, collective ways (as in organizing demonstrations on Parliament Hill to protest decisions made by the federal government). In such cases, rather than working on claiming and creating a space for these rights, they engage in actions that begin from the premise that they are already entitled to these rights. Where they criticized this policy, it was for not going far enough in addressing structural inequalities related to racialized exclusions in the labour market, for example. As I have illustrated throughout this dissertation, in many instances, the same discourses used throughout Canadian national institutions in attempts to constitute an ostensibly "authentic" Canadian national subjectivity became the basis of research participants' critiques of the Canadian nation state as failing to live up to the very image of Canadian national identity in which it has invested.

Throughout this dissertation I have also worked to negotiate a specific tension that is inherent in the project of attempting to theorize how the racialization and Eurocentrism that pervade institutionalized Canadian national identity discourses shape the experiences 
of research participants. How, I have continuously asked myself, do I analyze their narratives in a way that recognizes that they are changed by their immigration experiences without becoming so wrapped up in these changes that I would forget that immigration to Canada is only one part of how they interpret their complex experiences and identities? How, in other words, do I illustrate the impacts of their immigration experiences without thereby reducing them to a single category of "immigrants"? At the same time, I had to consider how I could discuss the importance of their pre-immigration experiences without reproducing an essentialist image of a homogeneous cultural community. These tensions are not only present in my work, however.

For example, as I mentioned in the previous chapter, Sunera Thobani's (2007) project involves illustrating how institutionalized liberal national discourses and policies in Canada produce a singular figure of "the immigrant" as distinct from an unmarked category of "Canadian" by marking racialized national subjects as members of distinct, homogeneous "cultural" communities. In considering my project in relation to her work, I was left wondering how I could avoid reproducing the type of institutionalized images of cultural communities which, as Thobani points out, elide how people are changed "by the process of migration and dislocation" (149). Yet, I had to do so without forgetting that, to a certain degree, the specificity of their experiences in Canada also depends on the cultural categories with which they identify themselves. This is a similar question as one that pervades and remains unresolved in critical race scholarship in general: how do we simultaneously recognize that race is a social construct and also keep in mind the very real ways it shapes our experiences of the world? 
I think any answer to these questions must begin from the recognition that while being racialized immigrants in Canada means people experience racism, the specific content of that racism reflects the particularity of the discourses which inflect the racializing processes through which the cultural categories with which they identify are (re)defined in the country. Being aware of these differences does not necessarily make forming anti-racist coalitions impossible. Instead, it may help us to avoid universalizing a specific experience of racism or process of racialization by taking seriously the very difficult task of simultaneously recognizing difference and similarity. Indeed, as feminist anti-racist scholars have long argued, the multidimensionality of identity necessitates that those of us committed to ending racism accept difference without thinking it will mean an inability to work together (Mohanty 1991, 2003; Reagon Johnson 2000).

Repeating the argument of anti-racist feminists about coalition-building, I am aware of its overlaps with elements of liberal discourses of multiculturalism that suggest a need to balance "diversity" and "unity." I am also aware that while there is some overlap, there is also considerable difference in that rather than a top-down approach that institutionalizes an ostensibly ideal "balance" and leaves deeply structured and sedimented power relations out of the equation, a feminist anti-racist approach places these relations front-and-centre and asks us to understand this difficult work as something that must take place experientially, relationally, and open-endedly. From this perspective, coalition and community building are on-going processes that can never be predetermined or final but must continuously be adapted to changes in political and social conditions and to the characteristics of coalition members. It is an understanding of 
community that overlaps considerably with the ways in which the people who participated in this study framed and enacted their senses of community.

It is precisely because of such overlaps between "state" and feminist ideals of community that I considered it necessary to leave my discussion of research participants' desires to overcome divisions among Arab Canadians in Ottawa until the final analysis chapter. I thought doing so would allow me to have already illustrated to readers that simply because a person frames her/his narrative in a language that echoes institutionalized discourses, it does not mean that person has therefore been duped by such discourses. S/he has certainly been shaped by them since, as Butler (1992) argues, "no subject is its own point of departure" (9), but her/his subjectivity and agency are not exhausted by any one such discourse. By ending rather than beginning with community I also aimed to illustrate that it is not a given, taken-for-granted point of departure for talking about Arab Canadians who live in the same city.

Beginning with research participant's senses of Canadian identity was thus important for three reasons: (1) to counteract exclusionary discourses used to deny the importance they place on this dimension of their sense of identity and suggest that they are, therefore, not "real" Canadians; (2) to illustrate important differences in their interpretations of various identity discourses and experiences prior to and after immigrating to Canada which might challenge any tendency to want to read them through a lens of sameness based on a shared "cultural" identity; and (3) to show the complexity of their interpretations of the dominant discourses and mythologies of the Canadian nation-state in order also to clarify that their yearnings for community might and do reflect more than the "communalizing power" of this state. Instead, as I showed in the 
last chapter, most research participants understood building pan-national Arab Canadian coalitions an avenue to challenge (1) racist discourse about Arabs and (2) the state policies they are used to justify both within and outside Canada. Most people with whom I spoke suggested such divisions had to be overcome (1) because they were products of a period of European colonization in the Middle East and/or (2) to build coalitions for important social and political work which would have repercussions both in Canada and in the Arab world. They often, as I have shown, envisioned this social and political work in relation to "unfair" and/or inaccurate media depictions of Arabs and Arab Canadians.

Research participants' understandings of community are particularly important for theorizing the complex relationships between the multidimensionality of identity, multiscalar politics, and the production of subjectivity and agency. An analytic lens that focuses exclusively on the national scale of the institutional reproduction of national identity discourses provides an excellent understanding of the uses to which such discourses might be put as governing rationalities aimed at disciplining thought and action from the outside in. If all of our scholarly analyses were to remain only at this scale without some scholars also investigating what happens at an experiential scale as people encounter such governmental rationalities, we might leave the impression that the institutional production of such discourses somehow directly produces either entirely subordinate immigrant subjects or wholly resistant political and social actors - a process we know is not the case.

The analytic lens I am proposing, as a complement to other types of analysis, shows that things are more complex than this "on the ground," so to speak. Because there are multiple scales of discourse which all interact with one another, our desires, 
motivations, and memories are necessarily also multiscalar and multidimensional. Only by recognizing them as such can we begin to understand the inseparability of subjectivity and agency. More specifically, if power relations are productive and if, as Foucault (1995) argues, we can never escape these power relations - such that even resistance to power is never exterior to it - then it follows that our agency is also a product of the power relations that constitute our subjectivities. Put differently, if power is productive, governmental rationalities produce subjectivity and agency in inseparable ways.

My arguments about agency as a product of the same encounters with discourses that shape subjectivity are based in Saba Mahmood's (2001) critiques of the tendency to frame only those actions and thoughts that we, as researchers, deem to be resistant in terms of agency. When considered with the attendant tendency to frame those actions and thoughts that are in keeping with particular governmental rationalities in terms of subjectivity, the distinction implies that subjectivity and agency are opposed to one another rather than produced in and through one another. Mahmood urges scholars to consider agency: (a) more in terms of capacities and skills required to undertake particular kinds of acts (of which resistance to a particular set of relations of domination is one kind of an act); and (b) as ineluctably bound up with the historically and culturally specific disciplines through which a subject is formed. (210)

The analysis I have presented in this dissertation builds on Mahmood's argument by illustrating such a conceptualization in relation to how people mobilize and experience multiple, intersecting, and multi-scalar discourses at once.

Following from the above, there are three important elements of my arguments about research participants' interpretations of their immigration experiences, senses of national identity, and ideas of community that illustrate the relationships I have proposed 
exist between the concept of multi-scalar politics, the multidimensionality of identity, and the idea that agency and subjectivity are produced through our interactions with multiple discourses and governing rationalities. First, the historical and cultural specificities of the discourses and disciplines that produce research participants' subjectivities cannot be understood through an analytic lens that focuses only on their experiences in Ottawa or Canada. Instead, taking these specificities into account requires a multi-scalar analysis because their experiences and senses of self are shaped by multiple cultural and historical discourses each of which influences how they interpret the others. Their subjective desires, political commitments, and ways of identifying are formed through a complex mix of multiple discourses. These certainly include liberal Canadian national identity discourses, but several other discourses and experiences are just as important to consider: discourses that emerged out of the colonial histories of Arab world, security discourses that are used in global attempts to silence elements of their understandings of the Palestinian-Israeli conflict, the specificity of their experiences in the city of Ottawa, racializing discourses often used in Canada and the United States to represent Arabs as violent, illiberal terrorists, specific national discourses from their countries of origin, gender discourses, religious discourses, and familial histories. Theirs are, in other words, multi-scalar yearnings. In other words, because they are shaped by all of these things $a t$ once, I conceptualize them as multi-scalar, rather than transnational, yearnings (Burman 2010). I use this terminology in order to emphasize the continuous co-constitutions of globalized, and certainly transnational, political discourses and power relations, those institutionalized at a national scale, in local enactments of community, in familial interactions, and at the scale of embodied experience. 
These co-constitutions are certainly evident in Jenny Burman's (2010) writing. Burman uses the term "transnational yearnings" to illustrate "that migration, leisure travel, and the formation of new local and transnational communities cannot be separated from participants' desires, hopes, longings, and other affective investments in their own mobility and stasis" (5). In her work, "the affective dimensions of these transnational movements" emerge as inseparable from "social and spatial practices" which include tourism and migration (5). I find her ability to illustrate the specific ways that "migrants' experiences of dislocation and relocation are textured" by desires that shape, and are shaped by, the interdependent "circulations of people, money, and cultural texts" (5) through the use of a multi-scalar analytic lens particularly striking and inspirational, and I hope that I have been able to produce a similarly textured text in the preceding pages. I use a slightly different terminology in order to emphasize the methodological and analytic decentring of the scale of the national that is evident in her work and which inspired my approach to this project. In the context of my dissertation, I also understand my terminological choice important as a way of foregrounding the anti-colonial Arab identity many of the people who participated in this study claimed which spans the space of more than one Arab nation-state. To call their desires trans(pan)national sounds more clumsy than to refer to them as multi-scalar and, thereby, simultaneously to highlight the methodological argument I make throughout this dissertation.

Returning to conceptualizing my project in relation, to Mahmood's (2001) arguments about subjectivity and agency, the second point I want to make follows from the first: if research participants' subjectivities are multi-scalar, so too are they multidimensional. The ways in which a person's subjectivity has been shaped by one set 
of historically and geographically located social relations doe not suddenly cease to exist only to be replaced by new ones they encounter once they move to Canada. Instead, the various discursive traditions they have encountered, and those they now encounter, intersect with one another and influence how they may interpret and embody each. In other words, the discourses and experiences they had prior to immigrating influence their interpretations of new ones they encounter in Canada even as their interpretations of the former are reshaped by this same process.

Third, this process further complicates an understanding of the relationships between subjectivity and agency because research participants" "capacities and skills" for "particular kinds of acts" (Mahmood 2001: 210) emerge out of the experiential intersections between the multi-scalar and multidimensional discursive traditions which shape their subjectivities. In some cases, this means they might willingly, as active agents and social actors, draw on a particular discursive tradition (such as liberal legal standards, multiculturalism, or humanism) which might open up the space to embody and enact desires and political commitments that have emerged out of a different context. Often, during fieldwork, it meant people would reproduce certain norms while simultaneously challenging others. Indeed, as I have shown, rarely did anyone draw on any discourse in a zero-sum way that illustrated an acceptance of every element of that discourse.

The findings and arguments presented in this dissertation suggest a need for greater exploration of the conditions under which people may (re)produce, embody, and/or challenge national or other identity discourses in their day-to-day lives. How, for instance, do the intersections between conflicting discourses in someone's life shape how $\mathrm{s} /$ he interprets each discourse? How does the multidimensionality of identity influence 
how people might come to form and interpret coalitions aimed at reshaping particular social discourses or institutions? While my main focus here has been on national identity discourses, it would be important to engage in similar analyses which centre on other identity discourses such as those related to gender, sexuality, disability, citizenship status, socio-economic standing, or race.

My analysis also suggests a need to expand our understanding of the ways institutionalized discourses shape a person's subjectivity so that we cease to write about subjectivity and agency as if they are respectively equivalent to accepting or resisting specific discourses or governmental rationalities. Instead, our analyses must begin from the understanding that precisely because discourses shape a person's subjectivity they also, by that very fact, shape her or his agency. Research participants' seemingly contradictory interpretations of and relationships with national discourses certainly point to the contradictions that are at the heart of liberal discourses such as multiculturalism; where their experiences were not in keeping with these discourses, they came to question images of the Canadian nation-state as fully liberal because it is multicultural. In most cases, they accepted the ideal of multiculturalism. This willing acceptance offered the space from which and language through which to critique Canadian national institutions for failing to live up to this ideal. In such cases, this acceptance also shaped their subjectivities in such a way that their actions began from and illustrated the premise that they were entitled to step into and enact a critical citizenship from within the Canadian national body rather than simply seek permission to do so from outside its boundaries. 


\section{Appendices}

Appendix A

PROJECT TITLE:

Bordering National Subjects: Immigration, Belonging, and Governmentality

\section{AIMS AND RESEARCH QUESTIONS:}

There are two main aspects to my research study. First, I aim to understand the processes involved in the formation of a sense of Arab "community" for first-generation Arab-Canadian immigrants living in Ottawa. Second, I want to explore possible relationships between these same community members' senses of Arab-ness and/or Canadian-ness and dominant media, political, and social images about what it means to be Arab.

These aims speak to a larger question in which I am also interested: what does it mean to speak of home and nation? Given the centrality of relocation for immigration experiences, I argue that they are useful sites for understanding a person's senses of home and national belonging. Thus, ultimately, I am interested in how ArabCanadians living in Ottawa imagine, produce, and experience their home(s), nation(s), selves, and communities. My specific research questions are as follows:

1. How are the experiences of first-generation Arab-Canadians residing in Ottawa understood in relation to their previous place(s) of residence? What strategies have been used to adjust to their relocation to Canada? How have they experienced and made sense of this (re)location?

2. Do first-generation Arab-Canadians living in Ottawa feel they have created new senses of home and community? Why or why not?

3. How do Arab-Canadians living in Ottawa understand and represent themselves?

4. Have any particular socio-political events influenced their senses of belonging in relation to Canada and/or to Ottawa's Arab community? Have such events changed the ways they understand and identify themselves?

WHY OTTAWA?

Although "Canadians of Arab origin make up one of the largest non-European ethnic groups in Canada... representing $1.2 \%$ of the total Canadian population," and although "the number of people in Canada of Arab origin is growing considerably faster than the overall population" (Colin 2001:9), there are few studies that examine their 
everyday experiences and lives in Canada. Moreover, while "over half of all Canadians of Arab origin live in either Montreal or Toronto" (10), "people of Arab descent" make up a significant percentage of the population of Ottawa as compared to other Canadian cities. Indeed, according to 2001 Census data "people of Arab descent" make up 4\% of Ottawa's overall population (10). The only other city with the same percentage of Arabdescended people in relation to its overall population is Montreal, followed by Toronto and Halifax at $2 \%$ each (10). Again, despite this, to date there have been few (if any), indepth, academic studies that address and examine the experiences of Arab-Canadians residing in Ottawa.

\section{MOTIVATIONS FOR THIS STUDY:}

There are two key motivations that guide my research. First, I hold that it is important to understand the ways Arab-Canadians in Ottawa define their own community (as opposed to definitions that may be imposed by others). People who immigrate to Ottawa from a similar region of the globe (or even from the same country, city, or village) do not necessarily or automatically form a (cohesive) community. In other words, my being an Arab-Canadian living in Ottawa does not automatically make me a member of the city's "Arab community." Instead, being a member of a community involves forming and maintaining social relations with others for whom being "Arab" is a shared meaningful identity and a basis for sustained social interaction and intimacy. Thus,

community is best understood as a social process; people must form and work to maintain social ties that join them as members of "a community."

The second important premise motivating this study is that multiple misrepresentations and misinformation about Arabs and, thus, Arab-Canadians circulate in Canadian media, political, social, and academic arenas. Moreover, $\mathrm{I}$ believe it is important to consider the effects of such dominant representations because they tend to (re)produce and justify power relations, thereby producing the possibilities and constraints that shape our lives and life chances. Although I acknowledge that stereotypes of Arabs may have changed over the last three centuries, this does not mean that they have disappeared. Instead, I contend, many policies, which meaningfully affect the lives of Arab-Canadians, continue to be based on stereotypical thinking. 


\section{RESEARCH METHODS:}

\section{Data Collection:}

In order to answer the research questions outlined above, I will be relying on data gathered from semi-structured interviews. For this reason, I am looking for research participants who would be willing to take part in such an interview. Depending on the preference of the participant, the interview may last between one and two hours, and can take place in any location where he/she feels comfortable meeting with me, such as a coffee shop, for example. Participation in this study is entirely voluntary, will be confidential, and participants may choose to provide a pseudonym (fake name) that will be used in any published material. Anyone who chooses to participate in this study may stop the interview at any time and may ask for any of the information they provided to be withdrawn at any time prior to the publication of this study.

I will begin each interview by asking participants some demographic questions to gain general information about them. These will include questions about age (or agerange), gender, length of time residing in Canada, and place of residence prior to arrival in Canada. I will come to each interview with a set of questions that will guide the interaction and will ensure a similar structure to all interviews. That said, however, participants will be given some control over the direction of the interview insofar as it is their answers to these questions that will guide the discussion. My hope is that conducting the interview in this way will allow the interview to also be a meaningful event for participants and to give them room to speak to those aspects of their experiences that are most important to them. If participants so choose, I can send them the list of interview questions before the interview. Likewise, if participants would like, they also may obtain a copy of the interview transcript. This will give participants an opportunity to read over the questions asked and answers given and - with reasonable notice given - ask for any changes and/or omissions to be made. Executive summaries of the research findings will also be made available upon request to research participants at the time of publication of this study. 
CONTACT INFORMATION:

Principal Investigator:

Samah Sabra (PhD Candidate)

School of Canadian Studies,

Carleton University

1125 Colonel by Drive,

1210 Dunton Tower

Ottawa, Ontario, Canada, K1S 5B6

(613) 668-7571

ssabra@connect.carleton.ca
Supervisor:

Dr. Eva Mackey

School of Canadian Studies,

Carleton University

1125 Colonel By Drive, 1204 Dunton Tower

Ottawa, Ontario, Canada, K1S 5B6

(613) 520-2600 (ext. 6697)

eva mackev@carleton.ca 


\section{Appendix B}

Project Title: Bordering National Subjects: Immigration, Belonging, and Governmentality

Principal Investigator:

Samah Sabra (PhD Candidate)

School of Canadian Studies, Carleton University

1125 Colonel by Drive, 1210 Dunton Tower

Ottawa, Ontario, Canada, K1S 5B6

(613) 668-7571, ssabra@connect.carleton.ca

\author{
Supervisor: \\ Dr. Eva Mackey \\ School of Canadian Studies, Carleton University \\ 1125 Colonel By Drive, 1204 Dunton Tower \\ Ottawa, Ontario, Canada, K1S 5B6 \\ (613) 520-2600 (ext. 6697), eva_mackey@carleton.ca
}

\section{Purpose of the Study}

You are invited to participate in a study that involves research. The purpose of this study is to explore Arab-Canadians' understandings of their community in Ottawa, their senses of self and feelings of belonging and/or exclusion to and in Canada, and what factors influence these feelings.

\section{Procedures involved in the Research}

As a participant, you will be asked to take part in an interview, which may take between one or two hours. I will begin the interview by asking you about demographic information such as your age or marital status. I will then ask you about your experiences of immigrating to Canada and living in Ottawa.

The interview can take place in a location you think you will be most comfortable and safe talking to me about these experiences. Based on your preference, I can take notes during the interview and/or I can audiotape it. If you give me permission to tape-record the interview, you can control the tape-recorder throughout the interview and can stop the tape-recorder at any time. If you choose, within one month of the interview, I can make and send you a type-written copy of our conversation so that you to edit any way you like. If you have chosen to have the interview tape-recorded, this tape will be destroyed once a transcript of the conversation has been produced.

\section{Potential Harms, Risks or Discomforts}

Discussing these experiences may bring up unpleasant memories and/or may be emotionally draining. I want to make sure that you know that you can refuse to answer any questions that I ask and you may stop the interview and the tape-recorder (if used) at any time, without explanation and with no questions asked. After meeting with me for the interview, you may decide that you do not want to be included in this research project. If this happens, please contact me as soon as possible so that I may omit any information that you have provided me with during your interview.

If you do feel emotionally overwhelmed at any point during the interview, you can ask to stop the interview. Also, although I am not a professional, if you feel overwhelmed at any point during or after our meeting, I can still listen and talk with you about your experiences. If you are not comfortable talking to me about your feelings, I can give you information about local counselling services (both legal and emotional) that you may contact, if you wish.

\section{Potential Benefits}

Although this research may not necessarily benefit you directly, there are a few good things that I hope will result from it. For example, there is little academic research about the lives of Arab-Canadians in general, and their how they understand define their senses of community and self more specifically. There is also little research about the Arab-Canadians' feelings of bleonging or exclusion in Canada and what factors 
influence these feelings. I think it is very important to understand the issues that influence the lives of Arab-Canadians in Ottawa insofar as this will increase awareness about how Arab-Canadians, themselves, define and understand their community/communities here in Ottawa. Moreover, I hope that this research will contribute to further understanding and apreciation about what aspects of their lives first-generation Arab-Canadians find most rewarding and/or challenging.

\title{
Confidentiality
}

Your participation in this study will be kept confidential and I will not use your name in published materials unless you specifically ask me to. Unless you wish to be directly identified in the study, I will label all notes, tapes, and transcripts using a pseudonym you provide. However, it is always possible that others in the field and/or community may be able to guess your identity. Please keep this in mind when deciding what you tell me and whether or not you want to participate in this study. If you choose not to take part in this research, or to withdraw from it, I will not reveal your decision to anyone and your choice will have no effect on any services you may currently be receiving.

Any information that you give during your interview will be stored in a locked filing cabinet in a location known only to me. If your interview is tape-recorded, I will immediately destroy the audiotape when I make a type-written copy of it. This transcript and any notes that I take will be labelled using the pseudonym you choose. They will be kept for five years, after which I will shred them. All information you provide will be kept confidential to the full extent of the law. In the case of any legal requests for any of my research material, I will defend the confidentiality of the information to the full extent of the law.

\section{Participation}

Participation in this study is entirely voluntary. If you decide to take part in this study, you can stop and/or withdraw your interview at any time prior to publication - even after signing the consent form, during the interview, and/or part-way through the study. If you change your mind about participating, there will be absolutely no consequences to you; you will not be asked to explain your decision, and any notes about you and/or your interview will be handled as you choose. I will not tell anybody of your choice to participate, to not participate, to withdraw, or to refrain from answering any interview questions.

\section{Information about the Study Results:}

You may obtain information about the findings from this study by contacting me directly at any point after your interview. If you choose, I will send you a type-written copy of our conversation within one month. You can make changes to this transcript by taking things out and/or adding things you think are important. Once I have completed all of my interviews, I will begin to put this data together and analyze it. Based on my current schedule, I anticipate being finished with my analysis and in the process of writing up my findings in October 2009. I hope to complete writing up this research study by April 2010. At that time, I can send you a summary of my findings. Again, when you receive this summary, you can contact me or my supervisor with any concerns and/or questions that you may have.

\section{Information about Participating as a Study Subject:}

If you have questions or concerns at this point, or if you require more information about this research study, please contact me, Samah Sabra, or my supervisor, Dr. Eva Mackey.

This study has been reviewed and approved by the Carleton Research Ethics Board. If you have concerns or questions about your rights as a participant or about the way the study is being conducted, you also may contact:

\author{
Carleton University Research Ethics Committee \\ Telephone: (613) 520-2517 \\ C/o Carleton University Research Office \\ E-mail: ethics@carleton.ca
}




\title{
Appendix C
}

\author{
Samah Sabra (PhD Candidate) \\ School of Canadian Studies, Dunton Tower \\ Carleton University \\ 1125 Colonel By Drive \\ Ottawa, Ontario, Canada \\ K1S 5B6 \\ (613) 668-7571 \\ ssabra@connect.carleton.ca
}

Date

\section{Letter of Invitation}

You are being invited to participate in a study titled, "Producing National Subjects: Immigration, Belonging, and Governmentality." The study is being conducted by me, Samah Sabra (ssabra@connect.carleton.ca), as part of my PhD dissertation research at Carleton University. I am working under the supervision of Dr. Eva Mackey (eva_mackey@carleton.ca) in the School of Canadian Studies.

\section{Who I am and why I am doing this:}

My name is Samah Sabra. I am a first-generation Arab immigrant to Canada. I came to Canada in 1989, at the age of nine, with my parents and brother. Currently, I am a PhD student at Carleton University who is interested to learn more about Arab-Canadians' immigration experiences. My research interests arise partly from my personal background and experiences and partly from my recognition that there is a general lack of appreciation, in academia (and elsewhere), of how ArabCanadians living in Ottawa understand their home(s), nation(s), selves, and communities and how these understandings influence their senses of self, including their feelings of belonging and/or exclusion to each of these locales (home; national; self; community).

\section{What I want to know:}

I want to do research about how Arab-Canadians understand their identities, and what being an ArabCanadian means to them. Achieving this goal requires me to find out how other Arab-Canadians understand their experiences of immigrating to and living in Canada. More specifically, there are three main questions that I hope this research will help me to answer:

1. How have first-generation Arab-Canadians experienced and made sense of their lives in Ottawa?

2. Do first-generation Arab-Canadians living in Ottawa feel that they have created new senses of home and community? Why or why not?

3. Have any particular events influenced their senses of belonging in relation to Canada and/or to Ottawa's Arab community? Have such events changed the ways they understand and identify themselves? 
My hope is that answering these questions will allow me and my research participants to increase awareness about how Arab-Canadians define their own community/communities here in Ottawa and what aspects of their lives have been most rewarding and/or challenging.

\section{What I am looking for:}

I am looking for people who would be interested in being interviewed as part of my study. If you choose to participate, you will be asked to take part in an interview which, depending on your own preference, might last between one to two hours. If you agree to participate in an interview, I will begin by asking you some demographic information, such as your age and marital status. I will then ask questions about your experience of immigrating to Canada, to what extent you feel as though Canada is your home, and your views about media representations of Arabs and Arab-Canadians.

\section{About the interview and research process:}

I will ask you to decide on a location where the interview will take place. This will allow you to choose a setting (such as a coffee shop) where you will feel most comfortable to meet with me to talk about your personal feelings and experiences. It will also be up to you whether or not I take notes as we discuss your experiences and/or if I audio-tape our discussion. If you give permission for the interview to be tape-recorded, you will have full access to the tape-recorder during the interview so that you may stop it at any time. You also may stop the interview at any time and can choose not to answer any question(s) that $I$ ask. If during the interview you change your mind and do not want to continue, you may leave the interview. You will not be expected to give any reason(s) for stopping the audio-tape, for stopping the interview or for deciding to withdraw from the research project. If you choose not to take part in this study, or if you withdraw from the study, I will not tell anyone else of your decision, and any services you are currently receiving will not be affected by your decision.

If you choose to participate, anything that you say or do during the course of this study will not be told to anyone else. Anything you say that has the potential to identify you will not be published or told to anyone else. Your privacy will be completely respected. To further ensure your anonymity, I will ask that you provide a fictitious name at the beginning of the interview, and any notes I take about you and/or your interview (including any audio-tapes, written notes, or transcripts) will be labelled using this name. Of course, if you do not want to use a pseudonym because you want to be identified, you may choose to provide me with your actual name instead of a fictitious one.

Finally, if you give me permission to tape the interview, this audio-tape will be destroyed as soon as I have made a type-written copy of it. If you would like, I can provide you with a copy of your interview within one month of the time of our meeting. This will allow you time to read over what you have said to me and let me know of any changes that you may feel are necessary to make to it before I write up my research findings.

\section{Information about Participating as a Study Subject:}

If, after reading this document, you are interested in taking part in this study, or if you have any questions about it, please feel free to contact me, Samah Sabra, or my supervisor, Eva Mackey. 
Samah Sabra (PhD Candidate)

(613) 668-7571

ssabra@connect.carleton.ca
Dr. Eva Mackey

(613) 520-2600 ext. 6697

eva_mackey@carleton.ca 


\section{Appendix D}

\section{Face Sheet:}

Date:

Pseudonym:

Age:

Gender:_

Sexual orientation: _

Marital Status:

Children: Y N \#

Career/Job:

Immigrant/ refugee:

Length of time in Canada:

Family in Canada: 
1. Now I would like to ask you some general questions about immigrating to Canada:

- Can you tell me something about how you made the decision to immigrate to Canada?

- Was your decision to immigrate influenced by other people or specific events in your life? If you don't mind talking about it, can you explain how?

- What key factors influenced your decision to immigrate to Canada?

- Did you know anyone here when you decided to immigrate?

- Do you think that made a difference in your immigration decision and/or experience? Could you tell me how?

- If you don't mind talking about it, would you talk to me about what it was like for you when you first came to Canada?

- If you're comfortable discussing it, what would you say was the most difficult part of immigrating to Canada? Why do you think that is?

- Has this changed at all for you? If so, would you mind telling me when it began to change and why you think that is?

- What do you think would have made your experience of immigrating to Canada easier?

- Has any aspect of immigrating to Canada been easy? Or is there anything that has made the experience easier than it might otherwise have been?

- Do you feel like becoming a Canadian citizen has changed your life in any way?

- If so, would you mind explaining how you feel your life has changed?

2. If you don't mind, I would like to ask you a few questions about Canada specifically:

- What, if anything, did you know about Canada before immigrating here?

- Did you have any expectations about what life would be like in Canada?

- Did anything that happened after arriving in Canada surprise you? Why or why not?

- If you learned new things about Canada (and life in Canada) after arriving here, would you mind telling me how you learned these things?

- Do you think of Canada as your home?

- If not, have you ever thought of Canada as home?

- If did once think of Canada as your home, would you mind telling me why/how that feeling changed?

- If you have never considered Canada as your home, can you explain why that is?

- If you do think of Canada as home, can you tell me if you have felt this since you first arrived in Canada and why you feel this way? 
- Would you mind telling me if there are any particular places in Canada where you feel more like you are "at home" or you "fit in?" What makes these places feel more like "home" than other places?

- Do you feel like you "fit in" in Canada? Would you mind telling me why that is?

- Do you generally feel like you are accepted in Canada? Could you tell me a little bit about why you feel this way?

3. The next couple of questions are intended to help me understand how you think Arabs and/or Arab-Canadians are understood in Canada.

- Do you read newspapers or watch television shows, news broadcasts, or movies that show or talk about Arabs in Canada?

- If yes, can you tell me a little bit about that? Which of these do you $\mathrm{read} / \mathrm{watch}$ and how do you feel about them?

- Do you see yourself reflected in Canadian media portrayals of Arabs? Of Canadians? Of Arab-Canadians?

- If not, is this a conscious decision not to watch/read these forms of media?

- How do you think the general Canadian public thinks about Arabs and/or ArabCanadians? Could you tell me a little bit about why you think that is the case?

4. If you don't mind, I would like to ask you a few questions specifically about your experiences immigrating to and living in Ottawa:

- Ottawa has a large number of Arabs and Arab-Canadians in it;

- Was this something you knew before deciding to live in Ottawa?

- Was this a factor in your decision to live in Ottawa?

- Is it something that has is (or had become) important to you?

- Could you tell me a little bit about whether or not you find it difficult to meet other in Ottawa?

- Is it important for you to be living in a city where you can socialize with other Arab-Canadians? Why or why not?

- Do you think of yourself as part of an Arab or Arab-Canadian community in Ottawa? Would you mind telling me why that is?

5. These next questions are meant to address your personal sense of identity:

- Do you tend to identify yourself as an Arab, Arab-Canadian, or Canadian? Why?

- Do you identify yourself differently depending on the specific situation you are in and/or the person to whom you are speaking? Why or why not?

- In what circumstances could you imagine emphasizing a different aspect of who you are? Why?

- In general, what does being Canadian mean to you? Does it factor in how you identify? 
- In general, what does being Arabic mean to you? Does it factor in how you identify?

- Has this meaning changed over time? In what ways?

- Has it changed as you have moved from one place to another? Would you mind telling me a little bit about why that is?

- If you have children, do you talk to them about being Arabic?

- If so, what sorts of things do you tell them and why? Is this different for male children than for female children? Why or why not?

- If not, and if you don't mind talking about it, could you tell me why not?

6. Is there anything I have not asked you about or that has not come up in our conversation that you think I should know about or that is important to how you understand yourself, your community, and/or your immigration experiences?

8. Thanks and debriefing. 


\section{References}

Abdulrahim, Sawsan. 2008. "Whiteness' and the Arab American Immigrant Experience." In Race and Arab Americans Before and After 9/11: From Invisible Citizens to Visible Subjects, edited by Amaney Jamal and Nadine Naber, 131-46. Syracuse, NY: Syracuse University Press.

Aboud, Brian. 2000. "Re-reading Arab World-New World Immigration History: Beyond the Prewar/Postwar Divide." Journal of Ethnic and Migration Studies 26(4): 65373.

Abu-Laban, Baha. 1980. An Olive Branch on the Family Tree: Arab Communities in Canada. Toronto, ON: McClelland and Stuart.

Abu-Laban, Yasmeen and Christina Gabriel. 2002. Selling Diversity: Immigration, Multiculturalism, Employment Equity, and Globalization. Peterborough, ON: Broadview Press.

Abu-Laban, Yasmeen and Tim Nieguth. 2000. "Reconsidering the Constitution, Minorities, and Politics in Canada." Canadian Journal of Political Science 33(3): 465-97.

Abu-Lughod, Lila. 1986. Veiled Sentiments: Honor and Poetry in Bedouin Society. Berkley, CA: University of California Press.

-----. 1989. "Zones of Theory in the Anthropology of the Arab World." Annual Review of Anthropology 18: 267-306.

-----. 1993. Writing Women's Worlds: Bedouin Stories. Berkley, CA: University of California Press.

-----. 2001. “Orientalism and Middle East Feminist Studies." Feminist Studies 27(1):10113.

----. 2002. "Do Muslim Women Really Need Saving? Anthropological Reflections on Cultural Relativism and its Others." American Anthropologist 104(3): 783-90.

Abu-Rabia. 1997. "Gender Differences in Arab Students' Attitudes toward Canadian Society and Second Language Learning." The Journal of Social Psychology 137(1): 125-9.

Adey, Peter. 2006. "If Mobility is Everything Then it is Nothing: Towards a Relational Politics of (Im)mobilities." Mobilities 1(1):75-94. 
Agamben, Giorgio. 1996. "Beyond Human Rights." In Radical Thought in Italy: A Potential Politics, edited by Paolo Virno and Michael Hardt, 159-66.

Minneapolis, MN: University of Minnesota Press.

Allen, John. 2004. "The Whereabouts of Power: Politics, Government and Space." Geografiska Annaler Series B: Human Geography 86(1): 19-32.

Anderson, Benedict. 1983. Imagined Communities: Reflections on the Origin and Spread of Nationalism. London, U.K.: Verso.

Anderson, Kay. 2000. "Thinking 'Postnationally': Dialogue across Multicultural, Indigenous, and Settler Spaces." Annals of the Association of American Geographers 90(2): 381-91.

-----. 2002. "The Racialization of Difference: Enlarging the Story Field." The Professional Geographer 54(1):25-30.

Andrew, Hugh. 2006. "Dual Citizens Dilute our Unity." The Ottawa Citizen. July 26, A13.

Anisef, Paul, Robert Sweet, and George Frempong. 2004. Field of Study and Labour Market Outcomes of Immigrant and Racial Minority University Graduates in Canada. Toronto, ON: Joint Centre of Excellence for Research on Immigration and Settlement.

Appadurai, Arjun. 1988. "Introduction: Place and Voice in Anthropological Theory." Cultural Anthropology 3(1): 16-20.

-----. 2005 (1996). Modernity at Large: Cultural Dimensions of Globalization. Minneapolis, MN: University of Minnesota Press.

Arat-Koç, Sedef. 1989. "In the Privacy of our Own Home: Foreign Domestic Workers as Solution to the Crisis in the Domestic Sphere in Canada." Studies in Political Economy 28: 33-58.

-----. 1999. "Neo-liberalism, State Restructuring and Immigration: Changes in Canadian Policies in the 1990s." Journal of Canadian Studies 34(2): 31-56.

-----. 2005. “The Disciplinary Boundaries of Canadian Identity after September 11: Civilizational Identity, Multiculturalism, and the Challenge of Anti-Imperialist Feminism." Social Justice 32(4): 32-49.

Arendt, Hannah. 1951. "The Decline of the Nation-State and the End of the Rights of Man." In Imperialism: Part Two of the Origins of Totalitarianism, Hannah Arendt, 147-82. New York, NY: Harvest Books. 
Aretxaga, Bagoña. 2003. "Maddening States." Annual Review of Anthropology 32: 393410.

Armstrong, Jeanette and Roxana Ng. 2005. "Deconstructing Race, Deconstructing Racism: A Conversation Between Jeannette Armstrong and Roxana $\mathrm{Ng}$ (with Postscript 2004 by Roxana Ng ). In Situating "Race" and Racism in Time, Space and Theory: Critical Essays for Activists and Scholars, edited by Jo-Anne Lee and John Sutton Lutz, 30-45. Montreal, QC and Kingston, ON: McGill-Queens University Press.

Asad, Talal, ed. 1973. Anthropology and the Colonial Encounter. London, U.K.: Ithaca Press.

-----. 1993. Genealogies of Religion: Discipline and Reasons of Power in Christianity and Islam. Baltimore, MD: John Hopkins University Press.

-----. 1997. "Ethnography, Literature, and Politics: Some Readings and Uses of Salman Rushdie's The Satanic Verses." Cultural Anthropology 5(3): 239-69.

-----. 2000. “Agency and Pain: An Exploration." Culture and Religion 1(1): 29-60.

Ashcroft, Bill, Gareth Griffiths, and Helen Tiffin. 1989. The Empire Writes Back: Theory and Practice in Postcolonial Literatures. London, U.K.: Routledge.

"Assisted Relatives." 2000 (July). CIC News: Canadian Immigration Newsletter. Accessed July 2, 2011. http://www.cicnews.com/2000/07/assisted-relatives07408.html.

"Attacks on Islam 'Shame' Chretien: 'A Great World Religion Has Been Unjustly Smeared by This Evil'." 2001. The Ottawa Citizen, September 22, B7.

Atwood, Margaret. 1972. Survival: A Thematic Guide to Canadian Literature. Toronto, ON: Anasi Publishing.

"Author Says Controversy Won't Change her Approach." 2006. Peterborough Examiner, April 1, B7.

Bakan, Joel. 1997. Just Words: Constitutional Rights, Social Wrongs. Toronto, ON: University of Toronto Press.

Bakker, Isabella and Katherine Scott. 1997. "From the Postwar to the Post-Liberal Keynesian Welfare State." In Understanding Canada: Building on the New Canadian Political Economy, edited by Wallace Clement, 286-310. Montreal, QC and Kingston, ON: McGill Queen's University Press. 
Balibar, Étienne. 2006. "Strangers as Enemies: Further Reflections on the Aporias of Transnational Citizenship." Institute on Globalization and the Human Condition Working Papers Series. Hamilton, ON: McMaster University Institute on Globalization and the Human Condition. Accessed June 29, 2010. http://www2.humnet.ucla.edu/mellon/images/stories/monthlyseminars/strangers\% 20as\%20enemies.pdf.

Bannerji, Himani. 1993a. "Returning the Gaze: An Introduction." In Returning the Gaze: Essays on Racism, Feminism and Politics, edited by Himani Bannerji, ix-xxix. Toronto, ON: Sister Vision Press.

-----, ed. 1993b. Returning the Gaze: Essays on Racism, Feminism and Politics. Toronto, ON: Sister Vision Press.

-----. 1995. Thinking Through: Essays on Feminism, Marxism, and Anti-Racism. Toronto, ON: Women's Press.

-.--. 2000. The Dark Side of the Nation: Essays in on Multiculturalism, Nationalism and Gender. Toronto, ON: Canadian Scholars Press.

--.- 2001. "Pygmalion Nation: Towards a Critique of Subaltern Studies and the Resolution of the Women's Questions'." In Of Property and Propriety: The Role of Gender and Class in Imperialism and Nationalism, edited by Himani Bannerji, Shahrzad Mojab, and Judith Whitehead, 3-33. Toronto, ON: University of Toronto Press.

Barker, Francis, Peter Hulme, and Margaret Iverson, eds. 1994. Colonial Discourse/Postcolonial Theory. Manchester: Manchester University Press.

Barclay, Harold. 1968. "An Arab Community in the Canadian Northwest: A Preliminary Discussion of the Lebanese Community in Lac La Biche, Alberta." Anthropologica 10(2): 143-56.

Bauder, Harald. 2003. “'Brain Abuse', or the Devaluation of Immigrant Labour in Canada." Antipode 35(4): 699-717.

Bayoumi, Moustafa. 2008. How Does it Feel to Be a Problem: Being Young and Arab in America. New York, NY: Penguin Press.

Bealey, Frank and Allan G. Johnson. 1999. "Liberalism." The Blackwell Dictionary of Political Science, 191-2. Oxford, U.K. and Malden, MA: Blackwell Publishers.

Bell, Duncan S.A. 2003. "Mythscapes: Memory, Mythology, and National Identity." British Journal of Sociology 54(1): 63-81. 
Berger, Carl. 1966. "The True North Strong and Free." In Nationalism in Canada, edited by Peter Russell, 3-26. Toronto, ON: McGraw-Hill.

Berland, Jodi. 1999. "Weathering the North: Climate, Colonialism and the Mediated Body." In Pop Can: Popular Culture in Canada, edited by Lynne Van Luven and Priscilla Walton, 207-18. Scarborough, ON: Prentice-Hall Allyn and Bacon Canada.

Berry, John W. 1997. "Immigration, Acculturation, and Adaptation." Applied Psychology 46(1): 5-34.

----. 2001. “A Psychology of Immigration.” Journal of Social Issues 57(3): 615-31.

Bhandar, Davina. 2000. "Critical Race Theory." In Encyclopedia of Feminist Theories, edited by Lorraine Code, 109-10. London, U.K. and New York, NY: Routledge.

----. 2004. "Renormalizing Citizenship and Life in Fortress North America." Citizenship Studies 8(3): 261-78.

Bialystok, Frank. 2006. "There Are Reasons Why The Merchant of Venice or To Kill a Mockingbird are Not Taught in Lower Grades, Says the Canadian Jewish Congress's Frank Bialystok." The Toronto Star, March 21, A23.

Billig, Michael. 1995. Banal Nationalism. London, U.K.: Sage Publishing.

Bissoondath, Neil. 2002 (1994). Selling Illusions: The Cult of Multiculturalism in Canada. Toronto, ON: Penguin.

Bhabha, Homi. 2002 (1990). "DissemiNation: Time, Narrative, and the Margins of the Modern Nation." In Nation and Narration, edited by Homi Bhabha, 291-322. London, U.K.: Routledge.

Bhattacharya, Kakali. 2009. "Negotiating Shuttling Between Transnational Experience: A De/Colonizing Approach to Performance Ethnography." Qualitative Inquiry 15(6): 1061-83.

Blanchfield, Mike. 2006. "Deaths of Canadians in Lebanon Put Political Pressure on Harper." The Ottowa Citizen, July 17, A5.

Bloemraad, Irene. 2011. “'Two Peas in a Pod,' 'Apples and Oranges,' and Other Food Metaphors: Comparing Canada and the United States." American Behavioral Scientist 55(9):1131-59.

Bloom, David, Gilles Grenier, and Morley Gunderson. 1995. "The Changing Labour Market Positions of Canadian Immigrants." Canadian Journal of Economics 28(4b): 987-1005. 
Blunt, Allison and Gillian Rose. 1994. "Introduction: Women's Colonial and Postcolonial Geographies." In Writing Women and Space: Colonial and Postcolonial Geographies, edited by Allison Blunt and Gillian Rose, 1-25. New York, NY: The Guilford Press.

Boski, Pawel. 1991. "Remaining a Pole or Becoming a Canadian: National Self-Identity among Polish Immigrants to Canada." Journal of Applied Social Psychology 21(1): 41-77.

Bornstein, Avram. 2002. "Borders and the Utility of Violence: State Effects on the 'Superexploitation' of West Bank Palestinians." Critique of Anthropology 22(2): 201-220.

Brah, Avtar. 1996. Cartographies of Diaspora: Contesting Identities. New York, NY: Routledge.

Brah, Avtar and Ann Phoenix. 2004. "Ain't I a Woman: Revisiting Intersectionality." Journal of International Women's Studies 5(3): 75-86.

Brenner, Neil. 2001. "The Limits to Scale? Methodological Reflections on Scalar Structuration." Progress in Human Geography 25(4): 591-614.

Breuilly, John. 1985. Nationalism and the State. Chicago, IL: University of Chicago Press.

Brodie, Janine. 1996. "Restructuring and the New Citizenship." In Rethinking Restructuring: Gender and Change in Canada, edited by Isabella Bakker, 126-40. Toronto, ON: University of Toronto Press.

----. 2002. "Three Stories of Canadian Citizenship." In Contesting Canadian Citizenship: Historical Readings, edited by Robert Adamoski, Dorothy Chunn, and Robert Menzies, 43-68. Peterborough, ON: Broadview Press.

Brotz, Howard. 1980. "Multiculturalism in Canada: A Muddle." Canadian Public Policy 6(1): 41-6.

Brown, Wendy. 1995. States of Injury: Power and Freedom in Late Modernity. Princeton, NJ: Princeton University Press.

----. 2006. Regulating Aversion: Tolerance in the Age of Identity and Empire. Princeton, NJ: Princeton University Press.

Bumstead, John Michael. 1992. The Peoples of Canada: A Post-Confederation History. Toronto, ON: Oxford University Press. 
Burman, Jenny. 2010. Transnational Yearnings: Tourism, Migration, and the Diasporic City. Vancouver, BC: University of British Columbia Press.

Burn, Catharine. 2001. "Reterritorializing the Relationship between People and Place in Refugee Studies." Geografiska Annaler 83(1): 15-25.

Burnett, Jean. 1979. "Myths and Multiculturalism." Canadian Journal of Education $4(4): 43-58$.

Butler, Judith. 1990. Gender Trouble: Feminism and the Subversion of Identity. New York, NY: Routledge.

-.-.- 1992. "Contingent Foundations: Feminism and the Question of 'Postmodernism'." In Feminists Theorize the Political, edited by Judith Butler and Joan W. Scott, 321. New York, NY: Routledge.

-.--. 1993. Bodies that Matter: On the Discursive Limits of "Sex". New York, NY: Routledge.

-----. 1997. The Psychic Life of Power: Theories in Subjection. Stanford, CA: Stanford University Press.

Butz, David. 1995. "Revisiting Edward Said's Orientalism." Brock Review 4(1/2): 54-80.

Butz, David and Kenneth I. MacDonald. 2001. "Serving Sahibs with Pony and Pen: The Discursive Uses of 'Native Authenticity'." Environment and Planning D: Society and Space 19: 179-201.

Butz, David and Michael Ripmeester. 1999. "Finding Space for Resistant Subcultures." Invisible Culture: An Electronic Journal for Visual Studies 2: 1-16.

Caincar, Louise. 2008. "Thinking Outside the Box: Arabs and Race in the United States." In Race and Arab Americans Before and After 9/11: From Invisible Citizens to Visible Subjects, edited by Amaney Jamal and Nadine Naber, 46-80. Syracuse, NY: Syracuse University Press.

Canada Border Services Agency (CBSA). 2009. "Canada-U.S. Safe Third Country Agreement." Government of Canada. Accessed April 23, 2010. http://www.cbsaasfc.gc.ca/agency-agence/stca-etps-eng.html.

Canada. 1947. "Canadian Citizenship Act." Revised Statutes of Canada. Ottawa: Queen's Printer.

----.. 1951. Royal Commission on Development in the Arts, Letters and Sciences (Massey Commission). Report of the Royal Commission on Development in the Arts, Letters and Sciences 1949-1951. Ottawa: Edmond Cloutier, C.M.G., O.A., 
D.S.P. Accessed June 2, 2011. http://www.collectionscanada.gc.ca/massey/h5400-e.html.

-.---. 1957. Royal Commission on Broadcasting (Fowler Commission). Report of the Royal Commission on Broadcasting 1957. Ottawa: Queen's Printer.

----.. 1962. Royal Commission on Publications (O'Leary Commission). Report of the Royal Commission on Publications 1962. Ottawa: Queen's Printer.

-----. 1976. “Immigration Act." Revised Statutes of Canada 1976-77. Ottawa: Queen's Printer.

1982. "Canadian Constitution Act." Revised Statutes of Canada. Accessed April 29, 2010. http://laws-lois.justice.gc.ca/eng/const/page-11.html\#anchorsc:7.

-.---. 1994. Parliament. House of Commons. Debate, $35^{\text {th }}$ Parliament, $1^{\text {st }}$ Session. Hansard 17. February 8, 1994. Accessed 23 April, 2010. http://www2.parl.gc.ca/HousePublications/Publication.aspx?Language=E\&Mode $=1 \&$ Parl $=35 \&$ Ses $=1 \&$ DocId $=2328749 \&$ File $=0$.

-----. 2001. Immigration and Refugee Protection Act 2001. Revised Statutes of Canada. Ottawa, ON: Queen's Printer. Accessed April 28, 2010. http://lawslois.justice.gc.ca/PDF/I-2.5.pdf.

---.. 2006a. Commission of Inquiry into the Actions of Canadian Officials in Relation to Maher Arar. Report of the Events Relating to Maher Arar: Analysis and Recommendations. Ottawa, ON: Gilmore Print Group.

-..-. 2006b. Commission of Inquiry into the Actions of Canadian Officials in Relation to Maher Arar. Report of the Events Relating to Maher Arar: Factual Background Volume 1. Ottawa, ON: Gilmore Print Group.

--.-. 2006c. Commission of Inquiry into the Actions of Canadian Officials in Relation to Maher Arar. Report of the Events Relating to Maher Arar: Factual Background Volume 2. Ottawa, ON: Gilmore Print Group.

-----. 2010. Office of the Prime Minister. "Pierre Elliot Trudeau." Accessed May 29, 2010. http://pm.gc.ca/eng/bio former.asp?id=71.

Cannella, Gail S and Yvonna S Lincoln. 2004. "Epilogue: Claiming a Critical Public Social Science - Reconceptualizing and Redeploying Research. Qualitative Inquiry 10 (2): 298-309.

CBC (Canadian Broadcasting Corporation). 2006. "Author of Book on Palestinian, Israeli Children Speaks Out." March 3, 2006. Accessed November 1, 2009. http://www.cbc.ca/arts/story/2006/03/23/threewishes-ellis.html 
-----. 2009. "Pierre Trudeau: Philosopher and Prime Minister." CBC Digital Archives. Accessed April 26, 2010. http://archives.cbc.ca/politics/prime_ministers/topics/2192-13259/.

CCR (Canadian Council for Refugees). 2000a. A Hundred Years of Immigration to Canada: 1900-1999 (Part One). Accessed February 10, 2008. http://ccrweb.ca/en/hundred-years-immigration-canada-1900-1999.

----. 2000b. A Hundred Years of Immigration to Canada: 1900-1999 (Part Two). Accessed February 10, 2008. http://ccrweb.ca/en/hundred-years-immigrationcanada-part-2.

-----. 2000c. Report on Systemic Racism and Discrimination in Canadian Refugee and Immigration Policies. Accessed November 13, 2009. http://www.ccrweb.ca/arreport.PDF.

"Censorship: Parents Best to Decide." 2006. Windsor Star, March 25, A6.

Chakrabarty, Dipesh. 1992. "Postcoloniality and the Artifice of History: Who Speaks for "Indian" Pasts?" Representations 37(Winter 1992): 1-25.

Chatterjee, Partha. 1986. Nationalist Thought and the Colonial World: A Derivative Discourse? London, U.K.: Zed Books.

-----. 1991. "Whose Imagined Community?" Millennium: Journal of International Studies 20(3): 521-5.

-----. 1993. The Nation and Its Fragments: Colonial and Postcolonial Histories. Princeton, NJ: Princeton University Press.

Chowdhry, Geeta. 2007. "Edward Said and Contrapuntal Reading: Implications for Critical Interventions in International Relations." Millennium: Journal of International Studies 36(1): 101-16.

CIC (Citizenship and Immigration Canada). N.d.a. Canada: What You Need to Go Before You Go. Accessed July 10, 2011. http://integration-net.ca/coaoce/english/index.htm.

----. N.d.b. Climate in Canada. Accessed July 10, 2011. http://integration-net.ca/coaoce/english/pdf/06climate.pdf.

N.d.c. Living in a Multicultural Society. Accessed July 10, 2011. http://integrationnet.ca/coa-oce/english/pdf/08multicultural.pdf. 
-.-.-. N.d.d. Rights and Responsibilities. http://integration-net.ca/coaoce/english/pdf/05rights.pdf.

-.--. 2003a. Study Guide: A Look at Canada. Ottawa: Government of Canada.

2003b. Welcome to Canada: What You Should Know. Ottawa: Government of Canada.

-----. 2005. "Report on the Evaluation of the Delivery of the Canadian Orientation Abroad Initiative." Accessed July 10, 2011. http://www.cic.gc.ca/english/resources/evaluation/orientation.asp\#summary.

----. 2007a. "Refugees: Sponsoring Refugees." Accessed June 28, 2011. http://www.cic.gc.ca/english/refugees/sponsor/index.asp.

-.--.-. 2007b. "Resettlement from outside Canada: Convention Refugees Abroad Class." Accessed June 28, 2011.

http://www.cic.gc.ca/english/refugees/outside/convention.asp.

-----. 2007c. "Sponsoring Your Family: Eligible Relatives." Accessed June 28, 2011. http://www.cic.gc.ca/english/immigrate/sponsor/relatives.asp.

---. 2008a. " $100^{\text {th }}$ Anniversary of the Continuous Passage Act." Accessed March 1, 2011. http://www.cic.gc.ca/english/multiculturalism/asian/100years.asp.

--.-. 2008b. "Canadian Experience Class." Accessed June 29, 2011. http://www.cic.gc.ca/english/immigrate/cec/index.asp.

-----. 2009. "Facts and Figures 2008 - Immigration Overview: Permanent and Temporary Residents." Accessed June 29, 2011. http://www.cic.gc.ca/english/resources/statistics/facts2008/permanent/01.asp.

2010a. "Backgrounder: Changes to the Federal Immigrant Investor Program Will Bring to Canada More Resources to Fund Economic Development and Job Creation Initiatives." Accessed August 2, 2010.

http://www.cic.gc.ca/english/department/media/backgrounders/2010/2010-0626b.asp.

-----. 2010b. "Immigrating to Canada." Accessed June 29, 2011. http://www.cic.gc.ca/english/immigrate/index.asp.

2010c. "Investors, Entrepreneurs and Self-Employed Persons." Accessed June 29, 2011. http://www.cic.gc.ca/english/immigrate/business/index.asp.

-----. 2010d. "Sponsoring Refugees: Joint Assistance Sponsorship." Accessed June 28, 2011. http://www.cic.gc.ca/english/refugees/sponsor/jas.asp. 
-----. 2010e. "Sponsoring Refugees: Private Sponsorship of Refugees Program." Accessed June 28, 2011.

http://www.cic.gc.ca/english/refugees/sponsor/private.asp.

-----. 2010f. Study Guide: Discover Canada. Ottawa: Government of Canada.

----. 2011a. "Provincial Nominees." Accessed June 29, 2011.

http://www.cic.gc.ca/english/immigrate/provincial/index.asp.

-.-.-. 2011b. "Refugees." Accessed June 29, 2011.

http://www.cic.gc.ca/english/refugees/index.asp

----. 2011 c. "Skilled Workers and Professionals: Who Can Apply." Accessed June 29, 2011. http://www.cic.gc.ca/english/immigrate/skilled/apply-who.asp.

Clarke, George Elliot. 1997. "White Like Canada." Transitions 73: 98-109.

Clifford, James. 1988. The Predicament of Culture: Twentieth Century Ethnography, Literature, and Art. Cambridge, MA: University of Harvard Press.

Clifford, James and George Marcus. 1986. Writing Culture: The Poetics and Politics of Ethnography. Berkley, CA: University of California Press.

Clifton, Rodney A. and Lance W. Roberts. 1982. "Misreading the Nature of Canadian Multiculturalism." Canadian Public Policy 8(4): 611-12.

Colin, Lindsay. 2001a. "Profiles of Ethnic Communities in Canada: The Arab Community in Canada." Statistics Canada. Ottawa, Ontario. Accessed August 25, 2008. http://dsp-psd.pwgsc.gc.ca/collection_2007/statcan/89-621-X/89-621XIE2007009.pdf.

Colin, Lindsay. 2001b. "Profiles of Ethnic Communities in Canada: The Lebanese Community in Canada." Statistics Canada. Ottawa, Ontario. Accessed August 25, 2008. http://dsp-psd.pwgsc.gc.ca/collection_2007/statcan/89-621-X/89-621XIE2007015.pdf.

Collins, Patricia Hill. 2000 (1990). Black Feminist Thought: Knowledge, Consciousness, and the Politics of Empowerment. New York, NY and London, U.K.: Routledge.

Comaroff, Jean and John L. Comaroff. 2001. "Millennial Capitalism: First Thoughts on a Second Coming." In Millennial Capitalism and the Culture of Neoliberalism, edited by Jean Comaroff and John L. Comaroff, 1-56. Durham, NC: Duke University Press. 
Coombes, Annie. 1994. "The Recalcitrant Object: Culture Contact and the Question of Hybridity." In Colonial Discourse/Postcolonial Theory, edited by Francis Barker, Peter Hulme, and Margaret Iverson, 89-114. Manchester, U.K.: Manchester University Press.

Côté , Mark. 2006. “A Book Kids Should Read.” The Globe and Mail, March 22, B8.

Cox, Jeremy and John Connell. 2003. "Place, Exile and Identity: The Contemporary Experience of Palestinians in Sydney." Australian Geographer 34(3): 329-43.

Crenshaw, Kimberlé. 1989. "Demarginalizing the Intersection of Race and Sex: A Black Feminist Critique of Antidiscrimination Doctrine, Feminist Theory and Antiracist Politics." University of Chicago Legal Forum 1989:139-67.

-----. 1991. "Mapping the Margins: Intersectionality, Identity Politics, and Violence against Women of Color." Stanford Law Review 43(6): 1241-99.

Crenshaw, Kimberlé, Neil Gotanda, Gary Peller, and Kendall Thomas, eds. 1995. Critical Race Theory: The Key Writings that Formed the Movement. New York, NY: New Press.

Creswell, John W. 2007. Qualitative Inquiry and Research Design: Choosing among Five Traditions, 2nd edition. Thousand Oaks, CA: Sage.

Dahab, F. Elizabeth. 1999. "Arabic Canadian Literature: Overview and Preliminary Bibliography." Canadian Ethnic Studies/Etudes Ethniques au Canada 31(2): 10014.

Dalgleish, Kim. 2008. A Call for Asset-Based Approaches to Immigrant Economic Integration. Toronto, ON: CERIS - The Ontario Metropolis Centre.

Das, Veena and Deborah Poole. 2004. "The State and its Margins." In Anthropology at the Margins of the State, edited by Veena Das and Deborah Poole, 2-32. New Delhi, India: Oxford University Press.

Dauvergne, Catherine. 2007. "Citizenship with a Vengeance." Theoretical Inquiries in Law 8(2): 488-508.

Dawson, Don. 1982. "The Structural Realities of Canadian Multiculturalism: A Response to Roberts and Clifton." Canadian Public Policy 8(4): 608-11.

Day, Richard. 2000. Multiculturalism and the History of Canadian Diversity. Toronto, ON: University of Toronto Press.

Dean, Mitchell. 1999. "Basic Concepts and Themes." In Governmentality: Power and Rule in Modern Society, edited by Mitchell Dean, 7-22. London, U.K.: Sage. 
Delaney, David. 2002. "The Space that Race Makes." The Professional Geographer 54(1): 6-14.

Delgado, Richard and Jean Stefancic. 2001. Critical Race Theory: An Introduction. New York, NY: New York University Press.

Denzin, Norman and Michael Giardana, eds. 2008. Qualitative Inquiry and the Politics of Evidence. Walnut Creek, CA: Left Coast Press.

Derrida, Jacques. 2003. On Cosmopolitanism and Forgiveness. Translated by Mark Dooley and Michael Hughes, with Preface by Simon Critchley and Richard Kearney. London, U.K. and New York, NY: Routledge.

Dirlik, Arif. 1994. "The Postcolonial Aura: Third World Criticism in the Age of Global Capitalism." Critical Inquiry 20(2): 328-56.

-----. 2002. "Bringing History Back In: Of Diasporas, Hybridities, Places, and Histories." In Beyond Dichotomies: Histories, Identities, Cultures, and the Challenge of Globalization, edited by Elisabeth Mudimbe-Boyi, 93-127. New York, NY: State University of New York Press.

Dobrowolsky, Alexandra. 2007. "(In)Security and Citizenship: Security, Im/migration, and Shrinking Citizenship Regimes." Theoretical Inquiries in Law 8(2): 628-62.

Dominion of Canada, Immigration Act. 1910. Revised Statutes of the Dominion of Canada . Ottawa: King's Printer.

Dua, Enakshi. 2003. "Towards Theorizing the Connections Between Governmentality, Imperialism, Race, and Citizenship: Indian Migrants and Racialisation of Canadian Citizenship." In Making Normal: Social Regulation in Canada, edited by Deborah Brock, 40-62. Scarborough: Nelson Thomson.

Du Gay, Paul, Jessica Evans, and Peter Redman. 2009 (2000). "General Introduction." In Identity: A Reader, edited by Paul du Gay, Jessica Ecans, and Peter Redman, 1-5. Los Angeles, CA; London, U.K.; New Delhi, India; Singapore, Singapore; and Washington DC: Sage Press in association with The Open University.

Eid, Paul. 2007. Being Arab: Ethnic and Religious Identity Building among Second Generation Youth in Montreal. Montreal, QC: McGill-Queens.

Ellis, Deborah. 2004. Three Wishes: Palestinian and Israeli Children Speak. Toronto, ON: Groundwood Books.

---.. 2006. "Kids are Tough Enough for the Truth." The Toronto Star, March 22, A18. 
Elton, Sarah. 2006. "The Author's Response." The Globe and Mail, March 21, A10.

Embree, John. 1950. "A Note on Ethnocentrism in Anthropology." American Anthropologist 52(3): 430-2.

Eriksen, Thomas Hylland. 2002. Ethnicity and Nationalism: Anthropological Perspectives. London, U.K.: Pluto Press.

Evans, Gwent. 2004 (August). "Book Reviews: Three Wishes." Quill and Quire. Accessed November $1^{\text {st }}, 2009$. http://www.quillandquire.com/books_young/review.cfm?review id=4044.

Fabian, Johannes. 1983. Time and the Other: How Anthropology Makes its Object. New York, NY: Columbia University Press.

Fathi, Asghar. 1973. "The Arab Moslem Community in the Prairie City." Canadian Ethnic Studies/Études Ethniques du Canada 5(1/2): 409-26.

Fleras, Augie. 2010. Unequal Relations: An Introduction to Race, Ethnicity, and Aboriginal Dynamics in Canada. Toronto, ON: Pearson Canada.

Fong, Karen. 2009. Overcoming Structural Barriers to Labour Market Integration: An Analysis of the Toronto Region Immigrant Employment Council's Approach. Toronto, ON: CERIS, the Ontario Metropolis Centre.

Fortier, Anne-Marie. 2006. "The Politics of Scaling, Timing and Embodying: Rethinking the 'New Europe'." Mobilities 1(3): 313-31.

Foucault, Michel. 1979. Discipline and Punish: The Birth of the Prison. Translated by Alan Sheridan. New York, NY: Vintage Books.

-----. 1980. Power/Knowledge: Selected Interviews and Other Writings 1972-1977. Edited by Colin Gordon, translated by Colin Gordon, Leo Marshall, John Mepham, and Kate Soper. New York, NY: Pantheon Books.

----.. 1983. "Subject and Power." In Michel Foucault: Beyond Structuralism and Hermeneutics, edited by Hubert Dreyfus and Paul Rabinow, 208-226. Chicago: University of Chicago Press.

-.-.- 1990a (1985). The History of Sexuality Vol. 1, An Introduction. Translated by Robert Hurley. New York, NY: Vintage Books.

-.--. 1990b (1985). The History of Sexuality Vol. 2, The Use of Pleasure. Translated by Robert Hurley. New York, NY: Vintage Books. 
-----. 1991 (1978). "Governmentality." In The Foucault Effect: Studies in Governmentality, edited by Graeme Burchell, Colin Gordon, and Peter Miller, 87104. Chicago, IL: University of Chicago Press.

----. 1995 (1975). Discipline and Punish: The Birth of the Prison. Translated by Alan Sheridan. New York, NY: Vintage Books.

----. 2003 (1969). The Archaeology of Knowledge. Translated by A.M. Sheridan Smith. London and New York, NY: Routledge.

Frankenburg, Ruth. 2001. "The Mirage of an Unmarked Whiteness." In The Making and Unmaking of Whiteness, edited by Brigit Brander Rasmussen, Eric Klinenberg, Irene J. Nexica, and Matt Wray, 72-96. Durham, NC and London, U.K.: Duke University Press.

Friedman, May. 2000. “Tangled Identities: Arab Canadian Women.” M.A. Thesis. Carleton University.

Froc, Kerri. 2010. "Multidimensionality and the Matrix: Identifying Charter Violations in Cases of Complex Subordination." Canadian Journal of Law and Society 25(1): 21-49.

Frye, Northrop. 1971. The Bush Garden: Essays on the Canadian Imagination. Toronto, ON: Anasi Publishing.

Gana, Nouri. 2009. "Everyday Arabness: The Poethics of Arab Canadian Literature and Film." CR: The New Centennial Review 9(2): 21-44.

Geertz, Clifford. 1973. The Interpretation of Culture: Selected Essays. New York, NY: Basic Books.

Gellner, Ernest. 1983. Nations and Nationalism. Oxford, U.K.: Blackwell.

George, Usha and Ferzana Chaze. 2009. "Social Capital and Employment: South Asian Women's Experiences." Affilia: Journal of Women and Social Work 24(4): 394405.

Gessel, Paul. 2001. "Chretien Blasts Museum for Cancelling Art Show: Museum of Civilization Postpones Display by Arab-Canadian Artists." The Vancouver Sun, September 27, A8.

Ghulam, Elen. 2006. Don't Shoot! ...I Have Another Story to Tell You. LuLu.com Publishing.

Gilroy, Paul. 1987. There Ain't No Black in the Union Jack: The Cultural Politics of Race and Nation. London, U.K.: Hutchison Press. 
---.- 1993. The Black Atlantic: Modernity and Double Consciousness. Cambridge, MA: Harvard University Press.

---.-. 2004. Between Camps: Nations, Cultures, and the Allure of Race. London, U.K. and New York, NY: Routledge.

-.-. 2005. Postcolonial Melancholia. New York, NY: Columbia University Press.

Goldberg, David Theo. 1993. Racist Culture: Philosophy and the Politics of Meaning. Cambridge, MA: Blackwell Publishers.

----. 1997a. "Introduction: Multicultural Conditions." In Multiculturalism: A Critical Reader, edited by David Theo Goldberg, 1-41. Malden, MA and Oxford, U.K.: Blackwell Publishers.

-----, ed. 1997b. Multiculturalism: A Critical Reader. Malden, MA and Oxford, U.K.: Blackwell Publishers.

-.-. 2002. The Racial State. Malden, MA, Oxford, U.K., and Victoria, BC: Blackwell Publishing.

Goonewardena, Kanishka and Stefan Kipfer. 2005. "Spaces of Difference: Reflections from Toronto on Multiculturalism, Bourgeois Urbanism and the Possibility of Radical Urban Politics." International Journal of Urban and Regional Research 29(3): 670-8.

Government of Ontario. 2008-2011. "Changing Your Name." Queen's Printer for Ontario. Last Modified March 28, 2011. Accessed June 13, 2011. http://www.ontario.ca/en/information bundle/individuals/119596.html\#formalself

Greenfeld, Liah. 1992. Nationalism: Five Roads to Modernity. Cambridge: Harvard University Press.

Gregory, Derek. 1995a. "Between the Book and the Lamp: Imaginative Geographies of Egypt, 1849-50." Transactions of the Institute of British Geographers 20(1): 2957.

----. 1995b. "Imaginative Geographies." Progress in Human Geography 19(4): 447-85.

-.---. 2000. "Edward Said's Imaginative Geographies." In Thinking Space, edited by Mike Crang and Nigel Thrift, 302-48. New York, NY: Routledge.

----. 2001. "(Post)Colonialism and the Production of Nature." In Social Nature: Theory, Practice, and Politics, edited by Noel Castree and Bruce Braun, 84-111. Malden, MA: Blackwell Publishers. 
---. 2004. The Colonial Present: Afghanistan, Palestine, and Iraq. Malden, MA: Blackwell Publishers.

-----. 2006. "The Black Flag: Guantánamo Bay and the Space of Exception." Geografiska Annaler Series B: Human Geography 88(4): 405-27.

Groundwood Books Ltd. (n.d.). "Three Wishes." Accessed November 1, 2009. http://www.groundwoodbooks.com/gw_titles.cfm?pub id=370.

Guibernau, Montserrat and John Rex. 1997. "Introduction." In The Ethnicity Reader: Nationalism, Multiculturalism, and Migration, edited by Montserrat Guibernau and John Rex, 1-12. Cambridge: Polity Press.

Gupta, Akhil and James Ferguson. 1992. "Beyond 'Culture': Space, Identity, and the Politics of Difference.” Cultural Anthropology 7(1): 6-23.

Haas, Amira. 2009. "History Did Not Begin with the Qassams." Haaretz (January 14, 2009). Accessed August 2, 2011. http://www.haaretz.com/printedition/opinion/history-did-not-begin-with-the-qassams-1.268097.

Habib, Jasmin. 2004. Israel, Diaspora and the Routes of National Belonging. Toronto, ON: University of Toronto Press.

Haddad, Yvonne Yazbeck. 2004. Not Quite American? The Shaping of Arab and Muslim Identity in the United States. Waco, TX: Baylor University Press.

Haeri, Niloofar. 2000. "Form and Ideology: Arabic Sociolinguistics and Beyond." Annual Review of Anthropology 29: 61-87.

Hafez, Ziad. 2011. "The Arab Renaissance Project: The Debates and Critique." Contemporary Arab Affairs 4(1): 62-75.

Hage, Ghassan. 1992. "Religious Fundamentalism as a Political Strategy: The Evolution of the Lebanese Forces' Religious Discourse during the Lebanese Civil War." Critique of Anthropology 12(1): 27-45.

----. 1998. White Nation: Fantasies of White Supremacy in a Multicultural Society. Annandale, Australia: Pluto Press.

-.--.. 2009. "Nationalist Anxiety and Fear of Losing Your Other." The Australian Journal of Anthropology 7(2): 121-40.

Halper, Jeff. 2008. An Israeli in Palestine: Resisting Dispossession, Redeeming Israel. London, U.K. and Ann Arbor, MI: Pluto Books. 
Hamdan, Amani. 2007. "Arab Muslim Women in Canada: The Untold Narratives." Journal of Muslim Minority Affairs 27(1): 133-54.

Hammer, Juliane. 2005. Palestinians Born in Exile: Diaspora and the Search for a Homeland. Austin, TX: University of Texas Press.

Haldrup Michael, Lasse Koefoed, and Kirsten Simonsen. 2006. "Practical Orientalism: Bodies, Everyday Life and the Construction of Otherness. Geografiska Annaler Series B: Human Geography 88 (2): 173-84.

Hall, Stuart. 1996. "Who Needs 'Identity'?" In Questions of Cultural Identity, edited by Stuart Hall and Paul Du Gay, 1-17. London, U.K., Thousand Oaks, CA, and New Delhi, India: Sage Publications.

----. 1999. "The Global, the Local, and the Return of Ethnicity." In Social Theory: the Multicultural and Classic Readings, edited by Charles Lemert, 626-33. Boulder, CO: Westview Press.

----. 2007. "The West and the Rest: Discourse and Power." In Race and Racialization: Essential Readings, edited by Tania Das Gupta, Carl E. James, Roger C.A. Maaka, Grace-Edwards Galabuzi, and Chris Andersen, 56-64. Toronto, ON: Canadian Scholars' Press.

Handler, Richard. 1984. "On Sociocultural Discontinuity: Nationalism and Cultural Objectification in Quebec." Cultural Anthropology 25(1): 55-71.

----. 1988. Nationalism and the Politics of Culture in Quebec. Madison, WI: University of Wisconsin Press.

Hannam, Kevin, Mimi Sheller, and John Urry. 2006. "Editorial: Mobilities, Immobilities, and Moorings." Mobilities 1(1):1-22.

Haraway, Donna. 1989. Primate Visions: Gender, Race, and Nature in the World of Modern Science. New York, NY: Routledge.

-.--. 1991. "A Cyborg Manifesto: Science, Technology, and Socialist-Feminism in the Late Twentieth Century." In Simians Cyborgs and Women: The Reinvention of Nature, 150-81. New York, NY: Routledge.

---. 2004. "Ecce Homo, Ain't (Ar'n't) I a Woman, and Inappropriate/d Others: The Human in a Post-Humanist Landscape". In The Haraway Reader, 47-61. New York, NY: Routledge.

Harding, Sandra. 1983. The Science Question in Feminism. Ithaca, NY: Cornell University Press. 
Harris, Angela. 1994. "Foreword: The Jurisprudence of Reconstruction." California Law Review 82: 741-85.

Harvey, David. 2005. A Brief History of Neoliberalism. Oxford, U.K. and New York, NY: Oxford University Press.

Haynes, Douglas and Gyan Prakash. 1991. "Introduction: The Entanglement of Power and Resistance." In Contesting Power: Resistance and Everyday Social Relations in South Asia, edited by Douglas Haynes and Gyan Prakash, 1-22. Berkley, CA: University of California Press.

Henry, Jules. 1951. "National Character and War." American Anthropologist 53(1): 1345.

Heritage Community Foundation. 2010. "Federal Multicultural Policy: Announcement of Implementation of Policy of Multiculturalism within Bilingual Framework." Alberta Online Encyclopedia. Accessed May 23, 2010.

http://www.abheritage.ca/albertans/speeches/trudeau.html.

Hiebert, Daniel. 1999. "Local Geographies of Labor Market Segmentation: Montréal, Toronto, and Vancouver, 1991." Economic Geography 75(4): 339-69.

Higgins, Alexa. 2006. "Don't Be Fooled by Glitzy Stories in Media; Find the Truth." The Record, April 12, A13.

Hobsbawm, Eric. 1990. Nations and Nationalism since 1780: Programme, Myth, Reality. Cambridge, U.K.: Cambridge University Press.

Hoebel, E. Adamson. 1967. "Anthropological Perspectives on National Character." Annals of the American Academy of Political and Social Science 370: 1-7.

Honig, Bonnie. 2001. Democracy and the Foreigner. Princeton, NJ: Princeton University Press.

hooks, bell. 1981. Ain't I a Woman: Black Women and Feminism. Boston, MA: South End Press.

Howard, Judith A. 2000. "Social Psychology of Identities." Annual Review of Sociology 26: 367-93.

Howard-Hassman, Rhoda. 1999. “"Canadian' as Ethnic Category: Implications for Multiculturalism and National Unity." Canadian Public Policy 25(4): 523-37.

Hutchinson, Darren Lenard. 1999. "Ignoring the Sexualization of Race: Heteronormativity, Critical Race Theory and Anti-Racist Politics." Buffalo Law Review 47:1-116. 
-----. 2001. "Identity Crisis: 'Intersectionality,' 'Multidimensionality,' and the Development of an Adequate Theory of Subordination." Michigan Journal of Race and Law 6: 285-317.

----. 2003. "Homophobia in the Halls of Justice: Sexual Orientation Bias and its Implications within the Legal System." American University Journal of Gender, Social Policy and the Law 11:13-24.

-----. 2004. "Critical Race Theory: History, Evolution, and New Frontiers." American University Law Review 53: 1187-215.

IOM (International Organization for Migration). N.d. "Canadian Orientation Abroad: Helping Future Migrants Adapt to Life in Canada." Accessed July 10, 2011. http://www.iom.int/jahia/Jahia/canadian-orientation-abroad.

Isin, Engin F. 2007. "City.State: Critique of Scalar Thought." Citizenship Studies 11(2): 211-28.

Isin, Engin F. and Bryan S. Turner. 2007. "Investigating Citizenship: An Agenda for Citizenship Studies." Citizenship Studies 11(1): 5-17.

Jabbra, Nancy W. 1983. "Assimilation and Acculturation of Lebanese Extended Families in Nova Scotia." Canadian Ethnic Studies/Etudes Ethniques au Canada 15(1): 54-72.

-----. 1997. "Politics and Acceptance: the Lebanese in Canada's Maritime Provinces." Canadian Ethnic Studies/Etudes Ethniques au Canada 29(1): 99-118.

Jamal, Amaney. 2008. "Civil Liberties and the Otherization of Arab and Muslim Americans." In Race and Arab Americans Before and After 9/11: From Invisible Citizens to Visible Subjects, edited by Amaney Jamal and Nadine Naber, 114-30. Syracuse, NY: Syracuse University Press.

Jean-Klein, Iris. 2001. "Nationalism and Resistance: The Two Faces of Everyday Activism in Palestine during the First Intifada." Cultural Anthropology 16(1): 83126.

Jenson, Jane. 1999. "Fated to Live in Interesting Times: Canada's Changing Citizenship Regimes." Canadian Journal of Political Science 30(4): 627-44.

Jonas, George. 2001. "Islamic Leaders Must Speak out Against the Hijacking of Islam." The Ottawa Citizen, October 22, 2001, A16.

Joseph, Suad. 1999. "Against the Grain of the Nation - the Arab." In Arabs in America: Building a New Future, edited by Michael Suleiman, 257-71. Philadelphia, PA: Temple University Press. 
Joseph, Suad and Benjamin D'Harlingue, with Alvin Ka Hin Wong. 2008. “Arab Americans and Muslim Americans in the New York Times, Before and After 9/11." In Race and Arab Americans Before and After 9/11: From Invisible Citizens to Visible Subjects, edited by Amaney Jamal and Nadine Naber, 229-275. Syracuse, NY: Syracuse University Press.

Kadi, Joanna, edited by 1994. Food For Our Grandmothers: Writings By Arab-American and Arab-Canadian Feminists. Cambridge, MA: South End Press.

Kalinowski, Tess. 2006. "Decision on Book to Be Reviewed: Kids' Book on Mideast Removed from Shelves. School Board Trustees to Debate Process." The Toronto Star, April 6, A24.

Kalinowski, Tess and Kerry Gillespie. 2006. "Boards Given Discretion on Book: Not about 'Censorship or Restriction,' Kennedy Says. But Controversial Story about Mideast Conflict under Review." The Toronto Star, March 1, B1.

Kanaaneh, Rhoda. 2002. Birthing the Nation: Strategies of Palestinian Women in Israel. Los Angeles, CA: University of California Press.

Kandiyoti, Deniz. 1991. "Identity and its Discontents: Women and the Nation." Millennium: Journal of International Studies 20(3): 429-43.

Karim, Karim H. 1991. Images of Arabs and Muslims: A Research Review. Ottawa, ON: Policy \& Research, Multiculturalism Branch, Multiculturalism \& Citizenship.

-----. 1993. "Constructions, Deconstructions, and Reconstructions: Competing Canadian Discourses on Ethnocultural Terminology." Canadian Journal of Communication 18(2): 197-218.

Karsh, Ifraim and Inari Karsh. 1996. "Reflections on Arab Nationalism: A Review Essay." Middle Eastern Studies 32(4): 367-92.

Kashmeri, Zuhair. 1991. The Gulf Within: Canadian Arabs, Racism, and the GulfWar. Toronto, ON: James Lorimer \& Company Publishers.

Kaouk, Aida and Dominique Bourque. 2004. The Lands within Me: Expressions by Canadian Artists of Arab Descent. Gatineau: Canadian Museum of Civilization.

Karsh Efraim and Inari Karsh. 1996. "Reflections on Arab Nationalism." Middle East Studies 32(4): 367-92.

Kay, Barbara. 2006. "A 'Neutral' Take on the Middle East? Hardly." National Post, March 8, A16. 
Kay, Johnathan. 2006. "Out of the Mouths of Babes." National Post, March 6, A19.

Kealey, Gregory S. 1992. "State Repression of Labour and the Left in Canada, 1914-20: The Impact of the First World War." Canadian Historical Review 73(3): 281-314.

Kenney, Jason. 2009. "Good Citizenship: The Duty to Integrate." Speech by the Honourable Jason Kenney, P.C., M.P. Minister of Citizenship, Immigration and Multiculturalism at Huron University College's Canadian Leaders Speakers' Series. April 30, 2009. Accessed July 19, 2011. http://www.cic.gc.ca/english/department/media/multimedia/video/speech/200903-18.asp.

Kernerman, Gerald. 2005. Multicultural Nationalism: Civilizing Difference, Constituting Community. Vancouver, BC: University of British Columbia Press.

Khalidi, Rashid. 1991. "Arab Nationalism: Historical Problems in the Literature." The American Historical Review 96(5): 1361-973.

----.. 1997. Palestinian Identity: Construction of Modern National Consciousness. New York, NY: Columbia University Press.

Khouri, Raja. 2003. Arabs in Canada: Post 9/11. Toronto, ON: G7 Books.

Kilbride, Kenise Murphy, Vappu Tyyskä, Rachel Berman, Mehrunnisa Ali, Isaac Woungang, Sepali Guruge, Laurie Clune, Susanna Edwards, and Robert Cazzola. 2008. Reclaiming Voice: Challenges and Opportunities for Immigrant Women Learning English. Toronto, ON: CERIS - The Ontario Metropolis Centre.

"Kingston Board Reinstates Book that Caused Controversy." 2006. Sudbury Star, March $16, \mathrm{~A} 2$.

Kinsman, Gary and Patrizia Gentile. 2010. The Canadian War on Queers: National Security as Sexual Regulation. Toronto, ON and Vancouver, BC: University of British Columbia Press.

Knowles, Valerie. 2006. "Forging Our Legacy: Canadian Citizenship and Immigration 1900-1977." Citizenship and Immigration Canada. Accessed November 12, 2008. http://www.cic.gc.ca/english/resources/publications/legacy/acknowledge.asp.

Kobayashi, Audrey. 1990. "Racism and Law in Canada: A Geographical Perspective." Urban Geography 11(5): 447-73.

-..-.-. 2007. "Ethnocultural Political Mobilization, Multiculturalism, and Human Rights in Canada." In Group Politics and Social Movements in Canada, edited by Miriam Smith, 131-57. Peterborough, ON: Broadview Press. 
Kobayashi, Audrey and Linda Peake. 2000. "Racism out of Place: Thoughts on Whiteness and an Antiracist Geography in the New Millennium." Annals of the Association of American Geographers 90(2): 392-403.

Kramer, Lauren. 2006. "Bias from the Mouths of Babes." Jerusalem Post. March 3 , 2006. Accessed November 1, 2009, from http://www.jpost.com/servlet/Satellite?cid=1139395519489\&pagename=JPArticl e\%2FShowFull

Kramer, Martin. 1993. “Arab Nationalism: Mistaken Identity.” Daedalus 122(3): 171206.

Kymlicka, Will. 1988. Liberalism, Ethnicity, and the Law. Toronto, ON: University of Toronto Press.

---.. 1989. Liberalism, Community and Culture. New York, NY: Oxford University Press.

-----. 1995. Multicultural Citizenship: A Liberal Theory of Minority Rights. Oxford, U.K.: Clarendon Press.

Lavie, Smadar. 1996. "Blowups in the Borderzones: Third World Israeli Authors' Gropings for Home." In Displacement, Diaspora, and Geographies of Identity, edited by Smadar Lavie and Ted Swedenburg, 55-96. Durham: Duke University Press.

Lawrence, Bonita. 2004. Real Indians and Others: Mixed-Blood Urban Native Peoples and Indigenous Nationhood. Vancouver, BC and Toronto, $\mathrm{ON}$ : University of British Columbia Press.

Lee, Erika. 2007. "The 'Yellow Peril' and Asian Exclusion in the Americas." Pacific Historical Review 76(4): 537-62.

LeGreco Marianne and Sarah L. Tracy. 2009. "Discourse Tracing as Qualitative Practice." Qualitative Inquiry 15(9): 1516-43.

Lemer, Adam. 1991. "Transcendence of the Nation: National Identity and the Terrain of the Divine." Millennium: Journal of International Studies 20(3): 407-27.

Levitt, Kari. 1970. Silent Surrender: The Multinational Corporation in Canada. Toronto, ON: McMillan.

Lewis, Paul. 2006. "Self-Imposed Danger." The Ottawa Citizen, July 21, A13.

Ley, David and Daniel Hiebert. 2001. "Immigration Policy as Population Policy." Canadian Geographer 45(1): 120-5. 
Li, Peter. 1990. "Race and Ethnicity." In Race and Ethnic Relations in Canada, edited by Peter Li, 3-17. Toronto, ON: Oxford University Press.

-----. 2003. "Deconstructing Canada's Discourse of Immigrant Integration." Journal of International Migration and Integration 4(3): 313-53.

Liladrie, Sirena. 2010. "Do Not Disturb/Please Clean Room: Hotel Housekeepers in Greater Toronto." Race and Class 52(1): 57-69.

Lindholm Schulz, Helena and Juliane Hammer. 2003. The Palestinian Diaspora: Formation of Identities and Politics of Homeland. London: Routledge.

Linke, Uli. 2006. "Contact Zones: Rethinking the Sensual Life of the State." Anthropological Theory 6(2): 205-25.

Liu, Eric. 2007. A Descriptive Study of Employers' Attitudes and Practices in Hiring Newcomer Job Seekers: The Study in Brief. Toronto, ON: CERIS.

Lohnes, David. 2006. "Evacuees Should Pay for Their Repatriation." The Ottawa Citizen, July $20, \mathrm{~A} 15$.

Loomba, Ania. 1998. Colonialism/Postcolonialism. New York, NY: Routledge.

Mackey, Eva. 1997. "The Cultural Politics of Populism: Celebrating Canadian National Identity." In Anthropology of Policy: Critical Perspectives on Governance and Power, edited by Cris Shore and Susan Wright, 136-64. London, U.K.: Routledge.

-----. 1999. The House of Difference: Cultural Politics and National Identity in Canada. London, U.K. and New York, NY: Routledge.

MacKinnon, Danny. 2011. "Reconstructing Scale: Towards a New Scalar Politics." Progress in Human Geography 35(1): 21-36.

Macklin, Audrey. 2001. "Borderline Security." In The Security of Freedom: Essays on Canada's Anti-terrorism Bill, edited by Ronald J. Daniels, Patrick Macklem, and Kent Roach, 383-404. Toronto, ON: University of Toronto Press.

--.-. 2007. "Who is the Citizen's Other? Considering the Heft of Citizenship." Theoretical Inquiries in Law 8(2): 476-508

Magat, Ilan. 1999. "Israeli and Japanese Immigrants to Canada: Home, Belonging, and the Territorialization of Identity." Ethos 27(2): 119-44.

Mahmood, Saba. 1996. "Cultural Studies and Ethnic Absolutism: Comments on Stuart Hall's 'Culture, Community, Nation."' Cultural Studies 10(1): 1-11. 
--.--. 2001. "Feminist Theory, Embodiment, and the Docile Agent: Some Reflections on the Egyptian Islamic Revival." Cultural Anthropology 16(2): 202-36.

Malhi, Rebecca L. and Susan D. Boon. 2007. "Discourses of 'Democratic Racism' in the Talk of South Asian Canadian Women." Canadian Ethnic Studies 39(3): 125-49.

Malkki, Liisa. 1992. "National Geographic: The Roots of Peoples and the Territorialization of National Identity among Scholars and Refugees." Cultural Anthropology 7(1): 24-44.

-----. 1995. "Refugees and Exiles: From 'Refugee Studies' to the National Order of Things." Annual Review of Anthropology 25: 495-523.

-----. 1996. "Speechless Emissaries: Refugees, Humanitarianism, and Dehistoricization." Cultural Anthropology 11(3): 377-404.

Maloney, Sean M. 2001. "Canadian Values and National Security Policy: Who Decides." Policy Options (December 2001): 45-9.

Mamdani, Mahmood. 2002. "Good Muslims, Bad Muslims: A Political Perspective on Culture and Terrorism." American Anthropologist 104(3): 766-75.

------. 2004. "Good Muslims, Bad Muslims: Post-Apartheid Perspectives on America and Israel." POLAR 27(1): 1-15.

Man, Guida. 2004. "Gender, Work and Migration: Deskilling Chinese Immigrant Women in Canada." Women's Studies International Forum 27(2): 135-48.

Mandel, Michael. 1994. The Charter of Rights and the Legalization of Politics in Canada. Toronto, ON: Thompson Educational Publishing.

Mandelbaum, David. 1953. "On the Study of National Character." American Anthropologist 55(2): 174-87.

Marcus, George. 1995. "Ethnography in/of the World System: the Emergence of MultiSited Ethnography." Annual Review of Anthropology 24: 95-117.

----. 1998. "What Comes (Just) After 'Post'?" In The Landscape of Qualitative Research: Theories and Issues, edited by Norman Denzin and Yvonna Lincoln, 383-406. Thousand Oaks, CA: Sage Publications.

Martin Alcoff, Linda. 2007. "Mignolo's Epistemology of Coloniality." CR: The New Centennial Review 7(3): 79-101. 
Martin, Paul. 1993. "Citizenship and the People's World." Belonging: Essays on the Meaning and Future of Canadian Citizenship, edited by William Kaplan, 64-78. Montreal: McGill-Queen's University Press.

Marston, Sallie A. 2000. "The Social Construction of Scale." Progress in Human Geography 24(2): 219-42.

Marston, Sallie A. and Neil Smith. 2001. "States, Scales and Households: Limits to scale Thinking? A Response to Brenner." Progress in Human Geography 25(4): 61519.

Massey, Doreen. 2004. "Geographies of Responsibility." Geografiska Annaler Series B: Human Geography 86 (1): 5-18.

McClintock, Anne. 1992. "The Angel of Progress: Pitfalls of the Term 'PostColonialism'." Social Text 31/32: 84-98.

----. 1995. Imperial Leather: Race, Gender, and Sexuality in the Imperial Context. NY and London, U.K.: Routledge.

-----. 2009. "Paranoid Empire: Specters from Guantánamo and Abu-Ghraib." Small Axe 13(1): 50-74.

McKittrick, Katherine. 2006. Demonic Grounds: Black Women and the Cartographies of Struggle. Minneapolis, MN: University of Minnesota Press.

McLennan, Hugh. 1945. Two Solitudes. Toronto, ON: Collins.

McMichael, Phillip. 2005. "Globalization and Development Studies." In Critical Globalization Studies, edited by Richard P. Applebaum and William I. Robinson, 111-20. New York, NY and London, U.K.: Routledge.

Mead, Margaret. 1951. "Anthropologist and Historian: Their Common Problems." American Quarterly 3(1): 3-13.

---.. 1954. "The Swaddling Hypothesis: Its Reception." American Anthropologist 56 (3): 395-409.

----.. 1961. "The Institute for Intercultural Studies and Japanese Studies." American Anthropologist 63(1): 136-7.

Mignolo, Walter. 2000a. "The Geopolitics of Knowledge and the Colonial Difference." South Atlantic Quarterly 101(1): 57-97.

----. 2000b. Local Histories/Global Designs: Coloniality, Subaltern Knowledges, and Border Thinking. Princeton, NJ: Princeton University Press. 
Mills, Sara. 2001. Discourses of Difference: An Analysis of Women's Travel Writing and Colonialism. New York, NY: Routledge.

-..... 2004. Discourse. New York, NY: Routledge.

Mitchell, Don. 1995. “There's No Such Thing as Culture: Towards a Reconceptualization of the Idea of Culture in Geography." Transactions of the Institute of British Geographers 20(1): 102-16.

Mitchell, Katharyne. 1993. "Multiculturalism, or the United Colors of Capitalism?" Antipode 25(4): 263-94.

Mohanty, Chandra Talpade. 1991. "Cartographies of Struggle: Third World Women and the Politics of Feminism." In Third World Women and the Politics of Feminism, edited by Chandra Talpade Mohanty, Ann Russo, and Lourdes Torres, 1-47. Indianapolis, IN: Indiana Press University.

----. 2000 (1986). "Under Western Eyes: Feminist Scholarship and Colonial Discourses." In Theories of Race and Racism: A Reader, edited by Les Black and John Solomos, 302-23. New York, NY: Routledge.

-----. 2002. “'Under Western Eyes' Revisited: Feminist Solidarity through Anti-capitalist Struggle." Signs: Journal of Women in Culture and Society 28(2): 499-535.

-----. 2003. Feminism Without Borders: Decolonizing Theory, Practicing Solidarity. Durham and London, U.K.: Duke University Press.

Mojab, Shahrzad. 2001. "Conflicting Loyalties: Nationalism and Gender Relations in Kurdistan." In Of Property and Propriety: The Role of Gender and Class in Imperialism and Nationalism, edited by Himani Bannerji, Shahrzad Mojab, and Judith Whitehead, 116-52. Toronto, ON: University of Toronto Press.

Moodley, Kogila. 1983. "Canadian Multiculturalism as Ideology." Ethnic and Racial Studies 6(3): 320-31.

Molnar, Balint. 2005. "In Dialogue Group, Jews and Arabs in Canada Eat, and Talk about Peace." Jewish Tribune. June 24, 2005. Accessed October 30, 2009. http://www.jewishtribune.ca/tribune/jt-050602-20.html.

Moore, Adam. 2008. "Rethinking Scale as a Geographical Category: From Analysis to Practice."Progress in Human Geography 32(2): 203-25.

Morgan, Ed. 2006. “Good Books - but Good for Whom?” The National Post, March 8, A17. 
Moughrabi, Fouad. 2007. "Three Representations of the Israeli-Palestinian Conflict in Children's Literature." Electronic Intifada. February 5, 2007. Accessed November 1, 2009, from http://electronicintifada.net/v2/article6513.shtml.

Mudimbe-Boyi, Elisabeth. 2002. "Preface." In Beyond Dichotomies: Histories, Identities, Culture, and the Challenge of Globalization, edited by Elisabeth Mudimbe-Boyi, xi-xxiv. New York, NY: State University of New York Press.

Mufti, Aamir and Ella Shohat. 1997. "Introduction." In Dangerous Liaisons: Gender, Nation, and Postcolonial Perspectives, edited by Anne McClintock, Aamir Mufti, and Ella Shohat, 1-12. Minneapolis, MN: University of Minnesota Press.

Mullard, Chris. 1982. "Multiracial Education in Britain: From Assimilation to Cultural Pluralism." In Race, Migration, and Schooling, edited by John Tierney, 120-33. London, U.K.: Holt, Rinehart and Winston.

Murphy, Alexander. 1996. "The Sovereign State System as Political-Territorial Ideal: Historical and Contemporary Consideration." In State Sovereignty as a Social Construct, edited by Thomas J. Biersteker and Cynthia Weber, 81-120. Cambridge, U.K.: Cambridge University Press.

Murphy, Peter and Brenda Peters McDermott. 2002. As the Cedars Grow: The Origins of St. John's Lebanese Community in Canadian History. St. John, NB: Saint John Canadian Lebanon Association.

Naber, Nadine. 2000. "Ambiguous Insiders: An Investigation of Arab American Invisibility." Ethnic and Racial Studies 23(1): 37-61.

-.-.-. 2008. "Introduction: Arab Americans and U.S. Racial Formations." In Race and Arab Americans Before and After 9/11: From Invisible Citizens to Visible Subjects, edited by Amaney Jamal and Nadine Naber, 1-45.Syracuse, NY: Syracuse University Press.

Nash, Catherine. 2003. "Cultural Geography: Anti-Racist Geographies.” Progress in Human Geography 27(5): 637-48.

Nash, Jennifer. 2008. "Re-thinking Intersectionality." Feminist Review 89: 1-15.

Nassar, Hala. 2006. "Stories From Under Occupation: Performing the Palestinian Experience." Theatre Journal 58: 15-37.

Nazzal, Nafez. 1978. The Palestinian Exodus from Galilee: 1948. Beirut, Lebanon: The Institute of Palestine Studies.

Niva, Seeve. 1999. "Contested Sovereignties and Postcolonial Insecurities in the Middle East." In Cultures of Insecurity: States, Communities, and the Production of 
Danger, edited by Jutta Weldes, forward by George Marcus, 147-72.

Minneapolis, MN: University of Minnesota Press.

Ng, Roxana. 1993. "Sexism, Racism, and Canadian Nationalism." In Returning the Gaze: Essays on Racism, Feminism and Politics, edited by Himani Bannerji, 223-41. Toronto, ON: Sister Vision Press.

Nirenstein, Fiamma. 2001. "How to Build a Suicide Bomber: 'Death to the Jews' is a Common Cry throughout an Arab World Where Young Men Grow up Willing to Die." The Ottawa Citizen, September 21, A15.

Nixon, Rob.1997. "Of Balkans and Bantustans: Ethnic Cleansing and the Crisis in National Legitimation." In Dangerous Liaisons: Gender, Nation, and Postcolonial Perspectives, edited by Anne McClintock, Aamir Mufti and Ella Shohat, 69-88. Minneapolis, MN: University of Minnesota Press.

"No Place Like Home." 2006. The Ottawa Citizen, July 20, A16.

Nyers, Peter. 2003. "Abject Cosmopolitanism: the Politics of Protection in the Antideportation Movement." Third World Quarterly 24(6): 1069-93.

---.- 2006. "The Accidental Citizen: Acts of Sovereignty and (Un)Making Citizenship." Economy and Society 35(1): 22-41.

Obeidat, Bayan Ahmad. 2002. "Food Habits of Arab Students Living in the United States." M.Sc. Thesis. Texas Tech University.

Obituary. 2008. "Samuel Huntington: Political Scientist Whose 'Clash of Civilisations' Thesis on Islam and the West Proved Highly Controversial." The Telegraph, December 28. Accessed June 28, 2011.

http://www.telegraph.co.uk/news/obituaries/3999461/Samuel-Huntington.html

Ohan, Farid Emile and Ibrahim Hayani. 1993. Arabs in Ontario: A Misunderstood Community. Toronto, ON: Near East Cultural and Educational Foundation of Canada.

O'Leary, Carole. 2002. "The Kurds of Iraq: Recent History, Future Prospects." Middle East Review of International Affairs 6(4): 17-29.

Oliphant, Elayne. 2005. "Il n'y a pas de "Potentially Hot Issue"?' The Paradoxes of Displaying Arab-Canadian Lands within the Canadian Museum of Civilization." M.A. Thesis, Carleton University.

Omidvar, Ratna and Ted Richmond. 2005. Immigrant Settlement and Social Inclusion in Canada. Toronto, ON: Joint Centre of Excellence for Research on Immigration and Settlement. 
Ong, Aihwa. 1987. Spirits of Resistance and Capitalist Discipline: Factory Women in Malaysia. Albany: State University of New York Press.

----. 1988. "Colonialism and Modernity: Feminist Re-Presentations of Women in NonWestern Societies." Inscriptions 3(4):79-93.

----- 1999. Flexible Citizenship: The Cultural Logics of Transnationality. Durham: Duke University Press.

----. 2006. "Neoliberalism as a Mobile Technology." Transactions 31: 1-6.

Ono, Kent. 2005. "From Nationalism and Migrancy: The Politics of Asian American Transnationalism." Communication Law Review 5(1): 1-18.

P4P (Potlucks for Peace). 2006. "Events." Accessed October 30, 2009. http://www.potlucksforpeace.ca/Event1.html.

-----. 2009. "Who Are We?" Accessed October 30, 2009. http://www.potlucksforpeace.ca/Who.html.

Panitch, Leo. 1977. The Canadian State: Political Economy and Political Power. Toronto, ON: University of Toronto Press.

Passaro, Joanne. 1997. "“You Can't Take the Subway to the Field!': 'Village' Epistemologies in the Global Village." In Anthropological Locations: Boundaries and Grounds of a Field Science, edited by James Ferguson and Akhil Gupta, 14762. Berkeley, CA: University of California Press.

Paasi, Anssi. 2004. "Place and Region: Looking Through the Prism of Scale." Progress in Human Geography 28(4): 536-46.

Page, Shelley. 2001. "Area Muslim Students Live in Fear." The Ottawa Citizen, September 25, A7.

Parmenter, Barbara. 1994. Giving Voice to Stones: Place and Identity in Palestinian Literature. Austin, TX: University of Texas Press.

Peake, Linda and Audrey Kobayashi. 2002: "Policies and Practices for an Antiracist Geography at the Millennium.” Professional Geographer 54(1): 50-61.

Peteet, Julie. 2005. Landscapes of Hope and Despair: Palestinian Refugee Camps. Philadelphia, PA: University of Pennsylvania Press. 
Pile, Steve. 1997. "Introduction: Opposition, Political Identities, and Spaces of Resistance". In Geographies of Resistance, edited by Steve Pile and Michael Keith, 1-32. New York, NY: Routledge.

Piterberg, Gabriel. 2001. "Erasures.” New Left Review 10: 31-46.

Pollock, Sheldon, Homi K. Bhabha, Carol A. Breckenridge, and Dipesh Chakrabarty. 2002. "Cosmopolitanisms." In Cosmopolitanism, edited by Carol A.

Breckenridge, Sheldon Pollock, Homi K. Bhabha and Dipesh Chakrabarty, 1-14. Durham, NC \& London: A Millennial Quartet Book.

Prakash, Gyan. 1992. "Postcolonial Criticism and Indian Historiography." Social Text 31/32: 8-19.

Pratt, Anna. 2005. Securing Borders: Detention and Deportation in Canada. Vancouver, BC: University of British Columbia Press.

Pratt, Anna and Mariana Valverde. 2002. "From Deserving Victims to "Masters of Confusion': Redefining Refugees in the 1990s." Canadian Journal of Sociology 27(2): 135-61.

Pratt, Geraldine. 1999. "From Registered Nurse to Registered Nanny: Discursive Geographies of Filipina Domestic Workers in Vancouver, B.C." Economic Geography 75(3): 215-36.

Price, Patricia L. 2010. "At a Crossroads: Critical Race Theories and Critical Geographies of Race." Progress in Human Geography 34(2): 147-74.

Proudfoot, Shannon. 2006. "Thousands Take Harper to Task at Protests against Israeli Attacks." The Ottawa Citizen. July 23, A5.

Puar, Jasbir. 2004. "Abu Ghraib: Arguing Against Exceptionalism." Feminist Studies 30(2): 522-34.

-----. 2005. "Queer Times, Queer Assemblages." Social Text 84-85, 23(3/4): 121-39.

----. 2011. "'I Would Rather Be a Cyborg than a Goddess': Intersectionality, Assemblage, and Affective Politics." European Institute for Progressive Cultural Policies. Accessed June 20, 2011. http://www.eipcp.net/transversal/0811/puar/en.

Puar, Jasbir and Amit S. Rai. 2002. "Monster, Terrorist, Fag: The War on Terrorism and the Production of Docile Patriots." Social Text 72 20(3): 117-48.

Quijano, Anibal. 2000. "Coloniality of Power and Eurocentrism in Latin America". International Sociology 15(2): 215-32. 
Rabinowitz, Dan. 1997. Overlooking Nazareth: The Ethnography of Exclusion in Galilee. Cambridge: University of Cambridge Press.

-.-.-. 2001a. "Natives with Jackets and Degrees. Othering, Objectification, and the Role of Palestinians in the Co-Existence Field in Israel." Social Anthropology 9(1): 6580.

-.-.- 2001b. "Strife in Nazareth: The Meaning of Place and Space in Nazareth." Ethnography 2(1): 93-113.

Ramadan, Tariq. 2004. Western Muslims and the Future of Islam. Oxford, U.K. and New York, NY: Oxford University Press.

Rancière, Jacques. 2004. "Who is the Subject of the Rights of Man?" South Atlantic Quarterly 103 (2/3): 297-310.

Razack, Sherene. 1998. Looking White People in the Eye: Gender, Race, and Culture in Courtrooms and Classrooms. Toronto, ON: University of Toronto Press.

-----, ed. 2002. Race, Space, and the Law: Unmapping White Settler Society. Toronto, ON: Between the Lines.

----. 2004. Dark Threats and White Knights: The Somalia Affair, Peacekeeping, and the New Imperialism. Toronto, ON: University of Toronto Press.

-----. 2008. Casting Out: The Eviction of Muslims From Western Law and Politics. Toronto, ON: University of Toronto Press.

Reagon Johnson, Bernice. 2000. "Coalition Politics: Turning the Century." In Home Girls: A Black Feminist Anthology, $2^{\text {nd }}$ ed., edited by Barbara Smith, 342-56. New York, NY: Kitchen Table Women of Color Press.

Reiser, Stewart. 1983. "Pan-Arabism Revisited." Middle East Journal 37(2): 218-33.

Reitz, Jeffery. 2001a. "Immigrant Skill Utilization in the Canadian Labour Market: Implications of Human Capital Research. Journal of International Migration and Integration 2(3): 347-78.

----. 2001b. "Immigrant Success in the Knowledge Economy: Institutional Change and the Immigrant Experience in Canada, 1970-1995. Journal of Social Issues 57(3): 579-613.

Roberts, Lance W. and Rodney A. Clifton. 1982. "Exploring the Ideology of Canadian Multiculturalism." Canadian Public Policy 8(1):88-94. 
Rofel, Lisa. 1994. "'Yearnings': Televisual Love and Melodramatic Politics in Contemporary China." American Ethnologist 21 (4): 700-22.

Rosaldo, Renato. 1988. "Ideology, Place, and People without Culture." Cultural Anthropology 3(1): 77-87.

Rose, Nikolas. 1996. "Governing 'Advanced' Liberal Democracies." In Foucault and Practical Reason: Liberalism, Neo-Liberalism, and Rationalities of Government, edited by Andrew Barry, Thomas Osborne, and Nikolas Rose, 37-64. Chicago, IL: University of Chicago Press.

----. 2001. "The Politics of Life Itself." Theory, Culture, and Society 18(6): 1-30.

Rose, Nikolas, Pat O'Malley, and Mariana Valverde. 2006. "Governmentality." Annual Review of Law and Social Science 2: 83-104.

Rostom, Kamal. 1989. Arab-Canadian Writing: Stories, Memoirs, and Reminiscences. Fredericton: York Press.

Roy, Sara. 2009. "If Gaza Falls..." London Review of Books 31(1). Accessed August 2, 2011. http://www.lrb.co.uk/v31/n01/sara-roy/if-gaza-falls-.

Sabra, Samah. 2005. (Re)writing the Other/Self: Autoethnography in the Transcultural Arena of Representation. M.A. thesis, Brock University.

-.-.-. 2007. "Imagining Nations: An Anthropological Perspective," NEXUS 20(1): 76104.

---. 2008a. "Re-Imagining Home and Belonging: Feminism, Nostalgia, and Critical Memory." Resources for Feminist Research 33(1/2): 79-102.

2008b. "(Un)desirable Subjects and National Threats: Globalization, Immigration, and Managing National Borders." In Institute on Globalization and the Human Condition Working Papers Series, Global Tensions, Global Possibilities:

Everyday Forces of Conformity and Contestation, edited by Michel Montsion and Samah Sabra, 95-100. Accessed February 23, 2010. http://www.socialsciences.mcmaster.ca/institute-on-globalization-and-the-humancondition/documents/IGHC-WPS 08-2_GraduateStudents.pdf.

Sadiqi, Fatima. 1997. "The Place of Berber in Morocco." International Journal of the Sociology of Language 123(1): 7-22.

Said, Edward. 1986. "On Palestinian Identity, a Conversation with Salman Rushdie." New Left Review 160: 63-80.

----. 1993. Culture and Imperialism. New York, NY: Vintage Books. 
1994a. The Politics of Dispossession. New York, NY: Pantheon Books.

----. 1994b (1978). Orientalism. New York, NY: Vintage Books.

----. 1997a (1981). Covering Islam: How the Media and the Experts Determine How we See the Rest of the World. New York, NY: Vintage Books.

-----. 1997b. "Zionism from the Standpoint of its Victims." In Dangerous Liaisons: Gender, Nation, and Postcolonial Perspectives, edited by Anne McClintock, Aamir Mufti, and Ella Shohat, 15-38. Minneapolis, MN: University of Minnesota Press.

----. 2000 (1984). "Reflections on Exile." In Reflections on Exile and Other Essays, edited by Edward Said, 173-86. Cambridge: Harvard University Press.

----. 2001. "The Clash of Ignorance." The Nation, October 4. Accessed January 20, 2008. http://www.thenation.com/article/clash-ignorance?page $=0,0$.

2007 (2003). "A Window on the World." Canadian International Youth Letter. Accessed July 21, 2011. http://www.paep.ca/en/CIYL/2006/doc/A\%20Window\%20on\%20the\%20World $\% 20-\% 20 \mathrm{Edward} \% 20 \mathrm{~W} . \% 20$ Said.pdf.

Salaff, Janet and Arent Greve. 2003. "Gendered Structural Barriers for Skilled Chinese Emigrants in Canada." International Journal of Population Geography 9(6): 44356.

Salaita, Steven. 2006. Anti-Arab Racism in the U.S.A.: Where It Comes from and What It Means. Ann Arbor, MI: Pluto Press.

Salameh, Franck. 2011. "Towards a New Ecology of Middle Eastern Identities." Middle Eastern Studies 47(2): 237-53.

Salter, Liora and Rick Salter. 1997. In Understanding Canada: Building on the New Canadian Political Economy, edited by Wallace Clement, 311-37. Montreal, QC and Kingston, ON: McGill Queen's University Press.

Sassen, Saskia. 2005. "The Many Scales of the Global: Implications for Theory and for Politics." In Critical Globalization Studies, edited by Richard P. Applebaum and William I. Robinson, 155-66. New York, NY and London, U.K.: Routledge.

Saukko, Paula. 2003. Doing Research in Cultural Studies: An Introduction to Classical and New Methodological Approaches. London, U.K. and Thousand Oaks, CA: Sage. 
Sayigh, Rosemary. 1994. Too Many Enemies. London, U.K.: Zed Books.

-.-.- 2008 (1979). The Palestinians: From Peasants to Revolutionaries. London, U.K.: Zed Press.

Scott, Joan W. 1991. "The Evidence of Experience." Critical Inquiry 17(4): 773-97.

"Self-Imposed Danger." The Ottawa Citizen, July 21, A13.

Semmerling, Tim Jon. 2004. Israeli and Palestinian Postcards: Presentations of National Self. Austin, TX: University of Texas Press.

Shaheen, Jack. 1980. ABSCAM: Arabophobia in America. Washington D.C.: AmericanArab Anti-Discrimination Committee.

---- 1984. The T.V. Arab. Bowling Green, OH: State University Press.

----. 2001. Reel Bad Arabs: How Hollywood Villifies a People. New York, NY: Olive Branch Press.

----. 2003. "Reel Bad Arabs: How Hollywood Villifies a People." Annals of the American Academy of Political and Social Science 588: 171-93.

-----. 2007. Guilty: Hollywood's Verdict on Arabs After 9/11. New York, NY: Olive Branch Press.

Shohat, Ella. 1992. "Notes on the 'Post-Colonial'." Social Text 31/32: 99-113.

-----. 1997. "Sephardim in Israel: Zionism from the Standpoint of its Jewish Victims." In Dangerous Liaisons: Gender, Nation, and Postcolonial Perspectives, edited by Anne McClintock, Aamir Mufti, and Ella Shohat, 39-68. Minneapolis: University of Minnesota Press.

Shohat, Ella and Robert Stam. 2004 (1994). Unthinking Eurocentrism: Multiculturalism and the Media. London, U.K. and New York, NY: Routledge.

Shore, Cris and Susan Wright. 1997. "Policy: A New Field of Anthropology." In Anthropology of Policy: Critical Perspectives on Governance and Power, edited by Cris Shore and Susan Wright, 3-39. London, U.K.: Routledge.

Shryock, Andrew. 2004. "The New Jordanian Hospitality: House, Host, and Guest in the Culture of Public Display." Comparative Studies in Society and History 46(1): 3562.

-----. 2008. "The Moral Analogies of Race: Arab American Identity, Color Politics, and the limits of Racialized Citizenship." In Race and Arab Americans Before and 
After 9/11: From Invisible Citizens to Visible Subjects, edited by Amaney Jamal and Nadine Naber, 81-113.Syracuse, NY: Syracuse University Press.

-----. 2009. "Hospitality Lessons: Learning the Shared Language of Derrida and the Balga Bedouins." Paragraph 32: 32-50.

Silvey, Rachel. 2004. "Power, Difference and Mobility: Feminist Advances in Migration Studies." Progress in Human Geography 28(4): 490-506.

Slyomovics, Susan. 1988. The Object of Memory: Arab and Jew Narrate the Palestinian Village. Philadelphia, PA: University of Pennsylvania Press.

Smith, Anthony. 1989 (1986). The Ethnic Origins of Nations. Oxford, U.K.: Blackwell Publishers.

Smith, Antonia. 2007. "'Cement for the Canadian Mosaic': Performing Canadian Citizenship in the Work of John Murray Gibbon." Ethnicity/Race:

Multidisciplinary Global Perspectives 1(1): 37-60.

Smith, Charles C. 2007. Conflict, Crisis, and Accountability: Racial Profiling and Law Enforcement in Canada. Ottawa, ON: Canadian Centre for Policy Alternatives.

Smith, Dorothy E. 1987. The Everyday World of Problematic: A Feminist Sociology. Boston, MA: Northeastern University Press.

Smith, Linda Tuhiwai. 1999. Decolonizing Methodologies: Research and Indigenous Peoples. London, U.K. and New York, NY: Zed Books.

Smith, Neil. 1992. "Geography, Difference and the Politics of Scale." In Postmodernism and the Social Sciences, edited by Jo Doherty, Elspeth Graham, and Mo Malek, 57-79. Basingstoke, U.K.: Macmillan.

----. 1993. "Homeless/Global: Scaling Places." In Mapping the Futures: LocalCultures, Global Change, edited by Jon Bird, Barry Curtis, Tim Putnam, George Robertson and Lisa Tickner, 87-119. London, UK: Routledge.

Smith, Neil and Anne Godlewska. 1994. "Introduction: Critical Histories of Geography." In Geography and Empire, edited by Anne Godlewska and Neil Smith, 1-8. Oxford, U.K. and Cambridge, MA: Blackwell.

Spivak, Gayatri. 1988. "Can the Subaltern Speak?" In Marxism and the Interpretation of Culture, edited by Cary Nelson and Lawrence Grossberg, 271-313. Urbana, IL: University of Illinois Press.

-.-.-. 1999. Critique of Postcolonial Reason: Toward a History of the Vanishing Present. Cambridge, MA: Harvard University Press. 
Stasiulis, Daiva and Abigail Bakan. 1997. "Negotiating Citizenship: The Case of Foreign Domestic Workers in Canada." Feminist Review 57: 112-39.

---.. 2005. Negotiating Citizenship: Migrant Women in Canada and the Global System. Toronto, ON: University of Toronto Press.

Statistics Canada. 2009a. Ethnic Origin Reference Guide, Census 2006. Accessed January 29,2010 . http://www12.statcan.gc.ca/census-recensement/2006/ref/rpguides/ethnic-ethnique-eng.cfm.

----. 2009b. Summary Table: Population by Selected Ethnic Origins, by Census Metropolitan Areas. Accessed January 29, 2010. http://www40.statcan.ca/101/cst01/demo27e-eng.htm.

-----. 2009c. Visible Minority Population and Population Group Reference Guide, Census 2006. Accessed January 29, 2010. http://www12.statcan.gc.ca/censusrecensement/2006/ref/rp-guides/visible minority-minorites visibles-eng.cfm.

-.-.-. 2010a. Language Reference Guide, 2006 Census. Accessed January 15, 2011. http://www12.statcan.gc.ca/census-recensement/2006/ref/rp-guides/lang-eng.cfm.

-.--. 2010b. Topic-based Tabulations: Detailed Mother Tongue (186), Knowledge of Official Languages (5), Age Groups (17A) and Sex (3) for the Population of Canada, Provinces, Territories, Census Metropolitan Areas and Census Agglomerations, 2001 and 2006 Censuses - 20\% Sample Data. Accessed January 15, 2011. http://wwwl2.statcan.gc.ca/census-recensement/2006/dp-pd/tbt/Rpeng.cfm?TABID $=1$ \&LANG=E\&APATH=3\&DETAIL=0\&DIM=0\&FL=A\&FRE $\mathrm{E}=0 \& \mathrm{GC}=0 \& \mathrm{GK}=0 \& \mathrm{GRP}=1 \& \mathrm{PID}=89201 \& \mathrm{PRID}=0 \& \mathrm{PTYPE}=88971,97154 \& \mathrm{~S}$ $=0 \&$ SHOWALL $=0 \& \mathrm{SUB}=701 \&$ Temporal $=2006 \&$ THEME $=70 \& \mathrm{VID}=0 \& \mathrm{VNA}$ $\underline{\mathrm{MEE}}=\& \mathrm{VNAMEF}=$.

----. 2010c. Topic-based Tabulations: Visible Minority Groups (15), Immigrant Status and Period of Immigration (9), Age Groups (10) and Sex (3) for the Population of Canada, Provinces, Territories, Census Metropolitan Areas and Census Agglomerations, 2006 Census - 20\% Sample Data. Accessed January 15, 2011. http://www12.statcan.gc.ca/census-recensement/2006/dp-pd/tbt/Rpeng.cfm?LANG $=E \&$ APATH $=3 \& D E T A I L=0 \& D I M=0 \& F L=A \& F R E E=0 \& G C=0$ $\& \mathrm{GID}=0 \& \mathrm{GK}=0 \& \mathrm{GRP}=1 \& \mathrm{PID}=92338 \& \mathrm{PRID}=0 \& \mathrm{PTYPE}=88971,97154 \& \mathrm{~S}=0$ $\&$ SHOWALL $=0 \& S U B=802 \&$ Temporal $=2006 \&$ THEME $=80 \&$ VID $=0 \&$ VNAME $\underline{E}=\&$ VNAMEF $=$.

Strong-Boag, Veronica. 2002. "'The Citizenship Debates': The 1885 Franchise Act." In Contesting Canadian Citizenship: Historical Readings, edited by Robert Adamoski, Dorothy Chunn, and Robert Menzies, 69-94. Peterborough, ON: Broadview Press. 
Suleiman, Michael. 1999. "Introduction: The Arab Immigrant Experience." In Arabs in America: Building a New Future, edited by Michael Suleiman, 1-21. Philadelphia, PA: Temple University Press.

Suleiman, Yasir. 1994. "Nationalism and the Arabic Language: A Historical Overview." In Arabic Sociolinguistics: Issues and Perspectives, edited by Yasir Suleiman, 324. Surrey, U.K.: Curzon Ltd. Press.

Swedenburg, Ted. 1989. "Occupational Hazards: Palestine Ethnography." Cultural Anthropology. 4(3): 265-72.

-----. 1990. "The Palestinian Peasant as National Signifier." Anthropological Quarterly 63 (1): 18-30.

--.-. 1995. Memories of Revolt: The 1936-39 Rebellion and the Palestinian National Past. Minneapolis, MN: University of Minnesota Press.

Tamari, Salim. 1980. "The Palestinians in the West Bank and Gaza: The Sociology of Dependency." In The Sociology of the Palestinians, edited by Khalil Nakhleh and Elia Zureik, 84-111. London, U.K: Croom Helm.

Taylor, Charles. 1997. "The Politics of Recognition." In Multiculturalism: A Critical Reader, edited by David Theo Goldberg, 75-106. Malden, MA and Oxford, U.K.: Blackwell Publishers.

Teelucksingh, Cheryl and Grace-Edward Galabuzi. 2005. Impact of Race and Immigrants Status on Employment Opportunities and Outcomes in the Canadian Labour Market. Toronto, ON: Joint Centre of Excellence for Research on Immigration and Settlement.

"The Siege on the Gaza Strip: 1.5 Million People Imprisoned." 2010. B'Tselem - The Israeli Information Center for Human Rights in the Occupied Territories (September 27, 2010). Accessed August 2, 2011. http://www.btselem.org/gaza_strip/20100531_the_siege_on_gaza.

“How about Giving Kids' Learning Abilities a Little More Credit?” 2006. This Week, March 27, p.1.

Thobani, Sunera. 2007. Exalted Subjects: Studies in the Making of Race and Nation in Canada. Toronto, ON: University of Toronto Press.

“Thugs, Cowards, Hypocrites." 2001. The Ottawa Citizen, Editorial, September 20, A19.

"Parents Best to Decide." 2006. Toronto Star, March 10, A20. 
Tortola, Tirza. 2006. "Be Grateful.” The Ottawa Citizen, July 24, A9.

Turner, Bryan S. 1997. "Citizenship Studies: A General Theory." Citizenship Studies 1(1): 5-18.

Turner, Garth. 2006. "Tory MP Questions Cost of Saving Dual Citizens." The Ottawa Citizen, Jul 19, A1.

Uniform Law Conference of Canada. 1988 (April). Uniform Change of Name Act. Accessed June 13, 2011. http://www.ulcc.ca/en/us/Changename En.pdf.

United States. 2010. Department of Homeland Security. Yearbook of Immigration Statistics 2009. Washington, D.C.: U.S. Department of Homeland Security Office of Immigration Statistics.

Valverde, Mariana. 1994. "Moral Capital." Canadian Journal of Law and Society 9(1): 213-32.

---.-. 2003. "“Which Side Are You On?' Uses of the Everyday in Sociolegal Scholarship." PoLAR 26(1): 86-98.

-----. 2007. "Genealogies of European States: Foucauldian Reflections." Economy and Society 36(1): 157-78.

-.--. 2008. "Analyzing the Governance of Security: Jurisdiction and Scale." Behemoth: A Journal on Civilisation 1: 3015.

-----. 2009. "Jurisdiction and Scale: Legal 'Technicalities' as Resources for Theory." Social and Legal Studies 18(2): 139-57.

----. 2010. "Practices of Citizenship and Scales of Governance." New Criminal Law Review 13(2): 216-41.

Van Luven, Lynne. 2006. "Three Wishes, a Controversy, and Some Good Advice." The Ottawa Citizen. April 9 2006. Accessed November 1, 2009. http://www.canada.com/story print.html?id=2e 57354f-bf $77-43 \mathrm{~b} 0-91 \mathrm{dc}-$ 6f8ea033f722\&sponsor $=$

Voegelin, Eric. 1987 (1952). The New Science of Politics: An Introduction. Chicago, IL: University of Chicago Press.

Volpe, Joe. 2005. "Speaking Notes: The Honourable Joe Volpe, Minister of Citizenship and Immigration, at the Progressive Governance Seminar 'Migration, Integration, and Diversity'." May 19, 2005. Accessed July 19, 2011.

http:/www.cic.gc.ca/English/department/media/speeches/2005/mid.asp 
Vukov, Tamara. 2003. "Imagining Communities through Immigration Policy: Governmental Regulation, Media Spectacles and the Affective Politics of National Borders." International Journal of Cultural Studies 6(3): 335-53.

Wagner, Eric. 2006/7. "The Peaceable Kingdom: The National Myth of Canadian Peacekeeping and the Cold War." Canadian Military Journal (Winter): 45-54.

Walcott, Rinaldo. 1999. “'Keep on Movin': Rap, Black Atlantic Identities and the Problem of Nation." In Pop Can: Popular Culture in Canada, edited by Lynne Van Luven and Pricsilla L. Walton, 27-41. Scarborough, ON: Prentice Hall Allyn and Bacon Canada.

-.----, ed. 2000. Rude: Contemporary Black Canadian Cultural Criticism. Toronto, ON: Insomniac Press.

----. 2001. "Caribbean Pop Culture in Canada; Or, the Impossibility of Belonging to the Nation." Small Axe 5(1):123-39.

-.---. 2003. Black Like Who? Writing Black Canada. Toronto, ON: Insomniac Press.

Wallace, Anthony and Raymond Fogelson. 1961. "Culture and Personality." Biennial Review of Anthropology 2: 42-78.

Walsh, James. 2008. "Navigating Globalization: Immigration Policy in Canada and Australia, 1945-2007." Sociological Forum 23(4): 786-813.

Warren, David. 2001a. "Fighting Intolerance." The Ottawa Citizen, October 28, A14.

---.-2001b. "It's Time to Set aside the Intractable 'Palestine issue'." The Ottawa Citizen, October 16, A1.

----.. 2001c. "Taking the Message to 'Arab Street': The West Should Create Its Own al Jazeera Network to Mount a Frontal Cultural Attack and Sell its Values to the Muslim World." The Ottawa Citizen, November 1, A4.

Werbner, Pnina. 2005. "The Translocation of Culture: 'Community Cohesion' and the Force of Multiculturalism in History." The Sociological Review 53: 745-58.

Whitehead, Judith, Himani Bannerji, and Shahrzad Mojab. 2001. "Introduction." In Of Property and Propriety: The Role of Gender and Class in Imperialism and Nationalism, edited by Himani Bannerji, Shahrzad Mojab, and Judith Whitehead, 3-33. Toronto, ON: University of Toronto Press.

Wilhelm, Trevor. 2006. "Book Catalyst for Controversy." The Windsor Star, March 22, A2. 
Wood, Patricia. 2001. "Defining Canadian: Anti-Americanism and Identity in Sir John A. MacDonald's Nationalism." Journal of Canadian Studies 36(2): 49-70.

Wood, Patricia and Liette Gilbert. 2005. "Multiculturalism in Canada: Accidental Discourse, Alternative Vision, Urban Practice." International Journal of Urban and Regional Research 29(3): 679-91.

Wright, Ouida. 2000. "Multicultural and Anti-Racist Education: The Issue is Equity." In Weaving Connections: Educating for Peace, Social, and Environmental Justice, edited by Tara Goldstein and David Selby, 57-98. Toronto, ON: Sumach Press.

Wright, Susan. 1998. "The Politicization of Culture." Anthropology Today 14(1): 7-15.

Yegenoglu, Meyda. 2003. "Liberal Multiculturalism and the Ethics of Hospitality in the Age of Globalization." Postmodern Culture 13(2). Project Muse.

http://muse.jhu.edu.proxy.library.carleton.ca/journals/postmodern_culture/v013/1 3.2yegenoglu.html.

Young, Robert. 2003. Postcolonialism: A Very Short Introduction. Oxford: Oxford University Press.

Yuval-Davis, Nira. 1997. "Women, Citizenship, and Difference." Feminist Review 57: 428.

Zabjek, Alexandra. 2006. "Hill Protesters Slam Harper for Response to Crisis: PM Showed 'Immaturity' by not Denouncing." The Ottawa Citizen, July 17, A2. 